Humberto Iván Pehovaz Alvarez

\title{
ENSAIOS NÃO CONVENCIONAIS PARA DETERMINAÇÃO DA TENACIDADE À FRATURA EM ROCHAS: ANÁLISE E COMPARAÇÃO
}

Dissertação apresentada à Escola de Engenharia de São Carlos da Universidade de São Paulo, como parte dos requisitos para a obtenção do Título de Mestre em Geotecnia

Orientador: Prof. Dr. Antônio Airton Bortolucci

São Carlos

2004 
Candidato: Engenheiro HUMBERTO IVÁN PEHOVAZ ALVAREZ

Dissertação defendida e julgada em 17-09-2004 perante a Comissão Julgadora:

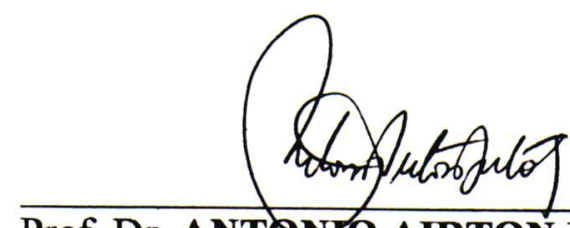

Prof. Dr. ANTONO AIRTON BORTOLUCCI (Orientador)

APROVA DO

(Escola de Engenharia de São Carlos/USP)

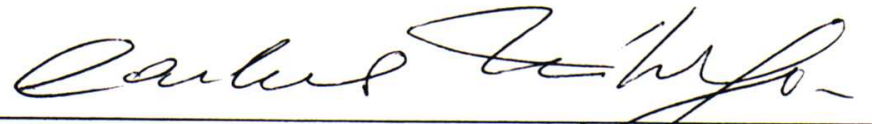

Prof. Dr. CARLOS DE ALMEIDA NÓbREGA

(UNESP/Campus de Rio Claro)

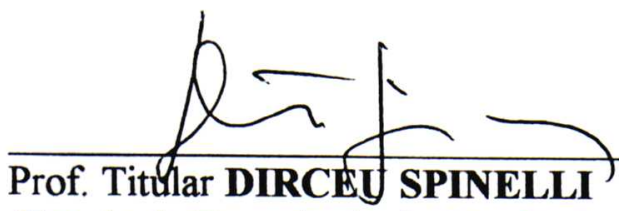

(Escola de Engenharia de São Carlos/USP)

ApROVADO

Prof. Associado/LAT4\$RO VALENTIN ZUQUETTE

Coordenador do Płogranta de Pós-Graduação ę Geotecnia

Profa. Titular MARIA DO CARMO CALJJUR

Presidente da Comissão de Pós-Graduação da EESC 
Às pessoas que mais amo nesta vida:

Minha mãe, Maria Alvarez de Pehovaz, meu esteio, meu exemplo de vida, luta, fortaleza, energia e bondade.

Meu irmão, Richard Paul Pehovaz Alvarez, meu amigo, apoio e confiança nos momentos difíceis. 


\section{AGRADECIMENTOS}

A Deus, pela oportunidade de vida, pelas pessoas que colocou em meu caminho e pela bondade e misericórdia em todos os momentos da minha vida.

A minha segunda mãe, a sempre Virgem Maria Imaculada pela proteção deste seu humilde servidor.

Ao Professor Dr. Antônio Airton Bortolucci, orientador e grande amigo, pela motivação, dedicação e incentivo, que alicerçaram minha formação acadêmica e pessoal.

Ao Professor Dr. Tarcísio Barreto Celestino, pela oportunidade e orientação na fase inicial do trabalho.

Ao Conselho Nacional de Ciência e Tecnologia - CNPq, pela bolsa concedida.

Ao Departamento de Geotecnia da EESC-USP pela oportunidade da realização do curso de Pós Graduação.

Aos Professores do Departamento de Geotecnia pelos conhecimentos transmitidos, saudável convivência, apoio e amizade.

Ao Professor Dr. Nelson Aoki pela motivação, frutíferas discussões e, sobretudo sua amizade do qual sinto-me muito orgulhoso e grato.

Ao Professor Dr. Dirceu Spinelli pela disponibilidade da máquina servo-controlada do Departamento de Materiais da EESC-USP e suas sugestões na minha qualificação.

Ao Professor Dr. José de Anchieta Rodrigues, excelente profissional e grande amigo, pela motivação, sugestões, discussões técnicas e por disponibilizar o equipamento servocontrolado e de dupla-torção do Departamento de Engenharia de Materiais (DEMA) da UFScar.

Aos funcionários do Departamento de Geotecnia, Sr. Antonio Garcia, pela confecção de vários dispositivos dos ensaios; Benedito Osvaldo de Souza pela realização dos ensaios na prensa servo-controlada; em especial, ao meu amigo Décio Lorenzo, pela ajuda na confecção das amostras e dedicação para o melhor desenvolvimento da pesquisa.

Ao Dr. Herivelto Moreira dos Santos, responsável pelo setor de informática, pela amizade e constante auxilio na parte computacional. 
Aos funcionários do Departamento de Geotecnia: Maristela Z. Batissaco, Neiva Cardoso, Álvaro Nery pelo apoio e amizade.

Aos funcionários da oficina mecânica, especialmente, ao Sr. Penazzi pela confecção de dispositivos necessários nos ensaios.

Aos Drs. Finn Ouchterlony, Mahinda Kuruppu, B.L. Karihaloo, Z. Zhang, David Doolin, Mark Fischer, Marc Thiercelin, James Donovan, Mario Karfakis, L. Liu, Ulrik Beste, B.L. Bradt por suas sugestões, discussões e informações enviadas.

Ao Dr. Luiz Felipe Ferreira por sua amizade, sugestões e informações proporcionadas.

As funcionárias da biblioteca, Marielza Ortega Roma por sua paciência, amizade e apoio na procura das referencias bibliográficas, em especial a Elena Luzia Palloni Gonçalves na formatação das referencias bibliográficas.

Aos meus colegas de turma, Marcilene, Enrique, Leonardo, Henry, Jean Carlo, Rossana, Victor Hugo, pela amizade e convivência harmoniosa.

Aos demais colegas do Departamento de Geotecnia, Jocy, Rogério, Leonardo, Karla, Luiz, Holden, Kleber, Sara, Jeselay, Domingo, Angelita, Marita, Josiely, Adelvan, Roger, Luiz Guilherme, Clébio pela amizade, carinho e paciência.

Ao Mestre Eng. Heraldo Pitanga pela correção do texto, sugestões, amizade e paciência.

Aos meus queridos amigos Miguel, Eliana e Dona Édy, muito obrigado pela amizade, carinho e apoio nos momentos difíceis.

Ao futuro Dr. Mauricio Giambastiani pelas frutíferas discussões técnicas, apoio e amizade. Meus agradecimentos finais se dirigem àqueles que sempre me apoiaram neste e em muitas outras etapas da minha vida: minha família, pelo esforço e dedicação para minha educação e formação, sem eles nada seria; em especial a minha mãe por seu esforço, sacrifício e ensinamentos; a meu irmão pela paciência e apoio, principalmente, na companhia de minha mãe, através do qual foi possível prosseguir com meus estudos.

A todos que, direta ou indiretamente, contribuíram para a realização deste trabalho. 


\section{RESUMO}

PEHOVAZ-ALVAREZ, H. I. (2004). Ensaios não convencionais para determinação da tenacidade à fratura em rochas: análise e comparação. Dissertação (Mestrado) - Escola de Engenharia de São Carlos, Universidade de São Paulo, São Carlos, 2004.

Desde o início dos anos 70, novos conceitos de mecânica da fratura foram desenvolvidos para explicar o comportamento das rochas. A tenacidade à fratura foi medida e considerada como uma propriedade intrínseca importante da rocha, a qual indica a magnitude da resistência à fratura ou sua habilidade para resistir à propagação da trinca.

A mecânica da fratura foi amplamente aplicada em operações de desmonte por explosivos, fraturamento hidráulico, fragmentação mecânica, análise da estabilidade de taludes, geofísica, mecânica de terremotos, na energia de extração geotermal e em outros problemas práticos. Salienta-se que ela é também relevante em tectônica, na tecnologia de recuperação e armazenamento de energia e na engenharia de rochas.

Nas últimas três décadas, diversos métodos para estudar a propagação da fratura no modo I foram desenvolvidos e uma série de artigos foi escrita para aumentar o conhecimento da tenacidade à fratura das rochas no modo I. Um grande número de metodologias de ensaio da tenacidade à fratura tem aparecido na literatura.

Alguns procedimentos de ensaio para a determinação da tenacidade à fratura em rochas no modo I foram padronizados pela ISRM em 1988 e em 1995. Entretanto, estes métodos de ensaio apresentam algumas dificuldades relacionadas à preparação do corpo de prova, à complexidade da instalação e à interpretação e validade dos resultados.

O objetivo deste estudo é o de comparar os métodos sugeridos pela ISRM com outros métodos sugeridos por outros pesquisadores. Alguns ensaios não padronizados podem ser úteis se conduzirem a resultados confiáveis e se seus procedimentos forem mais simples do que aqueles sugeridos pela ISRM.

Palavras chave: tenacidade à fratura, modo I, ensaios de laboratório, rochas, basalto, granito. 


\section{ABSTRACT}

PEHOVAZ-ALVAREZ, H. I. (2004). Non-conventional tests for determining the fracture toughness in rocks: analysis and comparison. Dissertation (M.Sc.) - Escola de Engenharia de São Carlos, Universidade de São Paulo, São Carlos, 2004.

Since early 1970’s new fracture mechanics concepts have been developed to explain rock fracture behavior. Fracture toughness has been measured and considered as an important intrinsic property of rock indicating the magnitude of fracture strength or its ability to resist crack propagation.

Rock fracture mechanics has been widely applied to tectonics, energy recovery and storage technology and rock engineering. It is relevant in blasting, hydraulic fracturing, mechanical fragmentation, rock slope analysis, geophysics, earthquake mechanics, geothermal energy extraction and many other practical problems.

Over the last three decades, several methods for studying the Mode I fracture propagation have been developed and a series of papers have been written to increase the knowledge of the Mode I fracture toughness in rocks. A great number of fracture toughness testing methodologies have appeared in the literature.

Some related Mode I rock fracture toughness test procedures have been standardized by ISRM in 1988 and in 1995. However, these testing methods present some relative difficulties in sample preparation, set-up complexity, interpretation and results trustworthiness.

The aim of this study is to compare the fracture toughness ISRM suggested testing methods with other suggested methodologies for other researchers. Some of the nonstandardized tests may be useful, if they lead to reliable results, and if their procedures are simpler than those suggested by ISRM.

Key words: Fracture toughness, mode I, laboratory tests, rocks, basalt, granite 


\section{LISTA DE FIGURAS}

Figura 1 Furo elíptico em uma placa submetida à tensões uniformes de tração

(WHITTAKER;SINGH e SUN, 1992)

Figura 2 Modos fundamentais de propagação da trinca (TADA; PARIS e IRWIN, 2000 apud DONOVAN, 2003)

Figura 3 Combinação dos modos fundamentais de propagação da trinca (HUDSON e HARRISON, 1997 apud BACKERS, 2001)

Figura 4 Zona Plástica na ponta da trinca (HABERFIELD e JOHNSTON, 1990)

Figura 5 Desenvolvimento da $Z P F$ em rochas (WHITTAKER; SINGH e SUN, 1992)

Figura 6 Forma e tamanho da zona plástica da trinca (SCHMIDT, 1980) 21

Figura 7 Zona de processo da fratura (KARIHALOO e NALLATHAMBI, 22 1989)

Figura 8 Faixa trincada de espessura definida (LIU; WANG e LI, 2000) 23

Figura 9 Corpo de prova cilíndrico com entalhe "chevron” sob flexão e 28 configuração do ensaio (WHITTAKER; SINGH e SUN, 1992)

Figura 10 Corpo de prova de haste curto com entalhe "chevron" sob tração e configuração do ensaio (WHITTAKER; SINGH e SUN, 1992)

Figura 11 Corpo de prova na forma de disco brasileiro com entalhe em “chevron” (WANG et al.; 2003)

Figura 12 Fator $p$ e evolução da zona do processo da fratura. As inclinações são construídas como regressões as inclinações correspondentes

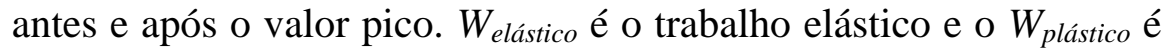
o trabalho irrecuperável realizado pelo avanço de um comprimento adicional de trinca. a)Exemplo esquemático de um ensaio. A trinca começa a propagar na carga de pico, onde o fator $p$ é determinado. b)Deformação perfeitamente elástica ( $\left.W=W_{\text {elástico e }} p=0\right)$. c)Deformação perfeitamente plástica $\left(W=W_{\text {elástico }}{ }^{+} W_{\text {plástico }}\right.$ e $\left.p=1\right)$ (BACKERS et al, 2003). 
Figura 13 Evolução da zona de processo dentro de um ciclo de carregamento.

(0) Estado inicial. A linha tracejada indica o trajeto futuro da trinca.

O deslocamento da abertura da trinca $\left(C M O D=X_{0}\right)$. (1) A trinca propagou-se uma determinada distância e uma zona de processo é estabelecida. A linha tracejada indica a posição hipotética da face da trinca, se nenhum aumento do volume devido à formação da zona de processo for evidente $\left(C M O D=X_{0}+X_{u}\right)$. (2) A trinca é fechada após descarregar. O deslocamento original não pode ser alcançado devido ao aumento do volume $\left(C M O D=X_{0}+X_{1}\right)$ (BACKERS et al, 2003).

Figura 14 Ciclos de carregamento e descarregamento para determinação da força $\left(F_{m}\right)($ OUCHTERLONY, 1989)

Figura 15 Metodologia para determinação de $F_{m}$ baseado no método da flexibilidade (OUCHTERLONY, 1989)

Figura 16 Ensaio de explosão (WHITTAKER; SINGH e SUN, 1992) 42

Figura 17 Ensaio de corpos de prova semicirculares submetidos à flexão em 45 três pontos (WHITTAKER; SINGH e SUN, 1992)

Figura 18 Ensaio de corpos de prova semicirculares com entalhe inclinado 50 submetidos à flexão em três pontos (LIM; JOHNSTON e CHOI, 1993)

Figura 19 Corpo de prova semicircular com entalhe tipo “chevron" 52 (KURUPPU, 1997)

Figura 20 Ensaio de anel trincado radialmente (WHITTAKER; SINGH e SUN, 1992)

Figura 21 Geometria do corpo de prova de anel modificado (WHITTAKER; 56 SINGH e SUN, 1992)

Figura 22 Duas trincas simetricamente radiais geradas no furo interno do corpo 56 de prova de anel modificado (WHITTAKER; SINGH e SUN, 1992)

Figura 23 Condições de contorno para o ensaio de anel modificado com 62 confinamento (THIERCELIN, 1987)

Figura 24 Representação esquemática de um contato pontiagudo mostrando os 65 parâmetros de indentação devidos à carga aplicada $(P)$; onde $\psi$ é a 
metade do ângulo de indentação, $a$ é a indentação diagonal e $c_{r}$ é o comprimento da trinca na superfície (OSTOJIC e McPHERSON, 1987)

Figura 25 Geometria do disco compacto e as condições de carregamento associadas (ALBURQUERQUE, 1998)

Figura 26 Corpo de prova prismático entalhado axialmente em ruptura por 70 compressão (KARIHALOO, 1987)

Figura 27 Corpo de prova cilíndrico entalhado axialmente em ruptura por 73 compressão (WHITTAKER; SINGH e SUN, 1992)

Figura 28 Geometria do corpo de prova e esquema do ensaio (WHITTAKER; SINGH e SUN, 1992)

$\begin{array}{llllll}\text { Figura } 29 & \text { Geometria do corpo de prova cilíndrico entalhado } 76\end{array}$ circunferencialmente submetido à flexão (WHITTAKER; SINGH e SUN, 1992)

Figura 30 Geometria do corpo de prova cilíndrico entalhado 77 circunferencialmente submetido a um carregamento excêntrico (WHITTAKER; SINGH e SUN, 1992)

Figura 31 Geometria e configuração do ensaio na placa retangular com entalhe 78 reto submetido à flexão em três pontos (WHITTAKER; SINGH e SUN, 1992)

Figura 32 Geometria e configuração do ensaio na placa retangular com entalhe 79 "chevron" submetido à flexão em três pontos (WHITTAKER; SINGH e SUN, 1992)

Figura 33 Geometria e configuração do ensaio na placa retangular com entalhe reto submetido à flexão em quatro pontos (WHITTAKER; SINGH e SUN, 1992)

Figura 34 Geometria e configuração do ensaio na placa retangular com entalhe 82 "chevron" submetido à flexão em quatro pontos (WHITTAKER; SINGH e SUN, 1992)

Figura 35 Geometria e configuração do ensaio na placa retangular com entalhe 83 reto submetido à flexão em quatro pontos em balanço (AMARAL; 
GUERRA-ROSA; CRUZ-FERNANDES, 1999)

Figura 36 Geometria do corpo de prova e configuração do ensaio dupla-torção (WHITTAKER; SINGH e SUN, 1992)

Figura 37 Principais tipos de viga em balanço duplo: a) ruptura por tração, b) 88 ruptura por flexão, c) ruptura por cunha (WHITTAKER; SINGH e SUN, 1992)

Figura 38 Ensaio em disco brasileiro sem entalhe: a) disco com corte plano 96 onde aplica o carregamento; b) disco sem o corte (ALBUQUERQUE, 1998)

Figura 39 Ensaio em disco brasileiro sem entalhe (ALBUQUERQUE, 1998) 97

Figura 40 Ilustração dos corpos de prova tipo disco brasileiro em compressão 98 diametral: a) entalhe reto central (CSCBD); b) disco com estria de aresta (SECBD) (WHITTAKER; SINGH e SUN, 1992)

Figura 41 Ensaio em disco modificado (WHITTAKER; SINGH e SUN, 1992) 101

Figura 42 Ensaio em disco brasileiro aplainado (WANG e XING, 1999) 102

Figura 43 Forças iguais e opostas geradas no corpo de prova (DONOVAN e 103 KARFAKIS, 2004)

Figura 44 Força de compressão aplicada por meio de uma cunha (DONOVAN 103 e KARFAKIS, 2004)

Figura 45 a) Geometria do corpo de prova, b) Carregamento do corpo de prova 108 (CHEN; SUN e XU, 2001)

Figura 46 Disposição do corpo de prova e a célula de carga utilizada no ensaio 109 (ROEGIERS e ZHAO, 1991)

Figura 47 Foto micrografia do basalto obtida via microscópio ótico por 122 transmissão: (a) nicoles cruzados (b) nicoles paralelos

Figura 48 Foto micrografia do plagioclásio do granito obtida via microscópio ótico por transmissão: (a) nicoles cruzados (b) nicoles paralelos

Figura 49 Foto micrografia do quartzo obtida via microscópio ótico por 124 transmissão: (a) nicoles cruzados (b) nicoles paralelos

Figura 50 Preparação dos corpos de prova $C B$ : (a) Extração dos testemunhos cilíndricos; (b) Corte das extremidades dos corpos de prova 
Figura 51 Preparação dos corpos de prova $C B$ : (a) Retificação das faces no torno; (b) Confecção do entalhe "Chevron"

Figura 52 Ensaio “Chevron Bend” sugerido pela ISRM (1988): (a) Dispositivos para fixação do corpo de prova; (b) Configuração geral do ensaio

Figura 53 Ensaio “Chevron Bend” sugerido pela ISRM (1988): (a) 132 Nivelamento do corpo de prova; (b) Detalhes dos dispositivos e colocação dos LVDTs e do extensômetro do tipo “clip gauge”

Figura 54 Gráfico Força versus $L P D$ típico do ensaio $C B$ 132

Figura 55 Preparação do corpo de prova SR: (a) Retificação das faces no torno; (b) Confecção do entalhe “Chevron” no ensaio $S R$

Figura 56 Ensaio "Short Rod” sugerido pela ISRM (1988): (a) Dispositivos 135 para fixação do corpo de prova; (b) Chapas coladas no corpo de prova e colocação das hastes do extensômetro do tipo "clip gauge"

Figura 57 Ensaio “Short Rod” sugerido pela ISRM (1988): (a) Configuração 136 geral do ensaio; (b) Detalhe do dispositivo de medida de deslocamentos

Figura 58 Gráfico Força versus CMOD típico do ensaio $S R$

Figura 59 Preparação do corpo de prova CCNBD: (a) Confecção do entalhe 138 "Chevron” no ensaio CCNBD; (b) Detalhe do entalhe

Figura 60 Configuração geral do ensaio "CCNBD”

Figura 61 Gráfico Força versus deslocamento típico do ensaio CCNBD 139

Figura 62 Preparação do corpo de prova CST: (a) Colocação do corpo de 141 prova; (b) Confecção do entalhe reto

Figura 63 Ensaio de corpos de prova cilíndricos entalhados axialmente em 142 ruptura por compressão (CST): (a) Configuração geral do ensaio; (b) Detalhe do ensaio e da placa de aço rígida de largura “ $w_{P}$ ” na superfície superior do corpo de prova

Figura 64 Propagação do pré-entalhe: (a) Detalhe do corpo de prova; (b) Depois da propagação do pré-entalhe

Figura 65 Gráfico Força versus deslocamento típico do ensaio CST

Figura 66 Preparação do corpo de prova SCB: Confecção do entalhe reto (a) 
Frente. (b) Perfil

Figura 67 Ensaio de corpos de prova semicirculares submetidos à flexão em três pontos (SCB): (a) Configuração geral do ensaio; (b) Detalhe do ensaio mostrando o controle da abertura da boca da trinca por meio do extensômetro do tipo "clip gauge"

Figura 68 Gráfico Força versus CMOD típico do ensaio SCB 147

Figura 69 Preparação do corpo de prova CNSCB: Confecção do entalhe 149 “chevron": (a) Perfil; (b) Frente

Figura 70 Ensaio de corpos de prova semicirculares com entalhe "chevron" 150 (CNSCB): (a) Configuração geral do ensaio; (b) Detalhe do ensaio mostrando o controle por meio do extensômetro do tipo "clip gauge"

Figura 71 Gráfico Força versus deslocamento típico do ensaio CNSCB 150

Figura 72 Preparação do corpo de prova MRT: (a) Confecção do furo central. 152 (b) Confecção das faces aplainadas

Figura 73 Ensaio de corpos de prova de anel modificado (MRT): (a) 153 Configuração geral do ensaio; (b) Detalhe do ensaio mostrando a propagação da trinca pelo centro do corpo de prova

Figura 74 Gráfico Força versus deslocamento típico do ensaio MRT 154

Figura 75 Preparação do corpo de prova END: Confecção do entalhe reto (a) 155 Frente. (b) Perfil

Figura 76 Ensaio de discos com entalhe na borda com partição por cunha 156 (END): (a) Configuração geral do ensaio; (b) Detalhe do ensaio mostrando a cunha utilizada

Figura 77 Ensaio de discos com entalhe na borda com partição por cunha 157 (END): (a) Detalhe da cunha penetrando no corpo de prova; (b) Corpo de prova pintado para visualizar a propagação da trinca, a partir do pré-entalhe

Figura 78 Gráfico Força versus deslocamento típico do ensaio END 157

Figura 79 Preparação do corpo de prova do ensaio de dupla torção: (a) 159 Confecção do sulco central. (b) Confecção do entalhe a $45^{\circ}$ 
Figura 80 Ensaio de dupla-torção: (a) Corpo de prova; (b) Configuração geral 160 do ensaio

Figura 81 Ensaio de dupla-torção: (a) Detalhe da aplicação da carga sob o 160 corpo de prova; (b) Corpo de prova ensaiado (notar a propagação do pré-entalhe pelo sulco central)

Figura 82 Gráfico Força versus deslocamento típico do ensaio DT 161

Figura 83 Ensaio de carga pontual com corpos de prova carregados axialmente: (a) Configuração geral do ensaio; (b) Detalhe do ensaio mostrando as pontas cônicas e o corpo de prova axial

Figura 84 Ensaio de carga pontual com corpos de prova irregulares: (a) Configuração geral do ensaio; (b) Detalhe do ensaio mostrando as pontas cônicas e o corpo de prova irregular

Figura 85 Comparação entre os diferentes métodos de ensaio - Basalto

Figura 86 Comparação entre os diferentes métodos de ensaio - Granito

Figura 87 Comparação entre os valores obtidos nos ensaios e os valores da literatura - Basalto

Figura 88 Comparação entre os valores obtidos nos ensaios e os valores da literatura - Granito 


\section{LISTA DE TABELAS}

Tabela 1 Dimensões do corpo de prova “CB” 27

Tabela 2 Dimensões do corpo de prova "SR" 30

Tabela 3 Fatores de intensidade de tensão no modo I normalizado para o ensaio SCB 47 (LIM; JOHNSTON e CHOI, 1993)

Tabela 4 Valores de $\phi$ e $\mu$ a partir do ensaio "tilt test" na interface rocha / aço 105 endurecido

Tabela 5 Propriedades físicas das rochas estudadas 125

Tabela 6 Propriedades mecânicas das rochas estudadas - Basalto 126

Tabela $7 \quad$ Propriedades mecânicas das rochas estudadas - Granito 127

Tabela 8 Propriedades físico-mecânicas das rochas estudadas 127

Tabela 9 Tenacidade à fratura das rochas estudadas utilizando correlações 128 empíricas

Tabela 10 Resultados do ensaio em corpos de prova cilíndricos com entalhe 133 “chevron” sob flexão $(C B)$

Tabela 11 Resultados do ensaio em corpos de prova de haste curto com entalhe 137 “chevron” sob tração (SR)

Tabela 12 Resultados do ensaio em corpos de prova em forma de disco brasileiro 140 fraturado com entalhe “chevron” (CCNBD)

Tabela 13 Resultados do ensaio em corpos de prova cilíndricos entalhados 144 axialmente em ruptura por compressão (CST)

Tabela 14 Resultados do ensaio em corpos de prova semicirculares submetidos à flexão em três pontos (segundo fórmula de Whittaker, Singh e Sun, 1992)

Tabela 15 Resultados do ensaio em corpos de prova semicirculares submetidos à 148 flexão em três pontos (segundo fórmula de Lim, Johnston e Choi, 1993)

Tabela 16 Resultados do ensaio em corpos de prova semicirculares com entalhe 151 tipo “chevron” submetidos à flexão em três pontos (CNSCB)

Tabela 17 Resultados do ensaio em corpos de prova de anel modificado (MRT) 154

Tabela 18 Resultados do ensaio em discos com entalhe na borda com partição por 158 
cunha $(E N D)$

Tabela 19 Resultados do ensaio em dupla-torção (DT) 161

Tabela 20 Resultados do ensaio de carga pontual com corpos de prova axiais 163

Tabela 21 Resultados do ensaio de carga pontual com corpos de prova irregulares 165

Tabela 22 Resumo dos resultados experimentais do basalto (CB, SR, CCNBD, SCB 171 e CNSCB)

Tabela 23 Resumo dos resultados experimentais do basalto (CST, Carga pontual, 172 Dupla-torção, $M R T$ e END)

Tabela 24 Resumo dos resultados experimentais do granito (CB, SR, CCNBD, SCB 172 e $C N S C B$ )

Tabela 25 Resumo dos resultados experimentais do granito (CST, Carga pontual, 173 Dupla-torção, $M R T$ e END) 


\section{LISTA DE SIGLAS}

ACI - American Concrete Institute

ACRBC - Axial Cracked Round Bar in compressive splitting (corpo de prova cilíndrico entalhado axialmente em ruptura por compressão).

ANSYS - ANSYS ${ }^{\circledR}$ código de analyses de elementos finitos

ASTM - American Society for Testing and Materials

$B D T$ - Uncracked Brazilian Disk test (ensaio de disco brasileiro sem entalhe)

$B E M$ - Método de elementos de contorno bidimensional.

$B T$ - Burst Test (ensaio de explosão)

$C A R$ - concreto de alta resistência

$C B$ - Chevron Bend test (ensaio em corpos de prova cilíndricos com entalhe "chevron” sob flexão).

CCNBD - Cracked Chevron Notched Brazilian Disc test (ensaio em corpos de prova em forma de disco brasileiro fraturado com entalhe "chevron”)

CDISK - discos brasileiros tipo "chevron"

$C N R B B$ - Circumferentially Notched Round Bar in Bending (corpo de prova cilíndrico com entalhe circunferêncial submetido à flexão).

CNSCB - Chevron Notched Semicircular Bend test (ensaio em corpos de prova semicirculares com entalhe tipo “chevron” submetidos à flexão em três pontos)

$C N 3 P B$ - Single edge chevron-notched rectangular plate in three point bending (placa retangular com entalhe “chevron” submetido à flexão em três pontos)

$C N 4 P B$ - Single edge chevron-notched rectangular plate in four point bending (placa retangular com entalhe “chevron” submetido à flexão em quatro pontos)

$C M O D$ - deslocamento da abertura da boca da trinca

CMOD - velocidade do deslocamento da abertura da boca da trinca

CRFA - concreto reforçado com fibras de aço

$C S 4 P B$ - Single edge straight-through cracked rectangular plate in four point bending (placa retangular com entalhe reto submetido à flexão em quatro pontos)

$C S C B D$ - Central straight-through cracked brazilian disk in diametral compression (disco brasileiro com entalhe reto central submetido à compressão diametral) 
CST - Compression Splitting Test (ensaio em corpos de prova cilíndricos entalhados axialmente em ruptura por compressão)

CTOD - deslocamento da abertura da ponta da trinca

$C T O D_{c}$ - deslocamento crítico de abertura da ponta da trinca

$D C B$ - Double Cantilever Beam in splitting (viga prismática em ruptura com balanço duplo)

DEMA - Departamento de Engenharia de Materiais da Universidade Federal de São Carlos.

DT - Double Torsion specimen (corpos de prova em dupla-torção)

EESC - Escola de Engenharia de São Carlos.

END - Edge Notched Disc wedge splitting test (ensaio em discos com entalhe na borda com partição por cunha)

FDT - Flattened brazilian Disk Test (ensaio de disco brasileiro aplainado)

FRANC - Fracture ANalysis Code

ISRM - International Society of Rock Mechanics

$M C$ - modelo coesivo

MDT - Modified Disk Test (ensaio de disco modificado)

MFEL - Mecânica da Fratura Elástica Linear

MFENL - Mecânica da Fratura Elástica Não Linear

$M R T$ - Modified Ring Test (ensaio de anel modificado)

MTS - Mechanics Testing System

NRBEL - Circumferentially Notched Bar in Eccentric Loading (corpo de prova cilíndrico com entalhe circunferêncial submetido a um carregamento excêntrico).

$L P D$ - deslocamento do ponto de carregamento

$P C$ - computador pessoal

PMMA - Polymethyl-methacrylate (plexigas)

PLT - Point Load Test (ensaios de carga pontual)

PSZ - zircônio estabilizado

PVC - Cloreto de polivinila.

$R C R$ - Radial Cracked Ring specimen (ensaio de anel trincado radialmente)

$R C T$ - Round Compact Disk in tension (disco compacto em tração) 
RILEM - Réunion Internationale dês Laboratoires et Experts dês Matériaux, systèmes de construction et ouvrages

SCB - Semicircular Bend Specimen test (ensaio em corpos de prova semicirculares submetidos à flexão em três pontos)

S.C.I.R.O - Commonwealth Scientific and Industrial Research Organisation

$S C 3 P B$ - Single edge straight-through cracked rectangular plate in three point bending (placa retangular com entalhe reto submetido à flexão em três pontos)

SECBD - Single Edge Crack Brazilian Disk in diametral compression (disco brasileiro com estria de aresta submetido à compressão diametral)

SENRBB - Single Edge Notched Round Bar in Bending (corpo de prova cilíndrico com entalhe reto submetido à flexão).

$S P$ - São Paulo

$S R$ - Short Rod test (ensaio em corpos de prova de haste curto com entalhe "chevron” sob tração)

$S S Y$ - deformação plástica em pequena escala

ZPF - Zona de Processo da Fratura 


\section{LISTA DE SIMBOLOS}

$\alpha$ - ángulo da cunha

$\alpha_{i}$ - ângulo de inclinação do entalhe em relação à direção de carregamento

$\alpha_{0}$ - comprimento adimensional do entalhe inicial

$\alpha_{1}$ - comprimento adimensional da trinca na face do corpo de prova

$\alpha_{B}$ - largura adimensional da trinca

$\alpha_{S}$ - raio adimensional da serra do corpo de prova $C C N B D$

$\beta$ - metade do ângulo sobre o qual a carga diametral é aplicada

$\gamma_{s}$ - energia específica de superfície

$\delta$ - deslocamento

$\delta_{c}$ - valor crítico do deslocamento da abertura na ponta da trinca verdadeira

$\delta_{F}-L P D$

$\delta_{F e}-L P D$ do ponto interpolado

$\delta_{F i}-L P D$ no ponto avaliado $F_{i}$

$\delta_{F l}-L P D$ do ponto intermediário

$\delta_{t}$ - deslocamento da abertura na ponta da trinca verdadeira

$\delta_{F}^{r}-L P D$ residual depois do deslocamento

$\delta_{F_{i}}^{r}$ - LPD residual depois do descarregamento no ponto de carga $F_{i}$

$\Delta \delta$ - deslocamento da abertura da trinca

$\Delta F$ - distância vertical entre a curva de carregamento e descarregamento no ponto $L$

$\Delta w, \Delta a_{0}, \Delta \theta$ - diferença entre os valores medidos e os valores nominais do comprimento do corpo de prova, do comprimento do entalhe inicial e do ângulo "chevron”, respectivamente no ensaio "SR"

$\emptyset_{\max }$ - fator de intensidade de tensão máximo adimensional

$\sigma$ - tensão aplicada ao sólido

$\sigma(x)$ - tensão coesiva

$\sigma_{a}$ - tensão axial acima da pressão confinante

$\sigma_{c}$ - pressão de confinamento

$\sigma_{t}$ - resistência à tração

$\sigma_{c r}$ - tensão crítica para a ruptura do corpo fraturado 
$\sigma_{y s}-$ tensão de escoamento

$\sigma_{\theta}^{i}$ - tensão tangencial induzida pela pressão interna

$\sigma_{\theta}^{o}$ - tensão tangencial induzida pela pressão extrena

$\varepsilon$ - deformação unitária

$\lambda$ - raio da zona plástica na ponta da trinca

$\lambda_{F}$ - flexibilidade no ponto de carga

$\lambda_{F i}$ - flexibilidade no ponto de carga $F_{i}$

$v$ - coeficiente de Poisson

$\xi$ - comprimento adimensional da trinca

$\psi$ - metade do ângulo de indentação

$\eta$ - porosidade

$\rho$ - densidade

$\rho_{d}$ - densidade seca

$\rho_{w}$ - densidade da água

$\theta$ - ângulo "chevron"

$\mu$ - coeficiente de atrito

$2 \theta$ - ângulo de distribuição de tensões

$a$, a - comprimento da trinca ou do entalhe

$a_{0}$ - comprimento inicial do entalhe, posição da ponta do entalhe "chevron"

$a_{e}$ - metade do comprimento do eixo maior da elipse

$a_{\text {eff }}$ - comprimento efetivo da trinca

$a_{t}$ - metade do comprimento da trinca

$a_{1}-a_{0}$ - comprimento do entalhe "chevron" no corpo de prova do ensaio "SR"

$a_{\text {cir }}$ - entalhe circunferencial

$A$ - área infinita; comprimento da trinca para a geometria de disco brasileiro com duplo entalhe na borda

$b$ - largura de superfície aplainada de carregamento

$b_{e}$ - metade da largura da elipse

$B$ - espessura do corpo de prova

$B_{n}$ - espessura da placa na estria no ensaio $D T$ 
$B^{*}$ - constante adimensional em função do comprimento do entalhe e raio do corpo de prova no ensaio SCB segundo Lim; Johnston e Choi (1993)

$c_{r}$ - comprimento radial da trinca na superfície no ensaio de indentação.

$C$ - flexibilidade da amostra $\left(C=\frac{\delta}{P}\right)$

$C_{K}$ - fator de correção em função da geometria do corpo de prova no ensaio " $S R$ "

$\left.C^{a c ̧ o}\right|_{a}$ - flexibilidade do corpo de prova de aço como uma função do comprimento da trinca

$\left.C^{\text {granito }}\right|_{a}$ - flexibilidade do corpo de prova de granito como uma função do comprimento da trinca

$d$ - diâmetro dos furos de carregamento no ensaio de disco compacto em tração

$D$ - diâmetro do corpo de prova

$D_{\text {ext }}$ - diâmetro externo do corpo de prova

$D_{\text {int }}$ - diâmetro do furo central

$D_{\text {min }}$ - diâmetro mínimo permitido para o corpo de prova no ensaio $C C N B D$

$e$ - distância entre o ponto de carga e o eixo do corpo de prova

$E$ - módulo de elasticidade

$E^{\prime}$ - módulo de elasticidade efetivo

$E^{a c ̧ o}$ - módulo de elasticidade do aço

$E_{\text {effetivo }}^{\text {granito }}$ - módulo de elasticidade efetivo para o granito

$f_{i}$ - fator de intensidade de tensão no modo I para a geometria de disco brasileiro com duplo entalhe na borda

$F_{C_{o}}$ - força compressiva no início do crescimento do entalhe

$F_{c}$ - carga crítica na curva carga-deslocamento

$F_{e}$ - Ponto interpolado

$F_{i}$ - interseção da linha reta final a $0.5 \Delta F$ abaixo da inclinação inicial $\left(s_{m}\right)$ com o contorno da curva $F$ vs $\delta_{F}$

$F_{m}$ - carga no ponto de avaliação

$F_{S}$ - força de separação

$F_{t}$ - carga de tração

$F_{v}$ - carga na direção vertical 
$F_{\text {máx }}$ - carga máxima aplicada

$F_{H}$ - carga correspondente ao ponto $H$

$F_{L}-F_{L}=0,50 F_{H}$

$F_{Q_{i}}$ - carga secante associada no ensaio $R C T$

$F_{l}$ - Ponto intermediário

$G_{F}$ - variação da liberação da energia de deformação

$G_{F C}$ - variação crítica da liberação da energia de deformação

$G_{I C}$ - variação crítica da liberação da energia de tensão

$h$ - metade da largura do corpo de prova no ensaio de viga prismática em ruptura por tração com balanço duplo.

$h_{c}$ : profundidade do corte no ensaio $C C N B D$

$H$ - ponto maior onde começa o descarregamento

$h(x, a)$ - função peso no ensaio de disco brasileiro com duplo entalhe na borda

I - momento de inércia da seção transversal do corpo de prova

$I_{s(50)}$ - resistência à carga pontual

$k$ - fator de concentração de tensões de Inglis

$K$ - fator de intensidade de tensão

$K_{c}$ - fator de intensidade de tensão crítica

$K_{q}$ - tenacidade à fratura calculada usando a fórmula elástica linear

$K_{c b}$ - tenacidade à fratura de uma rocha homogênea

$K_{n d}$ - fator de intensidade de tensão normalizado no ensaio $C N S C B$

$K_{n d_{\max }}$ - fator de intensidade de tensão máximo no ensaio $C N S C B$

$K_{C B}$ - tenacidade à fratura no nível I do ensaio " $C B$ ”

$K_{I}$ - fator de intensidade de tensão no modo I

$K_{I I}$ - fator de intensidade de tensão no modo II

$K_{I I I}$ - fator de intensidade de tensão no modo III

$K_{I C}$ - tenacidade à fratura no modo I.

$K_{q}$ - tenacidade à fratura calculada usando a fórmula elástica linear nos ensaios sugeridos pela ISRM 1988

$K_{Q}$ - tenacidade à fratura aparente

$K_{I}^{*}$ - fator de correção para a geometria do corpo de prova e para a forma de carregamento 
$K_{r}, U_{r}$ - fatores de intensidade de tensão e deslocamentos da abertura da boca da trinca no ensaio de disco brasileiro com duplo entalhe na borda

$K_{S R}$ - tenacidade à fratura no nível I do ensaio "SR"

$K_{\sigma}$ - Fator de intensidade de tensão devido à tensão remota aplicada

$K_{\sigma(x)}$ - Fator de intensidade de tensão devido à tensão coesiva

$K_{C B}^{c}$ - tenacidade à fratura para o corpo de prova “ $C B$ ” no nível II

$K_{S R}^{c}$ - tenacidade à fratura para o corpo de prova "SR" no nível II

$K_{I C}^{S}$ - fator de intensidade de tensão crítico

$K_{I}^{c}$ - fator de intensidade de tensão normalizado devido à pressão negativa “ $p$ ” aplicada ao longo dos setores circulares interiores e exteriores do corpo de prova

$K_{I}^{u}$ - fator de intensidade de tensão normalizado devido à pressão uniforme " $f$ ” ao longo da superfície de carregamento

$K_{I C\left(\sigma_{c}\right)}$ - tenacidade à fratura a uma pressão confinante determinada

$K_{I C(0)}$ - tenacidade à fratura sem confinamento

$l$ - deslocamento recuperado $\left(l=\delta_{F_{i}}-\delta_{F_{i}}^{r}\right.$ ), metade do comprimento da superfície aplainada de carregamento no ensaio $M R T$

$l_{e}$ - vão entre os pontos de carregamento externo no ensaio de placa retangular com entalhe reto submetido à flexão em quatro pontos em balanço

$l_{h}$ - distância vertical do centro do furo ao centro do corpo de prova

$l_{i}$ - vão entre os pontos de carregamento interno no ensaio de placa retangular com entalhe reto submetido à flexão em quatro pontos em balanço

$l_{1}$ - vão entre os apoios inferiores do corpo de prova no ensaio CS4PB e $C N 4 P B$

$l_{2}$ - vão entre os apoios superiores do corpo de prova no ensaio CS4PB e $C N 4 P B$

$L$ - comprimento do corpo de prova; ponto baixo na parte de recarregamento definido pela carga correspondente a $F_{L}=0.50 F_{H}$

$M$ - momento aplicado

$N_{I}\left(\frac{a_{t}}{R}\right)$ - coeficiente adimensional em função de $\frac{a_{t}}{R}$

$p$ - fator não linear 
$P$ - carga aplicada

$P_{i}$ - pressão interna correspondente ao mínimo local

$P_{\text {int }}-$ pressão interna

$P_{f}$ - pressão interna máxima

$P_{\min }$ - carga aplicada local mínima

$P_{o}$ - pressão confinante constante

$P_{Q}$ - carga crítica na curva carga-deslocamento

$q^{*}$ - carga máxima crítica no ensaio $R C R$

$r, \theta$ - coordenadas polares

$r_{o}$ - raio externo do corpo de prova

$r_{i}$ - raio do furo interno no corpo de prova

$r_{e}$ - raio da curvatura na ponta da elipse; zona elástica ou região k-dominante

$r_{y}$ - zona plástica

$r_{m c}$ - raio crítico da zona de processo da fratura

$R$ - raio do corpo de prova

$R_{s}$ - raio da serra de corte

$S$ - vão entre os apoios do corpo de prova

$S_{F}$ - inclinação no ponto de carga

$S_{F 0}$ - inclinação inicial da tangente da curva $F$ vs $\delta F$

$S_{F i}$ - inclinação da linha reta final, correspondente a $F_{i}$

$S_{F m}$ - inclinação no ponto de avaliação

$\frac{S_{a}}{R}$ - relação real do vão empregado

$\frac{S_{0}}{R}$ - relação do vão mais próximo dos valores de $\frac{S_{a}}{R}$ analisados por Lim; Johnston e Choi

$t$ - largura do entalhe; largura da trinca

$u, v$ : valores constantes determinados em função de $\alpha_{0}$ e $\alpha_{B}$ para o ensaio $C C N B D$

$u_{x}, u_{y}$ - deslocamentos precedentes ao pico no ensaio $B D T$

$U$ - energia elástica total

$U_{0}$ - energia elástica da chapa carregada ainda não trincada

$U_{E}$ - perda de energia de deformação elástica causada pela presença da trinca 
$U_{S}$ - variação na energia de superfície causada pela formação de superfícies trincadas (irreversível)

$V_{P}$ - velocidade de onda sônica

$V_{\text {tot }}$ - volume externo

$V_{\text {vazio }}$ - volume de vazios

$w$ - relação entre o raio do corpo de prova e o raio do furo interno

$w$ - $a$ - comprimento não trincado

$w_{P}$ - largura da placa superior de carregamento

$W$ - largura do corpo de prova

$W_{m}$ - braço do momento na placa no ensaio $D T$

$W_{\text {ext }}$ - trabalho realizado pela força externa (subtraído uma vez que não é parte da energia interna da placa)

$W_{\text {sat }}$ - peso saturado

$W_{\text {seco }}-$ peso seco

$W_{\text {sub }}$ - peso submerso

$W_{Z P F}$ - largura da zona de processo da fratura

$x, y, z$ - coordenadas cartesianas

$x$ - distância do centro da ponta da trinca verdadeira, ao longo do eixo $\mathrm{x}$ do sistema de coordenadas $x$ e $y$

$x_{1}$ - distância horizontal entre as retas $\left(S_{1}\right.$ e $\left.S_{2}\right)$ no eixo $L P D$ ou $C M O D$

$x_{u}$ - distância horizontal entre as retas $\left(S_{1}\right.$ e $\left.S_{2}\right)$ nos pontos $F_{1}$ e $F_{2}$.

$X$ - coordenada com o origem na abertura da trinca para a geometria de disco brasileiro com duplo entalhe na borda

$Y$ - fator de calibração; fator de correção para a geometria do corpo de prova e para a forma de carregamento em função do comprimento da trinca $(a)$; coeficiente do fator intensidade de tensão para um entalhe reto.

$Y_{K}$ - fator de intensidade de tensão adimensional

$Y_{I}$ - fator de intensidade de tensão adimensional no modo I

$Y_{I I}$ - fator de intensidade de tensão adimensional no modo II

$\bar{Y}$ - valor mínimo local de $Y$ para o $w$ dado 
xxiv

$\bar{Y}^{c}$ - valor mínimo local de $Y$ para $w$ e $\frac{P_{o}}{P_{i}}$ dados

$Y_{m}^{*}$ - coeficiente da intensidade de tensão mínima

$Y^{*}$ - coeficiente do fator de intensidade de tensão para um entalhe "chevron"

$Y_{m}^{*}$ - coeficiente da intensidade de tensão mínima para o ensaio em corpos de prova curtos

com entalhe em “chevron” submetidos a condições simuladas de pressão e temperatura.

$Y_{\min }^{*}$ - fator de forma para o corpo de prova $C C N B D$

$Y_{I}\left\{\frac{S_{0}}{R}\right\}$ - intensidade de tensão normalizada para uma determinada relação de vão $\frac{S_{0}}{R}$ 


\section{SUMARIO}

RESUMO

ABSTRACT

LISTA DE FIGURAS iii

LISTA DE TABELAS Xi

LISTA DE SIGLAS iii

LISTA DE SIMBOLOS Xvii

1 INTRODUÇÃO

2 CONTEXTO HISTÓRICO E INTRODUÇÃO À MECÂNICA DA FRATURA

2.1 Introdução 5

2.2 Mecânica da fratura elástica linear $\quad 7$

2.2.1 Conceito de balanço energético de Griffith (1921) 7

2.2.2 Conceito da variação da liberação da energia de deformação de Irwin 10 (1948)

2.2.3 Modos de propagação da trinca 13

2.3 Mecânica da fratura elástica não linear 14

2.4 Descrição geral das características da zona do processo da fratura 19

3 REVISÃO BIBLIOGRÁFICA 25

3.1 Introdução 25

3.2 Ensaios sugeridos pela ISRM 26

3.2.1 Introdução 26

3.2.2 Corpos de prova cilíndricos com entalhe “chevron” sob flexão - 27 "Chevron Bend $(C B)$ "

3.2.3 Corpos de prova de haste curto com entalhe “chevron” sob tração "Short Rod $(S R)$ " 
3.2.4 Corpos de prova na forma de disco brasileiro com entalhe em

"chevron” - "Cracked circumferential notched brazilian disc (CCNBD)”

3.2.5 Fator de correção plástica " $p$ ” 35

3.2.6 Análise da não linearidade para a determinação da tenacidade à fratura 36 do Nível II no modo I

3.2.7 Avaliação do Nível II no Modo I para a determinação da tenacidade à fratura com os corpos de prova $C B$ e $S R$

3.3 Ensaios não padronizados pela ISRM

3.3.1 Ensaio de explosão - "Burst test $(B T)$ "

3.3.2 Ensaio de corpos de prova semicirculares submetidos à flexão em três pontos - "Semi-circular bend specimen $(S C B)$ ”

3.3.3 Ensaio de corpos de prova semicirculares com entalhe tipo "chevron" submetidos à flexão em três pontos - “Chevron Notched Semicircular Bend test (CNSCB)"

3.3.4 Ensaio de anel trincado radialmente - "Radial cracked ring specimens $(R C R) ”$

3.3.5 Ensaio de anel modificado - "Modified Ring test (MRT)"

3.3.6 Ensaio de anel modificado com confinamento

3.3.7 Método de indentação - “Indentation Method”

3.3.8 Disco compacto em tração - "Round compact disk in tension (RCT)"

3.3.9 Corpo de prova cilíndrico entalhado axialmente em ruptura por compressão “Compression splitting test (CST)”

3.3.10 Corpo de prova cilíndrico com entalhe reto submetido a flexão - "Single edge notched round bar in bending (SENRBB)"

3.3.11 Corpo de prova cilíndrico com entalhe circunferencial submetido à flexão "Circumferentially notched round bar in bending $(C N R B B)$ "

3.3.12 Corpo de prova cilíndrico com entalhe circunferencial submetido a um 76 carregamento excêntrico - “Circumferentially notched bar in eccentric loading (NRBEL)"

3.3.13 Placas retangulares submetidas à flexão - "Rectangular plates in bending” 77

3.3.13.1 Placa retangular com entalhe reto submetido à flexão em três pontos - 
“Single edge straight-through cracked rectangular plate in three point bending $(S C 3 P B)$ "

3.3.13.2 Placa retangular com entalhe "chevron" submetido à flexão em três pontos - "Single edge chevron-notched rectangular plate in three point bending $(C N 3 P B)$ "

3.3.13.3 Placa retangular com entalhe reto submetido à flexão em quatro pontos "Single edge straight-through cracked rectangular plate in four-point bending $(C S 4 P B)$

3.3.13.4 Placa retangular com entalhe "chevron” submetido à flexão em quatro pontos - "Single edge chevron-notched rectangular plate in four-point bending $(C N 4 P B)$ ”

3.3.13.5 Placa retangular com entalhe reto submetido à flexão em quatro pontos em balanço

3.3.14 Corpos de prova em dupla-torção - "Double torsion specimen $(D T)$ "

3.3.15 Viga prismática em ruptura com balanço duplo - "Double cantilever beam in splitting $(D C B)$ ”

3.3.15.1 Viga prismática em ruptura por tração com balanço duplo 88

3.3.15.2 Viga prismática em ruptura por flexão com balanço duplo 91

3.3.15.3 Viga prismática em ruptura por cunha com balanço duplo

3.3.16 Ensaio em disco brasileiro sem entalhe - "Uncracked Brazilian disk test $(B D T)$ "

3.3.16.1 Proposta de Hua Guo (1990)

3.3.16.2 Proposta de Celestino e Bortolucci (1992)

3.3.17 Disco brasileiro com entalhe

3.3.17.1 Disco brasileiro com entalhe reto central submetido à compressão diametral - "Central Straight-through Cracked Brazilian Disk (CSCBD)"

3.3.17.2 Disco brasileiro com estria de aresta submetido à compressão diametral 100 "Single Edge Crack Brazilian Disk in diametral compression (SECBD)"

3.3.18 Ensaio em disco modificado - "Modified disk test (MDT)" 101

3.3.19 Ensaio em disco brasileiro aplainado - "Flattened Brazilian disk test (FDT)” 101

3.3.20 Ensaio em discos com entalhe na borda com partição por cunha - "Edge 102 
Notched Wedge Splitting test (END)"

3.3.21 Ensaio em disco brasileiro com duplo entalhe na borda - "Double Edge 106 Cracked Brazilian disk test”

3.3.22 Ensaio em corpos de prova curtos com entalhe em "Chevron" submetidos a 108 condições simuladas de pressão e temperatura

3.4 Relações empíricas para a determinação da tenacidade à fratura

3.4.1 Relação empírica entre o Modo I da tenacidade à fratura e a resistência à tração em rochas

3.4.2 Relação empírica entre o Modo I da tenacidade à fratura e a resistência à Compressão uniaxial

3.4.3 Relação empírica entre o Modo I da tenacidade à fratura e a resistência à carga pontual

3.4.4 Relação empírica entre o Modo I da tenacidade à fratura e o módulo de Elasticidade $(E)$

3.4.5 Relação empírica entre o Modo I da tenacidade à fratura e o coeficiente de 117 Poisson (v)

3.4.6 Relação empírica entre o Modo I da tenacidade à fratura e a velocidade de 118 onda acústica $\left(V_{P}\right)$

3.4.7 Relação empírica entre o Modo I da tenacidade à fratura e a densidade ( $\rho$ )

4 ENSAIOS REALIZADOS E RESULTADOS OBTIDOS

4.1 Introdução

4.2 Descrição petrográfica das rochas 121

4.3 Propriedade físicas e mecânicas das rochas ensaiadas 124

$\begin{array}{lll}\text { 4.3.1 Propriedades Físicas } & 125\end{array}$

4.3.2 Propriedades Mecânicas 126

4.4 Preparação,instrumentação e execução dos ensaios 128

4.4.1 Corpo de prova cilíndricos com entalhe "Chevron" sob flexão - "Chevron 128 Bend $(C B)$ "

4.4.2 Corpos de prova de haste curto com entalhe "chevron" sob tração - "Short 133 
Rod

$(S R)$

4.4.3 Corpos de prova em forma de disco brasileiro com entalhe "Chevron" -

“Cracked Circunferencial Notched Brazilian Disc (CCNBD)”

4.4.4 Corpos de prova cilíndricos entalhados axialmente em ruptura por compressão - “Compression Splitting test (CST)”

4.4.5 Corpos de prova semicirculares submetidos à flexão em três pontos "Semicircular Bend specimen (SCB)"

4.4.6 Corpos de prova semicirculares com entalhe tipo "Chevron" submetidos à

Flexão em três pontos - "Chevron Notched Semicircular Bend (CNSCB)"

4.4.7 Corpos de prova de anel modificado - "Modified Ring test (MRT)"

151

4.4.8 Discos com entalhe na borda com partição por cunha - "Edge Notched Disc Wedge Splitting test (END)”

4.4.9 Corpos de prova em dupla-torção - "Double torsion specimen (DT)”

4.4.10 Corpos de prova axiais e irregulares para o ensaio de carga pontual - “Axial and Irregular Point Load test (PLT)”

5 DISCUSSÃO E ANÁLISE DOS RESULTADOS

5.1 Introdução

5.2 Propriedades físicas e mecânicas das rochas estudadas

5.3 Ensaios sugeridos pela ISRM 168

5.4 Ensaios não padronizados pela ISRM 169

5.5 Comparação dos ensaios entre si e os valores encontrados na literatura

6 CONCLUSÕES E SUGESTÕES PARA TRABALHOS FUTUROS 


\section{INTRODUÇÃO}

Uma compreensão dos mecanismos de fratura das rochas é um pré-requisito essencial para projetar as escavações na mineração e as estruturas na engenharia civil, para desenvolver processos de fragmentação de rochas e para estabelecer programas destinados a prever situações perigosas tais como os fenômenos denominados “rock burst". Segundo Rossmanith (1983), deve-se fazer uma distinção entre a correntemente denominada mecânica da ruptura (Failure Mechanics) e a mecânica da fratura (Fracture Mechanics).

A mecânica da ruptura geralmente refere-se ao processo global de ruptura, no sentido contínuo, pelo qual uma rocha ou um maciço rochoso experimenta danos permanentes que afetam sua habilidade para resistir a uma carga. Exemplos podem incluir: i) a ruptura rápida de um corpo de prova cilíndrico carregado lentamente sob compressão no laboratório, ii) o fenômeno de “rock burst” ou iii) o colapso de piso de uma mina.

Por outro lado, a mecânica da fratura refere-se à propagação discreta de uma ou várias trincas individuais. Esta propagação da trinca é freqüentemente repentina, mas também pode ocorrer lentamente. Exemplos incluem o fraturamento de uma rocha carregada em flexão no laboratório e um fraturamento hidráulico no qual uma única trinca é propagada a partir da pressão de óleo ou gás, bem como pela aplicação de um fluido de pressão para incrementar a produtividade do processo de fraturamento.

A mecânica da fratura é a ciência que quantifica as condições sob as quais um sólido, pela ação de um carregamento, pode chegar ao colapso devido à propagação de uma trinca contida no mesmo. Pela própria natureza do fenômeno de fratura, essa disciplina compreende uma ponte de conhecimentos entre a mecânica aplicada e a ciência dos materiais.

Um parâmetro fundamental da mecânica da fratura é a tenacidade à fratura que indica a capacidade de materiais idealmente frágeis resistirem aos processos de fratura 
ocasionados por esforços de fadiga ou estáticos. Desde o início dos anos 70, novos conceitos baseados na mecânica da fratura foram desenvolvidos para explicar o comportamento das rochas. A tenacidade à fratura foi medida e considerada como uma propriedade intrínseca importante da rocha, que indica a magnitude da resistência à fratura ou a habilidade da rocha para resistir à propagação da trinca (OUCHTERLONY, 1980; SCHMIDT, 1976).

A mecânica da fratura foi amplamente aplicada em desmontes por explosão, no fraturamento hidráulico, na fragmentação mecânica, na análise da estabilidade de taludes, em geofísica, na mecânica de terremotos, na energia de extração geotermal e em outros problemas práticos, sendo também relevante em tectônica, na tecnologia de recuperação e de armazenamento de energia e na engenharia das rochas (ATKINSON, 1982; SCHMIDT e ROSSMANITH, 1983; SUN e OUCHTERLONY, 1986; ISRM, 1988; BACKERS, 2001).

Segundo Backers (2001), o crescimento da trinca ocorre predominantemente no modo I para a maioria dos materiais frágeis sob condições de plastificação em pequena escala. Mesmo nas situações onde as circunstâncias favorecem a propagação da trinca no modo II (plano de corte), o modo I parece assumir o controle da mesma. Este autor afirma que esta é a razão principal porque a mecânica da fratura no modo I tem sido estudada em detalhe.

Para introduzir alguma consistência e exatidão nos ensaios para a determinação da tenacidade à fratura, a International Society of Rock Mechanics (ISRM) sugere que os ensaios Chevron Bend (CB), Short Rod (SR) (ISRM, 1988) e Cracked Chevron Notched Brazilian Disc (CCNBD) (ISRM, 1995) deveriam ser adotados como procedimentos de ensaio recomendados.

Apesar da recomendação, pela ISRM, o uso dos ensaios de tenacidade à fratura para caracterização e propósitos de classificação não é unânime. Estes métodos de ensaio apresentam dificuldades em relação à preparação dos corpos de prova, à complexidade da instalação, à interpretação e validez dos resultados e também dificuldades na obtenção de dimensões consistentes dos entalhes para as tolerâncias especificadas.

A presente pesquisa foi desenvolvida com o objetivo de comparar os métodos sugeridos pela ISRM com outros métodos não padronizados por esta instituição, mas propostos por outros pesquisadores e apresentados na literatura especializada. Alguns 
ensaios não padronizados podem ser úteis se conduzirem a resultados confiáveis e se seus procedimentos forem mais simples do que aqueles sugeridos pela ISRM. É razoável ter a expectativa de que quanto mais simples for o procedimento de ensaio, maior será seu uso, pois maiores são as chances de redução de custos e tempo de execução.

No Capítulo 2, apresenta-se uma introdução à mecânica da fratura com definições e princípios básicos, evolução histórica, particularidades da zona de processo da propagação da trinca e desenvolvimento da mecânica da fratura elástica linear e elástica não linear em rochas.

Uma revisão bibliográfica das diferentes metodologias de ensaio para a determinação da tenacidade à fratura encontradas na literatura são apresentadas no Capítulo 3. Estes ensaios utilizam uma ampla variedade de corpos de prova, procedimentos de preparação, dispositivos de fixação, colocação e aplicação do carregamento e configuração dos ensaios. Salienta-se que este capítulo se subdivide em três: Métodos sugeridos pela ISRM, Métodos não padronizados pela ISRM e Métodos empíricos para a determinação da tenacidade à fratura. Foram realizados todos os métodos sugeridos pela ISRM com os dispositivos e equipamentos disponíveis no Laboratório de Mecânica das Rochas da EESC. Salienta-se que, para a presente pesquisa, foi necessário confeccionar outros dispositivos para a preparação, fixação e aplicação do carregamento dos ensaios não padronizados realizados, complementando e capacitando, desta maneira, o Laboratório de Mecânicas das Rochas com um aparato técnico e instrumental atualizado para a realização de ensaios para determinação da tenacidade à fratura de rochas por diferentes metodologias. Empregaramse também dispositivos e equipamentos do Laboratório de Propriedades Mecânicas do Departamento de Materiais da EESC e do Laboratório do Departamento de Engenharia de Materiais (DEMA) da Universidade Federal de São Carlos. No Laboratório de Mecânica das Rochas da EESC, foram realizados os seguintes ensaios: ensaios em corpos de prova cilíndricos com entalhe “chevron” sob flexão - “Chevron Bend (CB)”, ensaios em corpos de prova na forma de disco brasileiro com entalhe em "chevron" - "Cracked circunferencial notched brazilian disc (CCNBD)”, ensaios de corpos de prova semicirculares submetidos à flexão em três pontos - "Semi-circular bend specimen (SCB), ensaios de corpos de prova semicirculares com entalhe tipo Chevron submetidos à flexão em três pontos - "Semicircular bend specimen with Chevron-notched (CNSCB)”, ensaios de 
carga pontual - "Point Load Test (PLT)”, ensaios de anel modificado - "Modified ring test $(M R T)$ ”, ensaios em corpos de prova cilíndricos entalhados axialmente em ruptura por compressão - “Compression splitting test (CST)”, ensaio de discos com entalhe na borda com partição por cunha - "Edge Notched Disc Wedge Splitting Test (END)". No Laboratório de Propriedades Mecânicas do Departamento de Materiais da EESC, foram realizados os ensaios em corpos de prova de haste curto com entalhe "chevron" sob tração - "Short Rod (SR)”, e no Laboratório do Departamento de Engenharia de Materiais (DEMA) da Universidade Federal de São Carlos, foram realizados os ensaios em corpos de prova em dupla-torção - “Double torsion specimen (DT)”.

No Capítulo 4, são descritas as análises petrográficas realizadas nos materiais ensaiados, a determinação das características físico-mecânicas dos mesmos, assim como a preparação dos corpos de prova, a instrumentação e o procedimento de execução dos ensaios estudados. Os gráficos típicos força vs deslocamento são apresentados com os resultados experimentais com fins de exemplificação.

Uma discussão e análises dos resultados obtidos são apresentadas no Capítulo 5, descrevendo-se algumas considerações a serem levadas em conta na determinação da tenacidade à fratura, as dificuldades de realização dos ensaios e a validade e comparação dos mesmos. Salienta-se que esta comparação é feita entre os ensaios estudados (métodos sugeridos e não padronizados) e entre os valores da tenacidade à fratura encontrados na literatura. Alguns destes ensaios nunca foram feitos em rochas como no caso do ensaio em corpos de prova cilíndricos entalhados axialmente em ruptura por compressão “Compression splitting test (CST)”, ao passo que outros foram poucas vezes utilizados.

No Capítulo 6, são apresentadas algumas conclusões baseadas nos resultados experimentais obtidos, nas observações realizadas durante a execução dos ensaios e nos resultados obtidos da literatura especializada.

Salienta-se que o aporte desta pesquisa reside no fato de que pouco se sabe a respeito de estudos comparativos entre os métodos sugeridos pela ISRM com outros métodos não padronizados, utilizando-se corpos de prova extraídos de mesmos blocos para garantir a representatividade das amostras e realizar um melhor estudo comparativo. 


\section{CONTEXTO HISTÓRICO E INTRODUÇÃO À MECÂNICA DA FRATURA}

\subsection{Introdução}

Os blocos de rocha usados nas estruturas monumentais desde tempos antigos apresentavam, freqüentemente, trincas inexplicáveis. Tais trincas poderiam ter sido provocadas por imperfeições no trabalho (devido à tecnologia ou à instalação) que conduziam a tensões singulares. Tais singularidades são freqüentemente uma fonte da propagação das trincas. Nestes materiais, uma localização destas deformações ocorre de modo que a fratura é produzida com baixa dissipação de energia. Esta propriedade caracteriza as enormes pedras antigas selecionadas pelos construtores experientes justamente devido a sua fácil trabalhabilidade.

Na pré-história, o homem usou a pedra para produzir facas, pontas de flechas e outras ferramentas. Depois, houve o advento das atividades de mineração, pelas quais tornaram-se possíveis, principalmente, a extração dos metais e a obtenção de blocos de rochas para construções ou para esculturas. Os primeiros homens empregaram a energia de fratura para fazer ferramentas e armas. Depois, os cortadores de pedra, que trabalhavam com pedras para fazer esculturas e decoração, encontraram uma relação da energia aplicada e a energia consumida com o trabalho que tinham no processo de fratura.

Ao longo da história, a rocha tornou-se cada vez mais importante na engenharia estrutural, e as cargas aplicadas a essas estruturas chegaram a ser maiores, de modo que foi necessário entender porque fenômenos de “rock burst" eram produzidos (GRAMBERG, 1989). Salienta-se que, já em 1500, Leonardo da Vinci começou a pensar nestes problemas.

Outro aspecto peculiar relacionado aos sólidos frágeis é o fenômeno relacionado ao efeito escala, o qual pode ser explicado através da mecânica da fratura. O primeiro a estudar tal efeito foi Galileu Galilei, que investigou também a influência do tamanho 
das trincas nas estruturas para responder à seguinte pergunta: por quê os corpos quebram? Galileu, visitando o estaleiro veneziano, ficou surpreso com a grande atenção que os artesãos tinham na construção de grandes navios, diferentemente da atenção dirigida aos navios menores. Um construtor experiente explicou-lhe que essa atenção estava associada com a existência de uma maior fragilidade daqueles comparada com a correspondente fragilidade das embarcações menores.

Em 1633, Galileu trabalhou exaustivamente na redação de seu livro "Discorsi e dimostrazioni matematiche, intorno à due nove scienze attenenti allá mecânica \& $i$ movimenti locali" (MARDER e FINERBERG, 1996) na região correspondente a sua vila perto de Florença. Este livro está disponível como uma reimpressão chamada "Duas novas ciências” ( "Two new sciences”). A “primeira ciência” foi o estudo das forças que mantêm as coisas juntas e das condições que as façam cair. A "segunda ciência” tratou das leis que governavam os movimentos dos projéteis. A “primeira ciência” é de interesse básico para as atividades de construção de edifícios e também para a mecânica das rochas. Salienta-se, contudo, que as respostas para as perguntas sob os esforços dos materiais não são fáceis de ser encontradas. Galileu identificou a principal dificuldade: uma razão não pode ser de uma escala menor a uma maior, porque muitos comportamentos mecânicos acontecem em uma pequena escala que não pode existir em tamanho maior.

Em 1678, Hooke apresentou a lei da elasticidade das propriedades dos materiais. Em 1773, Coulomb realizou ensaios compressivos em rochas e introduziu, posteriormente, o critério do Coulomb que é usado até nossos dias. Os desenvolvimentos da mecânica da fratura são paralelos a este critério de ruptura para materiais frágeis, porém eles não se contradizem entre si.

Thomas Young apresentou em 1808 o conceito de modulo de elasticidade, e Poisson, em 1829, apresentou o chamado “coeficiente de Poisson”, que relaciona as deformações axiais e laterais. Em 1894, Voigt carregou amostras cilíndricas com uma pressão de confinamento e observou a ruptura por tração. No começo do século XIX, Otto Mohr carregou amostras de forma similar ao procedimento adotado por Coulomb cem anos antes. A partir de seus resultados, ele desenvolveu o conhecido critério de Mohr-Coulomb. Em 1911, Von Karman realizou seus clássicos ensaios triaxiais em mármore Carrara. Depois destes passos básicos nos conhecimentos das forças na rocha, nasceu o interesse pela mecânica da fratura e a propagação das trincas. 


\subsection{Mecânica da fratura elástica linear}

Os estudos pioneiros para o desenvolvimento matemático da mecânica da fratura e a análise das tensões próximas à ponta da trinca estão nos artigos de Inglis (1913), Griffith (1921) e Westergaard (1939) que serão apresentados a seguir.

\subsubsection{Conceito de balanço energético de Griffith (1921)}

Inglis (1913) apud Bortolucci (1993) forneceu uma solução para a análise de tensões na situação correspondente a um furo elíptico em uma placa tracionada como mostrado na Figura 1. Ele encontrou que a concentração de tensões perto da ponta da elipse era proporcional ao tamanho e ao raio do eixo maior da elipse.

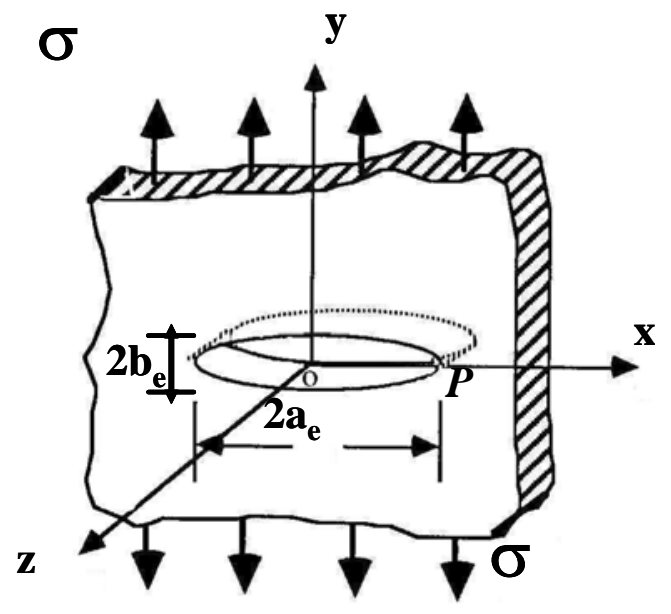

Figura 1 - Furo elíptico em uma placa submetida à tensões uniformes de tração (WHITTAKER; SINGH e SUN, 1992)

A tensão na ponta da elipse na direção $y$ é:

$\sigma_{y}(P)=\sigma\left(1+\frac{2 a_{e}}{b_{e}}\right)$

sendo:

$\sigma$ : tensão aplicada ao sólido;

$2 a_{e}$ : comprimento do eixo maior da elipse (comprimento da trinca);

$b_{e}$ : metade da largura da elipse.

Se $b_{e}<<a_{e}$ (condição mais real de simulação de uma fratura), então a expressão (1) se reduz a:

$\sigma_{y}(P)=2 \sigma \frac{a_{e}}{b_{e}}$ 
Se a expressão do raio da curvatura na ponta da elipse $\left(r_{e}\right)$ no ponto $P$ for utilizada $\left(r_{e}=\frac{b_{e}^{2}}{a_{e}}\right)$, esta expressão se reduz a:

$\sigma_{y}(P)=2 \sigma \sqrt{\frac{a_{e}}{r_{e}}}$

O fator de concentração de tensões de Inglis $(k)$ pode ser escrito como:

$k=2 \sqrt{\frac{a_{e}}{r_{e}}}$

onde:

$a_{e}$ : metade do comprimento do eixo maior da elipse;

$r_{e}$ : raio de curvatura na ponta da elipse.

Baseado na análise de tensão de Inglis, Griffith (1921) estabeleceu uma relação entre a tensão de fratura e o tamanho da trinca. Esta relação é conhecida como balanço energético de Griffith e é o ponto inicial para o desenvolvimento da mecânica da fratura. Alem disso, Griffith explicou qualitativamente porque a resistência à tração dos materiais frágeis era menor que o seu valor teórico e postulou que os materiais frágeis continham defeitos submicroscópicos. Esses defeitos são muitos pequenos para serem detectados por meios ordinários e funcionam como concentradores de tensões, e, conseqüentemente, a propagação da trinca é causada pela concentração de tensões nas pontas dessas microtrincas internas ao material. A concentração de tensões pode aumentar a tensão local até um valor maior que o necessário para o rompimento das ligações atômicas. A propagação da trinca pode não ocorrer se a energia fornecida for insuficiente para vencer a resistência à extensão da trinca, resultante da resistência coesiva molecular.

Conseqüentemente, isso implica que a ruptura de um sólido rígido sob tração envolve dois requisitos básicos:

a) deve existir um mecanismo para que a propagação da trinca possa ocorrer;

b) o processo deve ser energeticamente factível.

Balanceando a energia que atua em um sólido e em uma trinca dentro de um sólido, a energia elástica total $(U)$ é expressa por (EWALDS e WANHILL, 1986 apud ALBUQUERQUE, 1998): 
$U=U_{0}+U_{E}+U_{S}-W_{\text {ext }}$

onde:

$U$ : energia total da chapa trincada;

$U_{0}$ : energia elástica da chapa carregada ainda não trincada;

$U_{E}$ : perda de energia de deformação elástica causada pela presença da trinca;

$U_{S}$ : variação na energia de superfície causada pela formação de superfícies trincadas (irreversível);

$W_{\text {ext }}$ : trabalho realizado pela força externa (subtraído uma vez que não é parte da energia interna da placa).

Griffith usou a análise de tensão desenvolvida por Inglis para mostrar que o valor absoluto de $U_{E}$ é dado por:

$\left|U_{E}\right|=\frac{\pi \sigma^{2} a_{t}^{2}}{E^{\prime}}$

e a energia elástica de superfície $\left(U_{S}\right)$ foi admitida por Griffith como sendo:

$U_{S}=4 a_{t} \gamma_{S}$

onde:

$\sigma$ : tensão aplicada ao sólido;

$E^{\prime}$ : Módulo de elasticidade efetivo;

$a_{t}$ : metade do comprimento da trinca;

$\gamma_{s}:$ energia específica de superfície.

Em condições de deformação constante, o trabalho realizado pelas forças externas é zero ( $\left.W_{\text {ext }}=0\right)$ e a equação (5) se reduz a:

$U=U_{0}+U_{E}+U_{S}$

$U=U_{0}-\frac{\pi \sigma^{2} a_{t}^{2}}{E^{\prime}}+4 a_{t} \gamma_{s}$

A idéia de Griffith implica que o início da fratura ocorre se $\partial U / \partial a_{t}<0$ e o equilíbrio crítico para o início da fratura ocorre se $\partial U / \partial a_{t}=0$, isto é: 
$\frac{\partial}{\partial a_{t}}\left[-\frac{\pi \sigma^{2} a_{t}^{2}}{E^{\prime}}+4 a_{t} \gamma_{s}\right]=0$

o que conduz a:

$\sigma \sqrt{\pi a_{t}}=\sqrt{2 E^{\prime} \gamma_{s}}$

A expressão anterior indica que, de acordo com o critério de Griffith, a fratura poderia ocorrer quando $\sigma \sqrt{\pi a_{t}}$ alcançasse um valor crítico constante determinado pelas propriedades materiais características, a saber, $E, v$, e $\gamma_{\mathrm{s}}$.

Da expressão (10), resulta a tensão crítica para a ruptura do corpo fraturado:

$\sigma_{c r}=\sqrt{\frac{2 E^{\prime} \gamma_{s}}{\pi a_{t}}}$

\subsubsection{Conceito da variação da liberação da energia de deformação de Irwin (1948)}

Westergard (1939) publicou um método analítico para resolver o problema de determinação de tensões e deformações em corpos trincados. A forma da trinca deixa de ser elíptica, como proposto por Inglis, e passa a ter uma configuração reta e plana, mais próxima da trinca real (INGRAFFEA, 1977 apud MARCHIORI, 1997).

Para o caso de uma placa infinita, carregada biaxialmente com uma tensão remota $(\sigma)$ de tração e com uma fratura plana de comprimento $2 a$, os valores no ponto $P$, próximo à extremidade da trinca $(r<<\mathrm{a})$, são representados pelas seguintes equações (INGRAFFEA, 1977 apud MARCHIORI, 1997):

$$
\begin{aligned}
\sigma_{x} & =\sigma \sqrt{\frac{a}{2 r}} \cos \frac{\theta}{2}\left(1-\operatorname{sen} \frac{\theta}{2} \operatorname{sen} \frac{3 \theta}{2}\right)+\ldots \\
\sigma_{y} & =\sigma \sqrt{\frac{a}{2 r}} \cos \frac{\theta}{2}\left(1+\operatorname{sen} \frac{\theta}{2} \operatorname{sen} \frac{3 \theta}{2}\right)+\ldots \\
\tau_{x y} & =\sigma \sqrt{\frac{a}{2 r}} \operatorname{sen} \frac{\theta}{2} \cos \frac{\theta}{2} \cos \frac{3 \theta}{2}+\ldots
\end{aligned}
$$

onde:

$r$ : distância radial medida em relação à extremidade da fratura;

$\theta$ : ângulo entre o eixo da trinca e a direção de incremento da mesma.

Análises sobre a equação (13) mostram que a tensão $\sigma_{y}$ (responsável pela propagação da trinca) tende ao infinito quando $r$ tende a zero e que, para $\theta=0$, ao longo 
do eixo $x$, ela é igual a $\sigma_{y}=\sigma \sqrt{\frac{a}{2 r}}$, ou multiplicando-se os dois lados por $\sqrt{\pi}$, temos as seguintes expressões:

$\sigma_{y} \sqrt{2 \pi r}=\sigma \sqrt{\pi a}$

assim:

$K=\sigma_{y} \sqrt{2 \pi r}=\sigma \sqrt{\pi a}$

sendo $K$ o fator intensidade de tensão, o qual depende única e exclusivamente da geometria do corpo de prova, das tensões aplicadas e do tamanho da trinca, sendo independente de $r$ e $\theta$.

Durante a segunda guerra mundial, mais de 4700 navios foram construídos, dos quais mais de 200 sofreram ruptura catastrófica e 1200 mostraram danos severos devido ao fraturamento no casco (MARDER e FINENBERG, 1996). Em 1944, a ruptura catastrófica de um tanque de gás em Cleveland destruiu completamente 79 casas, duas fábricas e cerca de 217 carros, além de danificar várias outras fábricas e casas (STEPHANSSON, 2001.). Estas rupturas ocorreram em situações de tensões de tração sempre menores que a resistência à tração do material (tensão limite em meio continuo). Em conseqüência disto, a atividade de pesquisa foi incrementada e vários artigos científicos foram publicados sob a mecânica da fratura, como por exemplo Sneddon (1946) e o clássico de Irwin (1948).

Irwin e seus colaboradores (IRWIN, 1948; IRWIN e KIES, 1952,1954; WELLS, 1956) propuseram uma modificação da teoria de Griffith que, ao invés de analisar a energia específica de superfície $\left(\gamma_{S}\right)$, analisa a "velocidade" com que a energia de deformação é transformada em energia de superfície em função do comprimento da trinca, ou seja, a variação da liberação da energia de deformação $\left(G_{F}\right)$ durante o processo de fratura (BORTOLUCCI, 1993).

Essa teoria propõe ainda que o corpo adquire a condição de ruptura quando a variação da liberação da energia de deformação $\left(G_{F}\right)$ atingir a um valor crítico $\left(G_{F C}\right)$, entendido como uma propriedade do material. A substituição da energia específica de superfície $\left(\gamma_{S}\right)$ pela variação crítica da liberação da energia de deformação $\left(G_{F C}\right)$ tem a vantagem de introduzir um parâmetro mais fácil de ser obtido. A $G_{F C}$ pode ser facilmente determinada em ensaios de materiais em processo de fratura, usando uma configuração de ensaio simples. 
O processo de análise através do critério da liberação da energia de deformação fica extremamente facilitado: determina-se $G_{F}$ de um corpo trincado (função da rigidez e geometria do corpo, das tensões aplicadas e do tamanho da trinca) e compara-se com o $G_{F C}$ do material constituinte; se $G_{F}>G_{F C}$, a trinca se propaga instavelmente.

Rearranjando à equação (11) que vem do balanço energético de Griffith, obtémse:

$\frac{\pi \sigma^{2} a}{E}=2 \gamma_{S}$

O lado esquerdo da equação acima define o parâmetro chamado "variação da liberação de energia de deformação”. Então:

$G_{F}=\frac{\partial U_{E}}{\partial_{a}}=\frac{\pi \sigma^{2} a}{E}$

O aumento da variação da liberação da energia de deformação pode-se dar pelo aumento das tensões aplicadas ou pelo aumento do tamanho da trinca. A ruptura ocorre quando $G_{F}$ for igual a $G_{F C}$, considerando uma propriedade do material constituinte da placa e facilmente determinada em laboratório.

O fator intensidade de tensão para o início da trinca se dá próximo à condição na qual : $G_{F}=G_{F C}$, onde $G_{F C}$ é a variação da liberação crítica da energia de deformação do material. Esta condição crítica definida anteriormente foi sugerida por Irwin (1957). Quando $G_{F}$ alcança $G_{F C}$, ocorre a propagação da trinca. Desde que a propagação da trinca ocorra quando $G_{F}$ alcança um valor critico, o valor critico da intensidade de tensão pode ser definido como:

$$
K_{c}=\sqrt{\frac{G_{F C} E}{\left(1-v^{2}\right)}}
$$

Demonstrando a equivalência de $K$ e $G$, Irwin forneceu a base para o desenvolvimento da mecânica da fratura elástica linear (MFEL). Na $M F E L$, as tensões, as deformações e os deslocamentos da ponta da trinca podem ser caracterizados por $K$ contanto que a plastificação inelástica na ponta da trinca seja pequena. A vantagem da $M F E L$ é que ela fornece uma aproximação universal para determinar a resistência do material à fratura, a qual é definida por $K_{c}$. Contanto que a função explícita para a 
intensidade de tensão próxima da ponta da trinca seja conhecida para uma geometria da trinca e para uma configuração dada de carregamento, o $K_{c}$ pode ser medido experimentalmente (SCHMIDT e ROSSMANITH, 1983).

\subsubsection{Modos de propagação da trinca}

As diferentes configurações do carregamento na ponta da trinca conduzem a diferentes modos de deslocamento da ponta da trinca. Estes modos são caracterizados em função das tensões aplicadas e dos conseqüentes deslocamentos observados na extremidade da trinca. Há três modos básicos de deformação da trinca.

O modo I é o modo de abertura da trinca devido à tensão, onde as superfícies da trinca se movem apartando-se diretamente em seu próprio plano, com os deslocamentos de suas superfícies contidos no plano normal à fratura e simétricos aos planos $x y$ e $x z$.

O modo II é o modo deslizante devido ao cisalhamento, onde as superfícies da trinca se movem uma sobre a outra em um sentido perpendicular à frente da trinca. Os deslocamentos das superfícies da fratura estão contidos no seu próprio plano, sendo simétricos em relação ao plano $x y$ e simétrico-oblíquos em relação ao plano $x z$.

O modo III é um modo deslizante, também devido ao cisalhamento, onde as superfícies da trinca deslizam uma sobre a outra, mas em um sentido paralelo à frente da trinca. Os deslocamentos das superfícies da fratura estarão contidos no plano da fratura, sendo simétrico-obliquos em relação aos planos $x z$ e $x y$.

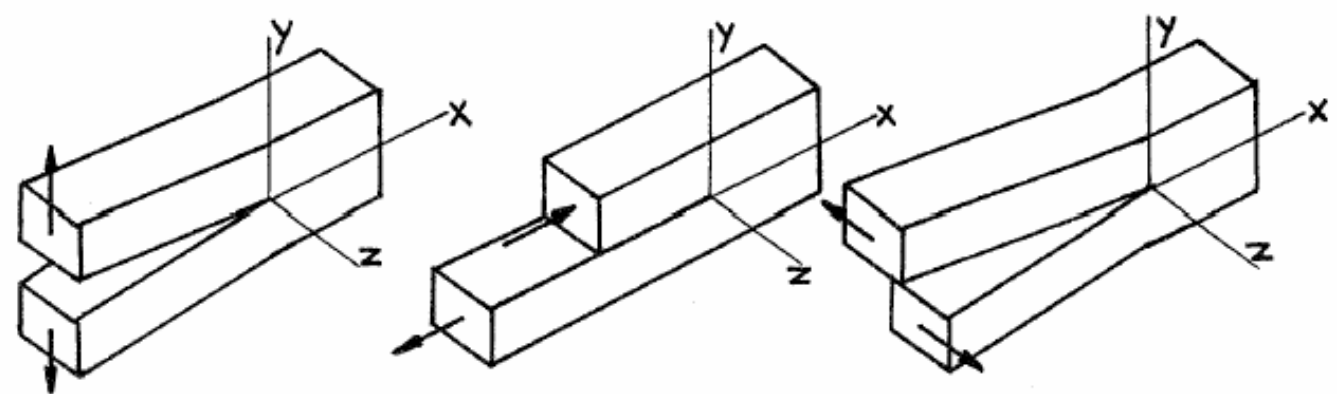

\section{Modo I Modo II $\quad$ Modo III}

Figura 2 - Modos fundamentais de propagação da trinca (TADA; PARIS e IRWIN, 2000 apud DONOVAN, 2003)

O fator de intensidade de tensão no modo I de propagação da fratura, é definido como fator de intensidade de tensão para o modo I $\left(K_{I}\right)$. Analogamente os demais 
modos de propagação definem o $K_{I I}$ e $K_{I I I}$. A equação (16) sob esta nova simbologia, pode ser expressa por:

$$
K_{I}=\sigma \sqrt{\pi a}
$$

De acordo com Cherepanov (1979) apud Marchiori (1997), para situações semelhantes às da Figura 2, mas com tensões cisalhantes $(\tau)$ que proporcionam individualmente modos II e III, o fator intensidade de tensão de cada modo é definido como:

$$
\begin{aligned}
& K_{I I}=\tau_{x y} \sqrt{\pi a} \\
& K_{I I I}=\tau_{y z} \sqrt{\pi a}
\end{aligned}
$$

Similarmente, a determinação da tenacidade à fratura do material é feita para um determinado modo de propagação. Assim, para um ensaio, cuja configuração proporciona somente tração, a tenacidade obtida é relativa ao modo I e é designada por tenacidade à fratura-modo I $\left(K_{I C}\right)$. Analogamente existem as tenacidades $K_{I I C}$ e $K_{I I I C}$.

Os três modos básicos podem também ocorrer nas combinações como carregamentos do tipo “modos mistos” com a superposição dos modos, combinações essas que são suficientes para descrever os casos tridimensionais mais gerais de tensões e de campo de deformações locais na ponta da trinca como mostrado na Figura 3 (HUDSON e HARRISON, 1997 apud BACKERS, 2001). O modo I é o modo mais comumente encontrado nas aplicações da engenharia e é também a mais fácil de se analisar, de produzir experimentalmente os corpos de prova e de se executar no laboratório (SCHMIDT e ROSSMANITH, 1983).

\subsection{Mecânica da fratura elástica não-linear}

A partir do começo dos anos sessenta, foram empregados maiores esforços no desenvolvimento da mecânica da fratura de rochas resistentes. Entretanto, depois da introdução dos conceitos da mecânica da fratura, foi evidente que a mecânica da fratura elástica linear produzia boas previsões quando a ruptura era frágil e quase frágil, o que significava que muitas das estruturas comportavam-se elasticamente no início da ruptura. Isso, contudo, não foi o caso para muitas situações práticas, em particular para 
aços de baixa resistência, os quais apresentaram-se como sendo capazes de desenvolver grandes zonas plásticas perto da ponta da trinca.

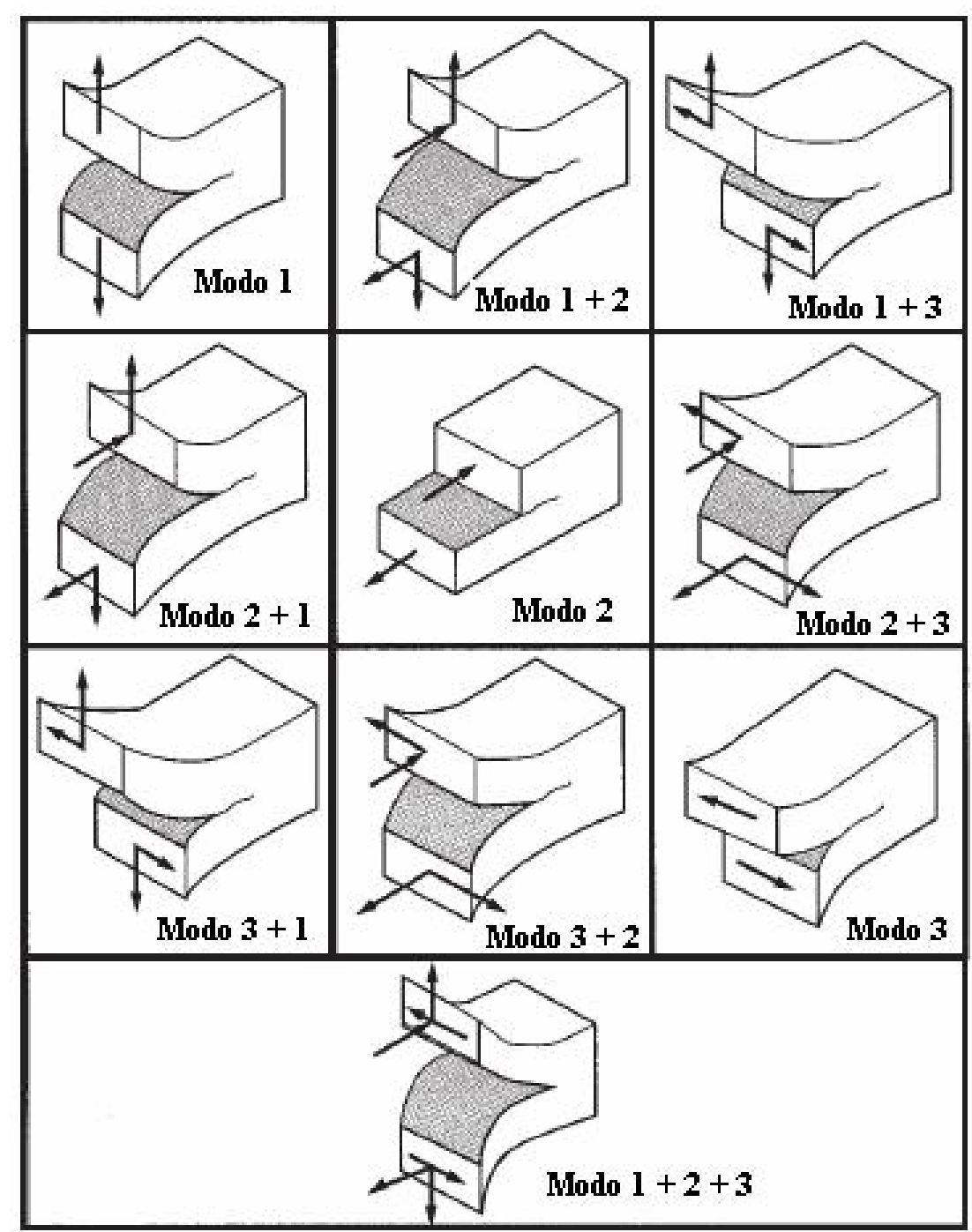

Figura 3 - Combinação dos modos fundamentais de propagação da trinca (HUDSON e HARRISON, 1997 apud BACKERS, 2001)

Normalmente, na ponta da trinca, o material apresenta uma região de deformações não lineares. Se esta região for grande em comparação com o tamanho da trinca, a $M F E L$ pode não descrever a adequada propagação da trinca e o comportamento de ruptura do material. Uma análise desenvolvida pela mecânica da fratura elásticoplástica (MFEP) tem sido utilizada para prever o comportamento de materiais dúcteis. Seus conceitos foram desenvolvidos a partir da região plástica formada na ponta da trinca de materiais metálicos. Este efeito é similar ao do microtrincamento observado na ponta da trinca em materiais rochosos. 
A Figura 4 mostra esta zona de plástica como uma área circular de raio $\lambda$. O comportamento de um corpo de prova trincado depende do tamanho e da forma desta zona plástica na ponta da trinca com relação às dimensões totais do corpo de prova. Se a zona plástica for pequena comparada com o tamanho do corpo de prova, então o efeito de uma zona plástica é também pequeno e o corpo de prova pode ser considerado como se comportando elasticamente.

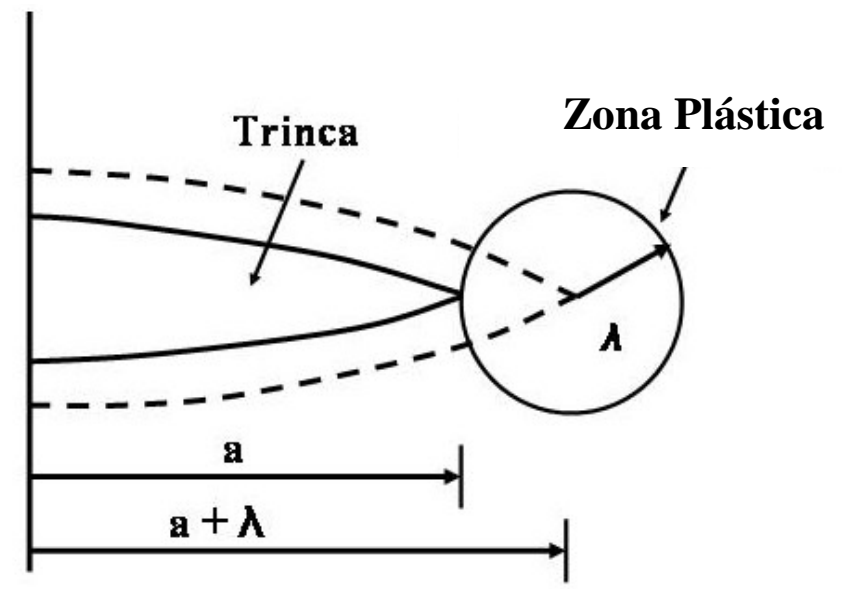

Figura 4 - Zona Plástica na ponta da trinca (HABERFIELD e JOHNSTON, 1990)

Entretanto, como a zona plástica na ponta da trinca aumenta em tamanho em relação ao tamanho do corpo de prova, a suposição da elasticidade linear torna-se cada vez mais questionável.

Embora a forma da zona plástica da ponta da trinca seja desconhecida, diversos modelos foram sugeridos, por exemplo, Irwin (1958), Dugdale (1960), Barenblatt (1962) para metais, e Schmidt (1980) e Labuz, Shah e Dowding (1985) para rochas. Todos estes modelos postulam que o tamanho e a forma da zona plástica dependem do valor do fator de intensidade de tensão na ponta da trinca e da resistência à tração do material. (HABERFIELD e JOHNSTON, 1990). Em particular, estes autores propuseram que o tamanho da zona plástica na ponta da trinca, definido como o raio $\lambda$ na Figura 4, é diretamente proporcional ao quadrado da relação entre a tenacidade à fratura no modo I e a resistência à tração , isto é:

$\lambda \propto\left(\frac{K_{I C}}{\sigma_{t}}\right)^{2}$

Estes modelos propõem também que a formação da zona plástica na ponta da trinca aumenta efetivamente o comprimento da trinca de $a$ para $a+\lambda$, como mostrado na Figura 4. 
Os estudos de Irwin, Kies e Smith (1958) identificaram o tamanho da zona plástica na ponta da trinca como uma fonte de desajuste. Logo depois, várias teorias da mecânica da fratura não linear foram desenvolvidas mais ou menos em paralelo. Dentro dos conceitos da mecânica da fratura elasto-plástica duas principais descrições foram desenvolvidas: uma correspondente aos modelos de ruptura elástica equivalente e outra aos modelos de ruptura coesivos.

Nos modelos de ruptura equivalente, a zona não linear é simulada aproximadamente por um estado no qual seu efeito promove o decréscimo na rigidez do corpo, o que é aproximadamente o mesmo que o incremento do comprimento da trinca quando o comportamento segue sendo elástico. Esta trinca mais longa é chamada trinca efetiva ou equivalente. Seu tratamento é similar à mecânica da fratura elástica linear $(M F E L)$, exceto que algumas regras devem ser adicionadas para expressar como a trinca equivalente estende-se sob forças incrementais.

Neste contexto, Irwin (1958), em termos gerais, e, mais claramente, Krafft, Sullivan e Boyle (1961) propuseram o conceito denominado de curva-R, no qual a resistência ao crescimento da trinca não é constante, mas varia com o comprimento da trinca de uma maneira empiricamente determinada. Este simples conceito ainda permanece como uma ferramenta válida que prevê que a forma da curva-R seja estimada corretamente, levando-se em conta a geometria da estrutura.

Aplicações da mecânica da fratura para materiais rochosos reais e artificiais continuaram com um considerável atraso em relação aos metais. O problema da fratura em rochas é analisado e estudado principalmente devido a obras subterrâneas (minas, escavações, túneis), de maneira que no começo dos anos sessenta são realizadas as primeiras aplicações do Modelo de Griffith para rochas e materiais tais como o concreto.

Mc Clintock e Walsh (1962) introduzem o conceito de atrito entre as faces das trincas. Anteriormente, Kaplan (1961) estudou a possibilidade de aplicar a mecânica da fratura elástica linear (MFEL) para o concreto. Importantes pesquisas relacionadas às rochas foram desenvolvidas por Bieniawski (1967) na África do Sul, onde as fraturas nas minas foram um problema que demandava resolução urgente. No mesmo período, as primeiras revistas especializadas na mecânica da fratura foram editadas (International Journal of Fracture Mechanics em 1964, Engineering Fracture Mechanics em 1970) e um tratado, editado por Liebowitz, apareceu em 1968. 
Em relação aos desenvolvimentos teóricos da mecânica da fratura, onde o próximo passo foi a aplicação para o concreto de parâmetros empregados de forma bem sucedida para os metais, um novo parâmetro foi empregado por Rice (1968), a chamada Integral-J. Este parâmetro é independente do caminho de integração ao redor da ponta da trinca. Demonstrou-se que, na mecânica da fratura elástica linear (MFEL), a IntegralJ é equivalente à variação da liberação da energia de deformação $\left(G_{F}\right)$. No entanto, ressalta-se que o método da Integral-J não fornece resultados corretos para o concreto ou para materiais parecidos ao concreto devido à curva de descarregamento característica de materiais frágeis e à difícil definição da posição da ponta da trinca (HILLERBORG, 1983).

Os modelos de fratura coesiva foram desenvolvidos para simular o comportamento não linear nas proximidades da ponta da trinca. Nesses modelos, assume-se que a trinca, apesar de se propagar e se abrir, ainda consegue transferir tensões de uma face para a outra, nas proximidades da ponta da trinca.

A atividade de pesquisa na mecânica da fratura de materiais quase-frágeis (concreto, rochas, cerâmicas, compósitos, gelo e alguns polímeros) aumentou durante os anos 80. Muitos esforços de pesquisa foram e ainda são dedicados a refinar os modelos, a melhorar as ferramentas analíticas e numéricas requeridas para manipular os modelos, a desenvolver métodos experimentais destinados a medir os parâmetros de várias teorias e a relacionar o comportamento da fratura macroscópica às feições micro-estruturais dos materiais. Neste aspecto, modelos idealizados que refletem a natureza heterogênea do concreto têm sido desenvolvidos para ajudar no entendimento do seu comportamento macroscópico. Bibliografias extensivas e revisões históricas da mecânica da fratura do concreto têm recentemente aparecidos nos relatórios de vários comitês (WITTMANN, 1983; ELFGREN, 1989; ACI committee 446, 1992).

Recentemente, reconhece-se que as trincas no concreto, nas rochas e nos materiais cerâmicos modernos resistentes exibem fortes similaridades. Os estudos destes materiais poderiam beneficiar tais disciplinas. Aplicações da mecânica da fratura são prioritários para estruturas como barragens de concreto e reatores nucleares ou reservatórios de contaminantes, para os quais as considerações de segurança são particularmente importantes e as conseqüências de um desastre potencial são enormes. 


\subsection{Descrição geral das características da zona do processo da fratura}

Fisicamente, o comportamento de um material metálico sob tensão é governado pelo seu comportamento plástico, e daí uma pequena região imediatamente adiante da ponta da trinca terá um comportamento plástico. Essa região é referida como zona plástica (IRWIN, 1958; BARENBLATT, 1962). Em materiais rochosos, tem sido demonstrado ser esta região uma zona de microtrincamento ou zona de processo de fratura (ZPF) (HOAGLAND; HAHN e ROSENFIELD, 1973; SCHMIDT, 1980; ROSSMANITH, 1983; LABUZ; SHAH e DOWDING, 1983, 1985, 1987). A principal diferença entre estas duas zonas está no fato que em metais estas são formadas por tensão, enquanto que em rochas elas são formadas pelo início, propagação e interação das microtrincas adjacentes à ponta da trinca. Para generalizar o problema, as duas zonas são chamadas de zona não linear dentro da qual as tensões são liberadas (WHITTAKER; SINGH e SUN, 1992).

A zona de processo da fratura $(Z P F)$ em rochas é a região na frente da ponta da trinca com comportamento não linear. Conforme a Figura 5, a $Z P F$ é formada pelo início e propagação das microtrincas na vizinhança da ponta da trinca. Os modelos usados para determinar o tamanho e a forma da $Z P F$ são baseados nos modelos usados para descrever a zona plástica em metais.

Hoagland, Hahn e Rosenfield (1973) apud Whittaker, Singh e Sun (1992) propuseram um modelo de quatro estágios para descrever a formação da $Z P F$ em rochas de acordo com a Figura 5. Ouchterlony (1980) e Labuz, Shah e Dowding (1985) indicaram que o tamanho da $Z P F$ aumenta com o aumento do tamanho dos grãos da rocha. Friedman, Handin e Alani (1972), Hoagland, Hahn e Rosenfield (1973) e Barton (1983) relataram que o tamanho da $Z P F$ é cerca de 5 a 10 vezes o tamanho médio dos grãos, mas observações experimentais no dolomito Stockbridge realizadas por NolenHoeksema e Gordon (1987) têm mostrado que a $Z P F$ se estende acima de 20 a 40 vezes o diâmetro médio do grão presente na superfície de ruptura.

Como não existem avaliações de modelos teóricos “perfeitos” para descrever completamente a forma e o tamanho da $Z P F$ na ponta da trinca, estes são freqüentemente descritos por modelos aproximados desenvolvidos para descrever a 
zona plástica em metais, como fez Schmidt (1980). Schmidt (1980) sugeriu um critério de tensão normal máxima para descrever a forma da $Z P F$ na ponta da trinca em rochas:

$r(\theta)=\frac{1}{2 \pi}\left(\frac{K_{I}}{\sigma_{t}}\right)^{2} \cos ^{2} \frac{\theta}{2}\left(1+\left|\sin \frac{\theta}{2}\right|\right)^{2}$

onde:

$\sigma_{t}$ : resistência à tração do material rochoso;

$r, \theta$ : são definidos pelo sistema coordenado da Figura 6.

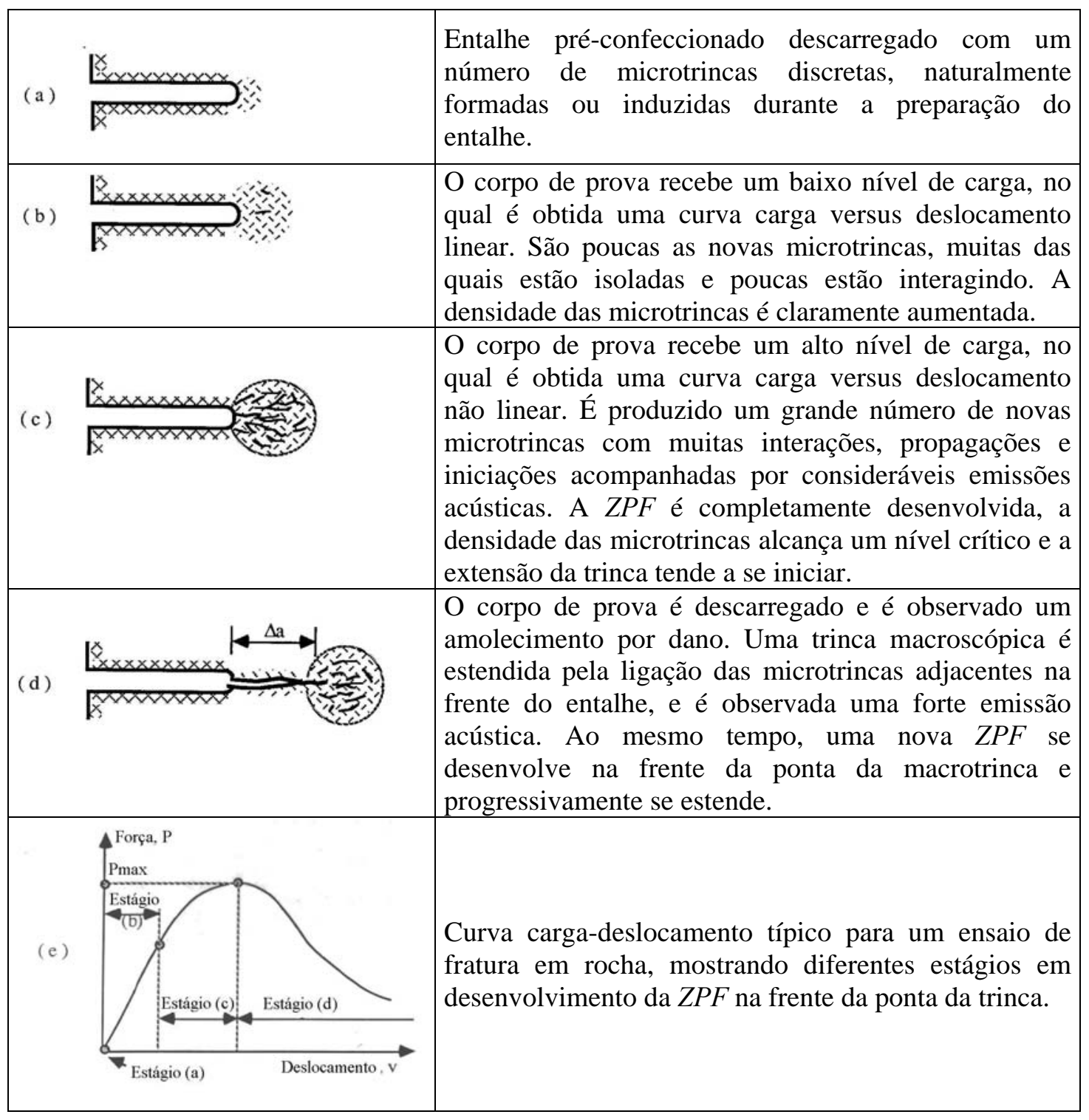

Figura 5 - Desenvolvimento da ZPF em rochas (WHITTAKER; SINGH e SUN, 1992)

Uma ilustração da $Z P F$ é mostrada na Figura 6 Para Schmidt (1980), a extensão máxima da $Z P F$ é definida quando $\theta$ é igual a $60^{\circ}$ e a extensão característica da $Z P F$ é 
definida quando $\theta$ é igual a zero e é idêntico à zona plástica nos metais sob condições de tensão plana.

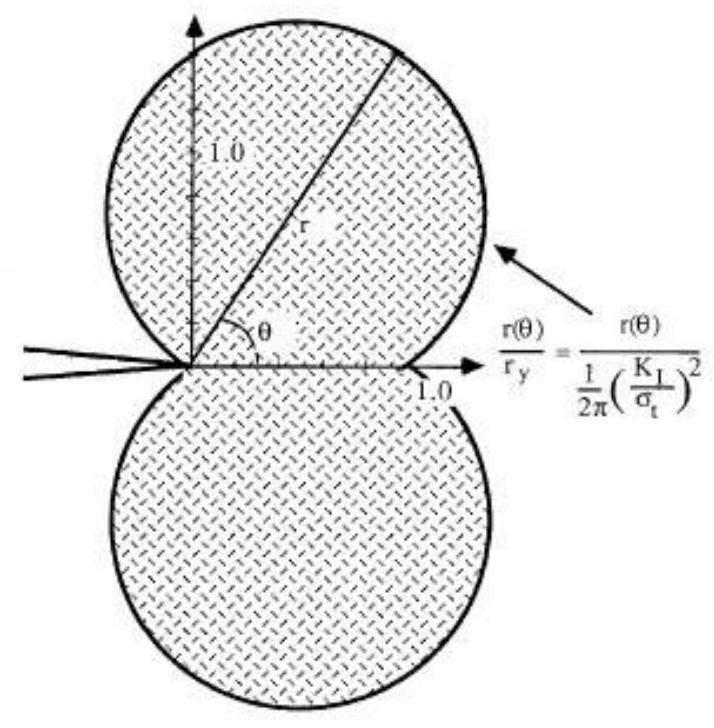

Figura 6 - Forma e tamanho da zona plástica da trinca (SCHMIDT, 1980)

Baseado em análises prévias, a forma e o tamanho da zona do processo de fratura é independente dos estados de tensão plana ou de deformação plana. NolenHoeksema e Gordon (1987) comprovaram isto experimentalmente usando dolomita, mostrando que a $Z P F$ é a mesma para uma trinca na superfície livre (tensão plana) e para uma trinca localizada dentro da rocha (deformação plana). Na comparação com a zona plástica dos metais, a $Z P F$ e a tenacidade à fratura não são afetadas pela espessura do corpo de prova.

Aspectos da zona plástica dos metais podem ser usados para definir as dimensões necessárias para levar a valores representativos da tenacidade à fratura (SCHMIDT, 1980; BARTON, 1983).

Os requisitos são:

$$
\left.\begin{array}{c}
a \\
w-a
\end{array}\right\} \geq 2.5\left(\frac{K_{I C}}{\sigma_{t}}\right)^{2}
$$

e

$$
B \geq \frac{27}{32 \pi}\left(\frac{K_{I C}}{\sigma_{t}}\right)^{2}
$$

onde: 
$a$ : comprimento da trinca;

$w-a$ : comprimento não trincado;

$B$ : espessura do corpo de prova.

As exigências anteriores são conservativas, e outros fatores têm sido propostos, mas, em geral, se os requerimentos dados não forem encontrados, os valores medidos da tenacidade à fratura (isto é, a tenacidade à fratura aparente) são considerados inválidos ou fora dos limites da MFEL.

O microtrincamento na frente da ponta da trinca e o desenvolvimento subseqüente da $Z P F$ são influenciados pela microestrutura ou tamanho do grão da rocha. As relações mínimas entre a menor dimensão do corpo de prova e o tamanho de grão foram sugeridas a fim de obter determinados valores representativos de $\mathrm{K}_{\mathrm{IC}}$ medidos. Uma relação mínima de 10:1 é recomendada pela ISRM para os dois métodos de ensaios sugeridos por esta entidade (ISRM, 1988).

Quando uma trinca se desenvolve e propaga nos materiais rochosos, forma-se uma zona de microtrincamento na frente da ponta da trinca na direção da propagação da fratura. Horii, Hasegawa e Nishino (1987) e Karihaloo e Nallathambi (1989) fizeram pesquisas com o objetivo de estudar a zona do processo de propagação das trincas em concreto, subdividindo esta zona em: i) trinca livre de tração, ii) zona ponte e iii) zona de microtrincamento conforme visto na Figura 7, a seguir. Estes autores enfatizaram que a resistência à tração da rocha cai para zero na ponta da trinca.

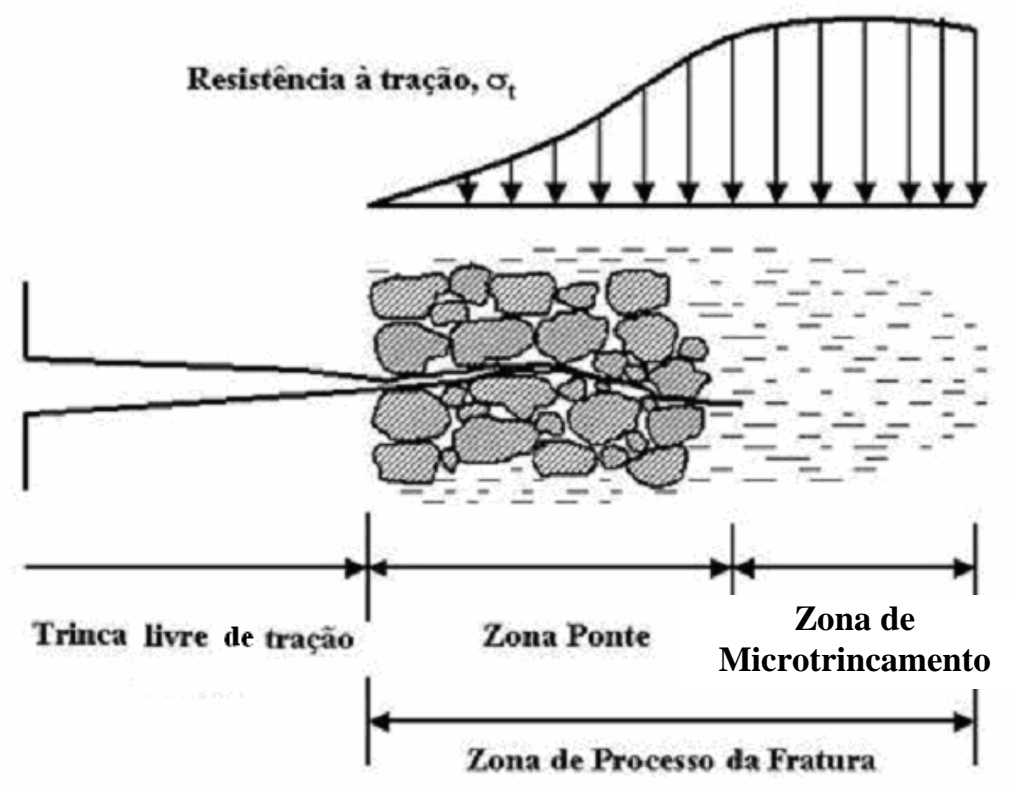

Figura 7 - Zona de processo da fratura (KARIHALOO e NALLATHAMBI, 1989) 
Liu, Sun e Wang (1994) encontraram que as ramificações, as bifurcações e as interações da propagação das trincas ocorrem em uma faixa trincada de espessura definida, definindo esta faixa trincada como a zona do processo da fratura. Liu, Wang e Li (2000) concluem que a espessura da zona do processo da fratura está relacionada com a textura e o tamanho do grão. Conseqüentemente, a zona trincada pode ser compreendida como uma região de microtrincas (zona de processo) e como uma região da propagação da trinca (ponta da trinca). Os contornos dos grãos são os primeiros a trincar, visto que são planos de fraqueza. Em pequena escala, a orientação aleatória dos contornos dos grãos poderia sempre causar uma ruptura no modo misto. Em macro escala, a propagação da trinca pode ser considerada como uma ruptura de modo puro. Na Figura 8, uma zona de processo da fratura ou faixa trincada de espessura definida é mostrada para o modo I.

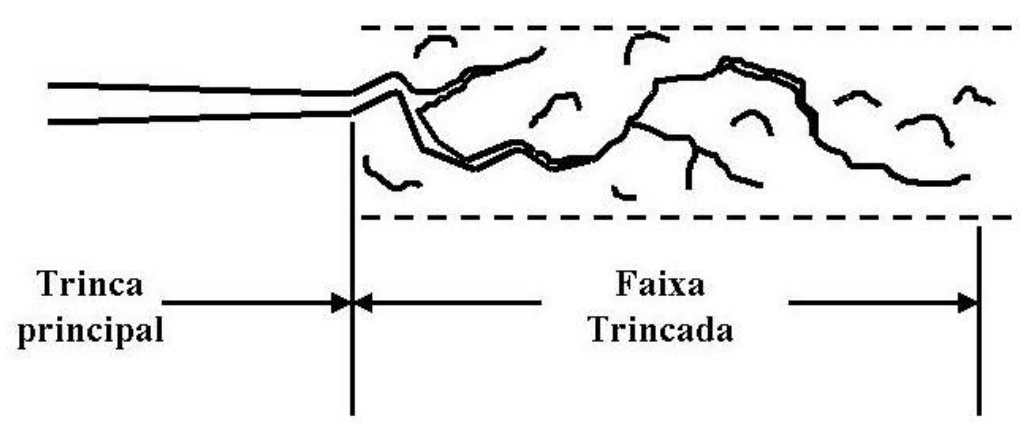

Figura 8 - Faixa trincada de espessura definida (LIU; WANG e LI, 2000) 


\section{REVISÃO BIBLIOGRÁFICA}

\subsection{Introdução}

De uma forma simplificada, a tenacidade flexional de um material pode ser definida como sendo a sua capacidade de absorção de energia. A tenacidade à fratura, por outro lado, é a propriedade mecânica que o material apresenta de absorver e dissipar energia durante o processo da fratura, indicando a resistência por ele apresentada, em termos de intensificação de tensões, ao avanço da fratura (FERREIRA, 2002).

A quantificação da tenacidade à fratura pode ser determinada em ensaios de diferentes naturezas, como os de tração direta, de compressão simples e de flexão de vigas. Assim como em outros ensaios de engenharia, há um grande número de fatores que podem interferir nas medições da tenacidade à fratura; como por exemplo a anisotropia do material, a dimensão das amostras (efeito escala) e o efeito de um pré entalhe. Cada metodologia de ensaio procura minimizar, ou pelo menos avaliar, o efeito de um determinado parâmetro, razão pela qual há um grande número de metodologias de ensaios encontrados na literatura (ALBURQUERQUE, 1998).

Atualmente, ensaios de tenacidade à fratura são realizados em uma ampla variedade de amostras submetidas a diferentes metodologias de ensaios. Os valores resultantes geralmente não são comparáveis, resultando no fato de que os valores de tenacidade à fratura medidos não são uma propriedade do material. Como estes valores representam um importante meio de previsões quantitativas dentro da engenharia, é de interesse que o valor da tenacidade à fratura seja encarado como um índice característico do material. Desta forma, é necessário o uso de métodos de ensaio padronizados e reconhecidos (ISRM, 1988).

Apresentam-se a seguir informações associadas a diversos ensaios destinados à determinação da tenacidade à fratura conforme apresentados na literatura. Para fins didáticos, dividiremos a revisão pertinente a estes ensaios em três partes: a primeira 
contempla aqueles sugeridos pela $\operatorname{ISRM}(1988,1995)$, a segunda abrange aqueles não padronizados pela $I S R M$ e, finalmente, a ultima parte contempla algumas relações empíricas destinadas à determinação da tenacidade à fratura em rochas.

\subsection{Ensaios sugeridos pela ISRM}

\subsubsection{Introdução}

Os métodos de ensaio sugeridos pela ISRM (1988) correspondem aos corpos de prova denominados "Chevron Bend" $(C B)$ e "Short Rod" $(S R)$, ao passo que o sugerido pela ISRM (1995) corresponde ao corpo de prova chamado "Cracked Chevron Notched Brazilian Disc" (CCNBD). Os ensaios sugeridos pela ISRM (1988) têm dois níveis, a saber, nível I e nível II. O nível I é realizado sob controle de carga e o nível II sob controle de deslocamento da abertura da boca da trinca (CMOD). Para medir o deslocamento do ponto de carregamento $(L P D)$, normalmente são usados dois LVDTs, e para medir o $C M O D$, usa-se um extensômetro do tipo "clip gauge".

O nível I é de rápida execução (máximo 10 segundos) e requer somente o registro da carga máxima, já que se considera que o ponto de avaliação da tenacidade à fratura ocorre na carga máxima. Isto implica que o material tenha um comportamento elástico linear. A rocha possui uma zona de processo da fratura $(Z P F)$ na ponta da trinca, de modo que essa só terá comportamento elástico linear se a condição de plastificação de pequena escala $(S S Y)$ for satisfeita, ou seja, se o corpo de prova for grande em relação à $Z P F$. O tamanho da $Z P F$ é uma função do tamanho dos grãos; desta forma, usando corpos de prova grandes com granulação fina, o valor do nível I do ensaio é válido, mas o inverso não produz valores de tenacidade à fratura válidos, sendo indispensável o nível II. O nível II é mais lento que o nível I e requer o registro da carga e do deslocamento durante todo o ensaio. Este procedimento fornece valores mais precisos que o nível I, pois considera a carga real que leva o corpo de prova ao ponto de avaliação da tenacidade à fratura, porém tem sua realização mais cara e difícil.

Em 1995, a ISRM sugeriu um terceiro ensaio, o qual avalia a tenacidade à fratura somente para o nível I. Salienta-se que uma característica interessante desse conjunto de três ensaios é que eles podem quantificar a anisotropia de rochas visto que usam o mesmo corpo de prova com os entalhes em três direções ortogonais entre si. 
Em todos os métodos, a área não entalhada tem a forma de $V$ ou "chevron", o que gera um período relativamente longo de crescimento estável da trinca sob o aumento de carga antes do ponto no qual a tenacidade à fratura é avaliada. Este ponto coincide com a carga máxima em um material frágil e elástico linear, mas, sob circunstâncias não ideais, o ponto de avaliação da tenacidade à fratura pode ocorrer antes ou depois da carga máxima. O nível II dos ensaios da ISRM (1988) leva esse aspecto em consideração, corrigindo a tenacidade à fratura em função da não linearidade e da não elasticidade do material. Também no nível II, o tamanho do corpo de prova não influencia nos resultados obtidos como mostra, por exemplo, os ensaios realizados por Yi et al (1991). O mesmo não ocorre no nível I, no qual a tenacidade à fratura aumenta com a diminuição da espessura do corpo de prova até um determinado tamanho, após o qual ela permanece constante.

Apresenta-se a seguir uma descrição dos principais aspectos relacionados a estes ensaios, salientando-se que, em vista do emprego destes ensaios na presente pesquisa, detalhes maiores de suas respectivas metodologias serão apresentados no Capítulo 4 correspondente a Materiais e Métodos.

\subsubsection{Corpos de prova cilíndricos com entalhe “chevron" sob flexão - “Chevron Bend $(C B)^{\prime}$}

Neste ensaio, o corpo de prova consiste de um cilindro longo com um entalhe central em "chevron" paralelo ao menor eixo do cilindro como mostrado na Figura 9. A Tabela 1 fornece as dimensões calibradas para este ensaio.

Tabela 1. Dimensões do corpo de prova " $C B$ "

\begin{tabular}{|c|c|c|}
\hline Parâmetros Geométricos & Valores & Tolerância \\
\hline Diâmetro do corpo de prova & $\mathrm{D}$ & $\begin{array}{c}>10 \text { vezes o tamanho do } \\
\text { grão }\end{array}$ \\
\hline Comprimento do corpo de prova & $4 \mathrm{D}$ & $>3.5 \mathrm{D}$ \\
\hline $\begin{array}{c}\text { Distância entre os apoios do corpo de } \\
\text { prova, } S\end{array}$ & $3.33 \mathrm{D}$ & $\pm 0.02 \mathrm{D}$ \\
\hline Ângulo "chevron", $\theta$ & $90^{\circ}$ & $\pm 1.0^{\circ}$ \\
\hline $\begin{array}{c}\text { Posição da ponta do entalhe "chevron", } \\
a_{0}\end{array}$ & $0.15 \mathrm{D}$ & $\pm 0.10 \mathrm{D}$ \\
\hline Largura do entalhe, $\mathrm{t}$ & $\leq 0.03 \mathrm{D}$ ou $1 \mathrm{~mm}^{*}$ & \\
\hline
\end{tabular}

* o maior valor

Fonte: ISRM, 1988 
Para a preparação dos corpos de prova e realização dos ensaios, são necessários alguns dispositivos de fixação e posicionamento sugeridos pela ISRM (1988). O dispositivo de posicionamento do corpo de prova para realização do ensaio deve garantir que a ponta do entalhe do corpo de prova fique exatamente embaixo do eixo de carregamento e centrado em relação aos suportes. Este deve ser tal que possa ser retirado para realização do ensaio. Para posicionar o entalhe "chevron", deve-se colocar um par de placas, sendo cada uma delas colocadas de um lado do rasgo do dispositivo.

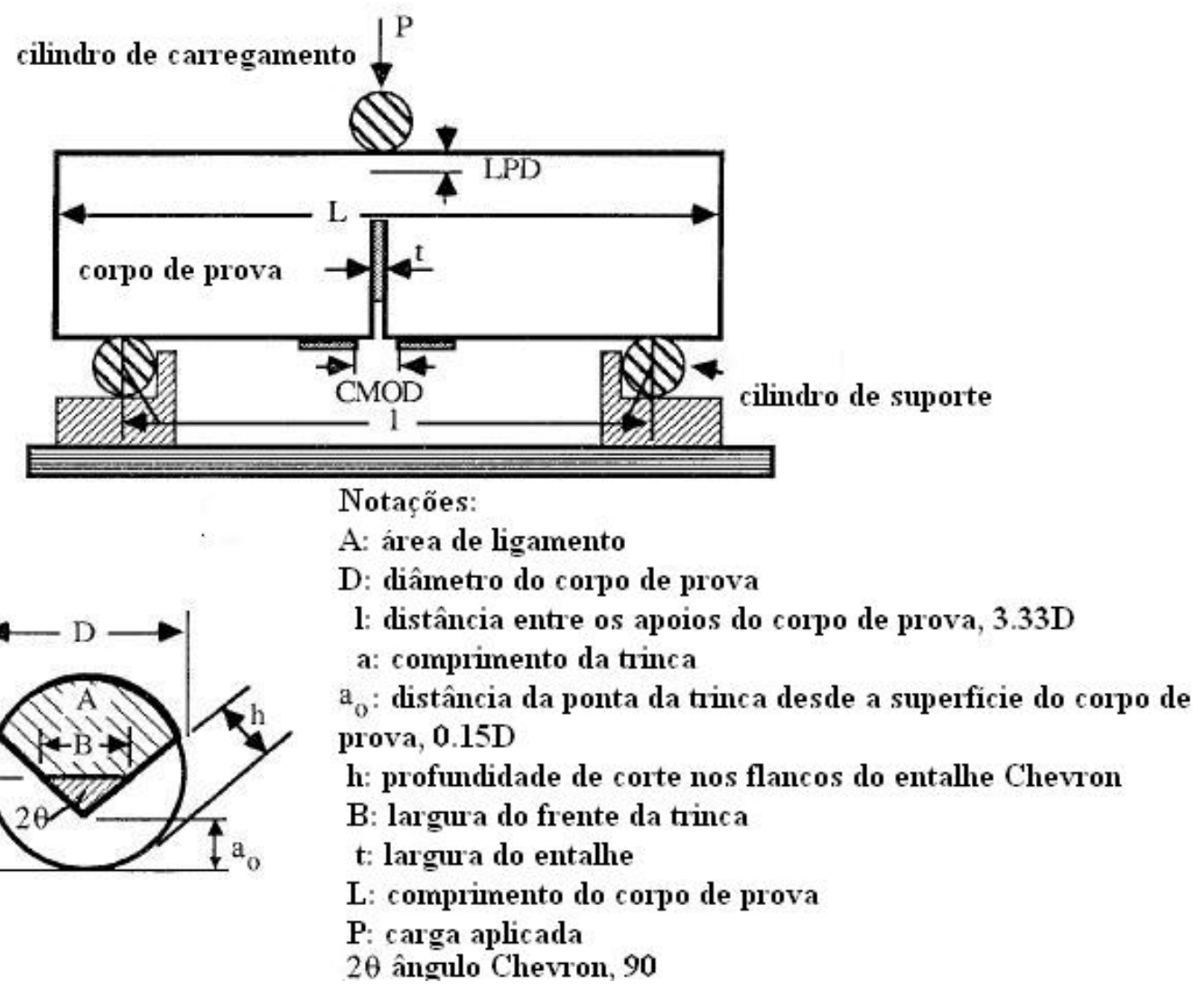

Figura 9 - Corpo de prova cilíndrico com entalhe "chevron" sob flexão e configuração do ensaio (WHITTAKER; SINGH e SUN, 1992)

Outro dispositivo a ser utilizado é o dispositivo de fixação dos LVDTs usados para medir o $L P D$. Esse dispositivo é apoiado sobre o corpo de prova, exatamente nas linhas de atuação dos apoios de reação. As pontas móveis dos LVDTs são apoiadas nos ombros de um dispositivo móvel, que é mantido pressionado ao entalhe por elásticos. Para medir a abertura do entalhe, utiliza-se um extensômetro tipo “clip gauge”. Para acomodar o "clip gauge”, deve-se colar um par de placas que suportarão os braços do “clip gauge” e que são centradas em relação ao eixo vertical do entalhe.

No nível I, a variação do aumento do fator de intensidade de tensão média durante o ensaio não deve ser menor que $0.25 \mathrm{MPa} \sqrt{\mathrm{m}} / \mathrm{seg}$ ou tal que a ruptura ocorra 
no máximo dentro de 10 segundos após aplicada a carga inicial. A tenacidade à fratura para o nível I é calculada através da equação (27).

$K_{C B}=\frac{F_{\max } A_{\min }}{D^{3 / 2}}$

sendo:

$A_{\text {min }}=\left[1,835+7,15 \frac{a_{0}}{D}+9,85\left(\frac{a_{0}}{D}\right)^{2}\right] \frac{S}{D}$

onde:

$D$ : diâmetro do corpo de prova;

$a_{0}$ : distância da ponta do entalhe "chevron" até a superfície do corpo de prova $(0,15 D)$;

$S$ : vão entre os apoios do corpo de prova $(3,33 D)$;

$F_{\text {max }}$ : carga máxima.

No nível II do ensaio, são realizados ciclos de carregamento-descarregamento, sendo necessários no mínimo quatro ciclos com pelo menos três ciclos antes do pico e um pós-pico. Neste nível, a velocidade do ensaio deve satisfazer à inequação (29):

$C M O D>\frac{0,006 K_{C B}}{E(D)^{\frac{1}{2}}} \mathrm{~m} / \mathrm{s}$

sendo:

$E$ : módulo de elasticidade;

$D$ : diâmetro do corpo de prova;

$K_{C B}$ : tenacidade à fratura do ensaio “ $C B$ ” para o nível I obtida pela equação (27).

Com o registro da relação carga-deslocamento $L P D$, o fator de correção não linear deve ser avaliado de acordo com um método gráfico explicado no item 3.2.7. abaixo.

\subsubsection{Corpos de prova de haste curta com entalhe "chevron" sob tração - "Short $\operatorname{Rod}(S R)$ "}

Neste ensaio, o corpo de prova consiste de um cilindro curto com entalhe centralizado em forma de "chevron" paralelo ao maior eixo como mostrado na Figura 10. Este corpo de prova sofrerá tração através de duas hastes encaixadas em duas placas coladas ao corpo de prova. A Tabela 2 mostra as dimensões do corpo de prova. 
Tabela 2. Dimensões do corpo de prova " $S R$ ”

\begin{tabular}{|c|c|c|}
\hline Parâmetros geométricos & Valores & Tolerância \\
\hline Diâmetro do corpo de prova & $D$ & $>10$ vezes o tamanho do grão \\
\hline $\begin{array}{c}\text { Comprimento do corpo de } \\
\text { prova }(L)\end{array}$ & $1.45 D$ & $\pm 0.02 D$ \\
\hline Ângulo "chevron" $(\theta)$ & $54.6^{\circ}$ & $\pm 1.0^{\circ}$ \\
\hline $\begin{array}{c}\text { Posição da ponta do entalhe } \\
\text { "chevron" }\left(a_{0}\right)\end{array}$ & $0.48 D$ & $\pm 0.02 D$ \\
\hline $\begin{array}{c}\text { Comprimento do entalhe } \\
\text { "chevron", }\left(a_{1}-a_{0}\right)\end{array}$ & $0.97 D$ & $\pm 0.02 D$ \\
\hline Largura do entalhe $(t)$ & $\leq 0.03 D$ ou $1 \mathrm{~mm}^{*}$ & \\
\hline
\end{tabular}

* o maior valor

Fonte: ISRM,1988
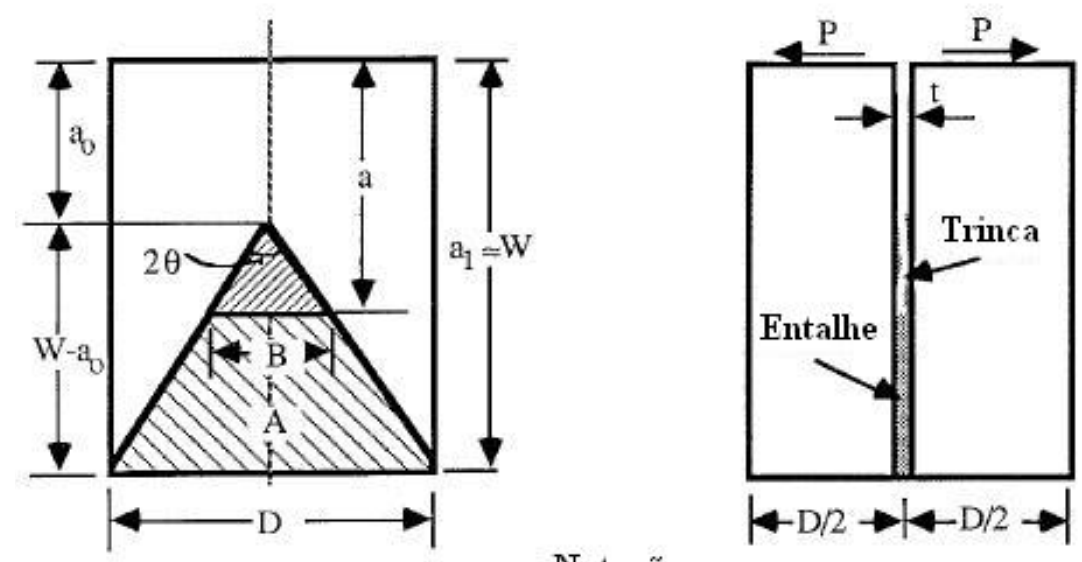

Notações:

A: área de ligamento

D: diâmetro do corpo de prova

a: comprimento da trinca

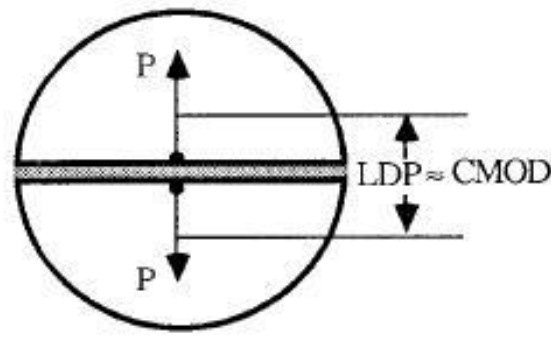

$a_{0}$ distância desde a ponta do Chevron ate linha de carregamento, 0.48D.

$a_{1}$ máxima profundidade dos flancos do Chevron

$B$ : largura do frente da trinca

t: largura do entalhe

W: altura do corpo de prova

P: carga aplicada na boca da trinca

$2 \theta$ : ângulo Chevron, $54.6^{\circ}$

Figura 10 - Corpo de prova de haste curto com entalhe "chevron” sob tração e configuração do ensaio (WHITTAKER; SINGH e SUN, 1992)

Para a aplicação da força de tração durante o ensaio, foi desenvolvido um dispositivo de acordo com as sugestões da ISRM (1988). O dispositivo possui uma rótula que permite pequenas acomodações do corpo de prova sem o aparecimento de esforços indesejados (torção, flexão). São usados dois dispositivos iguais, sendo um deles conectado na parte superior da máquina de ensaio e o outro na parte inferior. A força de tração é aplicada pelas hastes que puxam duas placas de alumínio que são coladas ao corpo de prova. 
O nível II de ensaio requer o registro da relação carga-deslocamento $C M O D$, sendo este último controlado durante todo o ensaio. Para medir o $C M O D$ no ensaio Short Rod $(S R)$, usa-se um extensômetro do tipo "clip gauge" com capacidade de abertura de $5 \mathrm{~mm}$.

A tenacidade à fratura no nível I $\left(K_{S R}\right)$ é fornecida pela seguinte equação:

$K_{S R}=\frac{24 C_{K} F_{\max }}{D^{1.5}}$

sendo $C_{K}$ um fator de correção encontrado em função da geometria do corpo de prova, conforme abaixo:

$C_{K}=\left(1-0.6 \frac{\Delta w}{D}+1.4 \frac{\Delta a_{0}}{D}-0.01 \Delta \theta\right)$

Os parâmetros $\Delta w, \Delta a_{0}$ e $\Delta \theta$ são a diferença entre os valores medidos e os valores nominais do comprimento do corpo de prova, do comprimento do entalhe inicial e do ângulo "chevron", respectivamente. Se o fator de correção $\left(C_{K}\right)$ estiver no intervalo $0,99<C_{K}<1,01$, adota-se $C_{K}$ igual a 1 na equação (30)

Para o nível II, da mesma forma que o ensaio $C B$, são realizados ciclos de carga e descarga, registrando-se os valores da relação carga-deslocamento CMOD. A velocidade do ensaio no nível II deve satisfazer à seguinte inequação:

$C M O D>\frac{0.017 K_{S R}}{E \sqrt{D}} \mathrm{~m} / \mathrm{s}$

sendo:

$E$ : módulo de elasticidade;

$D$ : diâmetro do corpo de prova;

$K_{S R}$ : tenacidade à fratura do ensaio "SR" para o nível I obtida pela equação (30).

As velocidades de ensaio devem satisfizer os requisitos sugeridos pela ISRM (1988) e os resultados obtidos devem ser corrigidos com os respectivos fatores de correção $(p)$ para o nível II correspondente.

\subsubsection{Corpos de prova na forma de disco brasileiro com entalhe em "chevron"- "Cracked circunferencial notched brazilian disc (CCNBD)"}

Neste ensaio, o corpo de prova tem forma de disco brasileiro com entalhe em "chevron", o qual é feito com dois cortes em ambos lados do disco, ao longo do mesmo 
plano de corte diametral como mostrado na Figura 11. Salienta-se que a carga deve ser aplicada paralelamente ao plano de entalhe.

No ensaio CCNBD, para posicionar o entalhe em “chevron” paralelo à aplicação da carga, deve ser utilizado um esquadro pequeno. A propagação da trinca inicia-se na ponta do entalhe em "chevron" e se propaga radialmente na direção externa do corpo de prova até o ponto onde a tenacidade à fratura é avaliada. $\mathrm{O}$ ensaio é feito sob controle de carga e requer somente o registro da carga máxima. Além disto, a ISRM (1995) sugere que a variação da velocidade de carregamento deve ser tal que a ruptura deve ocorrer dentro de no máximo 20 segundos após o início do ensaio.

A tenacidade à fratura deve ser calculada pela seguinte expressão:

$K_{I C}=\frac{F_{\max }}{B \sqrt{D}} Y_{\min }^{*}$

sendo:

$Y_{\min }^{*}$ : valor mínimo (crítico) do fator de intensidade de tensão adimensional para o corpo de prova, que é determinado em função das dimensões geométricas do corpo de prova $\alpha_{0}, \alpha_{1}$ e $\alpha_{B}$ conforme abaixo:

$Y_{\min }^{*}=u e^{v \alpha_{1}}$

onde $u$ e $v$ são valores constantes tabelados (ver Tabelas 26 e 27 do Anexo $A$ ) e determinados em função de $\alpha_{0}$ e $\alpha_{B}$. Salienta-se que se os valores de $\alpha_{0}$ e $\alpha_{B}$ não estiverem nas Tabelas 26 e 27, deverá ser feita uma interpolação linear para calcular os valores.

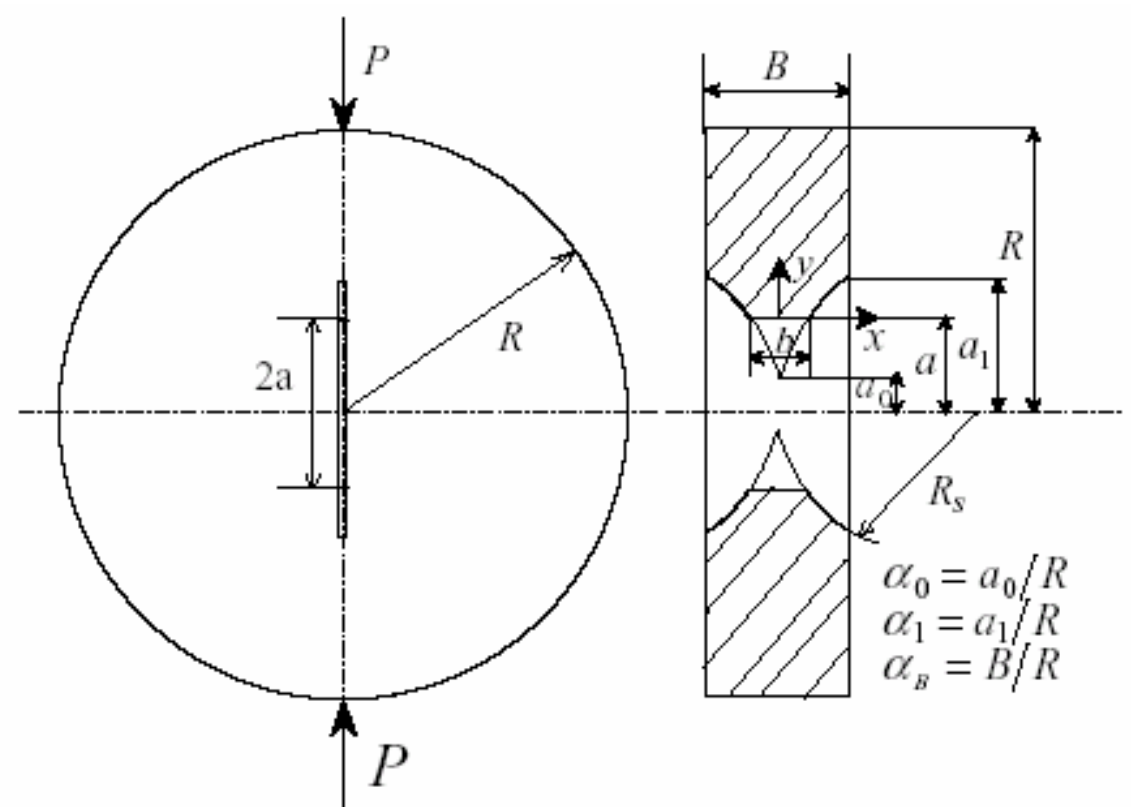

Figura 11 - Corpo de prova na forma de disco brasileiro com entalhe em "chevron" (WANG et al; 2003) 
Que o fator de intensidade de tensão adimensional $\left(Y^{*}\right)$ tenha um valor mínimo durante o ensaio é uma característica importante do ensaio $C C N B D$. $Y_{\min }^{*}$ é um parâmetro de cálculo importante que afeta a exatidão dos ensaios de tenacidade à fratura. $Y_{\min }^{*}$ é usualmente determinado por análise numérica. Antes do advento deste novo método sugerido pela ISRM (1995), foi utilizado o método dos elementos de contorno por Chen (1990), e o método de flexibilidade e o método de elementos de contorno por $\mathrm{Xu}$ e Fowell (1994) para calcular $Y_{\min }^{*}$. A ISRM (1995) apresentou especificamente uma geometria padrão do ensaio $\operatorname{CCNBD}\left(\alpha_{s}=0.6933, \alpha_{0}=0.2637\right.$, $\left.\alpha_{1}=0.65, \alpha_{B}=0.8\right)$ e foi dado o valor de seu fator adimensional crítico correspondente $\left(Y_{\min }^{*}=0.84\right)$. Wang (1998) mostrou que os valores de $Y_{\min }^{*}$ obtidos da maneira anteriormente exposta não tiveram a exatidão adequada (os valores obtidos por Chen em 1990 foram superestimadas e os valores obtidos por ISRM (1995) e Xu e Fowell (1994) foram subestimadas), posteriormente foi obtido pelo método de elementos finitos um valor mais exato de $Y_{\min }^{*}=0.943$ (WANG et al, 2003). Entretanto, observa-se que os estudos referem-se somente a geometrias restritas e limitadas do corpo de prova $C C N B D$, sendo necessária uma calibração para um amplo intervalo de valores de $Y_{\text {min }}^{*}$ para diferentes geometrias de $C C N B D$.

Wang, Jia e Wu (2004) propõem um método novo baseado na proposta de Bluhm (1975) sendo validado com a comparação cuidadosa dos métodos numéricos, o método dos elementos finitos e o método dos elementos de contorno.

Nesta pesquisa será utilizado o método sugerido pela $\operatorname{ISRM}(\operatorname{ISRM}, 1995)$.

O diâmetro mínimo do corpo de prova deverá ser:

$D_{\text {min }}=8.88+1.4744\left(\frac{K_{I C}}{\sigma_{t}}\right)^{-2}$

sendo $\sigma_{t}$ a resistência à tração das amostras. Geralmente, para materiais rochosos, $D_{\min }$ é aproximadamente $75 \mathrm{~mm}$.

Todas as dimensões da geometria do corpo de prova devem ser convertidas em parâmetros adimensionais com relação ao raio do corpo de prova $(R)$ como a seguir:

$\alpha_{0}=a_{0} / R$ 


$$
\begin{aligned}
& \alpha_{1}=a_{1} / R \\
& \alpha_{B}=B / R \\
& \alpha_{S}=R_{S} / R
\end{aligned}
$$

sendo $B$ a espessura do corpo de prova e $R_{S}$ o raio da serra que será usada para fazer o entalhe no corpo de prova. As dimensões do raio da serra de corte $\left(R_{S}\right)$ e a profundidade do corte $\left(h_{c}\right)$ podem ser calculadas pelas seguintes relações:

$$
\begin{aligned}
& \alpha_{S}=\frac{R_{S}}{R}=\sqrt{\alpha_{0}{ }^{2}+\left(\alpha_{1}{ }^{2}-\alpha_{0}{ }^{2}+\alpha_{B}{ }^{2} / 4\right)^{2} \div \alpha_{B}{ }^{2}} \\
& h_{c}=\left(\alpha_{S}-\sqrt{\alpha_{S}{ }^{2}-\alpha_{1}^{2}}\right) \cdot R=\left(\alpha_{S}-\sqrt{\alpha_{S}{ }^{2}-\alpha_{0}^{2}}\right) \cdot R+B / 2 \\
& \alpha_{0}=\sqrt{\alpha_{S}{ }^{2}-\left(\sqrt{\alpha_{S}{ }^{2}-\alpha_{1}{ }^{2}}+\alpha_{B} / 2\right)^{2}} \\
& \alpha_{1}=\sqrt{\alpha_{S}{ }^{2}-\left(\sqrt{\alpha_{S}{ }^{2}-\alpha_{0}{ }^{2}}-\alpha_{B} / 2\right)^{2}} \\
& \alpha_{B}=2 \cdot\left(\sqrt{\alpha_{S}{ }^{2}-\alpha_{0}{ }^{2}}-\sqrt{\alpha_{S}{ }^{2}-\alpha_{1}{ }^{2}}\right)
\end{aligned}
$$

Os corpos de prova serão descartados caso não satisfaçam às condições descritas abaixo:

$\alpha_{1} \geq 0.4$

$\alpha_{1} \geq \alpha_{B} / 2$

$\alpha_{B} \leq 1.04$

$\alpha_{1} \leq 0.8$

$\alpha_{B} \geq 1.1729 . \alpha_{1}^{1.6666}$

$\alpha_{B} \geq 0.44$

onde:

$\alpha_{0}$ : comprimento adimensional do entalhe inicial;

$\alpha_{1}$ : comprimento adimensional da trinca na face do corpo de prova;

$\alpha_{B}$ : largura adimensional da trinca e

$\alpha_{S}$ : raio adimensional da serra do corpo de prova $C C N B D$. 


\subsubsection{Fator de correção plástica "p"}

A partir dos métodos sugeridos pela ISRM (1988) para a determinação da tenacidade à fratura de rochas, observa-se que os resultados dos ensaios geralmente devem ser corrigidos por uma equação tal como:

$K_{I C}=\sqrt{\frac{1+p}{1-p}} K_{q}$

na qual $K_{q}$ é a tenacidade à fratura calculada usando-se a fórmula elástica linear e $p$ é o fator não linear, o qual tem sido estudado por muitos pesquisadores da tenacidade à fratura de rochas nos anos recentes. Para calcular o fator $p$, vários ciclos de carregamento e descarregamento devem ser realizados em um processo de ensaio de tenacidade à fratura, de acordo com os métodos sugeridos pela ISRM (1988).

O valor de $p$ é dado pela relação:

$p=\frac{X_{1}}{X_{u}}$

como se ilustra na Figura 12.

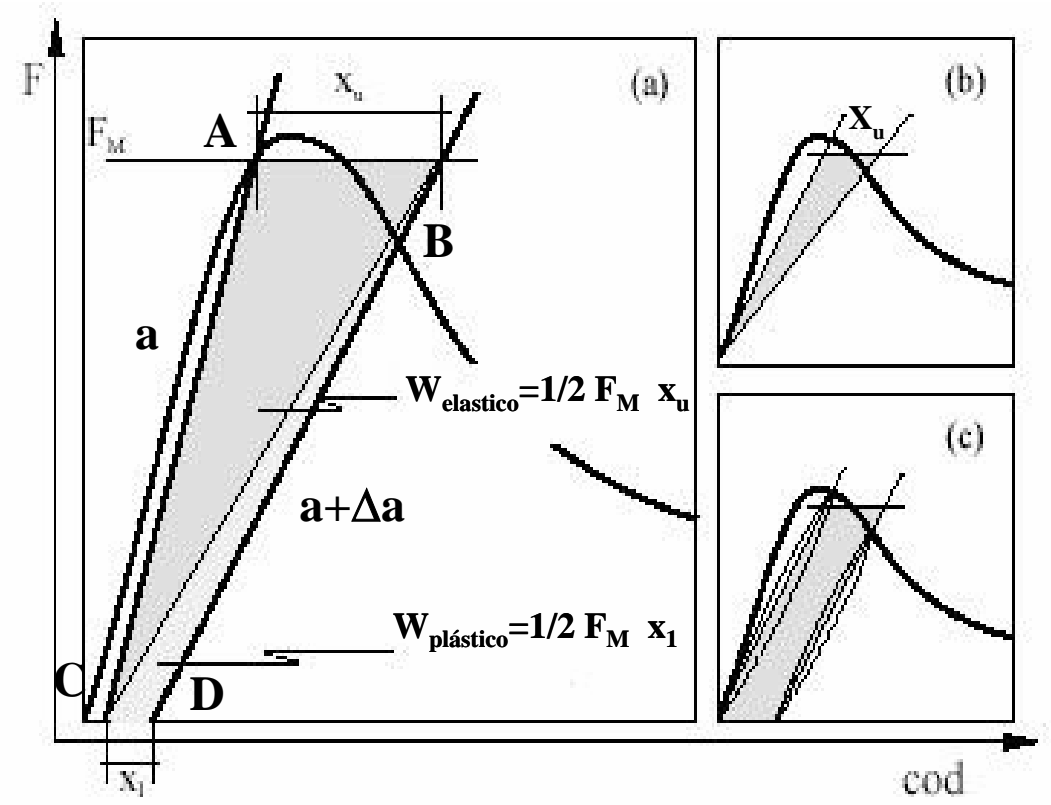

Figura 12 - Fator $p$ e evolução da zona do processo da fratura. As inclinações são construídas como regressões as inclinações correspondentes antes e após o valor pico. $W_{\text {elástico }}$ é o trabalho elástico e o $W_{\text {plástico }}$ é o trabalho irrecuperável realizado pelo avanço de um comprimento adicional de trinca. a)Exemplo esquemático de um ensaio. A trinca começa a propagar na carga de pico, onde o fator $p$ é determinado. b)Deformação perfeitamente elástica $\left(W=W_{\text {elástico }}\right.$ e $\left.p=0\right)$. c)Deformação perfeitamente plástica $\left(W=W_{\text {elástico }}+W_{\text {plástico }}\right.$ e $\left.p=1\right)($ BACKERS et al, 2003). 


\subsubsection{Análise da não linearidade para a determinação da tenacidade à fratura do} Nível II no modo I

De acordo com Barker (1979), " $p$ " pode ser interpretado como o grau de plasticidade exibido pelo corpo de prova entre dois pontos na curva de carregamento onde (a trinca) está crescendo (Figura 12a). Se $p=0$ o corpo de prova não sofreu nenhuma "deformação plástica" adicional durante o carregamento e o crescimento da trinca (Figura 12b). Um aumento de $p$ exibe conseqüentemente um aumento de "plasticidade" durante a propagação da trinca. O limite superior $p=1$ (Figura 12c) representa uma propagação completamente irreversível da abertura da trinca. Interpretando o deslocamento irreversível do $C M O D$ como um aumento do volume, adquirindo o fator $p$ como uma ferramenta para a medida relativa da formação da zona de processo.

Se $p=0$ significa que no descarregamento, as faces da trinca se fecham perfeitamente e a formação da zona de processo não causou nenhum aumento do volume. Assumindo que, sob o descarregamento, os efeitos friccionais estão completamente dissipados dentro do comportamento na histerese, qualquer $p>0$ indica a formação da zona de processo (Figura 13). Quanto maior valor de $p$, maior volume criado pelo desenvolvimento da zona de processo.

O fator $p$ representa a relação da deformação irreversível e é uma medida simplificada e objetiva da não linearidade nos ensaios de tenacidade à fratura de rochas. Com base em experiências anteriores (LIU; SUN e WANG, 1994), foi constatado que os fatores de $p$ para corpos de prova metálicos eram próximos de zero quando seus diâmetros eram pequenos. Foi visto que os fatores $p$ dos corpos de prova rochosos eram maiores que 0.15 , embora seus diâmetros fossem tão grandes quanto 100 milímetros, incluindo rochas mais duras tais como granitos. A tendência do fator $p$ era de um valor constante, ainda que o diâmetro do corpo de prova estivesse variando.

Considera-se que esta diferença significativa nos fatores não lineares entre o metal e a rocha é causada por seus mecanismos não lineares diferentes. Devido ao fato que a superfície de fratura da rocha é realmente uma faixa fraturada com uma espessura definida, as superfícies da trinca recentemente propagadas estão ainda intertravadas ao longo de um determinado comprimento. 


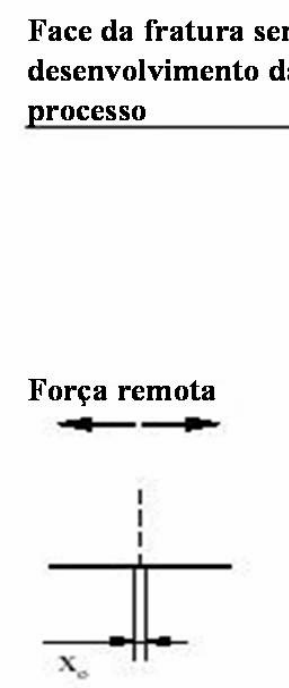

(0)

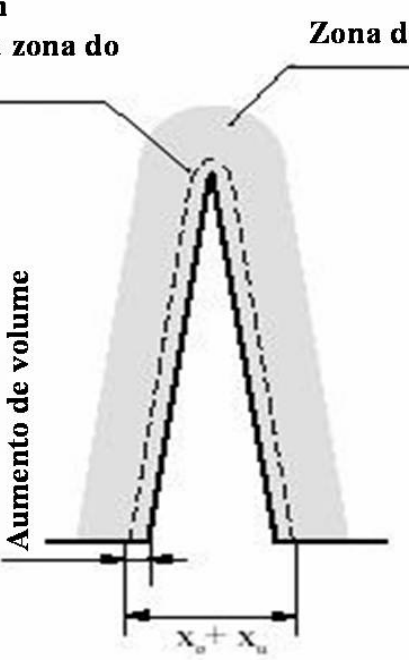

(1)

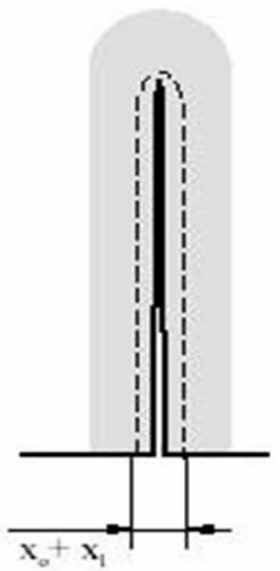

(2)

Figura 13 - Evolução da zona de processo dentro de um ciclo de carregamento. (0) Estado inicial. A linha tracejada indica o trajeto futuro da trinca. $\mathrm{O}$ deslocamento da abertura da trinca $\left(C M O D=X_{0}\right)$. (1) A trinca propagou-se uma determinada distância e uma zona de processo é estabelecida. A linha tracejada indica a posição hipotética da face da trinca, se nenhum aumento do volume devido à formação da zona de processo for evidente $\left(C M O D=X_{0}+X_{u}\right)$. (2) A trinca é fechada após descarregar. O deslocamento original não pode ser alcançado devido ao aumento do volume $\left(C M O D=X_{0}+X_{l}\right)$ (BACKERS et al, 2003).

A fragmentação e o deslocamento dos grãos das rochas na faixa fraturada ao longo da região de intertravamento causam o fechamento das microtrincas e da trinca principal, produzindo uma deformação permanente no ensaio como a deformação plástica dos metais. Como se pode imaginar, quando o tamanho do corpo de prova é bastante grande para permitir que a faixa fraturada desenvolva-se completamente na espessura e na região intertravada para alcançar seu limite do comprimento, as forças resistivas da faixa fraturada na região intertravada tenderão a um valor constante, resultando em um valor constante do fator $p$. Conseqüentemente, o fator não linear para a rocha reflete tanto os efeitos das micro-trincas na região na frente da ponta da trinca como os efeitos da faixa fraturada na região intertravada.

\subsubsection{Avaliação do Nível II no Modo I para a determinação da tenacidade à fratura com os corpos de prova $C B$ e $S R$}

Para completar a avaliação de $K_{C B}^{c}$ e $K_{S R}^{c}$, ou $G$, na prática nós ainda necessitamos prescrever como $\lambda_{F}$ ou $S_{F}$ e $\delta_{F}^{r}$ devem ser determinados em cada ponto $F_{i}$ ao longo da curva $F$ versus $\delta_{F}$. A necessidade surge porque as curvas de descarregamento real para as rochas indicam a não linearidade, da histerese e efeitos das variações das velocidades de carregamento. 
Nenhuns níveis de $F_{i}$ s são bem definidos desde que o descarregamento por se mesmo impeça que a curva de recarregamento alcance o nível de carga onde o descarregamento começou, como deveria ser de acordo as suposições precedentes no comportamento do corpo de prova.

Os métodos padronizados prescrevem o uso de uma linearização produzida por Barker (1980) e Meredith (1983) apud Ouchterlony (1989). Isto supõe que um número suficiente de ciclos de carregamento-descarregamento parciais até 0,1-0,2 $F_{\max }$ foram feitos durante o ensaio e registrados num gráfico $F$ versus $\delta_{F}$ (Figura 14).

O procedimento tem as seguintes etapas:

(i) Desenhar uma linha reta inicial para cada ciclo, através de um ponto maior $H$ onde começa o descarregamento (reversão do deslocamento) e um ponto baixo $L$ na parte de recarregamento onde $F_{L}=0,5 F_{H}$.

(ii) Determinar a quantidade de histerese no ciclo de carregamento - descarregamento como uma distancia vertical $\Delta F$ abaixo de $L$.

(iii) Desenhar uma linha reta final paralela à inicial mas a $0,5 \Delta F$ abaixo desta. A interseção desta linha com o contorno da curva $F$ versus $\delta_{F}$ define o ponto $F_{i}$ com coordenadas $\left(\delta_{F i}, F_{i}\right)$, sua inclinação define $S_{F i}$ e $\lambda_{F i}$, e sua interseção com o eixo $\delta_{F}$ define $\delta_{F_{i}}^{r}$.

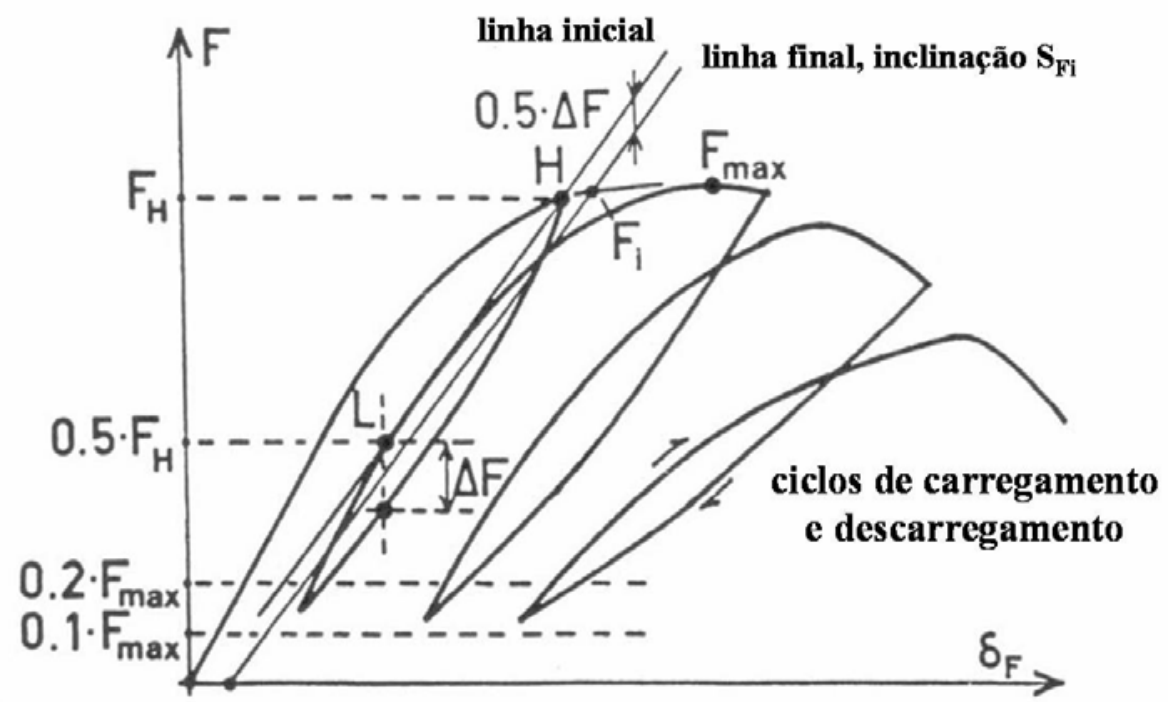

Figura 14 - Ciclos de carregamento e descarregamento para determinação da força $\left(\mathrm{F}_{\mathrm{m}}\right)$ (OUCHTERLONY, 1989)

A partir daqui os métodos sugeridos prescrevem a avaliação de $p$ de acordo com o método de Barker (1979). Uma interpolação em termos dos valores da inclinação 
$S_{F}=1 / \lambda_{F}$, foi encontrado ser o melhor que qualquer outro em termos de flexibilidade. O método encontra-se ilustrado na Figura 14 e obedece os passos (1) a (4) descritos a seguir:

(1) Começa-se com dois pontos $F_{i-1}$ e $F_{i}$, por exemplo, os quais têm os valores da inclinação entre parêntesis $1 / \lambda_{F}\left(a_{m}\right)=S_{F_{m}}=s_{m} . S_{F_{0}}$. Aqui $s_{m}$ refere-se às relações das equações (53) e (54) e $S_{F_{0}}=1 / \lambda_{F}\left(a_{0}\right)$ é a inclinação inicial da tangente da curva $F$ versus $\delta_{F}($ OUCHTERLONY, 1990).

$$
\begin{array}{ll}
S_{m}=1,05-2,15\left(\frac{a_{0}}{D}\right)+4,21\left(\frac{a_{0}}{D}\right)^{2} & \text { para o ensaio } C B \\
\mathrm{e} & \text { para o ensaio } S R
\end{array}
$$

Desenhar as linhas de descarregamento linearizadas de acordo com a equação (55) a través de $F_{i-1}$ e $F_{i}$ apoiada no eixo $\delta_{F}$ como indicado na etapa (iii) supramencionada.

$\delta_{F}^{r}=\delta_{F}-\lambda_{F} \cdot F$

(2) Definir um ponto $\left(\delta_{F l}, F_{l}\right)$ na linha de descarregamento através de $F_{i-l}$ o qual é definida por:

$$
\delta_{F_{l}}=\delta_{F_{i}}-\left(\delta_{F_{i}}^{r}-\delta_{F_{i-1}}^{r}\right) \text { e daqui, } F_{l}=F_{i} \cdot\left(\frac{S_{F_{i-1}}}{S_{F_{i}}}\right)
$$

Este nível da carga corresponde a um incremento de $F_{i}$ na proporção inversa à diminuição relativa na rigidez.

(3) Depois desenhar uma linha reta a través de $\left(\delta_{F i}, F_{i}\right)$ e $\left(\delta_{F l}, F_{l}\right)$ o que permite ao ponto $\left(\delta_{F e}, F_{e}\right)$ ser definido por:

$$
F_{e}=F_{i} \cdot\left(\frac{S_{F_{m}}}{S_{F_{i}}}\right) \text { ou } \frac{\left(F_{e}-F_{i}\right)}{\left(F_{l}-F_{i}\right)}=\frac{\left(S_{F_{m}}-S_{F_{i}}\right)}{\left(S_{F_{i-1}}-S_{F_{i}}\right)}
$$

Isto equivale a uma interpolação linear em termos de $S_{F}$. 
(4) Finalmente desenhar uma linha com inclinação $S_{F m}$ através do ponto $\left(\delta_{F e}, F_{e}\right)$ e permitir que sua intersecção com a curva $F$ versus $\delta_{F}$ defina o ponto de avaliação designado por $F_{m}$.

Desde que:

$\frac{F_{i}}{S_{F_{i}}}=\frac{F_{l}}{S_{F_{i-1}}}=\frac{F_{e}}{S_{F_{m}}}=\delta_{F_{i}}-\delta_{F_{i}}^{r}=l$

um descarregamento a partir de qualquer dos pontos $F_{i}, F_{l}$ e $F_{e}$ recuperam a mesma quantidade do deslocamento, $l$. A linha com inclinação $S_{F m}$ é construída facilmente encontrando o ponto $\left(\delta_{F e}-1,0\right)$ no eixo $\delta_{F}$ e desenhando uma linha reta através dela e $\left(\delta_{F e}, F_{e}\right)$. A partir de onde obtém-se a inclinação $S_{F m}$ como mostrado na Figura 15.

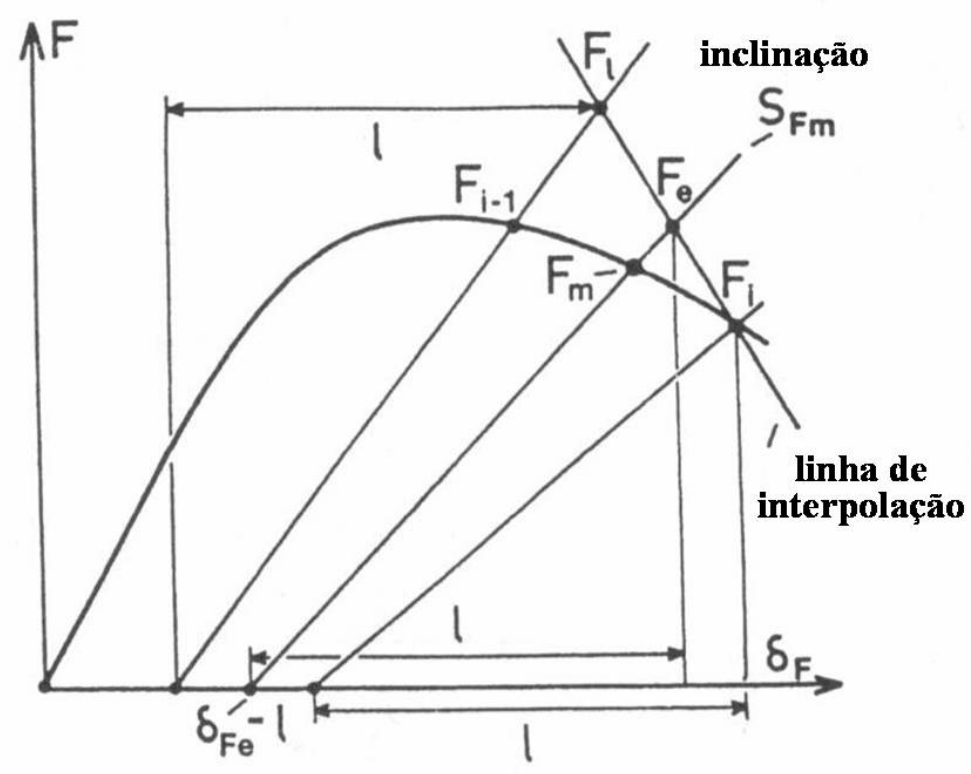

Figura 15. Metodologia para determinação de $F_{m}$ baseado no método da flexibilidade (OUCHTERLONY, 1989).

Este método para determinar $F_{m}$ tem um erro de segunda ordem. Os valores da tenacidade à fratura corrigidos por não linearidade no nivel II são calculados mediante as seguintes expresões:

$$
\begin{aligned}
K_{C B}^{c} & =\left[\frac{1+p}{1-p}\right]^{0.5} K_{C B} \\
K_{C B}^{c} & =\left[\frac{1+p}{1-p}\right]^{0.5} \frac{A_{\min } F_{m}}{D^{1.5}}
\end{aligned}
$$


$K_{S R}^{c}=\left[\frac{1+p}{1-p}\right]^{0.5} K_{S R}$

$K_{S R}^{c}=\left[\frac{1+p}{1-p}\right]^{0.5} \frac{A_{\min } F_{m}}{D^{1.5}}$

$F_{m}$ pode ser substituído por $F_{\max }$ nas equações (60) e (62) se $F_{m} \approx F_{\max }$.

\subsection{Ensaios não padronizados pela ISRM}

Salienta-se que a revisão aqui apresentada não contempla todos os ensaios não padronizados existentes, mas, a despeito disto, uma expressiva quantidade de ensaios foi encontrada na literatura e aqui descrita.

\subsubsection{Ensaio de explosão - "Burst test (BT)"}

Trata-se de uma configuração de ensaio para determinar a resistência da rocha na qual a trinca se propaga, sendo capaz de simular condições in-situ para aplicações de desmontes por explosivos e hidrofraturamento. Este método foi introduzido primeiro por Johnson et al (1973) e difundido por Clifton et al (1976). Clifton et al (1976) analisaram dois tipos de corpos de prova submetidos à pressão interna de um fluido: um que não considera nenhuma membrana entre o fluido e a parede interna do corpo cilíndrico e outro que considera uma membrana impermeável dentro do corpo de prova para impedir que o fluido penetre nas fissuras presentes na parede interior do mesmo. Este cilindro oco de parede grossa contém uma única trinca ou duas diametralmente opostas sujeitas a uma pressão interna " $p$ ” nas paredes do corpo cilíndrico (Figura 16).

Os autores supramencionados ensaiaram corpos de prova de arenitos de grão grosso com uma porosidade de $17 \%$ e xistos de grão fino com uma porosidade de $0.2 \%$ com $111 \mathrm{~mm}$ de diâmetro externo e 9,14 mm de diâmetro do furo interno. Todos os corpos de prova tiveram aproximadamente $63,5 \mathrm{~mm}$ de comprimento com as faces aplainadas e paralelas dentro de uma precisão de $0,002 \mathrm{~mm} / \mathrm{mm}$. Estas dimensões deram uma relação $W$ (relação do diâmetro do corpo de prova com o diâmetro do furo interno) de 11.1, a qual produz uma propagação estável da trinca, fornecendo os comprimentos 
iniciais de trinca no intervalo $2,54<\frac{a}{r_{0}-r_{i}}<5,08$. Ao final, os corpos de prova foram pré-trincados ou, mais precisamente, pré-entalhados a uma profundidade correspondente a $\frac{a}{r_{0}-r_{i}}=2,54$ ou $2 a=4,57 \mathrm{~mm}$. Eles usaram o princípio da superposição para deduzir o fator de intensidade de tensão para o caso de uma ou duas trincas e $\xi \leq 0,1$, sendo $\xi$ o comprimento adimensional da trinca, igual à $\frac{a}{r_{0}-r_{i}}$, onde $a$ é o comprimento da trinca, $r_{0}$ o raio externo do corpo de prova e $r_{i}$ o raio do furo interno no corpo de prova (Figura 16).

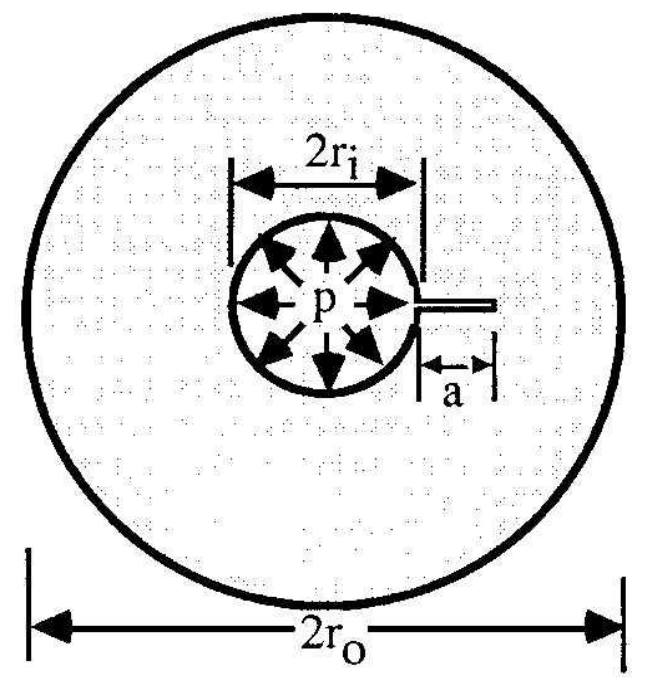

Figura 16. Ensaio de explosão (WHITTAKER; SINGH e SUN, 1992)

O pré-entalhe foi feito com um disco diamantado de 0,203 $\mathrm{mm}$ de diâmetro. As duas trincas diametralmente opostas foram feitas no diâmetro interno através do comprimento total do cilindro. Esta técnica produziu uma trinca de 0,23 $\mathrm{mm}$ de largura. Os medidores de deformação foram colados nas superfícies aplainadas em cada face dos corpos de prova. Estes medidores indicaram que duas trincas foram estendidas na rocha e que a propagação da trinca era simétrica.

A pressurização das faces do entalhe é prevenida pela membrana interna impermeável no furo central. Quando a pressão é restrita ao corpo de prova, a propagação da trinca além de um comprimento crítico é estável devido ao fato que a intensidade de tensão diminui na medida em que o comprimento da trinca aumenta.

Para uma superfície do corpo de prova pressurizado com faces de trinca livres de tração, o fator intensidade de tensão $\left(K_{I}\right)$ é dado por: 
$K_{I}=P_{\text {int }} Y(l, w) \sqrt{\pi r_{i}}$

onde:

$P_{\text {int }}$ : Pressão interna;

$Y$ : fator de calibração;

$r_{i}$ : raio do furo interno no corpo de prova;

$r_{o}$ : raio externo do corpo de prova;

$l$ : comprimento adimensional da trinca definida por $\frac{a}{r_{0}-r_{i}}$

a: comprimento inicial da trinca;

$w$ : relação entre o raio do corpo de prova e o raio do furo interno.

A função $Y$ foi determinada para diferentes valores de $w$ com incrementos de $l$ (CLIFTON et al,1976). Essas curvas mostram a presença de um mínimo local de $Y$ como uma função de $l$. Para certos valores de $w$, isto poderia sugerir a existência de um crescimento estável da trinca e poderia permitir a avaliação de $K_{I C}$ sem medição do comprimento de trinca. Assim, a pressão interna máxima $\left(P_{f}\right)$ na qual ocorre a ruptura é a única medida necessária.

$\mathrm{O}$ valor da tenacidade à fratura pode ser calculado mediante a seguinte equação:

$K_{I C}=\bar{Y}\left\lfloor P_{f} \sqrt{\pi r_{i}}\right\rfloor$

sendo:

$P_{f:}$ pressão interna máxima;

$r_{i}$ : raio do furo interno no corpo de prova;

$\bar{Y}$ : valor mínimo local de $Y$ para o $w$ dado.

Os valores reportados para $K_{I C}$ foram calculados a partir dos resultados de um ensaio simples e não representavam uma média de uma série de ensaios. Ensaios adicionais do mesmo material poderiam ser necessários para determinar o mínimo número de ensaios para avaliar a reprodutibilidade do ensaio.

Clifton et al (1976) estabeleceram que as vantagens deste método são as seguintes:

(1) A intensidade de tensão na ruptura não precisa ser determinada pelo tamanho da trinca na sua extensão inicial.

(2) O valor do fator de intensidade de tensão na ruptura deveria ser obtido de modo confiável a partir de uma medida precisa da pressão. 
(3) Os corpos de prova obtidos a partir de amostras tomadas de perfurações de campo são executados nos próprios testemunhos com um furo central.

Abou-Sayed (1977) apud Karfakis,Chong e Kuruppu (1986) modificou a técnica, incluindo pressões axiais e confinantes para pesquisar os efeitos das condições de tensão in-situ na determinação da tenacidade à fratura. $\mathrm{O}$ fator de intensidade de tensão sob carregamento axial e confinamento pode ser obtido pelo principio da superposição. Nas experiências que ele conduziu sob pressão confinante constante $\left(P_{o}\right)$, o crescimento da trinca foi estável durante toda a experiência, requerendo, conseqüentemente, o conhecimento preciso do comprimento da trinca para calcular a tenacidade à fratura da rocha sob pressão confinante. Ele também sugeriu que, para um valor $\mathrm{w}$ dado, se os ensaios foram testados a uma taxa constante de $\frac{P_{o}}{P_{i}}$, a relação $Y^{c}{ }_{c}-l$ mostra um mínimo local.

$\mathrm{O}$ valor da tenacidade à fratura pode ser calculado mediante a seguinte equação:

$K_{I C}{ }^{c}=\bar{Y}^{c}\left\lfloor P_{i}\left(\pi r_{i}\right)^{1 / 2}\right\rfloor$

sendo:

$P_{i}$ : pressão interna correspondente ao mínimo local;

$r_{i}$ : raio do furo interno no corpo de prova;

$\bar{Y}^{c}$ : valor mínimo local de $Y$ para $w$ e $\frac{P_{o}}{P_{i}}$ dados.

O corpo de prova empregado para este ensaio é especialmente útil para aplicações do processo de fratura em furos de sondagens, devido ao fato que a configuração do corpo de prova é a mais próxima às condições reais de campo e os ensaios de laboratório são conduzidos para as condições não confinadas e confinadas. Os corpos de prova são preparados facilmente a partir de amostras tomadas das perfurações de campo, perfurando um furo pequeno central e realizando o pré-entalhe deste. Neste método, não é requerido o comprimento inicial da trinca para a determinação da tenacidade à fratura.

Estes ensaios foram bastante usados para simular condições in-situ e para medir a tenacidade à fratura in-situ das rochas. (ABOU-SAYED, 1977 apud WHITTAKER; SINGH e SUN, 1992). Apesar de ser totalmente similar às condições geométricas e de carregamento do fraturamento hidráulico, esta técnica tem recebido pouca atenção devido à sua complexidade experimental. (ZHAO e ROEGIERS, 1990). 


\subsubsection{Ensaio de corpos de prova semicirculares submetidos à flexão em três pontos - "Semi-circular bend specimen (SCB)"}

Chong e Kuruppu (1984) propuseram a utilização de um corpo de prova semicircular com um simples entalhe reto de comprimento $a$, sujeito a um carregamento semelhante a um ensaio de flexão a três pontos. Desta forma, os ensaios devem ser feitos preferencialmente com carregamento compressivo, onde são induzidas as fraturas de tração (modo I) (LIM et al, 1994). O entalhe central reto pode ser vertical (Figura 17) para ensaios Modo I ou entalhe inclinado (Figura 18) para ensaios Modo Misto.

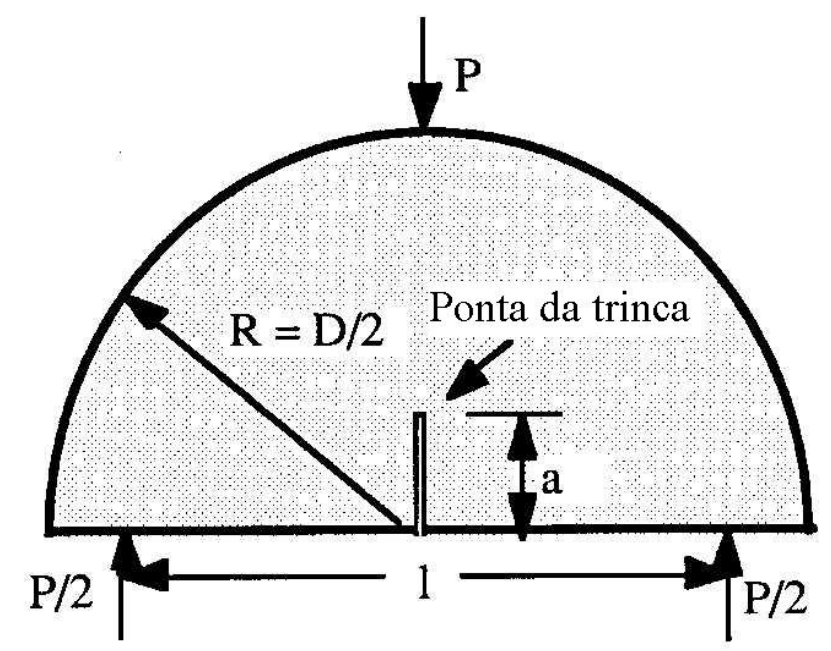

Figura 17 - Ensaio de corpos de prova semicirculares submetidos à flexão em três pontos (WHITTAKER; SINGH e SUN, 1992)

Os ensaios foram realizados em uma máquina hidráulica servo-controlada. A calibração da célula de carga e do medidor do deslocamento da abertura da boca da trinca $(C M O D)$ foram verificados para garantir uma resposta linear em cada um dos sinais (CHONG e KURUPPU, 1988). Foi projetado um dispositivo para carregar o corpo de prova em três pontos, minimizando os efeitos friccionais, permitindo aos suportes cilíndricos rotacionar e mover-se ligeiramente enquanto o corpo de prova é carregado. Este dispositivo ajuda a conseguir o alinhamento apropriado no sistema de transferência de carga.

Uma medida da abertura da boca da trinca usando um extensômetro do tipo “clip gauge" é mais exato e conveniente que uma medida do deslocamento na linha de carregamento (KARFAKIS; CHONG e KURUPPU, 1986). 
As hastes dos extensômetros são coladas no final do entalhe dos corpos de prova. Estas hastes suportam os ajustadores e servem como pontos de referência aos deslocamentos. Os corpos de prova foram carregados com controle de deslocamento da abertura da boca da trinca a uma velocidade constante de aproximadamente $3.4 \times 10^{-3}$ $\mathrm{mm} / \mathrm{s}$. As variáveis medidas são: a carga máxima aplicada $\left(F_{\text {máx }}\right)$ e o deslocamento da abertura da boca da trinca $(C M O D)$.

O corpo de prova pode ser preparado a partir de testemunhos de rochas típicas com pouco maquinário. Este ensaio é essencialmente adaptável a pequenos testemunhos compactos que requerem duas amostras (de composição similar) para ensaiar parâmetros tais como velocidade de deformação, temperatura, etc. No trabalho original de Chong e Kuruppu (1984) e Chong, Kuruppu e Kuszmaul (1987), a variação no fator de intensidade de tensão foi determinado numericamente usando o método dos elementos finitos para carregamento no modo I e no modo misto, respectivamente. Não obstante, somente foram examinados intervalos de vãos e de comprimentos de trinca muitos limitados.

Karfakis, Chong e Kuruppu (1986) desenvolveram uma fórmula para $K_{I}$ usando o método da variação da liberação da energia de deformação conforme apresentada abaixo:

$$
K_{I}=\frac{P_{Q} \sqrt{\pi a}}{D B} Y_{K}
$$

onde

$Y_{K}$ : fator de intensidade de tensão adimensional (obtido em função do comprimento adimensional da trinca $a / D)$;

$a$ : comprimento do pré-entalhe;

$D$ : diâmetro do corpo de prova;

$B$ : espessura do corpo de prova;

$P_{Q}$ : carga crítica na curva carga-deslocamento.

Estes autores definem a carga crítica como o ponto de interseção de uma linha secante construída seguindo a norma ASTM E399 (1981) e a curva obtida no ensaio. Eles comprovaram que, se $F_{\operatorname{máx}}$ fosse considerada como a carga crítica, a relação $\frac{F_{\operatorname{máx}}}{P_{Q}}$ seria 1,05 na maioria dos casos, mas menor que 1,10 em todos os ensaios.

Chong, Kuruppu e Kuszmaul (1987) concluíram que o corpo de prova proposto é aplicável para materiais estratificados e não estratificados baseados em análises 
experimentais e numéricas. A carga e a energia de fratura das rochas estratificadas foram medidas com ensaios estáticos, e a tenacidade à fratura determinada usando três métodos, a saber: i) método do fator de intensidade de tensão, ii) método da flexibilidade e iii) método baseado no Integral-J. Os resultados dos três métodos mostram satisfatoriamente que a determinação da tenacidade à fratura mediante uso da mecânica da fratura elástica linear é valida para materiais rochosos anisotrópicos. Baseados no tamanho do corpo de prova menor, o requisito dimensional mínimo para o corpo de prova $S C B$ pode ser dado por:

$2.0\left(\frac{K_{I C}}{\sigma_{t}}\right)^{2}$

Singh e Sun (1990) assumiram, implicitamente, que existe uma relação linear diretamente proporcional entre $Y_{I}$ e o comprimento de vão $(S)$ para o modo I puro. Em outras palavras, $Y_{I}$ foi assumido como diretamente proporcional a $S$.

Whittaker, Singh e Sun (1992) aproximaram $Y_{K}$ por um polinômio de terceiro grau conforme:

$Y_{K}=4.47+7.40 \frac{a}{D}-106.00\left(\frac{a}{D}\right)^{2}+433.3\left(\frac{a}{D}\right)^{3}$

Expressão esta que é válida no intervalo $0.25 \leq \frac{a}{D} \leq 0.35$ e para $\frac{S}{D}=0.8$, sendo $S$, conforme expresso anteriormente, o vão entre os apoios do corpo de prova.

Lim, Johnston e Choi (1993) estenderam os trabalhos prévios para abranger um amplo intervalo de geometrias possíveis de corpos de prova de interesse experimental. Comparando os resultados numéricos obtidos para o carregamento no modo I com $S / R=0.5,0.61,0.67$ e 0.80 , estes autores concluíram que os resultados de Chong e Kuruppu (1984) para $S / R=0.8$ foram os melhores.

Tabela 3. Fatores de intensidade de tensão no modo I normalizado para o ensaio SCB (LIM; JOHNSTON e CHOI, 1993)

\begin{tabular}{|c|c|c|c|c|c|c|c|c|c|}
\hline & & \multicolumn{9}{|c|}{$a / R$} \\
\hline$S / R$ & $\begin{array}{c}\alpha \\
\left({ }^{\circ}\right.\end{array}$ & 0.1 & 0.2 & 0.3 & 0.4 & 0.5 & 0.61 & 0.67 & 0.8 \\
\hline 0.5 & 0 & 2.7600 & 2.5140 & 2.5730 & 2.9180 & 3.6030 & 5.0060 & 6.3150 & 12.9300 \\
\hline 0.61 & 0 & 3.4360 & 3.2610 & 3.3940 & 3.8340 & 4.6700 & 6.3790 & 7.9800 & 16.0900 \\
\hline 0.67 & 0 & 3.8210 & 3.6720 & 3.8410 & 4.3340 & 5.2450 & 7.1300 & 8.8890 & 17.8100 \\
\hline 0.80 & 0 & 4.7020 & 4.5870 & 4.8230 & 5.8230 & 6.5200 & 8.7570 & 10.8600 & 21.5400 \\
\hline
\end{tabular}

Estes mesmos autores estabeleceram outra relação baseada em suas análises, onde observaram que a variação de $Y_{I}$ para o modo I puro $\left(\alpha=0^{\circ}\right)$ é linear com relação a 
$S / R$ para cada comprimento de trinca. Não obstante, os gradientes das linhas variam como uma função dos comprimentos das trincas. Eles propuseram a seguinte relação:

$\frac{K_{I}}{\sigma_{o} \sqrt{\pi a}}=Y_{I\left\{s_{0} / r\right\}}+\frac{\Delta S_{o}}{R} B^{*}, \quad 0.5 \leq \frac{S_{a}}{R} \leq 0.8$

onde:

$S_{a} / R$ : relação atual do vão empregado;

$S_{o} / R$ : relação do vão mais próximo dos valores de $S_{a} / R$ analisados por Lim, Johnston e Choi (1993), isto é, $S_{o} / R=0.5,0.61,0.67$ ou 0.80 ;

$\Delta S_{o} / R:$ diferença de $S_{o} / R$, isto é $\frac{\left(S_{a}-S_{o}\right)}{R}$

$Y_{I\left\{S_{o} / R\right\}}$ : intensidade de tensão normalizada a uma determinada relação de vão $S_{o} / R$.

$B^{*}=6.55676+16.64035\left(\frac{a}{R}\right)^{2.5}+27.97042\left(\frac{a}{R}\right)^{6.5}+215.0839\left(\frac{a}{R}\right)^{16}$

$0.03 \leq \frac{a}{R} \leq 0.8$

Um exemplo desta aproximação pode ser obtido considerando-se um corpo de prova com uma relação de vão entre os apoios do corpo de prova de 0.7 e um comprimento de trinca de 0.61 . O mais próximo $S_{o} / R$ seria 0.67 e isto daria um valor apropriado de $Y_{I\left\{S_{o} / R\right\}}$ (isto é $Y_{I\{0.67\}}$ ) a partir da Tabela 3. Assim, $\Delta S_{o} / R=0.03$. Para $a / R=0.61, B^{*}$ poderia ser calculado como 12,597. Substituindo $Y_{I\{0.67\}}=7.130$, $\Delta S_{o} / R=0.03$ e $B^{*}=12,597$ na equação (70), $Y_{I}$ poderia dar 7,508. Uma inspeção da Tabela 3 mostra este valor como uma aproximação razoável. Estas considerações poderiam ser úteis para avaliar as expressões analíticas para o termo $Y_{{ }_{I}\left\{S_{o} / R\right\}}$ dado na equação anterior. Com isto em mente, realizou-se uma análise de regressão para dar uma função analítica para $Y_{I\left\{S_{o} / R\right\}}$.

Assim, foi usada uma função da seguinte forma: 


$$
Y_{I\left\{S_{0} / R\right\}}=C_{1}+C_{2}\left(\frac{a}{R}\right)+C_{3} \exp \left(C_{4}\left(\frac{a}{R}\right)\right)
$$

onde $C_{i}$ são constantes.

Assim:

$$
\begin{aligned}
& Y_{I\{0.8\}}=4.782-1.219\left(\frac{a}{R}\right)+0.063 \exp \left(7.045\left(\frac{a}{R}\right)\right), \text { para } \frac{S_{o}}{R}=0.8 \\
& Y_{I\{0.67\}}=3.638-0.139\left(\frac{a}{R}\right)+0.039 \exp \left(7.387\left(\frac{a}{R}\right)\right), \text { para } \frac{S_{o}}{R}=0.67 \\
& Y_{I\{0.61\}}=3.286-0.432\left(\frac{a}{R}\right)+0.039 \exp \left(7.282\left(\frac{a}{R}\right)\right), \text { para } \frac{S_{o}}{R}=0.61 ; \\
& Y_{I\{0.5\}}=2.959-2.716\left(\frac{a}{R}\right)+0.076 \exp \left(6.305\left(\frac{a}{R}\right)\right), \text { para } \frac{S_{o}}{R}=0.50
\end{aligned}
$$

A validade destas equações se dá dentro do intervalo $0.03 \leq \frac{a}{R} \leq 0.8$.

Uma função analítica aproximada pode ser obtida para $Y_{I\left\{S_{a} / R\right\}}$ combinando as equações anteriores:

$\frac{K_{I}}{\sigma_{o} \sqrt{\pi a}}=Y_{I\{0.8\}}+\frac{\Delta S_{o}}{R} B^{*}$, para $S_{o} / R=0.8$

onde $Y_{I\{0.8\}}$ é como definido na equação (72).

Neste caso, poderia ser usada uma relação de 0.75 , onde poderiam ser usados $S_{a} / R=0.75$ e $\Delta S_{o} / R=-0.05$.

Segundo Lim, Jonhston e Choi (1993), as condições de modo-misto podem ser obtidas variando o ângulo formado entre a direção da carga e o entalhe (Figura 18). 


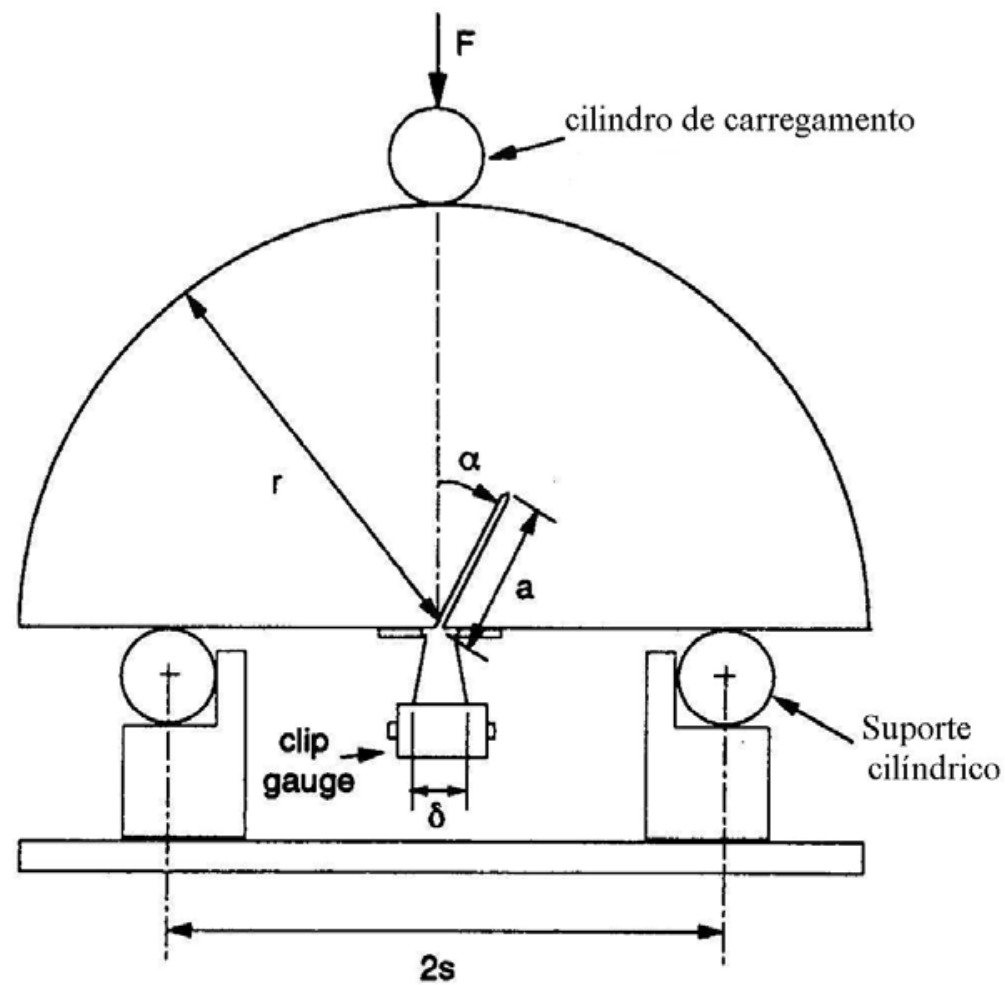

$a$ : comprimento da trinca

$r$ : raio do corpo de prova

$2 s$ : distância entre os pontos de apoio

$\alpha$ :ângulo de inclinação da trinca

$\Delta \delta$ : deslocamento da abertura da trinca

Figura 18 - Ensaio de corpos de prova semicirculares com entalhe inclinado submetidos à flexão em três pontos (LIM; JOHNSTON e CHOI, 1993)

Desenvolveram-se soluções para $K_{I}$ e $K_{I I}$ em corpos de prova $S C B$ (para $0.05 \leq \frac{a}{D} \leq 0.4$ e $\frac{S}{R}=0.50,0.61,0.67$ ou 0.80 ) conforme abaixo:

$K_{I}=\frac{P_{Q} \sqrt{\pi a}}{D B} Y_{I}$

$K_{I I}=\frac{P_{Q} \sqrt{\pi a}}{D B} Y_{I I}$

onde:

$Y_{I}, Y_{I I}$ : fatores de intensidade de tensão adimensionais;

$a$ : comprimento do pré-entalhe;

$D$ : diâmetro do corpo de prova;

$B$ : espessura do corpo de prova; 
$P_{Q}$ : carga crítica na curva carga-deslocamento.

Nas equações acima, os fatores de intensidade de tensão adimensionais $\left(Y_{I}\right.$ e $\left.Y_{I I}\right)$, são determinados pelos fatores adimensionais: i) relação comprimento do pré-entalhe diâmetro do corpo de prova $\left(\frac{a}{D}\right)$, ii) ângulo de inclinação do entalhe em relação à direção de carregamento $(\alpha)$ e iii) o vão entre os apoios do corpo de prova $(S)$.

Lim et al (1994) avaliaram a técnica do ensaio para determinação da tenacidade à fratura em um corpo de prova semicircular submetido à flexão de três pontos em uma rocha sintética saturada.

Krishnan et al (1998) utilizaram corpos de prova de configuração simples para a determinação da tenacidade à fratura das rochas não consolidadas realizando os primeiros ensaios em rochas brandas. Devido à dificuldade para fazer um entalhe “chevron”, decidiu-se usar corpos de prova semicirculares com simples entalhes e diferentes orientações submetidos a um ensaio de flexão a três pontos.

Chang, Lee e Jeon (2002) calcularam a tenacidade à fratura do Granito Keochang e do Mármore Yeosan na Coréia sob as correspondentes condições do modo I e do modo misto. O cálculo foi realizado a partir das soluções dos fatores de intensidade de tensões encontradas por Whittaker, Singh e Sun (1992) e Lim, Johnston e Choi, (1993). Os resultados obtidos por estes autores mostraram grande variabilidade e padrões incompatíveis com os comprimentos de entalhe. Sendo assim, eles recomendaram que o fraturamento inicial sempre seja realizado, especialmente para rochas sãs.

\subsubsection{Ensaio de corpos de prova semicirculares com entalhe tipo Chevron submetidos à flexão em três pontos - "Chevron Notched Semicircular Bend test $(C N S C B)$ "}

Kuruppu (1997) propõe um corpo de prova baseado na forma semicircular com um entalhe "chevron" na borda. A incorporação do entalhe "chevron" facilita a iniciação e o crescimento de uma trinca natural de uma maneira estável antes de alcançar o ponto de instabilidade, além de simplificar o cálculo da tenacidade à fratura.

Os corpos de prova cilíndricos são cortados em duas metades com um disco delgado e introduzido o entalhe "chevron" (Figura 19). Eles são submetidos a um 
carregamento semelhante a um ensaio de flexão a três pontos até à ruptura, determinando-se a carga máxima aplicada $\left(F_{\text {máx }}\right)$.

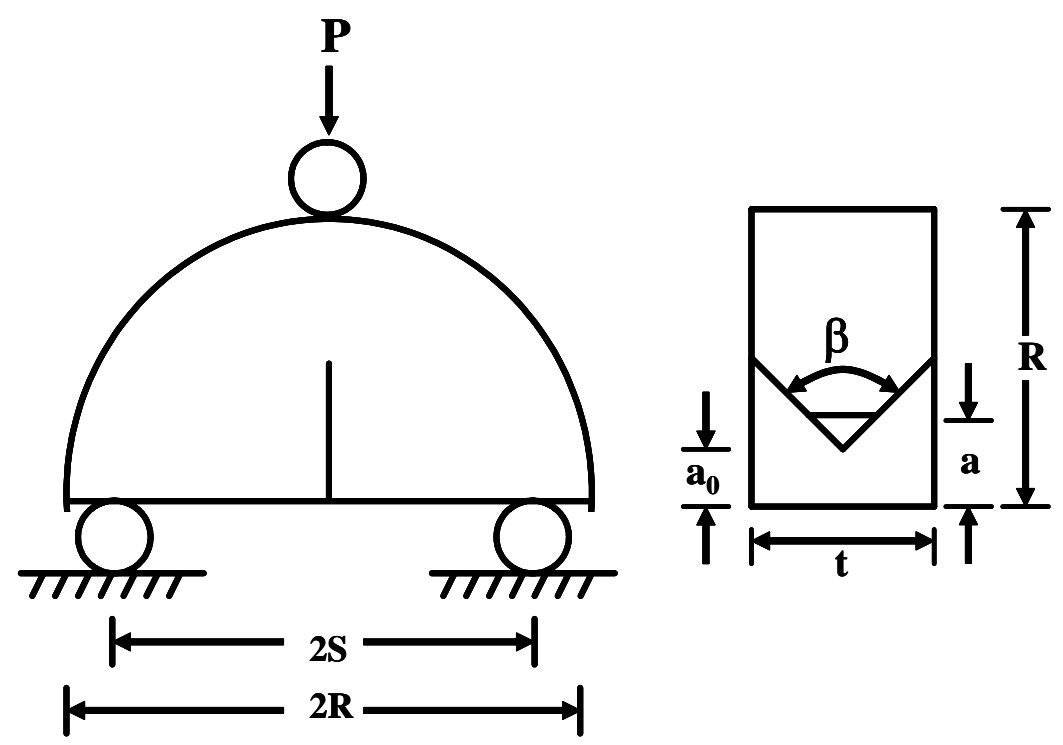

Figura 19 - Corpo de prova semicircular com entalhe tipo "Chevron” (KURUPPU, 1997)

Os fatores de intensidade de tensão adimensionais no modo I para o corpo de prova semicircular com entalhe "chevron" foram determinados usando uma simulação numérica de elementos finitos $3 D$. A derivação foi baseada nas relações do fator de intensidade de tensão e deslocamento. O fator de intensidade de tensão tem um valor mínimo $(a / R \approx 0.35)$ para esta geometria, o qual corresponde à relação adotada para a determinação da tenacidade à fratura do material. Esta observação está em acordo com as investigações feitas em outros tipos de corpos de prova com entalhes tipo "chevron" (KURUPPU, 1998).

A grande magnitude do fator de intensidade de tensão na frente estreita inicial do pré-entalhe causa o desenvolvimento de uma trinca natural a qual se propaga de uma maneira estável em um ambiente onde o fator de intensidade de tensão diminui. A fratura eventual ocorre além do valor mínimo do gráfico e, conseqüentemente, a tenacidade a fratura é avaliada nesse ponto. $\mathrm{O}$ valor médio do fator de intensidade de tensão determinada ao longo da frente da trinca é normalizado como segue:

$K_{n d}=\frac{K_{I}}{F_{\text {máx }}} B \sqrt{R}$

onde:

$K_{n d}$ : fator de intensidade de tensão normalizado;

$F_{\text {máx }}$ : carga máxima aplicada; 
$B$ : espessura do corpo de prova $\mathrm{e}$

$R$ : raio do corpo de prova.

O valor do fator de intensidade de tensão máximo é de 7,2, sendo este valor usado para a avaliação da tenacidade à fratura junto com os dados experimentais (KURUPPU, 1997; KURUPPU, 1998).

Assim, a tenacidade à fratura pode ser avaliada como:

$K_{I C}=\frac{K_{n d \max } F_{\text {máx }}}{B \sqrt{R}}=\frac{7,2 F_{\text {máx }}}{B \sqrt{R}}$

Salienta-se que, para utilizar a expressão anterior, os corpos de prova devem ser cuidadosamente preparados, pois os modelos para determinar o fator de intensidade de tensão são influenciados pela geometria do corpo de prova, pelo tipo de entalhe e pelas condições de contorno. Segundo recomendado por Kuruppu (1998), deve-se escolher um valor apropriado da relação entre o vão entre os apoios do corpo de prova e o raio $\left(\frac{S}{R}=0,8\right)$, além de uma relação $\frac{a_{0}}{R}$ de aproximadamente 0,24 .

Chang, Lee e Jeon (2002) compararam ensaios SCB, SCB com entalhe “chevron" e CCNBD em granito e mármore, utilizando corpos de prova de $75 \mathrm{~mm}$ de diâmetro e de 23 a $32 \mathrm{~mm}$ de espessura, concluindo que os resultados do ensaio $S C B$ com entalhe "chevron" foram muito próximos, ligeiramente maiores aos obtidos pelos ensaios $C C N B D$.

\subsubsection{Ensaio de anel trincado radialmente - "Radial cracked ring specimens $(R C R) "$}

Este ensaio proposto por Shiryaev e Kotkis (1982) para determinar a tenacidade à fratura de materiais frágeis porosos, simulando duas trincas opostas radiais no furo interior do corpo de prova, como mostrado na Figura 20. Ele foi utilizado como medida de resistência de materiais rochosos e aplicado em ensaios de fratura em rochas por Thiercelin e Roegiers (1986).

Em um corpo de prova de raio externo $r_{0}$, é realizado um furo interno de raio $r_{i}$ $\left(r_{i}<<r_{0}\right)$, realizando-se dois cortes delgados ao longo do diâmetro do corpo de prova. As trincas se propagam nos extremos dos cortes realizados dentro do furo interno. As trincas mostram um crescimento constante, o qual pode ser medido, por exemplo, pelo 
método de emissão acústica. Com o aumento da emissão acústica, a carga nas cunhas poderia ser removida e as trincas colorizadas (SHIRYAEV e KOTKIS, 1982).

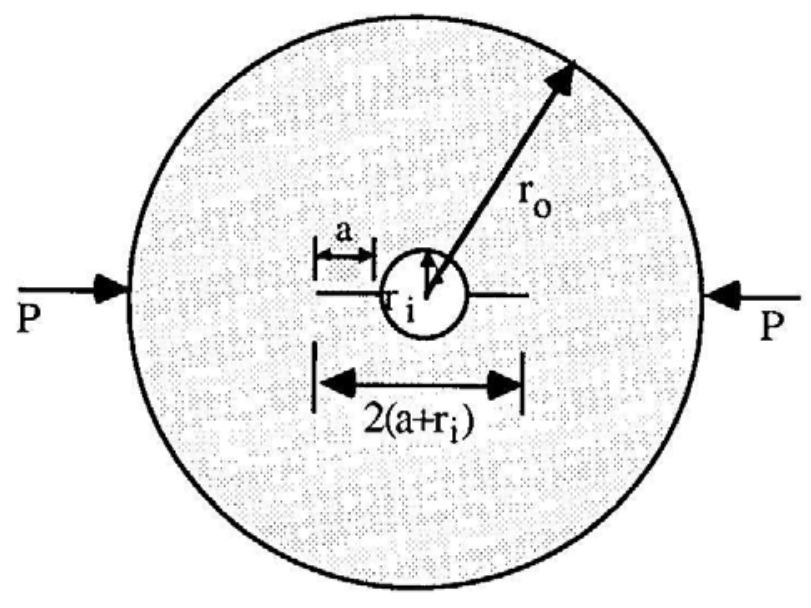

Figura 20 - Ensaio de anel trincado radialmente (WHITTAKER; SINGH e SUN, 1992)

Para eliminar o efeito do meio da superficie ativa e da substância colorida, os corpos de prova foram secos a $30^{\circ} \mathrm{C}$ por 24 horas, o que, de acordo com Panasyuk e Kovchik (1962) apud Shiryaev e Kotkis (1982), elimina a influência do efeito "Rebinder" causado pela preparação do corpo de prova (mudanças das propriedades das rochas causadas por duas reações, a hidrólise e a dissolução dos carbonatos, as quais poderiam diminuir as ligações na superfície externa do corpo de prova e causar uma desordem na estrutura química em presença de vapor de água).

Os corpos de prova são submetidos à compressão para determinar $K_{I C}$. O momento no qual a trinca começa a propagar é determinado por emissão acústica. Para calcular a carga máxima crítica $q^{*}$ do ensaio, Shiryaev e Kotkis (1982) resolveram o problema da determinação do estado de tensões em um corpo de prova de espessura uniforme e raio $r_{o}$ enfraquecido por uma trinca longa, começando no contorno do furo interno com raio $r_{i}$ carregado em seu contorno externo por uma carga concentrada $P$. Eles assumiram que:

$\frac{a}{r_{0}}=\varepsilon, \frac{r_{i}}{r_{0}}=\mu$ e também que $\mu \approx \varepsilon^{2}$ se $\varepsilon<1$ e $\mu<<1$.

onde:

2a: comprimento da trinca inicial;

$r_{0}$ : raio externo do corpo de prova e

$r_{i}$ : raio do furo interior no corpo de prova 
Estas três condições mostradas acima devem ser satisfeitas para selecionar as dimensões do corpo de prova com uma trinca radial.

Usando soluções da teoria elástica bi-dimensional e também o método das aproximações sucessivas, encontraram que a tenacidade à fratura $\left(K_{I C}\right)$ pode ser calculada por meio da seguinte relação:

$K_{I C}=\frac{q^{*}}{\sqrt{2 r_{i}}}\left[\sqrt{\varepsilon}\left(1+\frac{3 \varepsilon^{2}}{2}+\frac{20 \mu^{3}}{3 \pi \varepsilon^{3}}-\frac{3 \varepsilon \mu}{\pi}\right)\right]$

onde:

$q^{*}$ : carga máxima crítica;

$\varepsilon, \mu$ e $r_{i}$ como definidos anteriormente.

Se o raio interno do anel for muito menor que o raio externo, o corpo de prova em anel pode ser tratado como o disco brasileiro fraturado (THIERCELIN e ROEGIERS, 1986).

Danell et al (1987) apud Whittaker, Singh e Sun (1992) analisaram a configuração do corpo de prova e forneceram a seguinte expressão para a tenacidade à fratura $\left(K_{I C}\right)$ :

$K_{I C}=\frac{F_{\max } \sqrt{a+r_{i}}}{B r_{0} \sqrt{\pi}} x\left[1+\frac{3}{2}\left(\frac{a+r_{i}}{r_{0}}\right)^{2}+\frac{20}{3 \pi}\left(\frac{r_{0}}{a+r_{i}}\right)^{3}-\frac{3}{\pi} \frac{\left(a+r_{i}\right) r_{i}}{r_{0}^{2}}\right]$

onde:

$a$ : metade do comprimento da trinca $(\mathrm{mm})$;

$B$ : espessura do corpo de prova $(\mathrm{mm})$;

$F_{\text {máx }}$ : carga máxima aplicada $(\mathrm{kN})$;

$r_{i}$ : raio do furo interno no corpo de prova $(\mathrm{mm}) \mathrm{e}$

$r_{0}$ : raio externo do corpo de prova $(\mathrm{mm})$.

\subsubsection{Ensaio de anel modificado - "Modified ring test (MRT)"}

Thiercelin e Roegiers (1986) propuseram o ensaio de anel modificado, o qual é um ensaio de compressão diametral que pode ser analisado em tensão plana da $M F E L$ (Mecânica da Fratura Elástica Linear). A configuração do ensaio de anel modificado $(M R T)$ é mostrada na Figura 21. A carga compressiva é aplicada ao corpo de prova de anel modificado pelo deslocamento uniforme de dois pratos de carregamento paralelos e diametralmente opostos atuando sob as superfícies planas do anel modificado. 


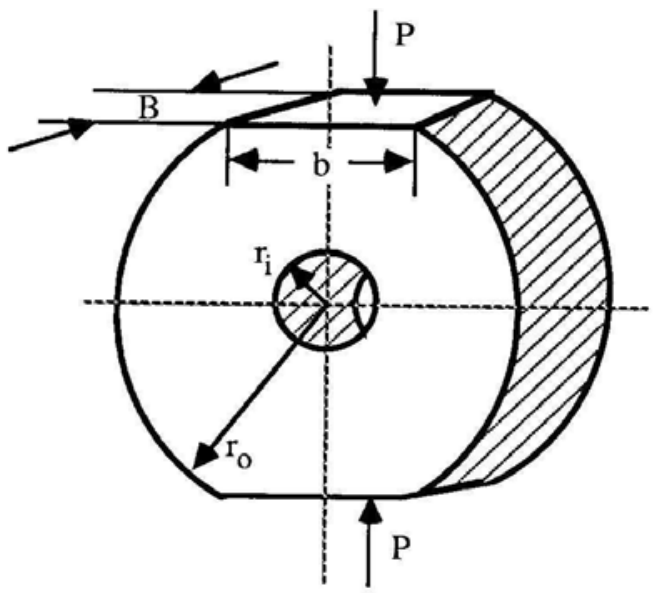

Figura 21 - Geometria do corpo de prova de anel modificado (WHITTAKER; SINGH e SUN, 1992)

As trincas no modo I começam no furo, que fornece uma trinca inicial e concentra um esforço de tração tangencial ao furo e normal à carga aplicada. $\mathrm{O}$ fator de intensidade de tensão aumenta com o comprimento da trinca. Quando a trinca aproxima-se do campo de atuação dos esforços compressivos, a tensão efetiva de tração é reduzida, a zona de processo entra em colapso e a trinca se propaga no eixo de carregamento até alcançar sua superfície, como mostra a Figura 22, sem necessitar de pré-entalhe.

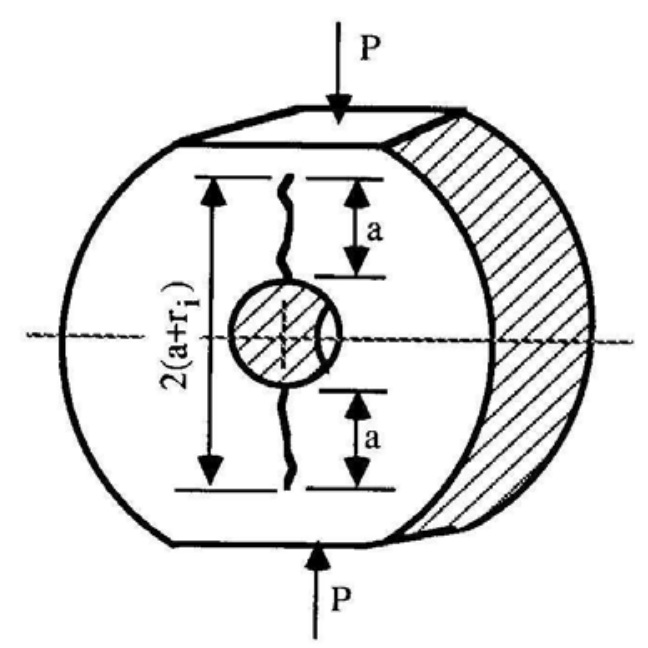

Figura 22 - Duas trincas simetricamente radiais geradas no furo interno do corpo de prova de anel modificado (WHITTAKER; SINGH e SUN, 1992)

O comprimento da trinca onde a zona de processo começa a colapsar é mostrado por Thiercelin e Roegiers (1986) como um comprimento da trinca onde o valor de $K_{I}$ é maximizado. Durante o ensaio, o máximo $K_{I}$ ocorre na primeira queda (mínimo local) 
da curva carga - deslocamento após a fratura do Modo I. O ensaio é realizado sob controle de deslocamento LPD (deslocamento do ponto de carregamento).

O padrão do fator de intensidade de tensão é função do comprimento da trinca assumido, o qual consiste em duas partes: uma propagação inicial instável e a subseqüente propagação estável. A primeira acontece a comprimentos de trincas relativamente pequenos de modo que a um incremento no comprimento da trinca resulta em um incremento correspondente no fator de intensidade de tensão. A segunda é alcançada após a trinca propagar-se de forma instável acima do comprimento de trinca $\left(a_{c}\right)$, condição na qual o fator de intensidade de tensão é um máximo. Logo depois, $K_{I}$ decresce com o incremento do comprimento de trinca. Este fenômeno é atribuído às tensões compressivas imediatamente abaixo da superfície de carregamento, condição esta que corresponde à mesma situação que ocorre no ensaio com discos ranhurados. Relacionando este padrão ao registro carga-deslocamento é facilmente compreensível o motivo pelo qual se obtém uma carga aplicada local mínima que corresponde a um $K_{\text {Imax }}$ e a um $a_{c}$. Salienta-se que, na prática, este fenômeno foi bem observado a partir de experimentos de Thiercelin e Roegiers (1986). Conseqüentemente, a tenacidade à fratura pode ser determinada a partir do ponto onde a carga aplicada $P$ é um valor mínimo local na região de propagação estável da trinca.

A preparação do corpo de prova consiste em três etapas: i) extração dos corpos de prova cilíndricos, ii) preparação do anel e iii) retificação das superfícies de carregamento lisas e opostas diametralmente. A geometria do corpo de prova é descrita pelo raio do furo interno $\left(r_{i}\right)$, o raio externo do corpo de prova $\left(r_{0}\right)$, a metade do comprimento da superfície aplainada $(l)$ e a espessura do corpo de prova $(B)$. Os primeiros três parâmetros podem ser normalizados como: $\alpha=\frac{r_{i}}{r_{0}}$ e $\beta=\frac{l}{r_{0}}$ (THIERCELIN e ROEGIERS, 1986).

Thiercelin e Roegiers (1986) calibraram $K_{\operatorname{Imax}}$ e $a_{c}$ para um amplo intervalo de geometrias. O ensaio de anel modificado $(M R T)$ consta de duas fases: deformações do corpo de prova no laboratório e cálculos numéricos dos fatores de intensidade de tensão na ponta de trinca em modelos com as mesmas dimensões do corpo de prova ensaiado (THIERCELIN e ROEGIERS, 1986; FISCHER et al, 1996; DOOLIN, 1994).

Doolin (1994) empregou uma máquina hidráulica servo-controlada para ensaiar os corpos de prova. Antes do ensaio, foram medidos o raio do furo interno, o raio 
externo do corpo de prova, o comprimento da superfície aplainada de carregamento e a espessura do corpo de prova.

Durante o ensaio, o tempo, a carga e o deslocamento (dos pratos de carregamento da maquina hidráulica servo-controlada) foram automaticamente registrados no microcomputador, obtendo-se gráficos deslocamento - tempo e carga tempo. Whittaker, Singh e Sun (1992) estabeleceram que, para $v=0.35$, pode-se utilizar uma regressão de terceira ordem polinomial como se segue:

$$
a_{c}=r_{0}\left[1.02-1.60\left(\frac{l}{r_{0}}\right)+0.35\left(\frac{l}{r_{0}}\right)^{2}+1.17\left(\frac{l}{r_{0}}\right)^{3}\right]
$$

A tenacidade à fratura pode ser determinada pela seguinte expressão:

$$
\begin{aligned}
& K_{\operatorname{Im} a x}=\frac{P_{\min }}{\pi B r_{0}} \sqrt{\pi\left(r_{i}+a_{c}\right)} \\
& \left\{\begin{array}{l}
3.23-13.73\left(\frac{l}{r_{0}}\right)+25.36\left(\frac{l}{r_{0}}\right)^{2}-14.8\left(\frac{l}{r_{0}}\right)^{3} \ldots \text { para. } . \frac{r_{i}}{r_{0}}=0.13 \\
3.50-14.86\left(\frac{l}{r_{0}}\right)+37.14\left(\frac{l}{r_{0}}\right)^{2}-40.0\left(\frac{l}{r_{0}}\right)^{3} \ldots \text { para. } . \frac{r_{i}}{r_{0}}=0.20
\end{array}\right.
\end{aligned}
$$

onde,

$r_{i}$ : raio do furo interno no corpo de prova;

$r_{0}$ : raio externo do corpo de prova;

$P_{\min }:$ carga aplicada local mínima;

$B$ : espessura do corpo de prova e

$l:$ metade do comprimento da superfície aplainada de carregamento

sendo válidos os resultados somente para $0.1 \leq \frac{l}{r_{0}} \leq 0.35$.

Pode-se observar que, para diferentes valores de $r_{i}$ e $r_{0}$, os valores de $a_{c}$ e $K_{\text {Imax }}$ são dependentes somente de $l$ (metade do comprimento da superfície aplainada de carregamento).

A análise de Donovan (1994) indicou que os parâmetros que podem controlar os comportamentos estável e instável da fratura nos corpos de prova de anel modificado são o diâmetro do furo interno com relação ao diâmetro externo do corpo de prova, o comprimento da superfície aplainada de carregamento, a variação da velocidade do deslocamento, além do tamanho e da forma dos grãos. 
Devido ao fato de que o tamanho da zona de processo da fratura está relacionado com o tamanho de grãos do corpo de prova, a natureza do campo de tensões no ensaio de anel modificado é provavelmente afetada pelo tamanho do grão. Uma maior zona de processo da fratura absorve mais energia, reduz a quantidade de energia necessária para propagar a fratura e favorece a fratura estável.

Doolin (1994) e Lemiszki e Landes (1996) indicam que a velocidade dos ensaios nos quais obtiveram-se uma propagação estável da trinca e apresentam uma carga mínima local (condições para ser considerado um ensaio válido) deve ter como máximo $0,0003 \mathrm{~mm} / \mathrm{s}$.

Fischer et al (1996) estudaram os parâmetros que afetam os resultados de um modelo numérico em elementos finitos para corpos de prova de anel modificado sem confinamento e recomendaram que, devido ao fato de que os valores de $K_{I C}$ determinados por este método eram fortemente dependentes das considerações de borda no modelo, os futuros estudos para a determinação do $K_{I C}$ por este ensaio deveriam ser acompanhados por um relatório detalhado das condições de borda no modelo. Estes autores concluíram que, sob um deslocamento uniforme das superfícies de carregamento do corpo de prova, $K_{I C}$ é essencialmente independente de $v$, apesar das condições de contato entre o prato e o corpo de prova.

\subsubsection{Ensaio de anel modificado com confinamento}

Poucos autores têm estudado a influência da pressão confinante no valor da tenacidade à fratura (THIERCELIN,1987). As dificuldades residem não somente na execução dos ensaios, mas também na interpretação dos resultados. Uma tendência geral é observar um incremento na tenacidade à fratura com um incremento da pressão confinante. $\mathrm{O}$ incremento da tenacidade à fratura com a pressão confinante é atribuído geralmente à mudança no comportamento na zona do processo da fratura, a qual existe na frente da ponta da trinca livre de trações.

O modelo desenvolvido por Schmidt (1980) foi usado para explicar esta influência. Este modelo assume que a zona de processo na frente da ponta da trinca resulta das microtrincas de tração, as quais são induzidas quando o campo de tensões singulares excede a resistência de tração da rocha. A partir da fórmula de Irwin, deduz- 
se a expressão abaixo, pela qual pode-se determinar o tamanho da zona de processo da fratura (THIERCELIN, 1987):

$$
r(\theta)=\frac{1}{\pi}\left[\frac{K_{I C}}{\sigma_{t}+\sigma_{c}}\right]^{2}\left(\cos \frac{\theta}{2}\left(1+\operatorname{sen} \frac{\theta}{2}\right)\right)^{2}
$$

onde:

$r, \theta$ : coordenadas polares com relação à ponta da trinca;

$K_{I C}$ : tenacidade à fratura;

$\sigma_{t}:$ resistência à tração da rocha e

$\sigma_{c}$ : pressão de confinamento.

Esta fórmula mostra que um incremento na pressão confinante resulta de um decréscimo da $Z P F$, obtendo-se um valor dado de $K_{I C}$. Como $K_{I C}$ aumenta com a pressão confinante, pode-se assumir que o tamanho da $Z P F$ é uma propriedade do material independente da pressão de confinamento.

Isto permitiu a Müller (1986) apud Thiercelin (1987) derivar uma equação que relaciona $K_{I C}$ em condições ambientais com $K_{I C}$ a uma pressão de confinamento dada:

$$
K_{I C\left(\sigma_{c}\right)}=K_{I C(0)}\left(1+\frac{\sigma_{c}}{\sigma_{t}}\right)
$$

onde:

$$
\begin{aligned}
& K_{I C\left(\sigma_{c}\right)}: \text { tenacidade à fratura a uma pressão confinante determinada e } \\
& K_{I C(0)}: \text { tenacidade à fratura sem confinamento. }
\end{aligned}
$$

Utilizando a expressão anterior e comparando os resultados com os dados experimentais obtidos por Winter (1985) apud Thiercelin (1987) em arenitos de Ruhr, pode-se concluir que seus valores estão próximos entre si. No entanto, este é um modelo simplificado para explicar o comportamento da propagação de trincas; sendo assim subestimado em grande parte o tamanho da zona de processo da fratura por Swanson e Spetzler (1984) apud Thiercelin (1987) e Labuz, Shah e Dowding (1985).

Conseqüentemente, existe uma necessidade na determinação da tenacidade à fratura em rochas como uma função da pressão confinante e como uma função das propriedades das rochas. 
Alguns problemas foram encontrados na realização de diferentes experiências conduzidas para a determinação da tenacidade à fratura sob pressão confinante:

1. Tem-se que assegurar que o corpo de prova não seja sub-dimensionado. Por outro lado, o tamanho da zona de processo na frente na ponta da trinca não é desprezível comparado com o comprimento da trinca, resultando numa sub-estimação da tenacidade à fratura.

2. Tem-se que assegurar que a rocha não plastifica sob pressões confinantes aplicadas devido às concentrações excessivas das tensões compressivas. Algumas geometrias são mais sensíveis aos mecanismos de plastificação que outras, especialmente quando é considerado um entalhe livre de tensões, o qual causa momentos de flexão secundários.

3. Devido à pressão confinante, os deslocamentos axiais e da abertura da boca da trinca não podem ser medidos facilmente.

Seguindo estas considerações, o ensaio de anel modificado apareceu como um tipo de ensaio adequado para determinar a tenacidade à fratura sob pressão confinante. A geometria do corpo de prova teve as seguintes características: um raio do furo interno de $6.5 \mathrm{~mm}$, um raio externo do corpo de prova de $38.5 \mathrm{~mm}$ e um comprimento da superfície aplainada de carregamento de $14 \mathrm{~mm}$. Estas superfícies de carregamento são aplainadas e paralelas dentro de uma tolerância de $0.02 \mathrm{~mm}$. A espessura do corpo de prova é de $40 \mathrm{~mm}$. Os corpos de prova com espaçadores foram empacotados em um revestimento de cloreto de polivinila $(P V C)$ e montados em uma célula triaxial. A pressão de confinamento e a tensão axial foram incrementadas simultaneamente até um valor predeterminado. A tensão axial foi incrementada aplicando um deslocamento axial médio de $0.008 \mathrm{~mm} / \mathrm{min}$. Os ensaios são conduzidos até conseguir uma determinada propagação da trinca, e depois a carga é diminuída lentamente. O comprimento da trinca durante o ensaio foi determinado pela técnica da flexibilidade, assumindo-se que a elasticidade linear é aplicável. O comprimento da trinca foi também checado visualmente depois de cada ensaio e comparado com o valor obtido a partir da técnica da flexibilidade.

O programa interativo de análise de fratura FRANC desenvolvido na Universidade de Cornell (WAWRZYNEK e INGRAFFEA, 1987 apud THIERCELIN, 1987) foi utilizado para calcular o fator de intensidade de tensão. Este programa de elementos finitos usa elementos de quatro pontos isoparamétricos na ponta da trinca e elementos isoparamétricos quadráticos no resto do corpo de prova. $\mathrm{O}$ modelo leva em conta a existência de pratos rígidos (Figura 23). Não é permitido o deslizamento entre o 
prato e o corpo de prova. O fator de intensidade de tensão, para qualquer condição de carregamento, é obtido pelo principio de superposição (Figura 23):

$$
K_{I}=K_{I}^{U} *\left(\sigma_{a}+\sigma_{c}\right) \sqrt{\pi a_{t}}-K_{I}^{c} * \sigma_{c} \sqrt{\pi a_{t}}
$$

onde:

$K_{I}^{c}$ : fator de intensidade de tensão normalizado devido a uma pressão de confinamento negativa " $p$ " aplicada ao longo dos setores circulares interiores e exteriores do corpo de prova, mas não ao longo da superfície de carregamento (Figura 23);

$K_{I}^{U}$ : fator de intensidade de tensão normalizado devido a uma pressão uniforme " $f$ ” ao longo da superfície de carregamento;

$\sigma_{c}:$ pressão de confinamento;

$\sigma_{a}$ : tensão axial acima da pressão confinante;

$a_{t}$ : metade do comprimento da trinca;

$K_{I}$ : fator de intensidade de tensão para qualquer condição de carregamento.

$K_{I}$ corresponde ao fator de intensidade de tensão para o ensaio de anel modificado sem confinamento.

Thiercelin (1987) demonstrou que a pressão confinante pode diminuir o fator de intensidade de tensão em grande quantidade. O decréscimo é também uma função do comprimento de trinca, indicando que a pressão confinante poderia produzir uma propagação da trinca mais estável. Para pressões confinantes muito altas, o valor mínimo local poderia não existir nem ser facilmente determinado, sendo necessário medir o comprimento de trinca.

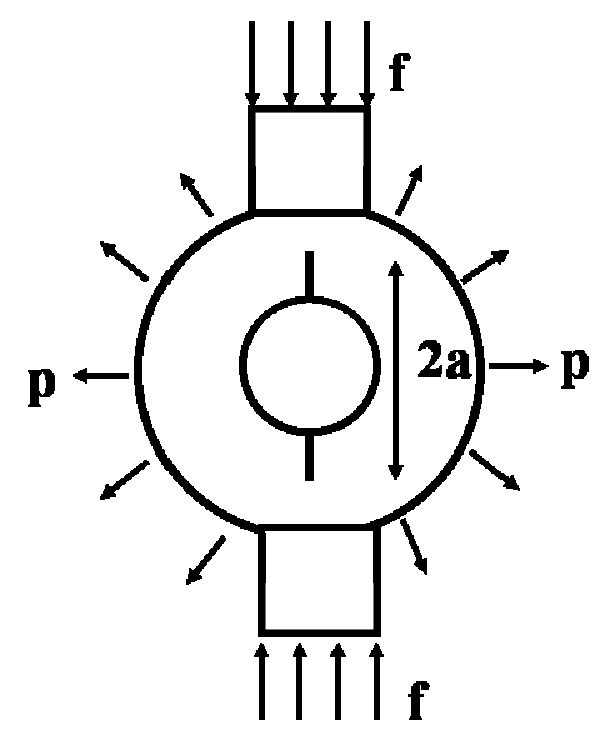

Figura 23 - Condições de contorno para o ensaio de anel modificado com confinamento (THIERCELIN, 1987). 


\subsubsection{Método de indentação - "Indentation Method”}

A importância das técnicas de indentação foi por muito tempo reconhecida no estudo da fratura de materiais frágeis e uma considerável atenção foi dada neste aspecto desde a metade dos anos 70 (por exemplo LAWN e WILSHAW, 1975; LAWN e SWAIN, 1975 apud WHITTAKER; SINGH e SUN, 1992). Pesquisas dentro da mecânica da fratura por indentação com relação às aplicações práticas tornaram-se intensas. A mecânica da fratura por indentação pode ser usada para estudar a resistência à fratura de superfícies não homogêneas e fazer medidas rápidas de propriedades da fratura em corpos de prova pequenos tais como a energia específica de superfície $\left(\gamma_{s}\right)$, a variação critica de liberação da energia de tensão $\left(G_{I C}\right)$ e antes de tudo a tenacidade à fratura em tensão plana $\left(K_{I C}\right)$.

Este método foi empregado freqüentemente para o vidro (SWAIN e LAWN, 1973) e para a cerâmica (LAWN, WILSHAW e HARTLEY, 1974; LAWN, FULLER e WIEDERHORN,1976; LAWN, 1981). Entretanto, muitos pesquisadores tentaram usar esta técnica para estudar a fratura em rochas e minerais, tendo um sucesso significativo em alguns destes materiais (SWAIN e ATKINSON, 1978; ATKINSON e AVDIS, 1980).

Segundo Ostojic e McPherson (1987), existem dois tipos de ruptura por indentação, dependendo somente do tipo de contato do indentador com a superfície do corpo de prova. Estes contatos podem ser classificados como "blunt" (cego) e "sharp" (agudo). O primeiro contato (contato "blunt") é usualmente produzido por indentadores “cegos" tais como indentadores esféricos em um material frágil submetido a carga. A principal característica deste contato é seu comportamento essencialmente elástico até que ocorra a fratura. Tais fraturas são usualmente chamadas de fraturas cônicas tipo Hertzian (LAUGIER, 1984). O segundo contato (contato "sharp") é produzido por um indentador agudo através de um equipamento padrão tipo "Vickers". Sua principal característica é que o contato é essencialmente plástico até que ocorra a fratura (ATKINSON e AVDIS, 1980).

Atkinson e Avdis (1980) apresentaram medidas da energia de superfície de fratura de calcita, galena, pirita, quartzo sintético, feldspato e vidros. Estas medidas foram obtidas usando uma técnica baseada em análise da fratura localizada a partir de um indentador agudo, neste caso um indentador piramidal tipo "Vickers". Muitas das 
experiências foram realizadas à temperatura ambiente. No entanto, uns poucos ensaios foram executados em quartzo e calcita a temperaturas acima $\operatorname{dos} 200^{\circ} \mathrm{C}$.

Segundo estes autores, as considerações a serem levadas em conta são aplicáveis somente para cargas que consigam alcançar trincas bem desenvolvidas, nas quais o diâmetro da trinca é pelo menos duas vezes tão grandes quanto o diâmetro de controle do indentador. Para cargas baixas, o campo de tensões elasto-plásticas e a distribuição dos defeitos naturais sobre a impressão permanente devem ser considerados. Eles usaram um indentador piramidal devido ao fato que as trincas usualmente são formadas nas esquinas da impressão. Isto permitiu o controle da orientação das trincas, sendo obtidos resultados mais reprodutíveis que os correspondentes ao uso de indentadores cônicos.

Ao contrário dos outros tipos de corpo de prova, os corpos de prova usados para o ensaio de indentação podem ser arbitrários em forma e de tamanho razoável. Entretanto, a fim de conseguir um desenvolvimento relativamente bom das trincas mediano-radiais, existe um número de exigências na preparação dos corpos de prova:

(a) Os corpos de prova devem ter pelo menos uma superfície lisa e bem polida sem produzir danos na superfície para assegurar contatos afiados ideais.

(b) Os corpos de prova devem ter uma espessura suficiente para assegurar a extensão da distância dos campos de tensões para desenvolver o sistema de trincas mediano-radiais sem modificar as tensões nas bordas dos corpos de prova (OSTOJIC e McPHERSON, 1987). Assim, sugeriu-se que a espessura do corpo de prova deva ser maior ou igual a dez vezes o comprimento da trinca de indentação (ANSTIS et al, 1981), isto é, B $\geq 10$ a.

(c) O corpo de prova deve ser inicialmente livre de tensões.

Os ensaios de indentação podem ser executados em condições ambientais com um equipamento convencional para medir a dureza. Os indentadores piramidais Vickers com um meio ângulo do cone de $68^{\circ}$ foram usados amplamente na prática.

O método consiste em provocar uma indentação no corpo de prova através de um carregamento, como mostra a Figura 24. Essa figura não mostra um corpo de prova, mas sim os parâmetros de indentação, sendo que o corpo de prova pode ter qualquer forma.

A tenacidade à fratura foi calculada mediante a seguinte expressão:

$$
K_{I C}=P /\left(\pi c_{r}\right)^{3 / 2} \tan \psi
$$

onde: 
$P$ : carga aplicada $(\mathrm{kN})$;

$c_{r}$ : comprimento radial da trinca na superfície $(\mathrm{mm})$;

$\psi$. metade do ângulo de indentação;

$E$ : módulo de elasticidade (MPa) e

v. coeficiente de Poisson.

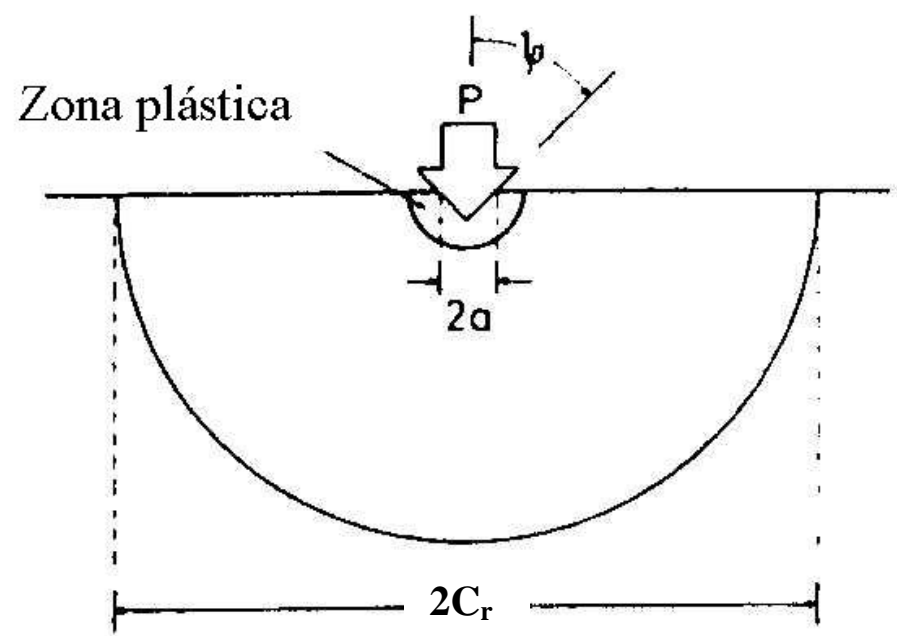

Figura 24 - Representação esquemática de um contato pontiagudo mostrando os parâmetros de indentação devidos à carga aplicada $(P)$; onde $\psi$ é a metade do ângulo de indentação, $a$ é a indentação diagonal e $c_{r}$ é o comprimento da trinca na superfície (OSTOJIC e McPHERSON, 1987).

No método de indentação, as observações diretas do processo de indentação são especialmente importantes, notavelmente em sólidos transparentes, desde que são usadas freqüentemente para determinar o comprimento da trinca mediano-radial para uma carga aplicada particular (ATKINSON e AVDIS, 1980). Os procedimentos para calcular $K_{I C}$ são como segue:

Da equação (87), nota-se que o lado direito é uma constante que indica que $\frac{P^{2}}{c_{r}{ }^{3}}$ (e daqui $\frac{P}{c_{r}^{3 / 2}}$ ) é também uma constante, isto é, a curva de $P^{2}$ versus $c_{r}^{3}$ ( e daqui $P$ versus $\left.c_{r}^{3 / 2}\right)$ é uma linha reta, sendo que o spinel (111), a pirita (001) e a galena (001) mostraram esse comportamento (ATKINSON e AVDIS, 1980). Experimentalmente, para cada material, faz-se necessário um número de 3 a 5 ensaios similares com diferentes valores de cargas (aproximadamente de 2 a $10 \mathrm{kN}$ ). Logo, traça-se uma curva $P$ versus $c_{r}{ }^{3 / 2}$. A inclinação desta curva é determinada por uma regressão linear. Com a metade do ângulo de indentação $(\psi)$ conhecido e com a inclinação da curva $P$ versus $c_{r}^{3 / 2}$; a tenacidade à fratura $\left(K_{I C}\right)$ pode ser calculada pela equação $(87)$. 
Alternativamente, $K_{I C}$ pode ser calculada de sua relação direta com $G_{I C}$ e $\gamma_{S}$. Neste caso, a inclinação de $P$ versus $c_{r}^{3 / 2}$ deve ser determinada e as propriedades mecânicas do material $E$ e $v$ devem ser conhecidas antes de realizar os cálculos.

O método de indentação descrito acima é aplicável somente se as seguintes circunstancias são satisfeitas (OSTOJIC e McPHERSON, 1987):

(a) A fratura deve ser circular no carregamento incrementado ou semicircular no descarregamento completo, descarregando de tal modo que $P^{2} / c_{r}{ }^{3}$ ou $P / c_{r}{ }^{3 / 2}$ são uma constante.

(b) A carga aplicada deve ser suficientemente alta para causar o bom desenvolvimento das trincas para quando o diâmetro de trinca $2 c_{r}$ for pelo menos duas vezes maior que o diâmetro da impressão da indentação $2 a\left(c_{r} \geq 32 a\right)$, isto é, tais que o fenômeno de lascamento da superfície do corpo de prova não ocorra. Isto assegura que a trinca seja influenciada somente pelas tensões do campo distante.

(c) O material a ser ensaiado deve ser razoavelmente homogêneo na escala da impressão para evitar toda variação no comprimento da trinca.

(d) Em materiais policristalinos, o tamanho de grão deve ser pequeno em comparação com o tamanho da indentação para evitar um rompimento possível do padrão da trinca.

(e) $\mathrm{O}$ indentador deve ser liso para evitar toda fricção entre o indentador e a superfície do corpo de prova na ponta do indentador. Se o indentador for áspero, deve ser levado em conta o efeito de atrito, substituindo o meio ângulo do cone $(\psi)$ na expressão acima por $\psi^{\prime}=\psi+\arctan (f)$, onde $f$ é o coeficiente de atrito (LAWN; FULLER e WIEDERHORN, 1976).

(f) Os efeitos dinâmicos e cinéticos são ignorados, isto é, são supostas condições quaseestáticas.

Existem muitas discrepâncias pelo uso deste método para avaliar a tenacidade à fratura $\left(K_{I C}\right)$ das rochas por uma importante razão. A razão é que as propriedades da fratura de um material sólido comportam-se similarmente para diferentes escalas, mas para as rochas isto não acontece.

Se a tenacidade à fratura for medida com o método Palmqvist, utiliza-se um indentador pequeno Vickers a cargas baixas e medem-se as trincas formadas em uma escala menor. Se fosse usado para rochas, as propriedades das rochas poderiam decidir o valor, isto devido às propriedades multi-minerais das rochas. Por exemplo, se fosse medido em um arenito com o indentador Vickers a uma carga baixa, poderia obter-se o $K_{I C}$ dos grãos de quartzo individuais. Mas se fosse analisado a uma escala maior, o 
material cimentante entre os grãos de quartzo poderia decidir o valor de $\mathrm{K}_{\mathrm{IC}} \mathrm{e}$, neste caso, poderia utilizar-se um indentador maior (BESTE, 2003). Segundo Bradt (2003), os métodos de indentação trabalham melhor com vidros, devido ao fato destes serem uma estrutura muito uniforme e fina. Estudando-se a fase individual das rochas, o método de indentação poderia ser usado, mas para escalas maiores, este pesquisador mostra-se cético do valor da tenacidade à fratura.

\subsubsection{Disco compacto em tração - "Round compact disk in tension (RCT)"}

A geometria deste corpo de prova é mostrada na Figura 25. Este tem tamanhos e localização dos furos internos que são ligeiramente diferentes dos propostos pela $A S T M$ E399 para materiais metálicos. O corpo de prova possui diâmetro $D$, comprimento de entalhe $a$, largura $w$ e espessura $B$. Os dois furos de carregamento têm um diâmetro $d$, com uma distância vertical $l_{h}$ do centro do furo ao centro do corpo de prova. A carga de tração $(F)$ é aplicada diretamente a fim de romper o corpo de prova.

Sun e Ouchterlony (1986) empregaram corpos de prova de $151 \mathrm{~mm}$ de diâmetro e o comprimento do entalhe inicial variou de 53 a $56 \mathrm{~mm}$. Três dos sete ensaios no granito Stripa foram exitosos. Os ensaios foram realizados com controle de abertura da boca da trinca mediante um extensômetro do tipo "clip gauge" colocado na boca do pré-entalhe. Os detalhes da instalação e realização do ensaio encontram-se em Sun (1983) apud Sun e Ouchterlony (1986). O deslocamento da abertura da boca da trinca (CMOD) foi incrementado a uma taxa de $0,06 \mu \mathrm{m} / \mathrm{seg}$ durante o carregamento. A tenacidade à fratura aparente $K_{Q}$ foi avaliada usando os ciclos de carregamento no corpo de prova pré-entalhado, o método secante e o método da flexibilidade com o $C M O D$ (em vez de $L P D$ ) para medir o comprimento da trinca.

$K_{Q}$ foi calculado a partir da seguinte expressão:

$K_{Q}=K_{I}\left(a_{i}, F_{Q_{i}}\right)$

onde:

$a_{i}$ : comprimento de trinca de cada ciclo de carregamento i, e

$F_{Q i}$ : carga secante associada.

$K_{I}$ foi calculado a partir da fórmula deduzida por Newman (1981) apud Sun e Ouchterlony (1986): 
$K_{I}=\frac{f(\beta) \cdot F}{B w^{0.5}}$

onde:

$f=(2+\beta)\left[\frac{0.76+4.8 \beta-11.58 \beta^{2}+11.43 \beta^{3}-4.08 \beta^{4}}{(1-\beta)^{1.5}}\right]$

$\beta=\frac{a}{w}$

Sendo $F$ a carga no corpo de prova.

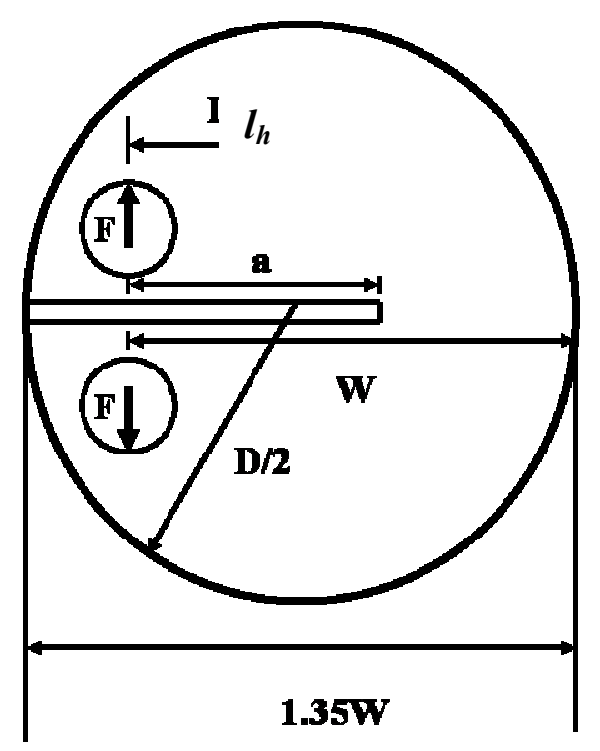

Figura 25 - Geometria do disco compacto e as condições de carregamento associadas (ALBURQUERQUE, 1998).

Os detalhes do método de flexibilidade, com o qual calcula-se o comprimento de trinca efetiva, são dados por Sun (1983) apud Sun e Ouchterlony (1986). Como pode ser observado, o tamanho destes corpos de prova são próximos aos tamanhos requeridos pela Mecânica da Fratura Elástica Linear $(M F E L)$ onde os valores de $K_{Q}$ obtidos deveriam ser precisos para a determinação de $K_{I C}$ em esforço plano.

O método da flexibilidade pode ser resumido como segue:

1. Cada ciclo sucessivo fornece um valor de tenacidade à fratura aparente, o qual é avaliado com o método secante compensado a 5\% (ASTM E399, 1990).

2. Uma curva típica carga- $L P D$ mostra uma curvatura inicial (devido à abertura da trinca), uma porção linear (onde a trinca está totalmente aberta), de novo uma curvatura (com um comportamento plástico na zona da ponta da trinca), seguido por um crescimento estável da trinca (apesar de a carga cair) e finalmente um descarregamento (OUCHTERLONY, 1982; 1983). 
3. O comprimento da trinca deve ser determinado a partir das medições de flexibilidade do $L P D$ como segue: o primeiro ciclo de carregamento (pré-entalhado) conduz à determinação do módulo de elasticidade do corpo de prova a partir da tangente inicial de flexibilidade, sendo que a melhor flexibilidade de carregamento linear de cada ciclo sucessivo é o comprimento de trinca equivalente $\frac{a}{D}$ em cada estágio a partir de uma inversão na formula de flexibilidade (deve-se procurar para detalhes SUN,1983 apud OUCHTERLONY,1986). O método de medição do LPD foi desenvolvido por Ouchterlony (1980) e tem provado dar resultados próximos na determinação do módulo de elasticidade quando comparado com as medições com "strain gauges" (OUCHTERLONY; SWAN e SUN, 1982).

\subsubsection{Corpo de prova cilíndrico entalhado axialmente em ruptura por compressão - “Compression splitting test (CST)"}

Este método foi usado para a determinação da tenacidade à fratura de materiais frágeis vítreos (Perspex, Araldita), de materiais cimentícios (argamassa de cimento, concreto) e de materiais cerâmicos, incluindo parcialmente o zircônio estabilizado (PSZ) desenvolvido pela S.C.I.R.O., não existindo na literatura valores em rochas.

Estudos realizados por Kendall (1978) e Karihaloo (1979, 1984) em materiais vítreos frágeis (PMMA-perspex e araldita) sugeriam que a energia da superfície da fratura, e não a resistência compressiva, era uma constante material apropriada para descrever uma fratura de tipo compressivo. Karihaloo $(1979,1980,1984)$ propôs um modelo mecânico simples, a saber, o modelo dos dois suportes ("two-strut model"), baseado no critério do balanço energético de Griffith para explicar o comportamento de ruptura por compressão observado nos dois tipos de polímeros vítreos. A teoria proposta (KENDALL, 1978 ; KARIHALOO, 1979, 1980, 1984) descreve como um pré-entalhe existente de comprimento " $a$ " em um bloco sólido de material frágil, largura “ $W$ " e espessura " $B$ " (normal ao plano do papel) pode ser propagada por uma força $F$ aplicada compressivamente através dos pratos. O bloco sólido é suportado na base e submetido a um carregamento por um prato rígido de largura " $w_{P}$ " na parte superior, como mostrado na Figura 26. 


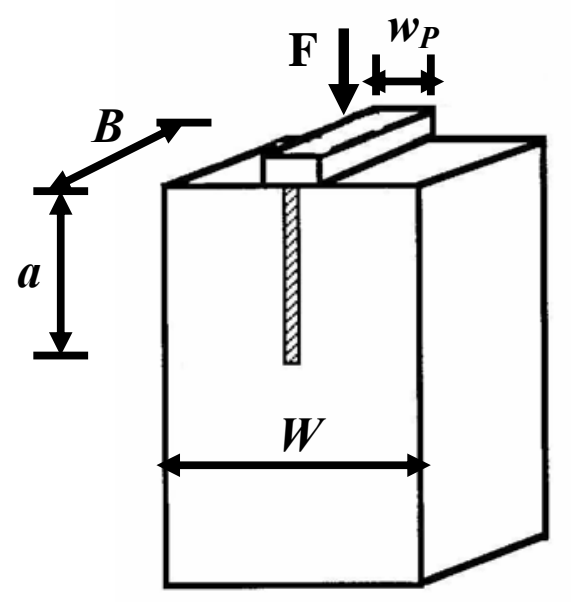

Figura 26 - Corpo de prova prismático entalhado axialmente em ruptura por compressão (KARIHALOO, 1987)

Karihaloo (1985) empregou corpos de prova de $50 \mathrm{~mm}$ de comprimento e uma seção quadrada de $10 \mathrm{~mm}$ x $10 \mathrm{~mm}$. Estes corpos de prova foram de tamanho intermediário aos empregados por Kendall em 1978 (20 mm de comprimento e seção retangular de $3 \mathrm{~mm}$ x $6 \mathrm{~mm}$ ) e o mesmo Karihaloo em 1984 (100 mm de comprimento e seção retangular de $40 \mathrm{~mm}$ x $18 \mathrm{~mm}$ ou quadrada de $40 \mathrm{~mm}$ x $40 \mathrm{~mm}$ ). Os pré-entalhes foram cortadas nos corpos de prova usando uma serra manual pequena de uma espessura aproximada de $1 \mathrm{~mm}$. Os entalhes manuais foram finalmente terminadas com um "razor blade" para dar forma à frente da trinca inicial a partir da qual esta pode propagar-se por compressão. A propagação foi induzida por uma placa de aço aplainada na superfície superior do corpo de prova, tendo-se o cuidado de garantir o contato com toda a área submetida à compressão.

As superfícies do corpo de prova foram pintadas e iluminadas por poderosas luzes para monitorar o progresso da frente da trinca, a qual aparece como uma linha escura na superfície pintada. A ponta da trinca foi marcada e foi indicado o nível de força correspondente. $\mathrm{O}$ padrão da trinca foi traçado para permitir a fácil medição da extensão da trinca.

O comprimento dos pré-entalhes e a largura da placa superior de carregamento devem ter os seguintes limites sugeridos por Karihaloo (1985):

$w_{P} / W \leq 1 / 2$ e $1 \leq a / W \leq 3 / 2$

onde:

$w_{P}$ : largura da placa superior de carregamento $(\mathrm{mm})$;

$W$ : largura do corpo de prova (mm) e 
$a$ : comprimento do pré-entalhe $(\mathrm{mm})$.

É preferível que o comprimento do pré-entalhe seja tal que a relação $a / W$ esteja tanto quanto possível próxima de 3/2 (KARIHALOO, 1984; 1985). Neste intervalo de valores de $a / W$ e $w_{P} / W$, os materiais ensaiados (polímeros) comportam-se mais ou menos elasticamente ou com uma deformação plástica muito pequena. Cálculos de elementos finitos e de elementos de contorno elásticos reportados em Karihaloo (1984) verificaram a existência de tais tensões para $w_{P} / W \leq 1 / 2$ e $1 \leq a / W \leq 3 / 2$. Karihaloo (1985) realizaram cálculos de elementos finitos nos corpos de prova, os quais confirmaram a existência de tensões de tração e permitiram a determinação do fator intensidade de tensão.

O modelo proposto por Karihaloo ignora completamente toda a deformação plástica, mas poderia ocorrer de o corpo de prova não apresentar uma ruptura axial compressiva se os limites acima indicados não fossem mantidos. $\mathrm{O}$ fator $R$ (energia da superfície da fratura de Griffith por unidade de área) refletiria não somente a energia da superfície da fratura elástica, mas também a energia perdida na dissipação plástica. Nesses casos, é apropriada uma análise elasto-plástica da fratura (KARIHALOO, 1984).

Para cada comprimento de pré-entalhe e para cada largura da placa superior de carregamento foram ensaiados pelo menos três corpos de prova. Todos os corpos de prova romperam por ruptura axial ao longo do plano do pré-entalhe. $\mathrm{O}$ valor da força compressiva $(F)$ foi usado para calcular a energia de superfície da fratura e o fator de intensidade de tensão crítico na base do modelo dos dois suportes ("two-strut model"). A tenacidade à fratura foi calculada mediante a seguinte equação:

$K_{I C}{ }^{2}=\left(\frac{F_{C_{O}}}{B W}\right)^{2} W \frac{3\left(1-\frac{w_{P}}{W}\right)^{2}}{16\left(1-v^{2}\right)} x\left[2+\frac{1.68 F-A E}{A E} k a \cdot \tan \frac{k a}{2}\right] \sec ^{2} \frac{k a}{2}$

onde:

$F_{C_{o}}$ : força compressiva no início do crescimento do pré-entalhe;

$B, W$ : dimensões do corpo de prova (B é a espessura e $\mathrm{W}$ é a largura do corpo de prova);

$w_{P}$ : largura da placa superior de carregamento;

v. coeficiente de Poisson;

$A=B W / 2$ (se apresentar forma retangular);

$E$ : Módulo de elasticidade; 
$k^{2}=\frac{F_{C_{o}}}{2 E I}$

com

$I=\frac{B W^{3}}{96}$

I: momento de inércia da seção transversal do corpo de prova e $a$ : comprimento do pré-entalhe.

Neste ensaio, a força máxima a partir da qual a ponta do entalhe pré-existente começa a propagar é de difícil definição por não se ter controle da abertura da boca da trinca, sendo difícil determinar o momento no qual acontece o início da propagação do pré-entalhe. Em alguns materiais, este início é facilmente visível e, portanto, facilmente determinado, não sendo o mesmo caso quando se trata de rochas.

O fator de intensidade de tensão crítico determinado pelo modelo das duas colunas não é dependente da geometria do corpo de prova (KARIHALOO, 1985). Para calcular o valor inicial de $K_{I}$, a saber $K_{I C}$, foram usados a força compressiva no inicio do crescimento do pré-entalhe e o valor inicial do comprimento do mesmo. A validade do modelo proposto por Karihaloo (1984) se baseia na existência das tensões de tração na frente da trinca que são produzidas devido à flexão dos braços do corpo de prova.

Assim, para um corpo de prova cilíndrico como mostrado na Figura 27, Karihaloo $(1984 ; 1985)$ propôs as seguintes expressões considerando os efeitos de cisalhamento:

$$
\begin{aligned}
& \frac{K_{I C}{ }^{2}}{Z^{*}}=B\left[2+\left(\frac{1.68 F_{C_{o}}}{A E}-1\right) k a \tan \frac{k a}{2}\right] \sec ^{2} \frac{k a}{2} \\
& B=\frac{\left[9 \pi\left(\frac{8}{3 \pi}-\frac{w_{P}}{D}\right)^{2}\right]}{\left[64\left(9-\frac{64}{\pi^{2}}\right)\left(1-v^{2}\right)\right]} \\
& Z^{*}=\left(\frac{4 F_{C_{o}}}{\pi D^{2}}\right)^{2} D
\end{aligned}
$$

e considerando-se adicionalmente a energia de superfície da fratura em condições de deformação plana:

$$
\begin{aligned}
& K_{I}^{2}\left(1-v^{2}\right)=E R \\
& R=\frac{F_{C_{o}}{ }^{2} e^{2}}{32 C}\left(2-k a \tan \frac{k a}{2}\right) \sec ^{2} \frac{k a}{2}
\end{aligned}
$$


$k^{2}=\frac{F_{C_{o}}}{2 E I}$

$e=\left[\frac{2 D}{3 \pi}-\frac{w_{P}}{4}\right]$

$I=\frac{D^{4}\left(9 \pi^{2}-64\right)}{1152 \pi}$

$C=E I D$

onde:

$a$ : comprimento do pré-entalhe ( $\mathrm{mm})$;

$D$ : diâmetro do corpo de prova $(\mathrm{mm})$;

$w_{P}$ : largura da placa superior de carregamento $(\mathrm{mm})$;

$F_{C_{o}}$ : força compressiva no início do crescimento do pré-entalhe $(\mathrm{kN})$;

$v$ : coeficiente de Poisson;

$E$ : módulo de elasticidade $(\mathrm{MPa})$;

$R$ : energia de superfície de fratura de Griffith por unidade de área;

I: momento de inércia do corpo de prova $\left(\mathrm{mm}^{4}\right)$.

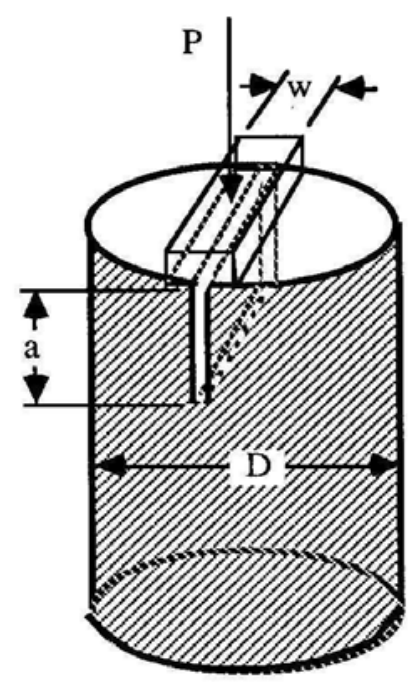

Figura 27 - Corpo de prova cilíndrico entalhado axialmente em ruptura por compressão (WHITTAKER; SINGH e SUN, 1992).

Salienta-se que assumindo um estado de deformação plana e negligenciando a influência da deformação cisalhante, que é muito menor que uno (1), o qual não influencia muito na determinação da tenacidade, obtêm-se as seguintes expressões:

$$
\frac{K_{I C}{ }^{2}}{Z^{*}}=B\left[2-k a \tan \frac{k a}{2}\right] \sec ^{2} \frac{k a}{2}
$$


$B=\frac{\left[9 \pi\left(\frac{8}{3 \pi}-\frac{w_{P}}{D}\right)^{2}\right]}{\left[64\left(9-\frac{64}{\pi^{2}}\right)\left(1-v^{2}\right)\right]}$

$Z^{*}=\left(\frac{4 F_{C_{o}}}{\pi D^{2}}\right)^{2} D$

onde as variáveis são as mesmas que as supramencionadas.

\subsubsection{Corpo de prova cilíndrico com entalhe reto submetido a flexão - "Single edge notched round bar in bending (SENRBB)"}

A geometria do corpo de prova cilíndrico com entalhe reto submetido à flexão é mostrada na Figura 28. É essencialmente a mesma geometria que a do ensaio Chevron Bend $(C B)$, a única diferença residindo no fato que consiste de um corpo de prova cilíndrico com um entalhe reto no centro, no qual será aplicada uma flexão a três pontos.
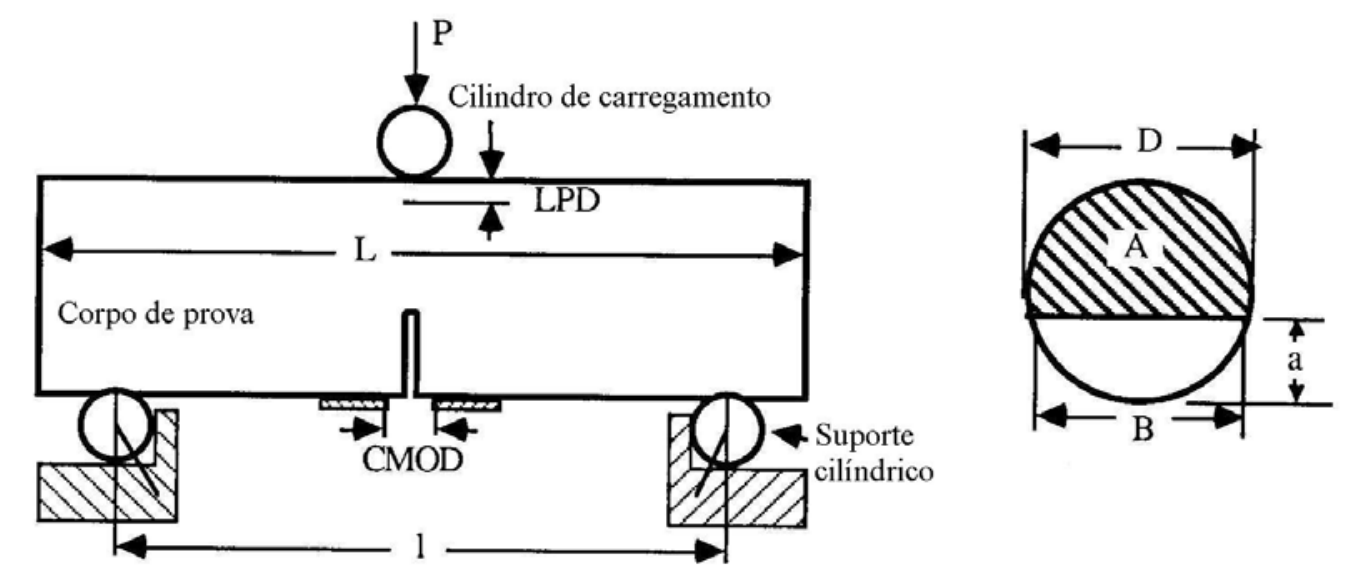

Figura 28 - Geometria do corpo de prova e esquema do ensaio (WHITTAKER; SINGH e SUN, 1992)

Este método foi introduzido por Bush (1976) e foi adotado por Ouchterlony (1980), Swan (1980) e Sun (1983) para determinar a tenacidade à fratura de rochas. Bush (1976) e Ouchterlony (1980) analisaram a configuração do corpo de prova extensivamente e propuseram expressões similares para o cálculo do fator de intensidade de tensão.

A expressão para o fator de intensidade de tensão é:

$K_{I}=\frac{F_{\max x}}{D^{3 / 2}} Y$ 
sendo:

$F_{\text {máx }}$ : carga máxima aplicada;

$D$ : diâmetro do corpo de prova e

$Y$ : fator de correção para a geometria do corpo de prova e para a forma de carregamento em função do comprimento da trinca $(a)$.

Ouchterlony (1980) propôs a seguinte expressão para Y:

$Y=0.25\left(\frac{S}{D}\right) Y^{\prime}$

onde,

$Y^{\prime}\left(\frac{a}{D}\right)=\frac{12.7527 \sqrt{\frac{a}{D}} \sqrt{1+19.646\left(\frac{a}{D}\right)^{4.5}}}{\left(1-\frac{a}{D}\right)^{0.25}}$

Haberfield e Johnston (1990) usaram as seguintes expressões para determinar a tenacidade à fratura para esta geometria de corpos de prova:

$K_{Q}=0.25 \frac{F_{\max } S}{D^{5 / 2}} Y\left(\frac{a}{D}\right)$

onde

$Y\left(\frac{a}{D}\right)=\frac{12.7527\left(\frac{a}{D}\right)^{1 / 2}}{\left(1-\frac{a}{D}\right)^{1 / 4}}$

onde:

$a$ : comprimento do pré-entalhe;

$D$ : diâmetro do corpo de prova;

$Y\left(\frac{a}{D}\right)$ : fator de correção para a geometria do corpo de prova e para a forma de carregamento em função de $\frac{a}{D}$;

$S$ : vão entre os apoios do corpo de prova;

$F_{\text {máx }}$ : carga máxima aplicada e

$K_{Q}$ : tenacidade à fratura aparente.

Os ensaios com corpos de prova cilíndricos com entalhe reto submetidos a flexão de três pontos foram comparados com os resultados obtidos com corpos de prova 
retangulares com entalhe reto submetidos a flexão em três pontos, obtendo-se resultados similares.

3.3.11 Corpo de prova cilíndrico com entalhe circunferencial submetido à flexão "Circumferentially notched round bar in bending $(C N R B B)$ "

O corpo de prova é um cilindro com diâmetro $D$ e com um entalhe circunferencial de profundidade $(a)$ como mostrado na Figura 29.

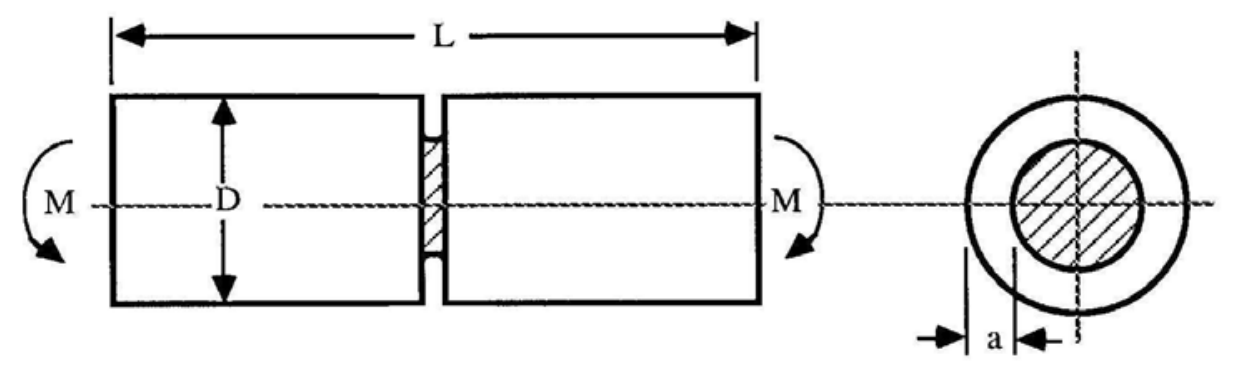

Figura 29 - Geometria do corpo de prova cilíndrico entalhado circunferencialmente submetido à flexão (WHITTAKER; SINGH e SUN, 1992)

Bear (1976) apud Whittaker, Singh e Sun (1992) propôs este método para determinar a tenacidade à fratura em rochas e concreto. $\mathrm{O}$ fator de intensidade de tensão é expresso por:

$$
K_{I}=6 M \sqrt{\frac{2 a}{\pi(D-2 a)^{5}[a+0.056(D-2 a)]}}
$$

sendo:

M: momento aplicado ao corpo de prova cilíndrico;

$D$ : diâmetro do corpo de prova e

$a$ : entalhe circunferencial.

3.3.12 Corpo de prova cilíndrico com entalhe circunferencial submetido a um carregamento excêntrico - "Circumferentially notched bar in eccentric loading (NRBEL)"

A configuração deste ensaio é mostrada na Figura 30. A geometria do corpo de prova é idêntica ao anterior, mudando somente a forma de aplicar a carga. Este ensaio também foi proposto por Bear (1976) apud Whittaker, Singh e Sun (1992). 


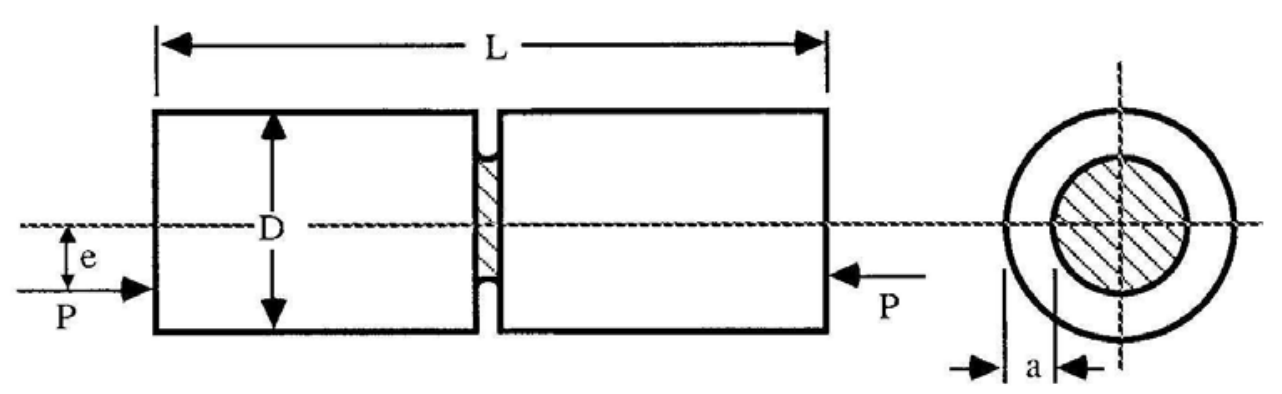

Figura 30 - Geometria do corpo de prova cilíndrico entalhado circunferencialmente submetido a um carregamento excêntrico (WHITTAKER; SINGH e SUN, 1992)

A aplicação da carga $(P)$ resulta em um momento $(M=P e)$ produzindo um fator de intensidade de tensão conforme abaixo:

$$
K_{I}=\frac{P \sqrt{2 a}}{\sqrt{\pi(D-2 a)^{3}}}\left[\frac{6 e}{(D-2 a) \sqrt{a+0.056(D-2 a)}}-\frac{1}{\sqrt{a+0.1(D-2 a)}}\right]
$$

sendo:

$P$ : carga aplicada;

$e$ : distância entre o ponto de carga e o eixo do corpo de prova;

$D$ : diâmetro do corpo de prova e

$a$ : entalhe circunferencial.

\subsubsection{Placas retangulares submetidos à flexão - "Rectangular plates in bending”}

\subsubsection{Placa retangular com entalhe reto submetido à flexão em três pontos - "Single edge straight-through cracked rectangular plate in three point bending $(S C 3 P B) ”$}

A geometria e a configuração do carregamento deste ensaio são mostradas na Figura 31. O corpo de prova é um prisma de seção retangular de espessura $B$ e largura $W$ com um entalhe reto $\boldsymbol{a}$ na direção do menor eixo submetido à flexão em três pontos.

Este método foi padronizado pela ASTM E399 para materiais metálicos. Schmidt $(1975,1976)$ seguiu exatamente esta técnica de ensaio para determinar a tenacidade à fratura do calcário Indiana, propondo este método para o estudo deste tipo de rochas. A equação de calibração do fator de intensidade de tensão para esta configuração do corpo de prova é (BROWN e SRAWLEY, 1966): 
$K_{I}=\frac{4 P \sqrt{a}}{B W}\left[2.9-4.6\left(\frac{a}{W}\right)+21.8\left(\frac{a}{W}\right)^{2}-37.6\left(\frac{a}{W}\right)^{3}+38.7\left(\frac{a}{W}\right)^{4}\right]$

que é válido para $a=(0.45$ a 0.55$) W$.

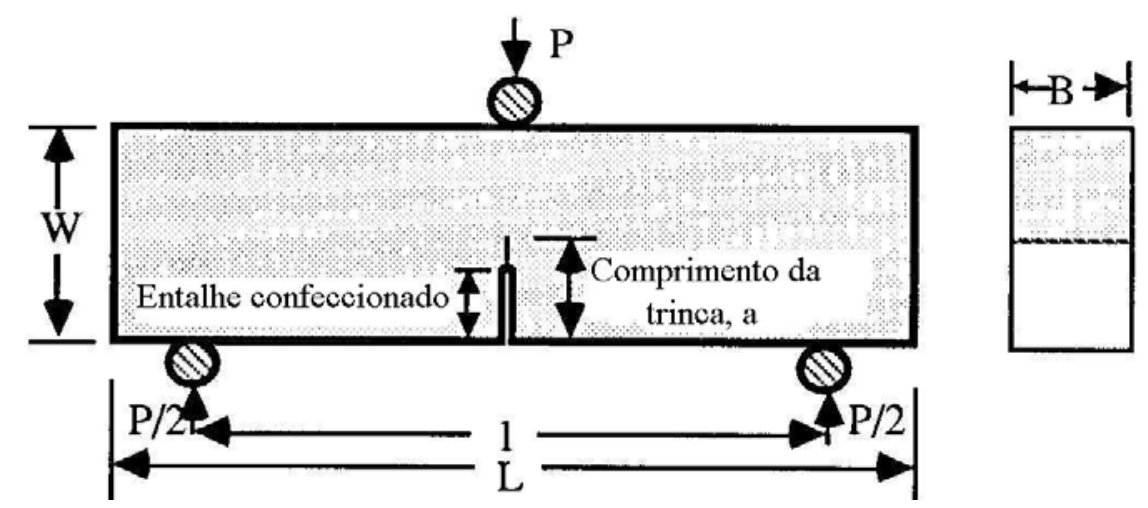

Figura 31 - Geometria e configuração do ensaio na placa retangular com entalhe reto submetido à flexão em três pontos (WHITTAKER; SINGH e SUN, 1992)

Haberfield e Johnston (1990) estudaram com rochas brandas saturadas, onde a tenacidade à fratura aparente $\left(K_{Q}\right)$ foi determinada mediante as seguintes expressões (ASTM E399):

$$
K_{Q}=\frac{F_{\max } S}{B W^{3 / 2}} f\left(\frac{a}{W}\right)
$$

onde

$f\left(\frac{a}{W}\right)=3\left(\frac{a}{W}\right)^{1 / 2} x\left[1.99-\frac{\frac{a}{W}\left(1-\frac{a}{W}\right)\left(2.15-3.95 \frac{a}{W}+2.7\left(\frac{a}{W}\right)^{2}\right)}{2\left(1+2 \frac{a}{W}\right)\left(1-\frac{a}{W}\right)^{3 / 2}}\right]$

onde:

$F_{\text {max }}$ : carga máxima aplicada;

$a$ : comprimento do pré-entalhe;

$W$ : largura do corpo de prova;

$Y\left(\frac{a}{W}\right)$ : fator de correção para a geometria do corpo de prova e para a forma de carregamento em função de $\frac{a}{W}$;

$B$ : espessura do corpo de prova;

$S$ : vão entre os apoios do corpo de prova e 
Marchiori (1997) obteve experimentalmente a curva força-deslocamento completa através de ensaios de flexão em três pontos realizados para quatro tamanhos diferentes e comparou as curvas obtidas nestes ensaios com as curvas obtidas nas simulações numéricas utilizando a Mecânica da Fratura Elástica Linear $(M F E L)$ e o modelo coesivo $(M C)$. Os ensaios de flexão a três pontos foram executados em rochas (cinco ensaios para cada tamanho) com um entalhe pré-determinado (localizado no centro inferior da viga). O tamanho dos corpos de prova variaram, mantendo sempre a relação comprimento-altura do corpo de prova $(L / B)$ igual a 4 . Os ensaio de flexão em três pontos foram executados numa máquina hidráulica servo-controlada de circuito fechado. O controle foi realizado através da variação constante da abertura da trinca (pré-entalhe), típico para ensaios de flexão em três pontos, onde se deseja obter a curva força-deslocamento completa.

Ferreira (2002) obteve experimentalmente o comportamento das curvas-R para o estudo do processo da fratura em rochas, em concretos de alta resistência $(C A R)$ e em concretos reforçados com fibras de aço $(C R F A)$.

As curvas de resistência fundamentadas na relação $P-C M O D$ foram inicialmente aplicadas aos resultados de ensaios de fratura de uma rocha sedimentar classificada como arenito rosa originária do estado do Paraná (FERREIRA et al, 2002). Nestes ensaios, os corpos de prova foram solicitados em flexão em três pontos.

\subsubsection{Placa retangular com entalhe "chevron" submetido à flexão em três pontos - "Single edge chevron-notched rectangular plate in three point bending $(C N 3 P B)$ ”}

A geometria e a configuração do carregamento deste ensaio são mostradas na Figura 32. O corpo de prova é um prisma retangular de espessura $B$ e largura $W$ com um entalhe "chevron" central submetido à flexão em três pontos.

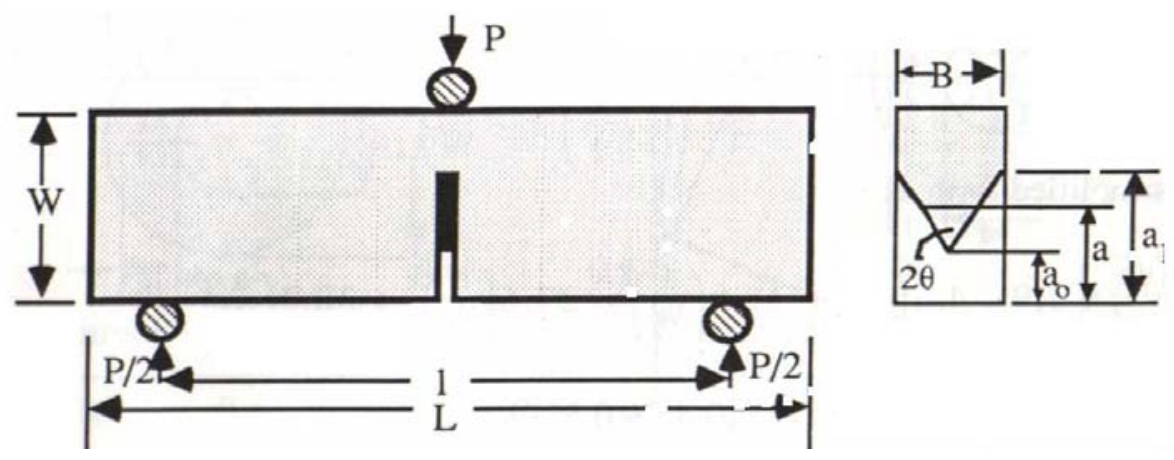

Figura 32 - Geometria e configuração do ensaio na placa retangular com entalhe "chevron" submetido à flexão em três pontos (WHITTAKER; SINGH e SUN, 1992) 
Wu (1984) adotou o modelo de fatias de Bluhm (1975) para calibrar o fator de intensidade de tensão adimensional $(Y)$ como função de $\alpha_{0}=\frac{a_{0}}{W}$. Os resultados para $2 \theta$ $=90^{\circ}$ são mostrados em Whittaker, Singh e Sun (1992) conforme abaixo:

$K_{Q}=\frac{F_{\max }}{B \sqrt{W}} Y$

sendo:

$Y=2.81+44.51 \alpha_{0}-269.6 \alpha_{0}^{2}+1338 \alpha_{0}^{3}-2736 \alpha_{0}^{4}+2242 \alpha_{0}^{5}$

(válida para $W / B=1.5$ );

$Y=1.49+77.60 \alpha_{0}-648.3 \alpha_{0}^{2}+22848 \alpha_{0}^{3}-5225 \alpha_{0}^{4}+3592 \alpha_{0}^{5}$

(válida para $W / B=2$ ).

onde:

$F_{\text {max }}$ : carga máxima aplicada;

$a$ : comprimento do pré-entalhe;

$W$ : largura do corpo de prova;

$Y\left(\frac{a_{0}}{W}\right)$ : fator de correção para a geometria do corpo de prova e para a forma de carregamento em função de $\frac{a_{0}}{W}$;

$B$ : espessura do corpo de prova;

$S:$ vão entre os apoios do corpo de prova e

$K_{Q}$ : tenacidade à fratura aparente.

\subsubsection{Placa retangular com entalhe reto submetido à flexão em quatro pontos - "Single edge straight-through cracked rectangular plate in four-point bending (CS4PB)”}

A Figura 33 mostra a geometria do corpo de prova e a configuração do ensaio. Esta configuração de ensaio elimina a tensão cisalhante na seção transversal da placa, o que leva à flexão pura (WHITTAKER; SINGH e SUN, 1992). 


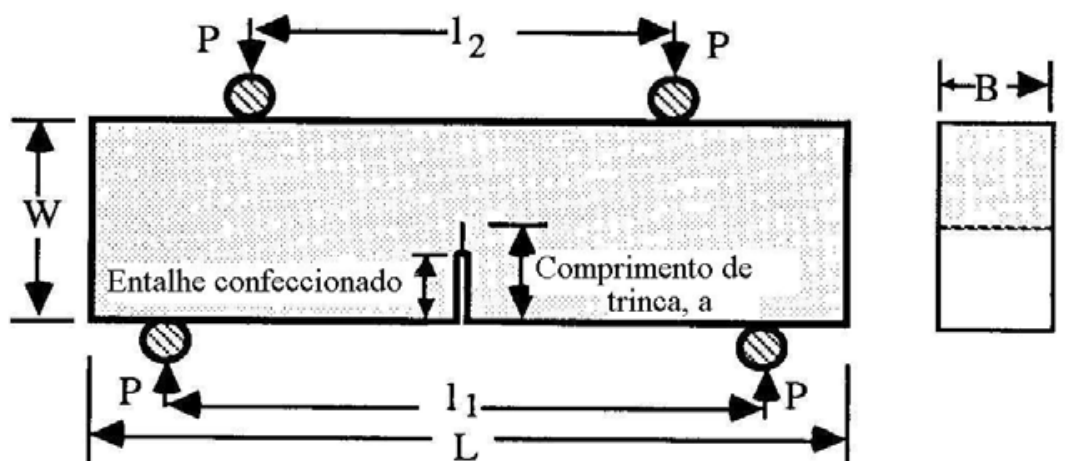

Figura 33 - Geometria e configuração do ensaio na placa retangular com entalhe reto submetido à flexão em quatro pontos (WHITTAKER; SINGH e SUN, 1992)

O fator de intensidade de tensão foi dado por Srawley e Gross (1976) apud Whittaker, Singh e Sun (1992):

$$
K_{I}=\frac{F_{\max }\left(l_{1}-l_{2}\right) \sqrt{a}}{B W^{2}} Y
$$

sendo:

$$
Y=\frac{3}{2\left(1-\frac{a}{W}\right)^{3 / 2}}\left\{1.989-1.33 \frac{a}{W}-\frac{\left[3.49-0.68 \frac{a}{W}+1.35\left(\frac{a}{W}\right)^{2}\right]\left(\frac{a}{W}\right)\left(1-\frac{a}{W}\right)}{\left(1+\frac{a}{W}\right)^{2}}\right\}
$$

onde:

$F_{\text {max }}$ : carga máxima aplicada;

$a$ : comprimento do pré-entalhe;

$W$ : largura do corpo de prova;

$Y\left(\frac{a}{W}\right)$ : fator de correção para a geometria do corpo de prova e para a forma de carregamento em função de $\frac{a}{W}$;

$B$ : espessura do corpo de prova;

$l_{1}$ : vão entre os apoios inferiores do corpo de prova;

$l_{2}$ : vão entre os apoios superiores do corpo de prova e

$K_{Q}$ : tenacidade à fratura aparente.

válida para o intervalo de $0 \leq \frac{a}{W} \leq 0.6$ e $\frac{l_{1}}{W}=4$. 
3.3.13.4 Placa retangular com entalhe "chevron" submetido à flexão em quatro pontos - "Single edge chevron-notched rectangular plate in four-point bending $(C N 4 P B)$ "

A geometria do corpo de prova e a configuração do ensaio são mostradas na Figura 34.
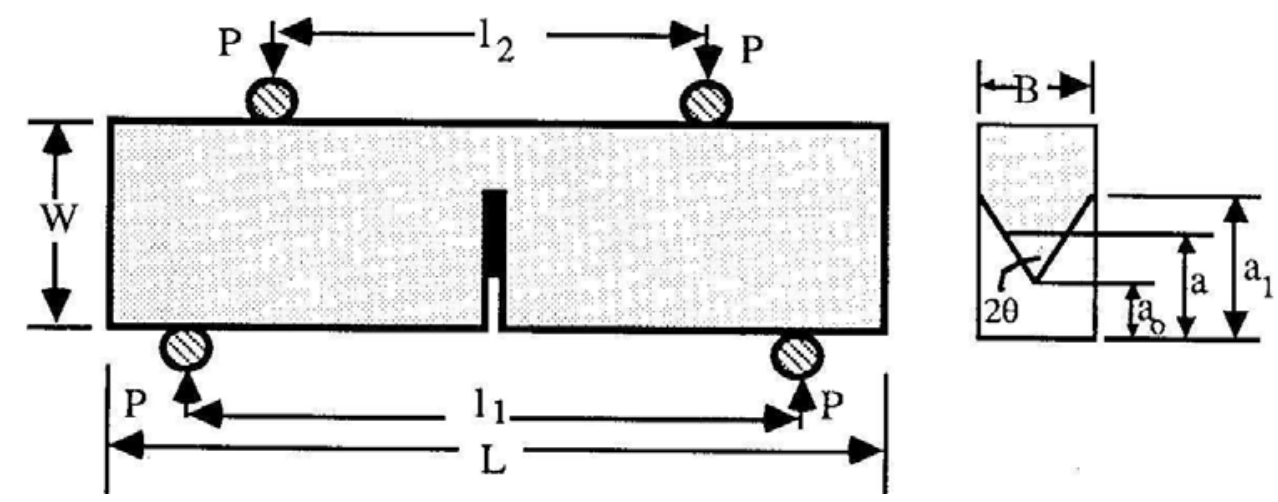

Figura 34 - Geometria e configuração do ensaio na placa retangular com entalhe “chevron” submetido à flexão em quatro pontos (WHITTAKER; SINGH e SUN, 1992)

Munz, Bubsey e Shannon (1980) apud Whittaker, Singh e Sun (1992), usaram o modelo de fatias de Bluhm (1975) para calibrar valores de $Y$ como função de $\alpha_{0}=\frac{a_{0}}{W}$. Seus resultados podem ser aproximados por um polinômio de terceiro grau conforme abaixo:

$Y=16.411+25.842 \alpha_{0}-2.238 \alpha_{0}^{2}+133.889 \alpha_{0}^{3}$

A expressão acima é válida para coeficiente de Poisson $v=0.2,0 \leq \alpha_{0} \leq 0.5, B / W=0.8$, $l_{1} / W=0.75$ e $l_{2} / W=0.25$.

A tenacidade à fratura pode ser determinada substituindo $Y$ na equação (121).

\subsubsection{Placa retangular com entalhe reto submetido à flexão em quatro pontos em balanço}

Os corpos de prova foram carregados em quatro pontos até que a trinca propagase (Figura 35). Essa geometria de ensaio foi escolhida porque na região entre os pontos de carregamento internos, o momento de flexão é constante e a carga transversal é nula.

Amaral, Guerra-Rosa e Cruz-Fernandes (1999) estudaram o comportamento da propagação da trinca em seis tipos diferentes de granitos (principalmente portugueses), usando corpos de prova com um único entalhe. Os entalhes foram efetuados utilizando- 
se uma serra de $0.3 \mathrm{~mm}$ contendo diamantes de $60 \mu \mathrm{m}$. O método é descrito como um ensaio de flexão em uma viga com uma barra estreita no lado tracionado.

Estes ensaios foram executados numa máquina hidráulica servo-controlada, com uma célula de carregamento de $1 \mathrm{kN}$ e com velocidade de $0,5 \mathrm{~mm} / \mathrm{min}$.

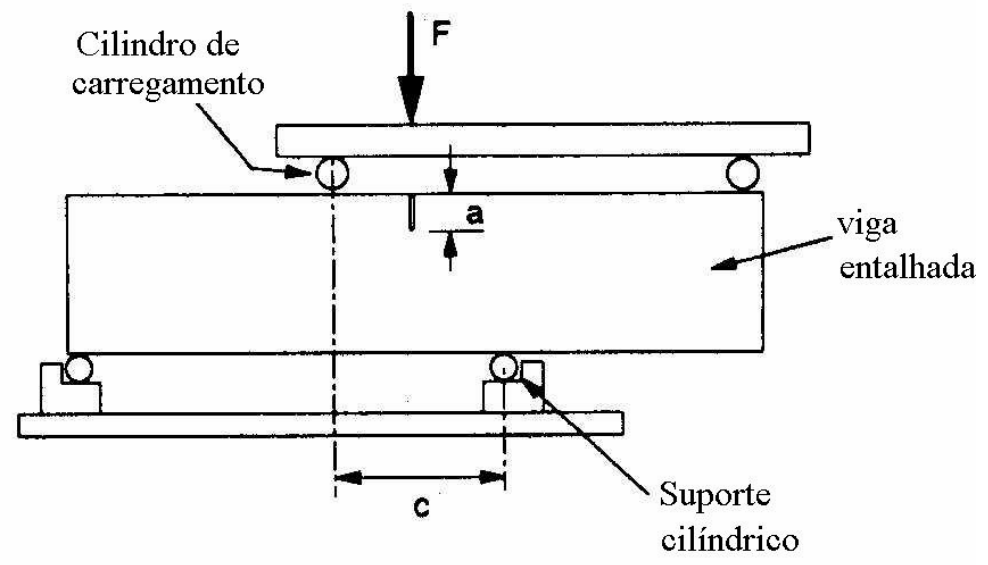

Figura 35 - Geometria e configuração do ensaio na placa retangular com entalhe reto submetido à flexão em quatro pontos em balanço (AMARAL; GUERRA-ROSA e CRUZ-FERNANDES, 1999)

Os valores da tenacidade à fratura $\left(K_{I C}\right)$ foram calculados de acordo com a equação proposta por Srawley e Gross (1976) apud Amaral, Guerra-Rosa e CruzFernandez, (1999).

$K_{I C}=\frac{F_{\max } Y}{\left(B W^{\frac{1}{2}}\right)}$

onde:

$F_{\text {máx }}$ : carga máxima aplicada;

$B, W$ : espessura e largura, respectivamente, dos corpos de prova, e

$Y$ : fator de correção para a geometria do corpo de prova e para a forma de carregamento, sendo dado por:

$$
Y=\frac{3\left(L_{e}-L_{i}\right) \alpha^{\frac{1}{2}} X}{2 h(1-\alpha)^{\frac{3}{2}}}
$$

com:

$$
X=1.9887-\left[\frac{\left(3.49-0.68 \alpha-1.35 \alpha^{2}\right) \alpha(1-\alpha)}{(1+\alpha)^{2}}\right]-1.32 \alpha
$$


onde $l_{e}$ e $l_{i}$ são os vãos entre os pontos de carregamento externo e interno, respectivamente. Neste caso, $l_{e}=120 \mathrm{~mm}, l_{i}=60 \mathrm{~mm}, \alpha=a / W$ e $a$ é o comprimento do pré-entalhe.

\subsubsection{Corpos de prova em dupla-torção - "Double torsion specimen (DT)"}

O ensaio de dupla-torção é bastante atrativo, como no caso do ensaio de flexão, devido à relativa facilidade de preparação dos corpos de prova e o uso de cargas compressivas. Este é um método para determinar a tenacidade à fratura onde o fator de intensidade de tensão na ponta da trinca é independente do comprimento da mesma. $\mathrm{O}$ método de dupla-torção foi desenvolvido por Evans (1972).

O corpo de prova é uma placa retangular com comprimentos típicos da ordem de duas vezes a largura; normalmente, faz-se um entalhe central no corpo de prova para orientar a propagação da trinca; o que pode ser evitado se o corpo de prova fora perfeitamente alinhado no dispositivo. Como nos outros casos, o corpo de prova deve ter um pré-entalhe antes da realização do ensaio $K_{I C}$. Um deslocamento constante é aplicado aos corpos de prova através de um esquema de flexão de quatro pontos, salienta-se que a frente da trinca prossegue ao longo de uma linha reta que parte de um entalhe inicial e é guiada por um entalhe lateral.

A geometria do corpo de prova em dupla-torção e a configuração do ensaio são mostradas na Figura 36.

Neste ensaio, quando a extremidade do corpo de prova é carregada em flexão a quatro pontos, a trinca estará sujeita à tensão de tração, resultante do momento fletor, e se propagará ao longo do entalhe central. Salienta-se que sua propagação é maior na face inferior do corpo de prova uma quantidade correspondente a $\Delta$ a comparativamente à face superior conforme demonstrado na Figura 36c (ATKINSON, 1979).

O método tem as várias vantagens, a principal delas é sua potencialidade para produzir a propagação estável da trinca, o que é muito conveniente para o estudo da fratura em materiais frágeis como rochas (ATKINSON, 1979). Outra vantagem do método é que ele requer somente que seja monitorada a diminuição da carga com o tempo para medir o fator de intensidade de tensão e a velocidade da propagação da trinca, sem nenhuma necessidade de medir o comprimento da trinca durante o ensaio. 
(a)

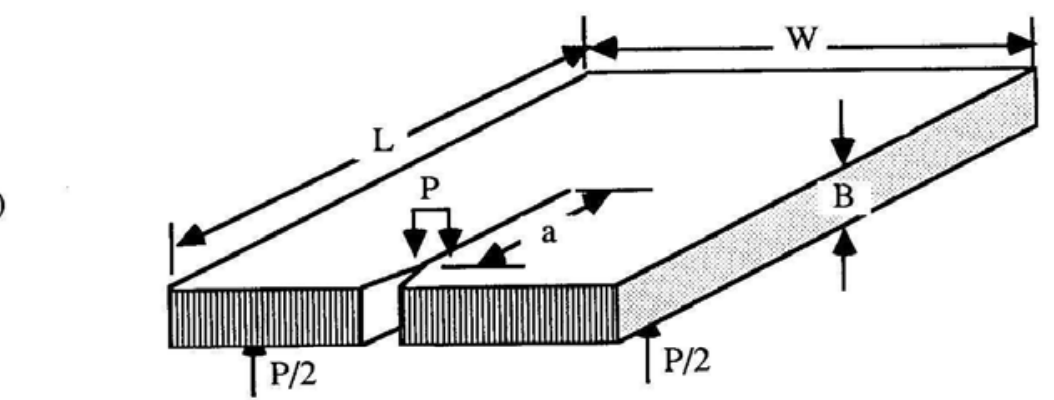

(b)

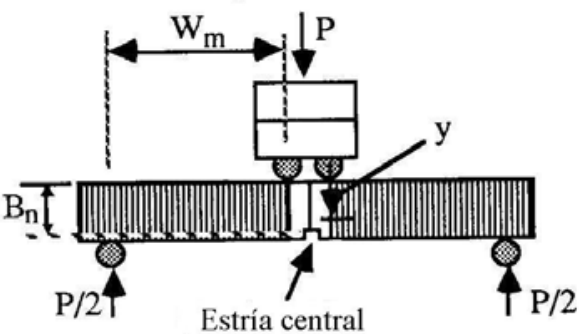

(c)

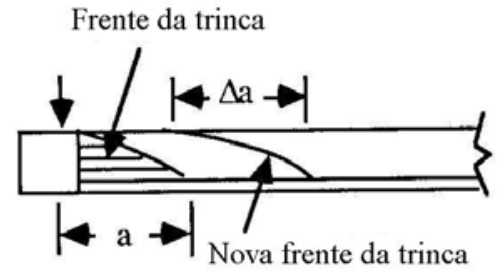

Figura 36 - Geometria do corpo de prova e configuração do ensaio dupla-torção (WHITTAKER; SINGH e SUN, 1992)

O fator de intensidade de tensão no modo I é dada pela seguinte expressão (WILLIAMS e EVANS, 1973):

$K_{I C}=\sqrt{E G_{F}}=F_{\max } \sqrt{\frac{3(1+v)}{W B^{3} B_{n}}}$

onde:

$E$ : módulo de elasticidade;

$G_{F}$ : variação da liberação da energia de deformação;

$F_{\text {max }}$ : carga máxima aplicada;

$W_{m}$ : braço do momento de cada barra;

$v$ : coeficiente de Poisson;

$W$ : largura do corpo de prova;

$B$ : espessura do corpo de prova;

$B_{n}$ : espessura da placa na estria (espessura do corpo de prova menos a profundidade do entalhe central).

A principal dificuldade associada com este ensaio é que a trinca se propaga com a frente curvada, estendendo-se mais na região onde há tensões normais de tração do que na região onde há tensões normais de compressão. Teoricamente, este problema levanta a seguinte questão: é a solicitação da trinca exclusivamente $K_{I}$ (modo I) ou existe uma componente adicional em modo III $\left(K_{I I I}\right)$ ? A frente curva implica, também, em uma variação da velocidade da trinca e de $K$ ao longo desta frente. 
Henry, Paquet e Tancrez (1977) estudaram experimentalmente a propagação das trincas em rochas calcáreas. Destes estudos, foram estabelecidas curvas experimentais relacionadas com a velocidade da propagação da trinca em função do fator de intensidade de tensão $K_{I}$ para um calcáreo microgranular (1-4 $\left.\mu \mathrm{m}\right)$ e para um mármore de grão fino $(100-300 \mu \mathrm{m})$. As relações calculadas foram verificadas experimentalmente mediante ensaios de flexão em três pontos. As dimensões dos corpos de prova foram de $3 \times 70 \times 150 \mathrm{~mm}$.

Segundo Henry, Paquet e Tancrez (1977), o método experimental do ensaio de dupla-torção aplicado em suas pesquisas é como descrito a seguir:

(i) Os corpos de prova foram cortados a partir de blocos simples de materiais apropriados utilizando uma serra de precisão diamantada;

(ii) $\mathrm{O}$ eixo maior dos corpos de prova de arenito Tennessee foi orientado perpendicularmente às camadas em todos os casos, contudo o eixo maior dos corpos de prova de mármore Carrara foi orientado em uma direção arbitrária constante;

(iii) As superfícies superior e inferior dos corpos de prova foram aplainadas e com lados paralelos com um erro de $0.025 \mathrm{~mm}$. Realizou-se um entalhe central de aproximadamente $1 \mathrm{~mm}$ de largura ao longo do comprimento de cada corpo de prova com um disco diamantado com uma profundidade de aproximadamente B/3 (B é a espessura do corpo de prova);

(iv) Adicionalmente, um entalhe de $1 \mathrm{~cm}$ de comprimento e $1 \mathrm{~mm}$ de largura foi cortado em um dos extremos de cada barra de dupla-torção ao longo da cunha axial. O objetivo foi para que durante o carregamento, a propagação da trinca ocorresse a partir do entalhe na direção paralela ao comprimento do corpo de prova.

(v) Todos os corpos de prova de dupla-torção foram fabricados na mesma relação largura- espessura de 15:1 para reduzir os erros das variações microestruturais nos materiais considerados.

Atkinson (1979) estudou a tenacidade à fratura do arenito Tennessee e do mármore Carrara. O arenito Tennessee consiste de grãos de quartzo sub-arredondeados, com um tamanho de grão relativamente uniforme de $150 \mu \mathrm{m}$. O mármore Carrara consiste quase inteiramente em grãos de calcita poligonais com um tamanho de grão relativamente uniforme de $200 \mu \mathrm{m}$. As dimensões absolutas do corpo de prova eram aproximadamente como segue: Para o arenito Tennessee, 0.25 x 40 x $70 \mathrm{~mm}$; para o mármore Carrara, 0.40 x 60 × $80 \mathrm{~mm}$. O ensaio mecânico foi realizado com controle de 
deslocamento $L P D$ por um sistema hidráulico servo-controlado de circuito fechado, sendo considerada a carga de pico resultante da propagação da trinca como carga crítica para a determinação da tenacidade à fratura.

Todos os corpos de prova dupla-torção foram feitos da mesma relação largura/espessura de 15:1. Em experiências preliminares, encontrou-se que, para corpos de prova com relações largura: espesssura menores que 12:1, as estimativas de $K_{I C}$ foram anomalamente elevadas e a magnitude destas estimativas variou inversamente com a relação largura:espessura. Os valores de $K_{I C}$ eram independentes das dimensões do corpo de prova para relações maiores que 12:1 de largura:espessura.

Segundo Atkinson (1979), as principais características deste ensaio são:

(i) Valores de $K_{C}$ podem ser determinados sem necessidade de se conhecer o comprimento da trinca $(a)$;

(ii) Os corpos de prova requerem só uma modesta quantidade de preparação;

(iii) Os ensaios envolvem um simples carregamento compressivo.

Swanson (1981) estudou este ensaio com corpos de prova do Granito Westerly. As dimensões destes corpos de prova foram 1.5 x 27 x $150 \mathrm{~mm}$. O carregamento foi realizado a uma velocidade de deslocamento constante e por meio de métodos de relaxação a $23^{\circ} \mathrm{C}$ e aproximadamente $50 \%$ de umidade relativa. Foram avaliados os efeitos não friccionais ao longo do plano de fratura por meio de eventos de emissões acústicas. Um interferômetro holográfico foi utilizado para examinar a deformação (deslocamento da superfície) e para checar a hipótese assumida de independência das constantes elásticas.

Albuquerque (2003) realizou estudos visando adaptar o ensaio de dupla-torção para determinação da curva- $R$ e verificar se este ensaio é adequado para caracterização de um concreto refratário. Verificou-se que as curvas carga-deslocamento do piso cerâmico comercial e do concreto refratário completo apresentaram quedas após as respectivas cargas máximas, implicando correspondentes quedas em $K_{I}$, embora, normalmente na literatura, o ensaio de dupla-torção seja citado como um experimento que apresenta $K_{I}$ constante.

Como resultado adicional, os estudos mostraram que o comportamento do material pode ser representado por corpos de prova com espessura menor que cinco vezes o tamanho do maior grão, tornando viável o processamento de materiais com tamanho de grão muito grande no ambiente laboratorial. 


\subsubsection{Viga prismática em ruptura com balanço duplo - "Double cantilever beam in splitting $(D C B)$ "}

Existem três tipos principais de configuração de carregamento de vigas em balanço duplo comumente usados para se determinar a tenacidade à fratura ou a energia do processo da fratura em rochas: ruptura por tração, ruptura por flexão e ruptura por cunha, como mostra a Figura 37.

(a)

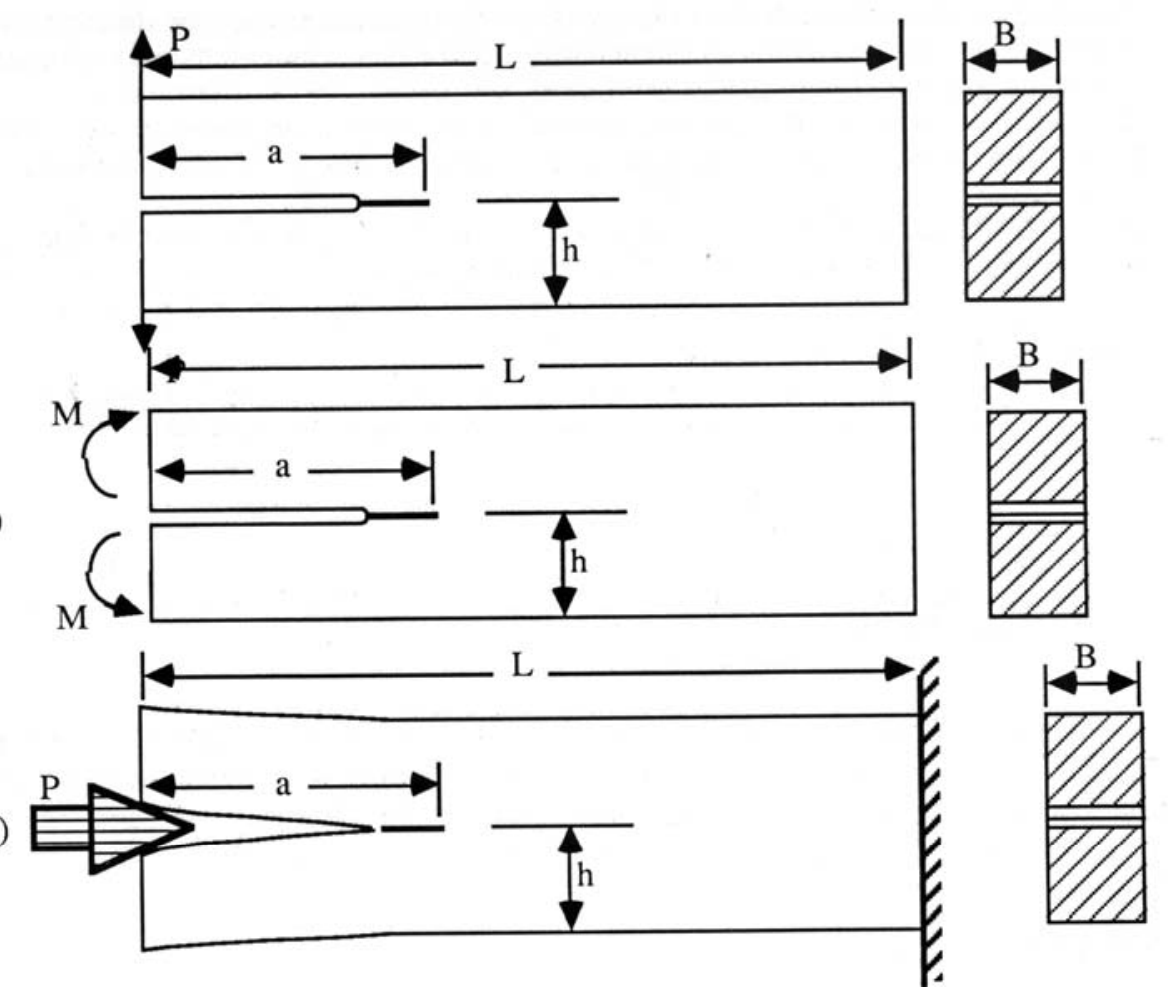

Figura 37 - Principais tipos de viga em balanço duplo: a) ruptura por tração, b) ruptura por flexão, c) ruptura por cunha (WHITTAKER; SINGH e SUN, 1992).

\subsubsection{Viga prismática em ruptura por tração com balanço duplo}

A geometria do corpo de prova e a configuração do ensaio são mostradas na Figura 37a.

Kanninem (1973) apud Whittaker, Singh e Sun (1992) levou em conta o efeito da tensão cisalhante e deduziu uma equação com objetivo de determinar o fator de intensidade de tensão no modo I $\left(K_{I}\right)$ para o ensaio de ruptura por tração:

$$
K_{I}=3.45 \frac{P a}{B h^{3 / 2}}\left[1+0.64 \frac{h}{a}\right]
$$

onde:

$P$ : carga aplicada;

$a$ : comprimento da trinca; 
$B$ : espessura do corpo de prova $\mathrm{e}$

$h$ : metade da largura do corpo de prova.

Este método foi adotado por Perkins e Krech (1966) para medir a energia do processo da fratura em rochas, por Brown e Srawley (1966) e Wiederhorn e Shorb (1968) para determinar o crescimento subcrítico da trinca e por Kim e Stout (1978) para determinar o módulo de elasticidade e a tenacidade à fratura do granito Westerly (WHITTAKER; SINGH e SUN, 1992).

O método consistiu em ensaiar uma série de corpos de prova com vários comprimentos de trinca e comparar a curva de flexibilidade com a curva de comprimento de trincas obtidas deste modo com aquela de um material de propriedades elásticas conhecidas. As propriedades elásticas do granito Westerly foram determinadas por este método e comparadas com as constantes elásticas obtidas a partir de ensaios de compressão uniaxial e por ultra-som. A suposição inicial atrás destes métodos é que a plastificação ou microtrincamento na ponta da trinca está ocorrendo em uma escala pequena e, conseqüentemente, o material de ensaio deve exibir um comportamento elástico linear.

Os corpos de prova foram preparados a partir do granito Westerly e aço e, posteriormente, estes foram submetidos às mesmas condições de carregamento. Os corpos de prova tiveram 76,2 $\mathrm{mm}$ de comprimento, 19,1 $\mathrm{mm}$ de espessura e uma largura de trinca de 7,9 mm. Os sulcos ao longo do entalhe servem para colocar os dispositivos de carregamento; estes sulcos foram necessários para manter a propagação da trinca ao longo do comprimento do corpo de prova. Trincas centrais variando de 12,7 $\mathrm{mm}$ a 43,2 $\mathrm{mm}$ em comprimento foram cortadas no granito Westerly por meio de um disco diamantado de $0,17 \mathrm{~mm}$. Finalmente, os corpos de prova foram colocados num forno a $110^{\circ} \mathrm{C}$ por 24 horas e guardados em um dessecador até seu ensaio.

O dispositivo de carregamento consiste de dois braços do tipo "cantilever" que carregam o corpo de prova com um medidor de deformações incorporado. A calibração destes braços de carregamento foi realizada usando uma célula de carga. $O$ deslocamento da linha de carregamento foi medida usando um extensômetro do tipo “clip gauge” localizado nos sulcos de carregamento, tornando possível o registro da carga e do deslocamento da abertura da boca da trinca. Os procedimentos de ensaio foram idênticos para os corpos de prova de aço e de granito.

Kim e Stout (1978) deduziram a seguinte expressão para o calculo da tenacidade à fratura no modo I para condições de esforços planos: 
$K_{I C}=\sqrt{\frac{E}{1-v^{2}} \frac{P^{2}}{2 t}\left(\frac{\partial C}{\partial a}\right)_{P}}$

onde :

$E$ : módulo de elasticidade;

$v$ : coeficiente de poisson;

$P$ : carga aplicada;

$t$ : largura da trinca;

$C=\frac{\delta}{P}:$ flexibilidade da amostra (relação deslocamento / carga aplicada);

$a$ : comprimento da trinca.

A carga aplicada e a largura da trinca são facilmente avaliadas experimentalmente, onde $\left(\frac{\partial C}{\partial a}\right)$ pode ser determinada mediante técnicas teóricas ou experimentais. As soluções teóricas para o calculo de $K_{I C}$ supõem que o módulo de elasticidade do material é uma constante, dificultando a avaliação do $K_{I C}$ para um material tal como o granito Westerly que apresenta uma curva tensão-deformação não linear. Experimentalmente, medindo-se a flexibilidade do corpo de prova como uma função do comprimento da trinca e normalizando-se estes resultados para aqueles corpos de prova de aço com geometria idêntica, um módulo de elasticidade efetivo para o granito pode ser estabelecido pela seguinte expressão:

$$
\frac{\left.C^{a \varsigma o}\right|_{a}}{\left.C^{\text {granito }}\right|_{a}} x E^{\text {aco }}=E_{\text {effetivo }}^{\text {granito }}
$$

onde:

$\left.C^{a c ̧ o}\right|_{a}$ : flexibilidade do corpo de prova de aço como uma função do comprimento da trinca;

$\left.C^{\text {granito }}\right|_{a}$ : flexibilidade do corpo de prova de granito como uma função do comprimento da trinca; $E^{a \varsigma \varsigma o}:$ módulo de elasticidade do aço e $E_{\text {effetivo }}^{\text {granito }}$ : módulo de elasticidade efetivo para o granito.

O módulo de elasticidade efetivo resultante pode ser comparado com a obtida mediante tração uniaxial para checar a aplicabilidade da MFEL. Combinando-se isto 
com os valores experimentais, determinou-se uma função para $\frac{\partial C}{\partial a}$ de maneira que $K_{I C}$ pode ser calculada.

As principais vantagens deste método incluem a simples e apropriada geometria para o estudo do crescimento subcrítico da trinca. Entretanto, este método requer o préentalhe do corpo de prova, medidas do comprimento da trinca e o carregamento a tração. Os entalhes que servem como guia devem ser feitos em ambos lados para evitar o desvio da propagação da trinca.

\subsubsection{Viga prismática em ruptura por flexão com balanço duplo}

Segundo Whittaker, Singh e Sun (1992), o fator de intensidade de tensão $\left(K_{I}\right)$ pode ser independente do comprimento da trinca se, ao invés de aplicar carga de tração, for aplicado um momento fletor constante na extremidade do corpo de prova $(M)$, como mostra a Figura 37b. Neste caso o fator de intensidade de tensão é expresso por:

$$
K_{I}=\frac{M}{\sqrt{I B}}
$$

onde $I$ é o momento de inércia.

Neste ensaio, a variação na configuração de carregamento tem a vantagem de não necessitar das medidas de comprimento da trinca. Salienta-se que os autores supramencionados não proporcionam maiores informações nem referências bibliográficas a serem consultadas.

\subsubsection{Viga prismática em ruptura por cunha com balanço duplo}

Para simplificar o dispositivo de carregamento, a força de ruptura pode ser aplicada por meio de uma carga compressiva através de uma cunha (Figura 37c). O fator de intensidade de tensão $\left(K_{I}\right)$ para este caso é:

$$
K_{I}=0.866 \frac{E \delta_{t} h^{3 / 2}}{a^{2}\left(1+0.64 \frac{h}{a}\right)^{2}}
$$

onde:

$\delta_{t}$ : deslocamento da abertura na ponta da trinca $(C M O D)$

$E$ : módulo de elasticidade do material;

$a$ : comprimento da trinca $\mathrm{e}$ 
$h$ : metade da largura do corpo de prova.

Kobayashi, Matsuki e Otsuka (1986) apud Whittaker, Singh e Sun (1992) usaram este método para estudar o efeito escala na determinação da tenacidade à fratura usando o tufo Ogino. Eles mostraram que, imediatamente após do início da fratura, a propagação da trinca é macroscopicamente estável, mas microscopicamente instável. Este método pode ser usado para estudar o comportamento da curva- $R$ de rochas.

Brühwiler e Saouma (1990) usaram este método para fornecer um método de ensaio que conseqüentemente concordasse com as propriedades da fratura considerando a $Z P F$ (Zona de processo da fratura) na avaliação. Estes autores usaram corpos de prova cilíndricos com três direções ortogonais da propagação da fratura para levar em conta a anisotropia do material e também pela possibilidade de se preparar os corpos de prova usando um só testemunho. Estes corpos de prova são fáceis de preparar e não têm risco de romper-se durante a sua preparação. As áreas de fratura dos corpos de prova são grandes comparadas aos seus pesos próprios. Isto é importante com relação à investigação dos efeitos escala (grandes corpos de prova) e para o caso de ensaio das rochas de grãos grandes.

Segundo Brühwiler e Saouma (1990), o método experimental do ensaio de ruptura por cunha aplicado em suas investigações é como descrito a seguir:

(i) O corpo de prova é colocado em um suporte fixo no prato inferior da máquina de ensaio;

(ii) Colocam-se suportes especiais nos dois dispositivos de carregamento localizados na parte superior do corpo de prova;

(iii) Fixa-se, na parte superior da máquina de ensaio, um perfil de aço com duas cunhas idênticas. O atuador da máquina de ensaio é movido de modo que as cunhas entrem entre os suportes, resultando numa componente horizontal da força da ruptura.

As dimensões da ranhura e o entalhe são escolhidos de modo que a trinca se propague na direção vertical, e o corpo de prova separa-se em duas metades. Neste ensaio, são registrados a carga na direção vertical $\left(F_{v}\right)$ e o deslocamento da abertura da boca da trinca $(C M O D)$.

A força de separação $\left(F_{s}\right)$ é a componente horizontal da força atuando sobre os suportes e calculada levando em conta o ângulo da cunha e as forças friccionais: 
$F_{S}=\frac{F_{v}}{2 \cdot \tan \alpha} \cdot \frac{1}{(1+\mu \cdot \operatorname{ctg} \alpha)}$

onde:

$\alpha$ : ángulo da cunha e

$\mu$ : coeficiente de atrito.

Desde que os efeitos de atrito no ensaio de partição por cunha podem, na prática, diminuir em $2 \%$, eles podem ser omitidos em uma primeira aproximação e a força de separação pode ser calculada a partir da força vertical medida:

$F_{S}=\frac{F_{V}}{2 \cdot \tan \alpha}$

O deslocamento da abertura da boca da trinca $(C M O D)$ é controlado usando um transdutor ou um extensômetro do tipo "clip gauge" fixo no nível onde a força resultante de separação atua no corpo de prova.

Em uma máquina hidráulica servo-controlada, os ensaios são realizados com controle do deslocamento da abertura da boca da trinca (CMOD) a uma velocidade "quase-estática" de $1 \mu \mathrm{m} / \mathrm{s}$. Os ciclos de carregamento e descarregamento foram usados para controlar a mudança da inclinação na curva de flexibilidade durante a propagação da trinca.

Em uma curva representativa carga versus deslocamento da abertura da boca da trinca $\left(F_{s^{-}} C M O D\right)$, a qual é uma resposta estrutural do corpo de prova, a porção linear e não linear podem ser observadas no trecho ascendente pré-pico e no trecho descendente pós-pico com cinco ciclos de carregamento-descarregamento.

A tenacidade à fratura $\left(K_{I C}\right)$ é avaliada usando o método de flexibilidade, no qual o comprimento efetivo da trinca $\left(a_{e f f}\right)$, o qual é maior que a trinca verdadeira, é determinado pela calibração do ensaio mediante método de elementos finitos:

$$
K_{I}=\frac{F_{S}}{H \cdot B} \sqrt{\pi a_{e f f}} \cdot f(\beta)
$$

onde:

$B$ : espessura do corpo de prova;

$H$ : altura do corpo de prova;

$a_{\text {eff: }}$ comprimento efetivo da trinca;

$\beta=\frac{a_{e f f}}{H}$

$f(\beta)$ : função da geometria para corpo de prova do ensaio de partição por cunha; 
$F_{S}$ força de separação onde $F_{S}=\frac{F_{V}}{2 \cdot \tan \alpha}$.

A tenacidade à fratura $\left(K_{I C}\right)$ obtida dos corpos de prova em escala de laboratório deve ser avaliada de dados de ensaios empregando-se modelos de ruptura que levem em conta a presença da $Z P F$.

\subsubsection{Ensaio em disco brasileiro sem entalhe - "Uncracked Brazilian disk test $(B D T) ”$}

Apresenta-se abaixo uma descrição das metodologias de ensaio em discos brasileiros sem entalhe segundo as propostas de Hua Guo (1990) e Celestino e Bortolucci (1992).

\subsubsection{Proposta de Hua Guo (1990)}

O fundamento do ensaio foi descrito por Mellor e Hawkes (1971), e o procedimento de ensaio recomendado pela $\operatorname{ISRM}(I S R M, 1971)$. Somente uma breve explicação do ensaio é aqui descrita. Um corpo de prova na forma de disco é carregado por duas superfícies curvas de aço em duas superfícies diametralmente opostas sob um arco de contato de aproximadamente $10^{\circ}$ na ruptura. $\mathrm{O}$ raio do corpo de prova foi de 27 $\mathrm{mm}$, e a espessura é igual ao raio do corpo de prova. $\mathrm{O}$ raio das superfícies curvas de aço é igual a 1.5 vezes o raio do corpo de prova. Uma rótula permite a rotação de uma superfície curva de aço em relação à outra.

Guo, Aziz e Schmidt (1993) propõem este ensaio para a determinação da tenacidade à fratura em rochas. Eles deduzem que o fator de intensidade de tensão pode ser expresso pela seguinte expressão:

$$
K_{I}=\frac{2 P}{\pi R t \alpha} \sqrt{c} \int_{0}^{c}\left[\frac{\Phi(r / R)}{\sqrt{c^{2}-x^{2}}}\right] d r
$$

onde $\Phi(r / R)$ é definido por:

$$
\Phi(r / R)=\frac{\left[1-(r / R)^{2} \sin 2 \alpha\right]}{1-2(r / R)^{2} \cos 2 \alpha+(r / R)^{4}}-\tan ^{-1}\left[\frac{1+(r / R)^{2}}{1-(r / R)^{2}} \tan \alpha\right]
$$

Por conveniência, a equação anterior pode ser expressa como: 
$K_{I}=B P \Phi(c / R)$

onde $B$ e $\Phi(c / R)$ são definidos como:

$B=\frac{2}{\pi^{3 / 2} R^{1 / 2} t \alpha}$

e

$\Phi\left(\frac{c}{R}\right)=\left(\frac{c}{R}\right)^{1 / 2} \int_{0}^{c / R}\left[\frac{\Phi\left(\frac{r}{R}\right)}{\sqrt{\frac{c^{2}}{R}-\frac{r^{2}}{R}}}\right] d\left(\frac{r}{R}\right)$

Como pode ser visto, quando $\alpha$ é definido, $\Phi(c / R)$ é somente dependente da posição da ponta da trinca (ou do comprimento da trinca). Por conveniência, $\Phi(c / R)$ pode ser denominado coeficiente do fator de intensidade de tensão adimensional. $B$ é uma constante para uma geometria e uma dada condição de carregamento do corpo de prova.

A equação (138) implica, para uma carga fixa $(P)$, que as mudanças do fator de intensidade de tensão como função do comprimento adimensional de trinca $(c / R)$ se dão de acordo com $\Phi(c / R)$. Identificando a variável $K_{I}$ como sendo a tenacidade à fratura $K_{I C}$, e rearranjando a equação (138), a carga crítica que forma a trinca $(c / R)$ pode ser predita como se segue:

$P_{c}=\frac{K_{I C}}{B \Phi(c / R)}$

Assume-se que a pressão no corpo de prova devido às superfícies curvas de aço é distribuída uniformemente ao longo do arco de contato, o qual corresponde a $5^{\circ}$ na ruptura. Para a geometria do corpo de prova estudado, isto é, $R=27 \mathrm{~mm}$ e $t=27 \mathrm{~mm}$, a constante $B$ é igual a $920\left(\mathrm{~m}^{3 / 2}\right)$ e $\Phi_{\operatorname{máx}}(c / R)$ é igual a 0.112 , calculando-se a tenacidade à fratura mediante a seguinte expressão:

$K_{I C}=104.1 P_{\min }$

onde, $P_{\min }$ é a carga aplicada local mínima e pode ser determinada a partir da curva carga-deslocamento.

Foi empregada uma máquina hidráulica servo-controlada com capacidade de 500 $\mathrm{kN}$ e uma rigidez de $1060 \mathrm{kN} / \mathrm{mm}$. O ensaio foi realizado mediante controle de deslocamento com uma velocidade de $0.01 \mathrm{~mm} / \mathrm{s}$. 
A principal característica deste ensaio é a de não haver necessidade de se introduzir fratura ou entalhe no corpo de prova em forma de disco (Figura 38b). Uma trinca diametral central é induzida no ensaio durante o carregamento, a qual leva o corpo de prova à ruptura.

Segundo Whittaker, Singh e Sun (1992), a fórmula para $K_{I}$ pode ser dada como se segue:

$$
K_{I}=\left(\frac{2 F}{\pi^{3 / 2} R^{1 / 2} B \alpha}\right) Y
$$

sendo:

$$
Y_{K}=\left(\frac{a}{R}\right) \int_{0}^{a / R}\left(\frac{\sqrt{R}}{\sqrt{a^{2}-r^{2}}} \phi\left(\frac{r}{R}\right)\right) d\left(\frac{r}{R}\right)
$$

onde $Y_{K}$ é o fator de intensidade de tensão adimensional;

$$
\phi\left(\frac{r}{R}\right)=\frac{1-\left(\frac{r}{R}\right)^{2} \operatorname{sen} 2 \alpha}{1-2\left(\frac{r}{R}\right)^{2} \cos 2 \alpha+\left(\frac{r}{R}\right)^{4}}-\operatorname{arctg} \frac{1+\left(\frac{r}{R}\right)^{2} \tan \alpha}{1+\left(\frac{r}{R}\right)^{2}}
$$

onde:

$r$ : distância radial do centro do corpo de prova;

$a$ : comprimento da trinca;

$R:$ raio do corpo de prova;

$B$ : espessura do corpo de prova e

$\beta$ : metade do ângulo sobre o qual a carga diametral é aplicada.

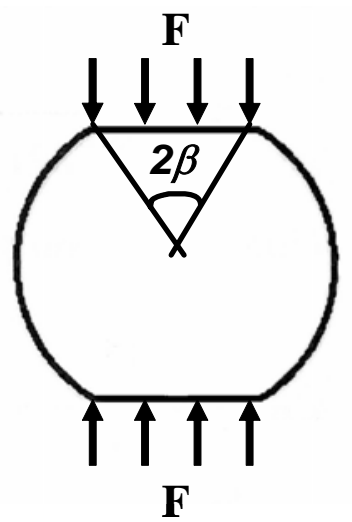

(a)

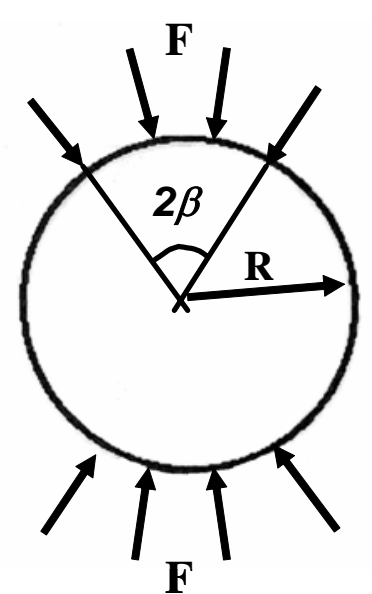

(b)

Figura 38 - Ensaio em disco brasileiro sem entalhe: a) disco com corte plano onde aplica o carregamento; b) disco sem o corte (ALBUQUERQUE, 1998). 
Salienta-se que, para evitar esmagamento no local de carregamento, o disco pode sofrer um corte plano no local de aplicação da carga (Figura 38a). A principal vantagem desse método está no fato dele não necessitar de entalhe no corpo de prova, facilitando uma boa aproximação para determinar a tenacidade à fratura de rochas.

\subsubsection{Proposta de Celestino e Bortolucci (1992)}

Celestino e Bortolucci (1992) apud Celestino, Bortolucci e Nobrega (1995) propuseram o uso de amostras "intactas" ou sem entalhe para determinação da tenacidade à fratura, utilizando corpos de prova submetidos a ensaios em forma de discos brasileiros sem entalhe. É um ensaio estável, utilizando como variável de controle o deslocamento diametral, perpendicular ao eixo do carregamento. $\mathrm{O}$ deslocamento e o fator de intensidade de tensão são numericamente analisados em função das propriedades do material e do comprimento da trinca. As soluções são colocadas em termos adimensionais e a interpretação dos resultados é bastante confiável.

O esquema do ensaio é mostrado na Figura 39. As constantes elásticas são obtidas baseando-se nos deslocamentos $u_{x}$ e $u_{y}$ precedentes ao pico. Quando o pico do carregamento é alcançado, a trinca é criada e inicia-se o processo de fratura do corpo de prova.

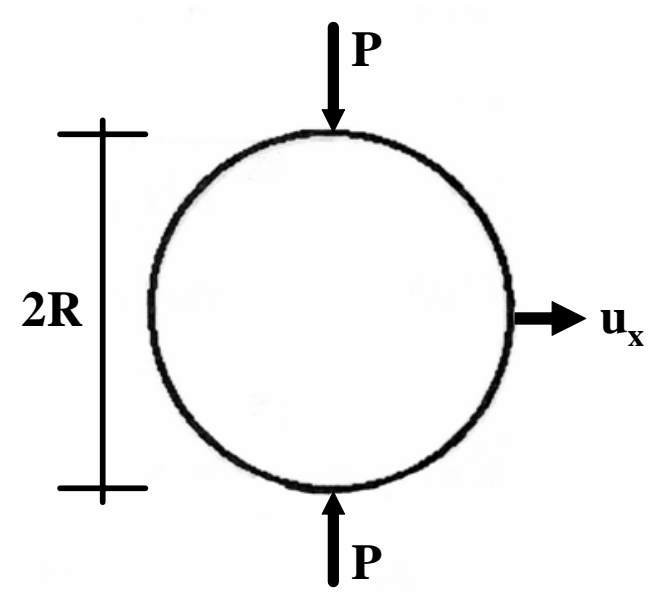

Figura 39 - Ensaio em disco brasileiro sem entalhe (ALBUQUERQUE, 1998).

O comprimento da trinca é determinado por uma série de ciclos de carregamento-descarregamento pós-pico. A inclinação da curva durante o carregamento está diretamente ligada ao comprimento da trinca e, conseqüentemente, à tenacidade à fratura, que podem ser determinados em muitos pontos para uma mesma amostra. 
Este ensaio foi usado para determinar a tenacidade à fratura em mármore (MONTEIRO e COHEN, 1993), basalto, arenito e granito (CELESTINO; BORTOLUCCI e NOBREGA, 1995).

\subsubsection{Disco brasileiro com entalhe}

Existem vários métodos para determinar a tenacidade à fratura usando o disco brasileiro com entalhe. Existem os ensaios em discos brasileiros com entalhe "chevron" normalizados pela ISRM (1995), em discos brasileiros com entalhe reto central $(C S C B D)$, em discos brasileiros com estria de aresta ( $S E C B D)$ e em discos brasileiros com estria dupla de aresta. A Figura 40 ilustra estes corpos de prova.

a)

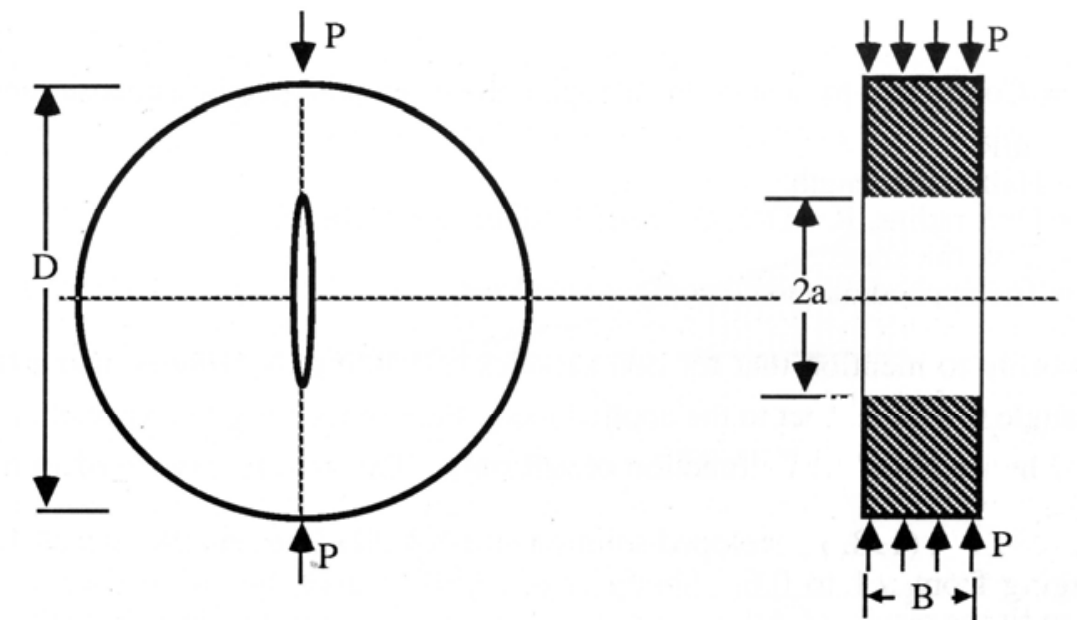

b)

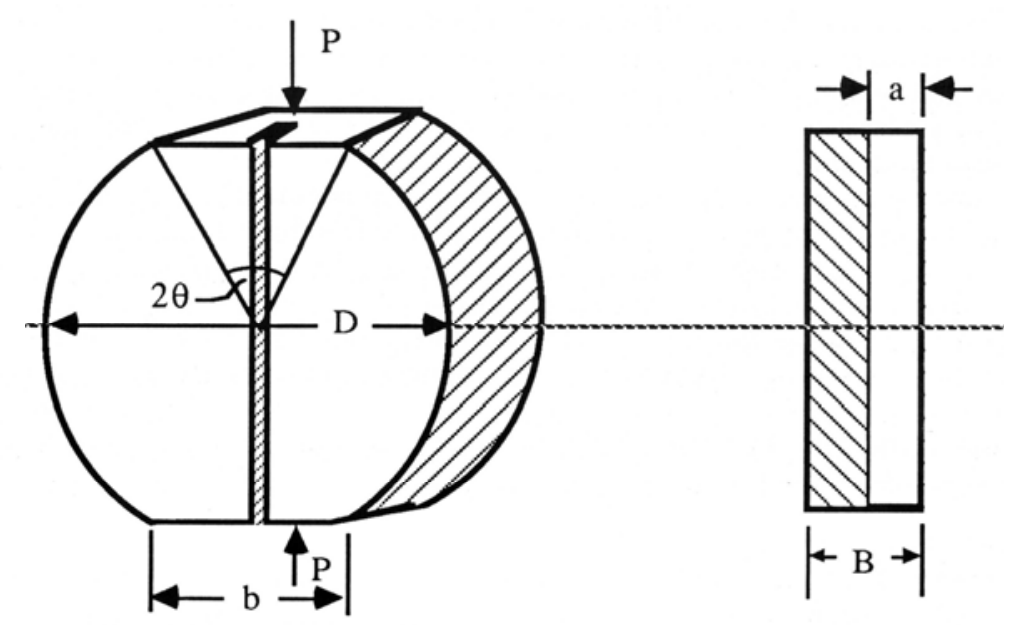

Figura 40 - Ilustração dos corpos de prova tipo disco brasileiro em compressão diametral: a) entalhe reto central (CSCBD); b) disco com estria de aresta (SECBD) (WHITTAKER; SINGH e SUN, 1992).

Nestes ensaios, a carga é aplicada diametralmente ao disco, sendo paralela ao plano do entalhe em todos os casos. 


\subsubsection{1.- Disco brasileiro com entalhe reto central submetido à compressão diametral- “Central Straight-through Cracked Brazilian Disk (CSCBD)"}

A Figura 40a mostra um entalhe reto no centro do disco que é cortado diametralmente. Muitos pesquisadores como Atkinson, Smelser e Sanchez (1982) e Shetty, Rosenfield e Duckworth (1986) usaram os corpos de prova com entalhe reto central $(C S C B D)$ para medir a tenacidade à fratura no modo I. Além disso, eles mediram o modo II e o modo misto I-II orientando a trinca com um determinado ângulo em relação à carga diametral tal que as envoltórias da tenacidade à fratura de materiais frágeis pudessem ser determinadas nos mesmos corpos de prova e nas mesmas condições de ensaio (SUN e OUCHTERLONY, 1990).

Atkinson, Smelser e Sanchez (1982) analisaram os corpos de prova com entalhe reto central representando a trinca como uma distribuição contínua dos deslocamentos nas bordas e simulando as descontinuidades nas componentes normais dos deslocamentos. Além disso, eles forneceram uma solução numérica para o fator de intensidade de tensão:

$K_{I}=\frac{P}{\sqrt{\pi R} B} x Y_{K}^{s}$

sendo:

$Y_{K}^{s}=\sqrt{\frac{a_{t}}{R}} N_{I}\left(\frac{a_{t}}{R}\right)$

onde:

$N_{I}\left(\frac{a_{t}}{R}\right):$ coeficiente adimensional em função de $a_{t} / R$;

$a_{t}$ : metade do comprimento da trinca;

$R$ : raio do corpo de prova;

$B$ : espessura do corpo de prova e

$P$ : carga aplicada.

Salienta-se que Atkinson, Smelser e Sanchez (1982) desenvolveram soluções para $N_{I}\left(\frac{a_{t}}{R}\right)$ considerando uma série dos cinco primeiros termos para $\frac{a_{t}}{R}$ variando de 0.1 a 0.6 .

Shetty, Rosenfield e Duckworth (1985) usaram um polinômio de terceiro grau para os resultados de Atkinson, Smelser e Sanchez (1982). O parâmetro $a_{t}$ é a metade do 
comprimento da trinca, $R$ é o raio do corpo de prova, $B$ a espessura do corpo de prova e $P$ a carga compressiva diametral. Shetty, Rosenfield e Duckworth (1985), com um erro de $0.1 \%$, chegaram à seguinte expressão:

$$
N_{I}\left(\frac{a_{t}}{R}\right)=0.99+0.14\left(\frac{a_{t}}{R}\right)+0.86\left(\frac{a_{t}}{R}\right)^{2}+0.89\left(\frac{a_{t}}{R}\right)^{3}
$$

Para comprimentos de entalhe relativamente pequenos $\left(\frac{a_{t}}{R} \leq 0.3\right)$, Atkinson, Smelser e Sanchez (1982) chegaram a um valor constante de $\mathrm{N}_{\mathrm{I}}=1$.

\subsubsection{Disco brasileiro com estria de aresta submetido à compressão diametral - "Single Edge Crack Brazilian Disk in diametral compression (SECBD)"}

A Figura 40b mostra esquematicamente a configuração do corpo de prova em disco com estria de aresta em compressão diametral. Este disco apresenta os seguintes parâmetros: $D$ é diâmetro do corpo de prova, $a_{0}$ é o comprimento da estria, $B$ é a espessura do corpo de prova, $2 \theta$ é o ângulo de distribuição de tensões e $b$ corresponde à largura da superfície aplainada de carregamento correspondente $(b=D \operatorname{sen} \theta)$.

O ensaio usando os corpos de prova com estria de aresta (SECBD) foi desenvolvido por Szendi-Horvath $(1980,1982)$ com o objetivo de determinar a tenacidade à fratura de materiais frágeis. A trinca é iniciada pela tensão de tração transversal resultante da compressão diametral. Os autores chegaram à seguinte expressão para $K_{I}$ (WHITTAKER; SINGH e SUN, 1992):

$$
K_{I}=1.264 \frac{F_{\text {máx }} \sqrt{a_{0}}}{B D}
$$

Essa expressão é válida para uma carga pontual, isto é, $\beta=0$. A tenacidade à fratura é obtida substituindo o valor da carga máxima aplicada $\left(F_{m a ́ x}\right)$ na Equação 149 , sendo as notações $a_{0}, B$ e $D$ aquelas mostradas na Figura 40.

Segundo Szendi-Horvath (1980), as equações do disco com estria de aresta são também aplicáveis ao corpo de prova com estrias de arestas duplas. Em suma, os corpos de prova com estria de aresta podem ser usados para determinar a tenacidade à fratura de materiais frágeis.

Singh e Pathan (1988) usaram este ensaio para determinar a tenacidade à fratura de uma grande variedade de rochas. Os efeitos das dimensões dos corpos de prova foram investigados extensivamente. Seus resultados indicaram que os valores de $K_{I C}$ 
eram independentes do comprimento da trinca, mas mostraram uma forte dependência da espessura do corpo de prova.

\subsubsection{Ensaio em disco modificado - "Modified disk test (MDT)"}

Outro corpo de prova baseado em disco entalhado foi proposto por Czoboly et al (1986) apud Whittaker, Singh e Sun (1992), que propôs um ensaio em disco modificado para determinar a tenacidade à fratura em rochas. A configuração do ensaio é ilustrada na Figura 41. A tensão de tração na região da ponta da trinca é resultante da força aplicada diretamente sob o entalhe.

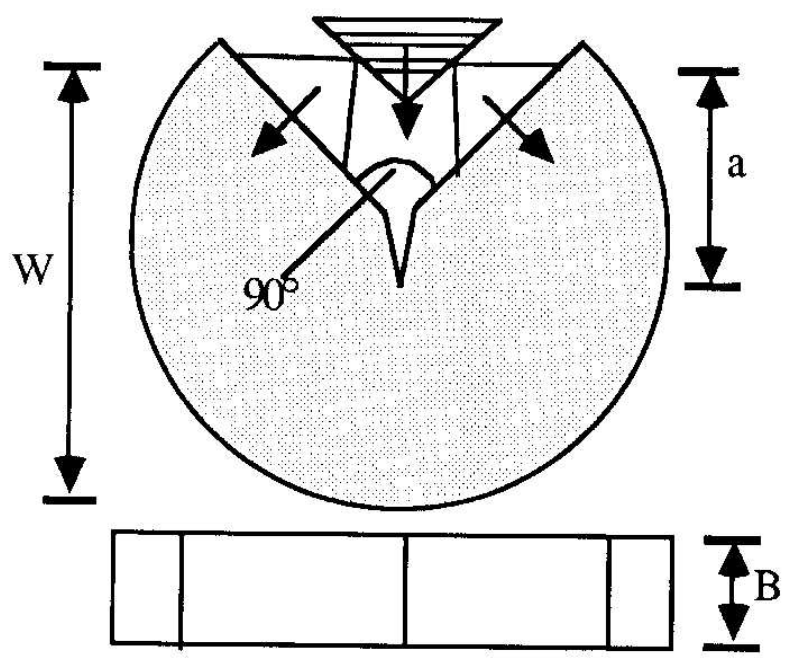

Figura 41 - Ensaio em disco modificado (WHITTAKER; SINGH e SUN, 1992)

\subsubsection{Ensaio em disco brasileiro aplainado - "Flattened Brazilian disk test (FDT)"}

Wang e Xing (1999) propuseram uma modificação ao corpo de prova do ensaio em disco brasileiro para ensaios da tenacidade à fratura em rochas. Esta modificação consiste em realizar no corpo de prova do ensaio brasileiro dois aplainamentos paralelos de igual largura sem necessidade de realizar qualquer tipo de entalhe, conforme apresentado na Figura 42. Estas superfícies planas facilitam o carregamento do corpo de prova.

Os resultados numéricos do fator de intensidade de tensão com corpos de prova em discos brasileiros aplainados são apresentados utilizando-se o método de elementos de contorno bidimensional (BEM). 
A fórmula para calcular a tenacidade à fratura $K_{I C}$ usando uma carga mínima local como ponto crítico é a seguinte:

$K_{I C}=\frac{P_{\min }}{\sqrt{R} B} x \phi_{\max }$

onde:

$P_{m i n}$ : carga aplicada local mínima (que pode ser identificada diretamente do registro do ensaio);

$R, B$ : raio e a espessura do corpo de prova, respectivamente;

$\phi_{\max }$ : fator de intensidade de tensão máximo adimensional (o qual é determinado para dois ângulos de carregamento, $20^{\circ}$ e $30^{\circ}$ ).

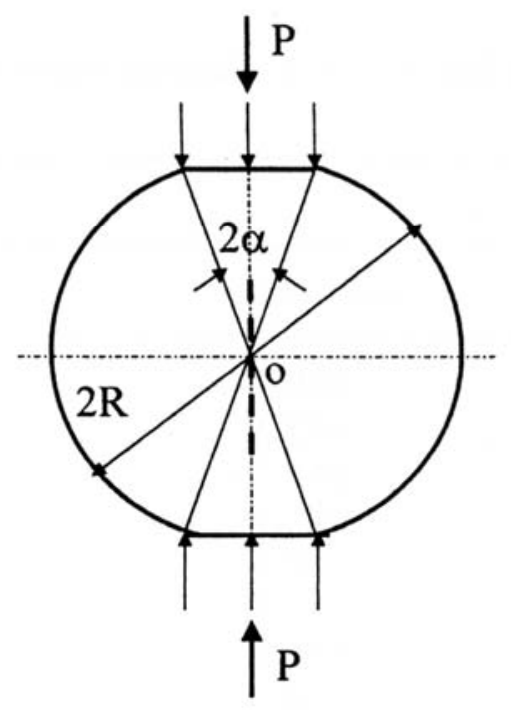

Figura 42 - Ensaio em disco brasileiro aplainado (WANG e XING, 1999).

\subsubsection{Ensaio em discos com entalhe na borda com partição por cunha - "Edge Notched Disc Wedge Splitting Test (END)”}

Donovan (2003) e Donovan e Karfakis (2004) propõem o ensaio em discos com entalhe na borda mediante um ensaio de partição por cunha devido a duas forças iguais e opostas (Figura 43) carregadas na boca da trinca, para a determinação rápida da tenacidade à fratura no modo I para uma classificação expedita e com fins comparativos. 


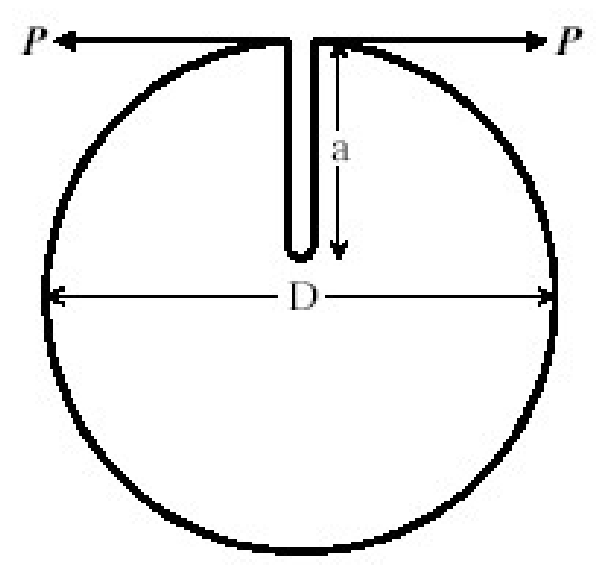

Figura 43 - Forças iguais e opostas geradas no corpo de prova (DONOVAN e KARFAKIS, 2004).

Uma força de compressão aplicada na cunha propaga o pré-entalhe (Figura 44). $\mathrm{O}$ ensaio requer que seja registrada somente a carga de pico. Os resultados do ensaio END não mostram nenhuma dependência com relação à velocidade de carregamento, mas mostram alguma dependência com o comprimento da trinca e o tamanho do grão.

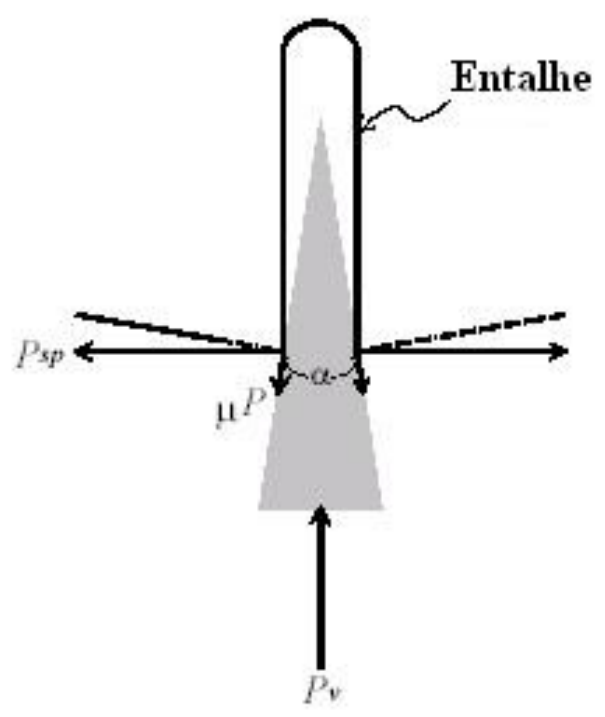

Figura 44 - Força de compressão aplicada por meio de uma cunha (DONOVAN e KARFAKIS, 2004).

Estes autores concluíram que a solução de Gregory (1979) fornece uma análise mais simples para $K$ dado que Gregory apresentou uma expressão para $F$ onde $K$ pode ser determinada precisamente para qualquer relação $a / D$. Baseados na solução de Gregory (1979) para determinar o fator de intensidade de tensão e $F$, eles calcularam a tenacidade à fratura usando a seguinte equação: 
$K_{I C}=2 \sqrt{\frac{D}{2 a}}\left[\frac{F_{v}}{2 \tan \left(\frac{\alpha}{2}\right)} * \frac{1-\mu \tan \left(\frac{\alpha}{2}\right)}{1+\mu \cot \left(\frac{\alpha}{2}\right)}\right]\left[\frac{a}{0.355715(D-a)^{3 / 2}}+\frac{1}{0.966528(D-a)^{1 / 2}}\right]$

onde:

$D$ : diâmetro do corpo de prova;

$a$ : comprimento da trinca;

$F_{v}$ : Força vertical aplicada;

$\alpha$ : ângulo da cunha;

$\mu$ : coeficiente de atrito na interface.

As seguintes equações foram propostas como requisitos do tamanho dos corpos de prova:

$\left.\begin{array}{c}a \\ D-a\end{array}\right\} \geq 2.5\left[\frac{K_{I C}}{\sigma_{t}}\right]^{2}$

e

$B \geq r_{m c}=0.269\left[\frac{K_{I C}}{\sigma_{t}}\right]^{2}$

onde:

$a$ : comprimento da trinca;

$D-a$ : comprimento do ligamento não fraturado;

$\sigma_{t}:$ resistência à tração;

$B$ : espessura do corpo de prova;

$r_{m c}$ : raio crítico da zona de processo da fratura $(F P Z)$ correspondente à distância radial medida a partir da ponta do pré-entalhe e

$K_{I C}$ : Fator de intensidade de tensão no modo I.

O corpo de prova END é colocado na cunha e a força vertical é aplicada sob o controle de deslocamento por uma máquina hidráulica servo-controlada de circuito fechado.

A carga e os dados do deslocamento da linha da carga ("load-line displacement") são registrados diretamente por um sistema de aquisição de dados. Os 
dados da carga-deslocamento foram registrados e convertidos em força de partição, e os dados $C M O D$ foram calculados para verificar se a carga máxima era também a carga crítica aplicada resultante da propagação da trinca.

Uma análise das curvas carga-deslocamento para todos os ensaios realizados por Donovan e Karfakis (2004), usando a aproximação secante de 5\%, permitiu a constatação que a carga aplicada crítica coincide com a carga máxima. Em cada caso, a carga máxima coincidiu com a propagação da trinca. Desta maneira, este ensaio foi proposto com fins comparativos e como uma avaliação rápida da tenacidade à fratura.

Para os ensaios sugeridos pela ISRM, a velocidade de carregamento não pode ser maior que $0,25 \mathrm{MPa} \sqrt{\mathrm{m}} / \mathrm{s}$ ou tais que a ruptura ocorra dentro dos 10 segundos.

Donovan e Karfakis (2004) recomendam que o deslocamento da linha de carregamento não seja maior que $0.0254 \mathrm{~mm} / \mathrm{seg}$, variando a velocidade de carregamento entre as taxas de $0.0254,0.003$ e $0.001 \mathrm{~mm} / \mathrm{seg}$ para o granito de grão maior.

De acordo com o ensaio de tenacidade à fratura no nível I, somente a carga máxima deve ser registrada para calcular $K_{I C}$. Entretanto, os dados da curva carga deslocamento devem ser registrados para verificar a que carga máxima corresponde a carga crítica aplicada resultante da propagação da trinca. A análise prévia de tensões requer que o END seja carregado na boca da trinca por forças iguais e opostas. Esta configuração de carregamento pode ser obtida simplesmente usando uma cunha.

O dispositivo de cunha usado para aplicar a força de partição ao longo da boca da trinca consiste de aço endurecido. O ângulo de cunha é de $11^{\circ}$ e a cunha fornece uma vantagem mecânica que se incrementa com ângulos de cunha menores. Entretanto, para o acunhamento de uma trinca em rocha, a quantidade de atrito entre o material da cunha e a rocha pode ser substancial, podendo ocorrer perdas friccionais. Para aplicar o ensaio $E N D$ aos ensaios de tenacidade à fratura em rochas, o coeficiente de atrito necessita ser quantificado para cada tipo de rocha ensaiada. Um ensaio "tilt test" foi usado para determinar $\mu$, onde o ângulo de deslizamento é $\phi$ e $\tan \phi$ é igual a $\mu$. Os coeficientes de atrito para os dois tipos de rochas e para o aço endurecido são apresentado na Tabela 4. abaixo:

Tabela 4. Valores de $\phi \mathrm{e} \mu$ a partir do ensaio "tilt test" na interface rocha/aço endurecido

\begin{tabular}{|c|c|c|}
\hline Rocha & $\phi$ & $\mu$ \\
\hline Basalto & $13.0^{\circ}$ & 0.2309 \\
\hline Granito & $10.5^{\circ}$ & 0.1853 \\
\hline
\end{tabular}




\subsubsection{Ensaio em disco brasileiro com duplo entalhe na borda - "Double Edge Cracked Brazilian disk test”}

Chen, Sun e Xu (2001) propõem um corpo de prova com duplo entalhe na borda sujeita a compressão diametral calculando os fatores de intensidade de tensão mediante emprego do método da função peso. A geometria do corpo de prova é mostrada na Figura 45a, onde $A$ é o comprimento da trinca, $R$ é raio do corpo de prova e $X$ é a coordenada com sua origem na abertura da trinca. Então, o comprimento da trinca normalizado e sua coordenada são, respectivamente, $a=A / R$ e $x=X / R$.

As distribuições de tensão devidas à compressão diametral nas faces das trincas em um disco brasileiro sem entalhe foram primeiramente calculadas e ajustadas com polinômios de diferentes ordens e logo foi aplicado o método semi-analítico da função peso para derivar o fator de intensidade de tensão no modo I $\left(f_{i}\right)$ para esta geometria. No cálculo de $f_{i}$, o ângulo $\theta$ da inclinação da trinca variou de $10^{\circ}$ a $90^{\circ}$, e o comprimento de trinca normalizado $a=A / R$ variou de 0,01 a 0,7 . Encontrou-se que os valores de $f_{i}$ foram negativos em um amplo intervalo de valores de $\theta$ e $a$. Considerando a existência do modo cisalhante nesta geometria, isto denota que o modo compressivo-cisalhante (Modo I-II) nas pontas das trincas podem ser facilmente obtidos usando a geometria proposta. Desde que este modo é necessário para uma propagação co-planar, ele pode ser usado para obter os valores relacionados de tenacidade à fratura no modo II de rochas frágeis.

O método semi-analítico da função peso consiste na determinação dos fatores de intensidade de tensão dos corpos de prova com distribuição de tensões complexas, resultando da integração do produto da função peso $h(x, a)$ e da distribuição de tensões $\sigma(x)$ atuando na face da trinca de um corpo finito (BÜECKNER (1970), RICE (1972) apud CHEN; SUN e XU, 2001):

$$
K=\int_{0}^{a} \sigma(x) h(x, a) d x
$$

A função peso $h(x, a)$ é definida como:

$$
h(x, a)=\frac{H}{K_{r}} \frac{\partial U_{r}}{\partial a}
$$

onde:

$H=E$ para tensão plana e

$H=\frac{E}{1-v^{2}}$ para deformação plana. 
$E$ : módulo de elasticidade;

$v$ : coeficiente de Poisson;

$K_{r}$ e $U_{r}$ : respectivamente, fatores de intensidade de tensão e deslocamentos da abertura da boca da trinca causados pela carga de referência.

Para o fator de intensidade de tensão no modo I no ensaio em disco brasileiro com duplo entalhe na borda submetido a compressão diametral, a tensão uniforme normal na face da trinca $(\sigma)$ é usualmente tomada como a carga de referência. Os fatores de intensidade de tensão de referência $\left(K_{r}\right)$ determinados por Rooke e Tweed (1973) apud Chen, Sun e Xu (2001) podem ser ajustados com os seguintes polinômios:

$f_{r}(a)=\frac{K_{r}}{\sigma \sqrt{\pi a R}}=\sum_{i=0}^{7} \alpha_{i} a^{i}$

onde $\alpha_{i}(\mathrm{i}=0,1,2, \ldots, 7)$ são $1.1213,0.8979,-1.5051,9.9934,-43.4420,87.6721$, 85.4498, 33.9741, respectivamente. Chen, Sun e Xu (2001) usaram o método da função peso de Wu e Carlsson (1991) para derivar os fatores de intensidade de tensão no modo I para a configuração proposta por eles.

De acordo com o procedimento, o deslocamento da abertura da boca da trinca normalizado causado pela carga de referência pode ser expresso como:

$u_{r}(x, a)=U_{r}(x, a) / R=\frac{\sigma a \sqrt{1-(x / a)}}{\sqrt{2} H} x \sum_{j=1}^{3} F_{j}(a)\left(1-\frac{x}{a}\right)^{j-1},(0 \leq x \leq a<1)$

onde $F_{j}(a)(j=1,2,3)$ pode ser determinado através dos fatores de intensidade de tensões $\left(f_{r}(a)\right)$ como segue:

$$
\begin{aligned}
& F_{1}(a)=4 f_{r}(a) \\
& F_{2}(a)=\frac{35 \sqrt{2}}{12} \Phi(a)-8 f_{r}(a) \\
& F_{3}(a)=\frac{28}{15} f_{r}(a)-\frac{7 \sqrt{2}}{12} \pi \Phi(a) \\
& \Phi(a)=\frac{1}{a^{2}} \int_{0}^{a} s\left[f_{r}(s)\right]^{2} d s
\end{aligned}
$$

Conseqüentemente, a função peso é da seguinte forma:

$h(x, a)=\frac{1}{\sqrt{2 \pi a}} \sum_{i=1}^{4} \beta_{i}(a)\left(1-\frac{x}{a}\right)^{i-3 / 2}$

onde: 
$\beta_{1}(a)=2$

$\beta_{2}(a)=\left[4 a f_{r}^{\prime}(a)+2 f_{r}(a)+1.5 F_{2}(a)\right] / f_{r}(a)$

$\beta_{3}(a)=\left\{a F_{2}^{\prime}(a)+0.5\left[5 F_{3}(a)-F_{2}(a)\right]\right\} / f_{r}(a)$

$\beta_{4}(a)=\left[a F_{3}^{\prime}(a)-1.5 F_{3}(a)\right] / f_{r}(a)$

$F_{i}(\mathrm{i}=1,2,3)$ podem ser calculados a partir de $f_{r}(a)$. Os valores de intensidade de tensão $\beta_{i}(a)(\mathrm{i}=1,2,3,4)$ para diferentes valores de comprimento de trinca $(a)$ são dados por Wu e Carlsson (1991) apud Chen, Sun e Xu (2001).

O método aplicado é útil em análises de fraturas, especialmente para condições complexas de carregamento. Adicionalmente, com o procedimento de preparação da amostra estabelecido por este método, é fácil de se obter a geometria do corpo de prova, podendo o mesmo ser usado amplamente em pesquisas relativas ao processo de fratura de materiais frágeis, tais como rochas, materiais cerâmicos e concretos.
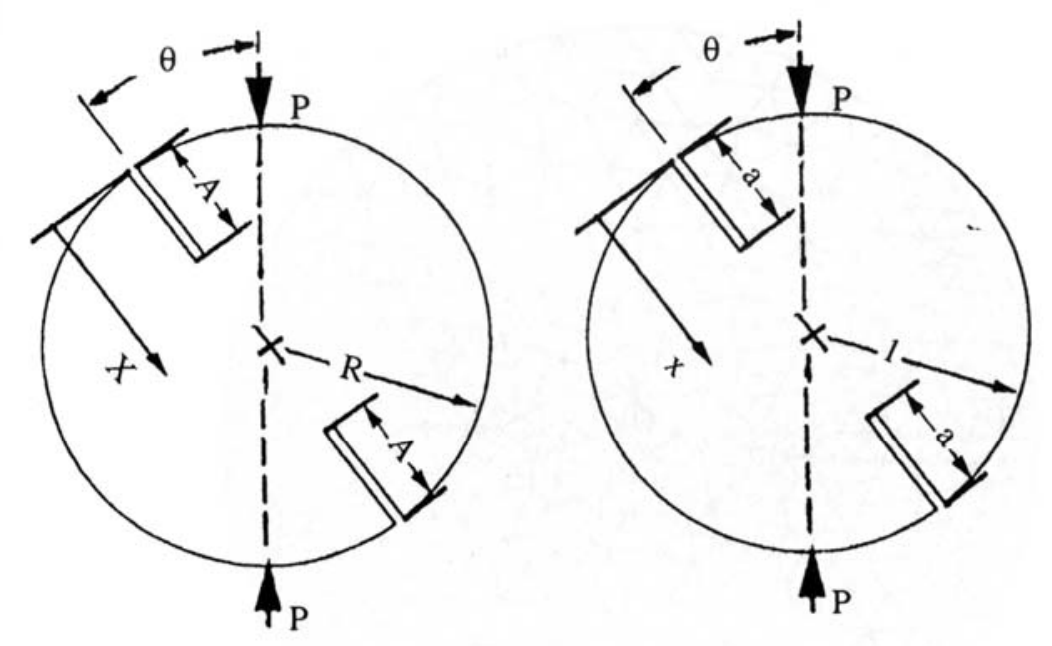

Figura 45 - a) Geometria do corpo de prova, b) Carregamento do corpo de prova (CHEN; SUN e XU, 2001)

\subsubsection{Ensaio em corpos de prova curtos com entalhe em "Chevron" submetidos a condições simuladas de pressão e temperatura}

Roegiers e Zhao (1991) realizaram ensaios de laboratório para medir a tenacidade à fratura submetida a condições simuladas de pressão e temperatura. Um problema inerente associado com a determinação in situ da tenacidade à fratura das 
rochas a partir de ensaios de fraturamento hidráulico consiste na difícil avaliação da sua precisão.

Os autores empregaram corpos de prova em forma de discos brasileiros tipo "Chevron" (CDISK) como mostra a Figura 46, ignorando-se as tensões térmicas e considerando-se que o único fator que influencia na distribuição de tensões ao redor da trinca é a pressão de confinamento.

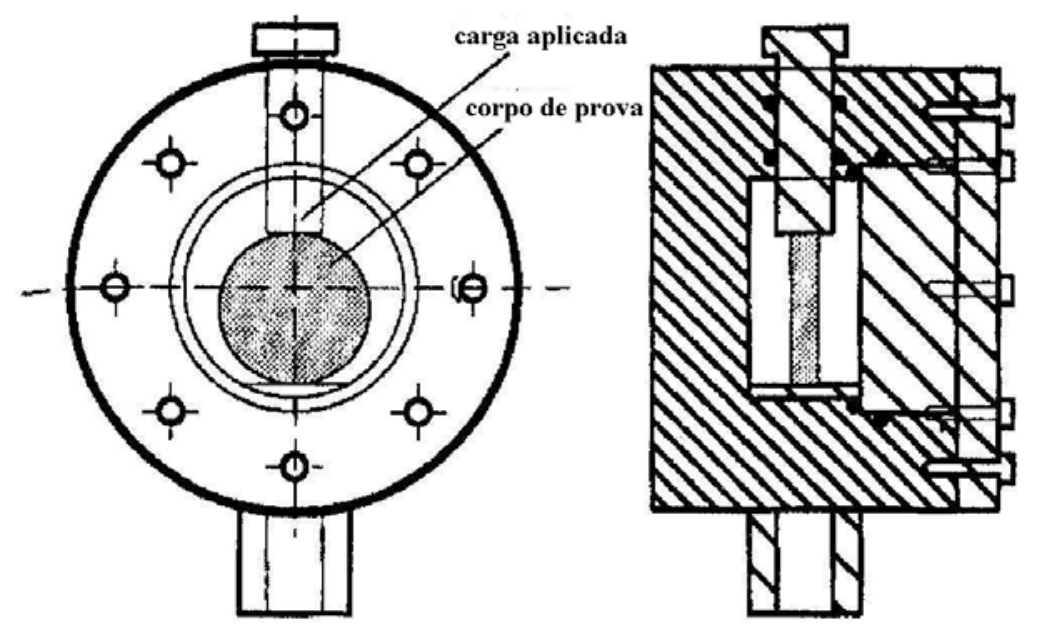

Figura 46 - Disposição do corpo de prova e a célula de carga utilizada no ensaio (ROEGIERS e ZHAO, 1991)

Eles usaram as seguintes rochas: arenito Berea de grão fino e o calcário Indiana. Todos os corpos de prova possuíam raio de $79.4 \mathrm{~mm}(R)$ e espessura de $19.1 \mathrm{~mm}(B)$, com uma trinca na superfície de $53.3 \mathrm{~mm}$ cortada com uma serra de raio $38.1 \mathrm{~mm}\left(R_{s}\right)$. Os corpos de prova foram secados a $110^{\circ} \mathrm{C}$ por 5 horas e posteriormente resfriados antes do ensaio para minimizar os possíveis efeitos da umidade.

As variáveis foram:

(i) Pressão de confinamento: 0.0,12.06, 24.13, 36.19 e $48.26 \mathrm{MPa}$

(ii) Temperatura: $26^{\circ} \mathrm{C}$ (temperatura ambiente) e $66^{\circ} \mathrm{C}$.

(iii) tempo de saturação: 96 horas.

Uma célula de pressão foi especificamente desenhada para estes ensaios (Figura 46). Um atuador servo-controlado de $70 \mathrm{MPa}$ foi usado para exercer a pressão confinante. $\mathrm{O}$ calor foi produzido por uma correia de aquecimento, a qual é presa ao redor da célula. 
Foi utilizada uma máquina hidráulica servo-controlada com velocidade de carregamento de $0.023 \mathrm{~cm} / \mathrm{min}$ até a carga máxima, sendo registradas as cargas e os deslocamentos da ponta da trinca.

Para os corpos de prova com entalhe tipo "Chevron", a tenacidade à fratura $\left(K_{I C}\right)$ pode ser determinada conhecendo-se a carga máxima aplicada $\left(F_{\text {máx }}\right)$ :

$$
K_{I}=\frac{F_{m a x}}{B \sqrt{W}} Y_{m}^{*}
$$

onde

$Y_{m}^{*}$ : coeficiente da intensidade de tensão mínima;

$B$ : espessura do corpo de prova e

$W$ : largura do corpo de prova.

Baseado em um método simples dado por Munz, Bubsey e Shannon (1980) apud Roegiers e Zhao (1991), foi encontrada uma relação entre os coeficientes de intensidade de tensão para discos com um entalhe reto e com um entalhe "chevron", a qual poderia ser expressa como (ZHAO e ROEGIERS, 1990):

$$
Y^{*}=\frac{Y}{\sqrt{k}}
$$

onde:

$Y^{*}$ : coeficiente do fator de intensidade de tensão para um entalhe "chevron";

$Y$ : coeficiente do fator de intensidade de tensão para um entalhe reto;

$$
k=1+\frac{2 R\left(\left(\Re^{2}-\alpha_{1}^{2}\right)^{1 / 2}-\left(\Re^{2}-\alpha^{2}\right)^{1 / 2}\right)}{B}
$$

$\alpha=a / R$

$\alpha_{1}=a_{1} / R$;

$\mathfrak{R}=R_{S} / R$ e

$R_{S}$ : raio da serra.

Para as soluções dadas por Yarema e Krestin (1966) e Libatskii e Kovchik (1967) apud Roegiers e Zhao (1991), para o corpo de prova com entalhe "chevron” obtém-se a seguinte expressão:

$$
Y^{*}=\sqrt{\frac{\alpha}{k}}\left(1+\frac{3}{2} \alpha^{2}+\frac{3}{4} \alpha^{6}+\frac{3}{64} \alpha^{8}\right)
$$

Os coeficientes de intensidade de tensão mínimo $\left(Y_{m}{ }^{*}\right)$ podem ser determinados mediante a expressão acima mostrada. 
Se as pressões termais são ignoradas, o único fator que influi na distribuição de tensões ao redor da trinca é a pressão confinante.

Utilizando o principio de superposição, o fator de intensidade de tensão para qualquer condição de carregamento é obtido por:

$K_{I}=K_{I}^{u}+K_{I}^{c}$

onde:

$K_{I}^{u}$ : fator de intensidade de tensão devido ao carregamento vertical;

$K_{I}^{c}$ : fator de intensidade de tensão devido à pressão de confinamento.

$K_{I}^{u}$ pode ser determinado pelas equações (167) e (168). Para calcular $K_{I}^{c}$, o corpo de prova sob condições de pressão confinante é considerado como um corpo infinito contendo uma trinca pressurizada e submetida a um campo de tensões similar. Assim, introduzindo o resultado apresentado por Rummel e Winter (1983) apud Roegiers e Zhao (1991), tem-se a seguinte expressão:

$K_{I}^{c}=-2 \sigma_{c} \sqrt{a_{0}} \sqrt{\frac{\rho^{2}-1}{\pi \rho^{3}}}$

onde:

$K_{I}^{c}$ : fator de intensidade de tensão devido à pressão de confinamento;

$\sigma_{c}$ : pressão de confinamento;

$a_{0}$ : comprimento inicial do entalhe e

$\rho=a / a_{0}$.

A fórmula acima apresentada é utilizada para calcular a tenacidade à fratura para o caso de um entalhe reto. Seguindo o mesmo procedimento, a tenacidade à fratura de um disco com entalhe "chevron" pode ser calculada mediante a seguinte expressão:

$$
K_{I}^{c}=-2 \sigma_{c} \sqrt{\frac{a_{0}}{k}} \sqrt{\frac{\rho^{2}-1}{\pi \rho^{3}}}
$$

\subsection{Relações empíricas para a determinação da tenacidade à fratura}

Com referência às derivações dos diferentes parâmetros para determinação da tenacidade à fratura apresentados no Capítulo 2, sabe-se que estes parâmetros estão relacionados entre si mediante a seguinte expressão: 


$$
K_{I C}=\sqrt{E^{\prime} G_{I C}}=\sqrt{2 E^{\prime} \gamma_{e f f}}
$$

onde:

$E^{\prime}=E$ ou $E^{\prime}=E /\left(1-v^{2}\right)$, dependendo de se tratar de um estado plano de tensões ou de um estado plano de deformação.

Desta equação, é evidente que a tenacidade à fratura está relacionada diretamente com as constantes elásticas das rochas, e também dependente das outras propriedades físico-mecânicas. Apresentam-se, na seqüência, algumas correlações empíricas encontradas na literatura.

Gunsallus e Kulhawy (1984); Bhagat (1985) verificaram experimentalmente que o modo I da tenacidade à fratura de diferentes tipos de rochas e solos é diretamente proporcional à resistência à tração. Além disso, Whittaker, Singh e Sun (1992) obtiveram algumas relações aproximadas entre a tenacidade à fratura, a resistência à tração, a resistência à compressão, o esforço de carga pontual, a dureza e a velocidade de onda acústica das rochas com base nos dados experimentais encontrados na bibliografia. Depois disso, Bearman (1999) investigou experimentalmente a relação entre o Modo I da tenacidade à fratura e o esforço de carga pontual. Brown e Redish (1997) exploraram a relação experimental entre a tenacidade à fratura no modo I e a densidade.

\subsubsection{Relação empírica entre o Modo I da tenacidade à fratura e a resistência à tração em rochas}

De acordo com Whittaker, Singh e Sun (1992), a relação entre a tenacidade à fratura no modo I e a resistência à tração de vários tipos de rochas, inclusive carvão, pode ser expressa por:

$\sigma_{t}=9.35 K_{I C}-2.53$

onde:

$\sigma_{t}$ : resistência à tração $(\mathrm{MPa}) \mathrm{e}$

$K_{I C}$ : tenacidade à fratura no modo I $\left(\mathrm{MPa} \cdot \mathrm{m}^{1 / 2}\right)$.

A equação acima apresenta um coeficiente de correlação de 0.62 .

Zhang et al (1998), fazendo uso dos próprios dados experimentais, obtiveram uma relação entre a tenacidade à fratura no Modo I e a resistência à tração para vários tipos de rochas: 
$\sigma_{t}=8.88 K_{I C}{ }^{0.62}$

A equação acima apresenta um coeficiente de correlação de 0.94 .

Com base nos resultados experimentais de Whittaker, Singh e Sun (1992), Zhang et al (1998), Khan e Al-Shayea (2000), Yu (2001) e Norlund, Li e Carlsson (1999); Zhang (2002) encontrou que a tenacidade à fratura no Modo I e a resistência à tração das rochas podem ser empiricamente relacionadas pela equação: $\sigma_{t}=6.88 K_{I C}$

A equação acima apresenta um coeficiente de correlação de 0.94 .

Esta equação deveria ser válida para rochas brandas a duras sob condições quase-estáticas ou carregamentos de baixa velocidade.

Experimentalmente, a medida da tenacidade à fratura da rocha é mais complicada e mais cara que um ensaio para obter a resistência à tração. Desta forma, relações como as mostradas nas equações (173), (174) e (175), são úteis para estimar a tenacidade à fratura a partir dos valores de resistência à tração, os quais podem ser medidos mais facilmente.

\subsubsection{Relação empírica entre o Modo I da tenacidade à fratura e a resistência à compressão uniaxial}

Segundo Gunsallus e Kulhawy (1984), uma relação empírica entre a tenacidade à fratura da rocha e as propriedades índices mais comumente medidas poderia ser útil. Uma relação entre a tenacidade à fratura e alguns dos outros ensaios pode ser estabelecida devido à predominância da fratura em suas formas de ruptura. Conseqüentemente, estes autores realizaram análises estatísticas de mínimos quadrados e regressões lineares entre os resultados experimentais para a determinação da tenacidade à fratura em função da resistência à compressão uniaxial, do índice de carga pontual e da resistência à tração indireta das rochas.

Estes autores obtiveram a seguinte equação de regressão linear que relaciona a tenacidade à fratura no modo $\mathrm{I}\left(K_{I C}\right)$ e a resistência à compressão uniaxial:

$K_{I C}=1.04+0.0044 \sigma_{c}$

onde:

$\sigma_{c}$ : resistência à compressão uniaxial $(\mathrm{MPa}) \mathrm{e}$ 
$K_{I C}$ : tenacidade à fratura no modo I $\left(\mathrm{MPa} \cdot \mathrm{m}^{1 / 2}\right)$.

Salienta-se que a equação acima apresenta um coeficiente de correlação de 0.72 .

Segundo Whittaker, Singh e Sun (1992), a tenacidade à fratura no modo I $\left(K_{I C}\right)$ e no modo II $\left(K_{I I C}\right)$ geralmente aumenta com o incremento da resistência à compressão uniaxial.

As equações de regressão linear obtidas por estes autores foram as seguintes:

$K_{I C}=0.708+0.006 \sigma_{c}$

$K_{\text {IIC }}=0.114+0.005 \sigma_{c}$

onde:

$K_{I I C}$ : tenacidade à fratura no modo II $\left(\mathrm{MPa}^{1 / 2}\right)$.

Salienta-se que as equações acima apresentam coeficientes de correlação de 0.72 e 0.83 , respectivamente.

É interessante notar que o fenômeno apresentado no incremento da tenacidade à fratura com o aumento da resistência compressiva tem sido também observado no comportamento do concreto por John e Shah (1987) apud Whittaker, Singh e Sun (1992).

Alternativamente, Fong e Nelson (1986) apud Whittaker, Singh e Sun (1992) determinaram a variação crítica de liberação de energia e as resistências à tração e a compressão para um número de rochas e encontraram relações entre elas. Isto mostra que um aumento na resistência (tração ou compressão) conduz a um aumento na variação crítica da liberação de energia de deformação.

As equações de regressão linear obtidas foram as seguintes:

$G_{I C}=39.588+3.136 \sigma_{\mathrm{t}}$

$G_{I C}=33.769+0.267 \sigma_{\mathrm{c}}$

onde:

$\sigma_{t}:$ resistência a tração $(\mathrm{MPa}) \mathrm{e}$

$G_{I C}$ : taxa crítica da liberação de energia de deformação no modo I (N/m).

Salienta-se que as equações acima apresentam coeficientes de correlação de 0.62 e 0.69 , respectivamente. 


\subsubsection{Relação empírica entre o Modo I da tenacidade à fratura e a resistência à carga pontual}

O ensaio de carga pontual baseia-se no princípio do esforço de tração induzido dentro do corpo pela aplicação de uma força pontual compressiva. Os corpos de prova de forma cilíndrica ou irregular são carregados até a ruptura, empregando uma carga pontual através de ponteiras cônicas.

$\mathrm{O}$ ensaio de carga pontual tem sido freqüentemente considerado como uma medição indireta da tração uniaxial ou resistência compressiva da rocha (BROCH e FRANKLIN, 1972). Este ensaio é amplamente usado na prática devido a seus simples requisitos de ensaio e a seus campos potenciais de aplicações (GUNSALLUS e KULHAWY, 1984).

Para predizer a tenacidade à fratura no modo I de rochas a partir de suas relações com sua resistência, Gunsallus e Kulhawy (1984) determinaram a tenacidade à fratura no modo I, a resistência à tração, a resistência à compressão e a resistência à carga pontual para uma ampla variedade de rochas. Uma análise de correlação mostra relações próximas entre a tenacidade à tração e a compressão, tão boas como a resistência à carga pontual.

Gunsallus e Kulhawy (1984) propuseram a seguinte equação:

$K_{I C}=\left(0.0995 I_{s(50)}\right)+1.11$

onde

$I_{s(50)}$ : resistência à carga pontual $(\mathrm{MPa}) \mathrm{e}$

$K_{I C}$ : tenacidade à fratura no Modo I $\left(\mathrm{MPa} \cdot \mathrm{m}^{1 / 2}\right)$.

O coeficiente de correlação obtido foi de 0.67. Salienta-se que estes autores estudaram dolomitos, siltitos e arenitos.

Em outro estudo, Bearman (1991) examinou a correlação entre a tenacidade à fratura no Modo I e a resistência ao carregamento pontual usando o método $C B$ sugerido pela $I S R M$ (1988). Ele propôs, como resultado, a seguinte equação:

$K_{I C}=\left(0.199 I_{s(50)}\right)$ ou $K_{I C} \approx 0.2 I_{s(50)}$

O coeficiente de correlação para esta equação foi de 0.948 . Salienta-se que este autor estudou dolomitos, arenitos, granitos, andesitos, dioritos, grauvacas e quartzitos.

É possível que a diferença entre os coeficientes obtidos nestes estudos possa ser atribuída às diferentes rochas usadas. Bearman (1991) usou tipos de rochas consideradas 
geralmente como homogêneas com valores de tenacidade à fratura que variavam de 0,732 a 2,770 MPa.m ${ }^{1 / 2}$. A anisotropia era cuidadosamente observada e a orientação do corpo de prova durante o ensaio era uniforme para os ensaios da determinação da tenacidade à fratura e o ensaio de carga pontual. Contudo, Gunsallus e Kulhawy (1984) usaram rochas com valores de tenacidade à fratura que variavam de 1,36 a 2,47 MPa.m $\mathrm{m}^{1 / 2}$, não sendo, contudo, conhecido o grau de anisotropia de seu estudo.

O estudo original de Bearman (1991), do qual a equação (182) foi proposta, restringiu-se a corpos de prova cilíndricos carregados diametralmente. A fim de calibrar a extensão e a confiabilidade da relação, o autor revisou esse estudo usando corpos de prova cilíndricos carregados axialmente, corpos irregulares e prismáticos, além dos corpos de prova carregados diametralmente. A inclusão destes corpos de prova adicionais alterou ligeiramente o coeficiente empírico, mas não afetou o significado estatístico da relação.

A relação obtida nesse estudo foi:

$$
K_{I C}=0.209 I_{S(50)}
$$

Segundo Bearman (1999), a relação empírica para ensaios de carga pontual de corpos de prova carregados diametralmente pode ser indicada como:

$$
K_{I C}=\frac{29.84 F}{D^{3 / 2}}
$$

onde

$F$ : força na ruptura $(\mathrm{kN})$;

$D$ : distância entre os pontos da carga pontual (mm) e

$K_{I C}$ : tenacidade à fratura no modo I $\left(\mathrm{MPa} \cdot \mathrm{m}^{1 / 2}\right)$.

Para ensaios com corpos de prova irregulares ou carregados axialmente, a relação empírica é:

$$
K_{I C}=\frac{26.56 F}{(W D)^{3 / 4}}
$$

onde

$W$ : largura do corpo de prova ensaiado $(\mathrm{mm})$;

$F$ : força na ruptura $(\mathrm{kN})$;

$D$ : distância entre as pontas cônicas (mm) e

$K_{I C}$ : tenacidade à fratura no modo I $\left(\mathrm{MPa}^{\mathrm{m}} \mathrm{m}^{1 / 2}\right)$. 
Para os ensaios realizados por Bearman (1999), a configuração de ensaio mais favorável em termos de consistência, repetibilidade e menores fraturas inválidas é o ensaio com corpos de prova axiais. O corpo de prova diametral pode ficar desalinhado e em superfícies de rochas brandas as pressões tendem a dispersar-se e, conseqüentemente, as fraturas são consideradas inválidas.

\subsubsection{Relação empírica entre o Modo I da tenacidade à fratura e o módulo de elasticidade (E)}

Segundo Whittaker, Singh e Sun (1992), a relação existente entre o módulo de elasticidade $(E)$ e a tenacidade à fratura no modo I $\left(K_{I C}\right)$ e no modo II $\left(K_{I I C}\right)$ parecem similares àqueles entre a tenacidade à fratura e a resistência. Um incremento no valor do módulo de elasticidade resulta em um aumento da tenacidade à fratura

As equações de regressão linear obtidas foram as seguintes:

$K_{I C}=0.336+0.026 E$

$K_{I I C}=0.251+0.018 E$

onde:

$E$ : módulo de elasticidade (GPa);

$K_{I C}$ : tenacidade à fratura no modo $\mathrm{I}\left(\mathrm{MPa} \cdot \mathrm{m}^{1 / 2}\right) \mathrm{e}$

$K_{I I C}$ : tenacidade à fratura no modo II $\left(\mathrm{MPa}^{1 / 2}{ }^{1 / 2}\right)$.

Salienta-se que as equações acima apresentam coeficientes de correlação de 0.85 e 0.87 , respectivamente.

O fenômeno crescente da tenacidade à fratura com o incremento do módulo de elasticidade foi estudado também em vidros reforçados por Swearenger, Beauchamp e Eagan (1978) apud Whittaker, Singh e Sun (1992).

\subsubsection{Relação empírica entre o Modo I da tenacidade à fratura e o coeficiente de Poisson (v)}

Segundo Whittaker, Singh e Sun (1992), as relações existentes entre o coeficiente de Poisson $(v)$ e a tenacidade à fratura no modo I $\left(K_{I C}\right)$ e no modo II $\left(K_{I I C}\right)$ 
parecem relativamente pobres quando comparadas àquelas entre a tenacidade à fratura $\mathrm{e}$ a resistência e o módulo de elasticidade.

As equações de regressão linear obtidas foram as seguintes:

$K_{I C}=0.991+1.653 v$

$K_{I I C}=-1.249+7.814 v$

onde:

$v$ : coeficiente de Poisson;

$K_{I C}$ : tenacidade à fratura no modo I $\left(\mathrm{MPa}^{1 / 2}\right) \mathrm{e}$

$K_{\text {IIC }}$ : tenacidade à fratura no modo II $\left(\mathrm{MPa}^{\mathrm{m}} \mathrm{m}^{1 / 2}\right)$.

Salienta-se que as equações acima apresentam coeficientes de correlação de 0.21 e 0.47 , respectivamente.

A dispersão experimental pode ter sido parcialmente responsável pelas pobres relações entre a tenacidade à fratura e o coeficiente de Poisson. Entretanto, quando comparadas com outras relações de tenacidade à fratura com outros parâmetros físicomecânicos, as pobres relações entre a tenacidade à fratura e o coeficiente de Poisson podem implicar na expectativa de que a tenacidade à fratura não esteja relacionada com a deformação horizontal das rochas.

\subsubsection{Relação empírica entre o Modo I da tenacidade à fratura e a velocidade de onda acústica $\left(V_{P}\right)$}

Segundo Huang e Wang (1985), a velocidade acústica varia com a composição mineral, a densidade, a porosidade e, especialmente, o grau de fratura e de trincamento. Conseqüentemente, considerando-se o fato de que a tenacidade à fratura representa a resistência do material à fratura, é de se supor que a onda de velocidade acústica pode representar a resistência da rocha à fratura ou à ruptura melhor que qualquer outra propriedade físico-mecânica.

Whittaker, Singh e Sun (1992) apresentam uma relação entre a velocidade de onda sônica $\left(V_{P}\right)$ e a tenacidade à fratura no modo I $\left(K_{I C}\right)$ e no modo II $\left(K_{I I C}\right)$.

As equações de regressão linear obtidas foram as seguintes:

$K_{I C}=-1.68+0.65 V_{P}$ 
$K_{I I C}=-1.15+0.45 V_{P}$

onde:

$V_{P}$ : velocidade de onda acústica $(\mathrm{Km} / \mathrm{s})$;

$K_{I C}$ : tenacidade à fratura no modo $\mathrm{I}\left(\mathrm{MPa}^{1 / 2}\right) \mathrm{e}$

$K_{I I C}$ : tenacidade à fratura no modo II $\left(\mathrm{MPa}^{1 / 2}{ }^{1 / 2}\right)$.

Salienta-se que as equações acima apresentam coeficientes de correlação de 0.90 e 0.84 , respectivamente.

\subsubsection{Relação empírica entre o Modo I da tenacidade à fratura e a densidade $(\rho)$}

Brown e Reddish (1997) estudaram diferentes tipos de rochas (granito, tonelita, dolerito, anortito, norito, basalto, siltito, arenito, quartzito, mármore e calcáreo). Para cada tipo de rocha, foram preparados 10 corpos de prova de aproximadamente $37 \mathrm{~mm}$ de diâmetro e um comprimento nominal de $200 \mathrm{~mm}$. Estes corpos de prova foram ensaiados sob as condições e as exigências do ensaio Chevron Bend $(C B)$ sob o nivel I sugerido pela ISRM (1988). A geometría do corpo de prova foi medida para verificar as dimensões e as tolerâncias requeridas. Entretanto, em alguns casos de granitos e anortitos, alguns dos tamanhos de graõs constituintes excederam ligeiramente a relação 10:1 sugerida como diâmetro máximo, embora fosse improvável que esta relação tenha afetado significativamente os resultados.

$\mathrm{O}$ corpo de prova com o valor de tenacidade à fratura mais próximo da média, para cada tipo de rocha, tinha aproximadamente $200 \mathrm{~g}$. As densidades foram determinadas a partir da metade dos corpos de prova, medindo-se o peso por volume medido sob condições ambientais. Os diâmetros dos corpos de prova foram determinados calculando-se a média de quatro medidas igualmente espaçadas, sendo todas as dimensões tomadas o mais próximo possível de $0.01 \mathrm{~mm}$.

Segundo Brown e Reddish (1997), a tenacidade à fratura de uma rocha homogênea está linearmente relacionada com a densidade da seguinte forma:

$K_{I C}=3.21 \rho-6.95$

onde:

$\rho$ : densidade $\left(\mathrm{g} / \mathrm{cm}^{3}\right)$ e

$K_{I C}$ : tenacidade à fratura no modo I $\left(\mathrm{MPa}^{1 / 2}{ }^{1 / 2}\right)$. 
Bearman (1991) apud Brown e Reddish (1997), usando o mesmo método de ensaio, mostrou também uma tendência entre a tenacidade à fratura da rocha e a densidade. Uma representação matemática daqueles dados é apresentada na seqüência, entretanto, há uma dispersão mais significativa dos resultados.

A equação de regressão linear obtida foi a seguinte:

$K_{I C}=3.35 \rho-6.87$

onde:

$\rho$ : densidade $\left(\mathrm{g} / \mathrm{cm}^{3}\right)$ e

$K_{I C}$ : tenacidade à fratura no modo I $\left(\mathrm{MPa}^{\mathrm{m}} \mathrm{m}^{1 / 2}\right)$.

Salienta-se que a equação acima apresenta coeficiente de correlação de 0.70 . 


\section{ENSAIOS REALIZADOS E RESULTADOS OBTIDOS}

\subsection{Introdução}

Neste capítulo são apresentados os ensaios realizados e os resultados obtidos nas amostras selecionadas (basalto e granito). Primeiro, realizaram-se as análises petrográficas a nível macroscópico e a nível microscópico das rochas estudadas. Logo, caracterizaram-se as amostras mediante ensaios para determinar suas propriedades físicas e mecânicas. Descreve-se a preparação, instrumentação e execução dos ensaios, com a finalidade de compreender e verificar os mecanismos de propagação das trincas, segundo diferentes tipos de carregamentos, geometrias e tipos de entalhes realizados nos corpos de prova. Apresentam-se os resultados experimentais e uma curva típica de cada tipo de ensaio, com a finalidade de mostrar o comportamento do material sob diferentes solicitações.

\subsection{Descrição petrográfica das rochas}

A descrição petrográfica de uma amostra tem por objetivo estimar as características mecânicas das rochas. Esta descrição consta de duas partes:

1) A descrição macroscópica que consiste em fazer uma descrição das propriedades da rocha que podem ser importantes para estimar o comportamento mecânico da mesma e que são determinadas por meio de uma inspeção visual direta ou com ajuda de uma lente de pouco aumento. Isto inclui a cor, a tenacidade, a textura, o grau de alteração ou intemperismo, o tamanho de grão, as análises quantitativa e qualitativa do fraturamento, os sistemas e redes de fraturas, a porosidade, as reações químicas que permitam a determinação de alguns dos minerais, por exemplo, a reação do ácido clorídrico com o carbonato de cálcio, etc. 
2) A descrição microscópica inclui a determinação de todos os parâmetros que não podem ser determinados no estudo macroscópico do material, a saber, o conteúdo de mineral, o tamanho de grão e a textura da rocha. O método empregado no estudo microscópico de materiais translúcidos é o uso de seções delgadas e luz refratária; os materiais opacos podem ser cortados e polidos e, logo, fazer-se uso de técnicas de luz reflexa. Para assegurar uma correta classificação, o primeiro passo é averiguar a composição mineralógica e a textura da rocha. Estudos mais completos incluíram a fábrica ou arranjo dos minerais e análises mineralógicas (no caso de rochas fortemente anisotrópicas), a determinação do grau de alteração ou intemperismo, o tamanho e a forma de grão, o microfraturamento e a porosidade.

As amostras estudadas pertencem a dois tipos diferentes de rochas: basalto e granito. Estas rochas foram selecionadas em função de suas características de homogeneidade e isotropia e também pela facilidade de obtenção na região de São Carlos.

O basalto da Formação Serra Geral foi extraído da pedreira Santa Luiza no município de Descalvado (SP). Esta rocha apresenta coloração cinza escura, com uma estrutura isotrópica e compacta. Sua textura é fanerítica fina, de granulação submilimétrica, com granulação variável de 0,1 a 0,6 mm e, predominantemente, entre 0,2 a $0,3 \mathrm{~mm}$. O material vítreo ocorre tanto sob forma intersticial quanto constituindo esparsas amorfas, com formas irregulares e alongadas, com dimensões que podem superar 2,0 mm e que se irradiam intersticialmente, conforme mostrado na Figura 47.

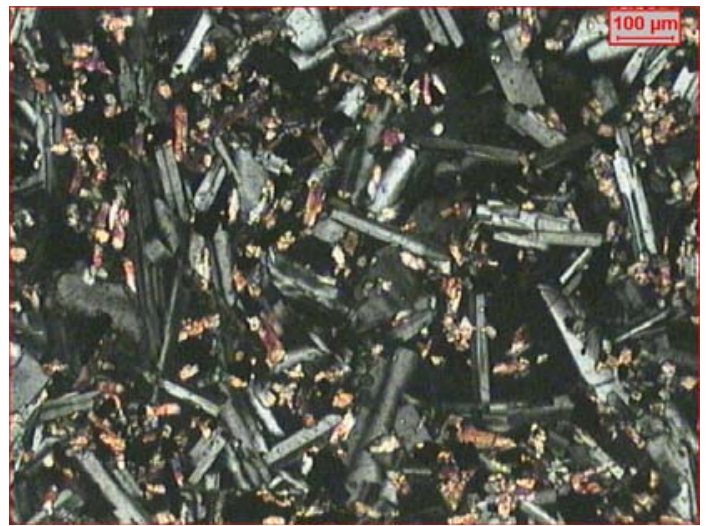

(a)

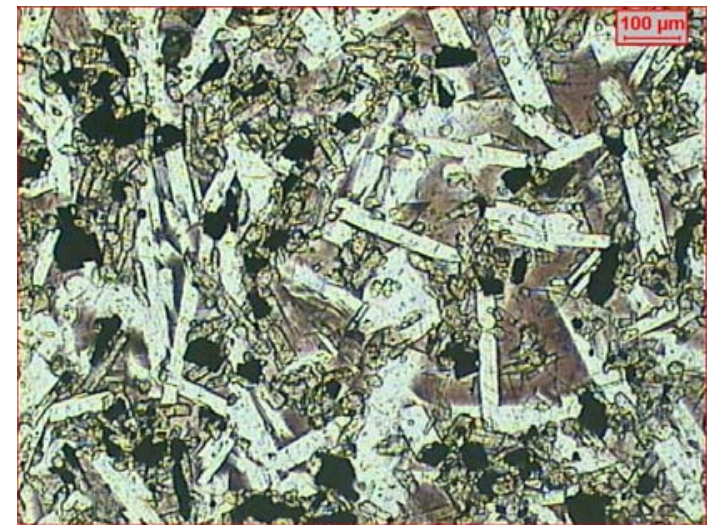

(b)

Figura 47 - Foto micrografia do basalto obtida via microscópio ótico por transmissão: (a) nicoles cruzados (b) nicoles paralelos.

As massas vítreas, bem como a rede intersticial, encontram-se parcialmente desvitrificadas, constituindo agregados criptocristalinos e, freqüentemente, 
argilomineralizados. Transformações minerais são poucos freqüentes e basicamente representadas por agregados submilimétricos de clorofeítas e/ou argilo-minerais (celadonita/nontronita), resultantes, principalmente, da alteração de cristais de olivinas. Também ocorrem, de forma discreta, materiais de aspecto pulverulento (filossilicatos, epidotos e óxidos/hidróxidos de ferro) disseminados ao longo de alguns planos de clivagem e em interfaces minerais. A caulinização de cristais de plagioclásio é extremamente rara.

Salienta-se que a sua homogeneidade é alta, o estado da rocha é são e seu estado microfissural varia de ausente a incipiente. Ele é constituído principalmente de plagioclásio (labradorita/bytownita), clinopiroxênios (augita e rara pigeonita), opacos (magnetita/titano-magnetita), mesóstose (material vítreo parcialmente desvitrificado originando agregados criptocristalinos e/ou argilomineralizados).

O granito Prata Interlagos, pertencente à Fácies Cantareira da idade précambriana do estado de São Paulo, foi proveniente da mineração Viterbo Machado Luz situada no bairro de Interlagos na cidade de São Paulo. Esta rocha é de cor branca a branca acinzentada, com estrutura isotrópica homogênea e textura inequigranular média a média grossa, salpicada de pontos pretos representados por pequenos agregados de biotita, parcialmente envoltos por hidróxido de ferro de tonalidade acastanhada. O aspecto geral inequigranular deve-se a cristais maiores de feldspato cinza claro, que podem atingir até $1,5 \mathrm{~cm}$, regularmente distribuídos na matriz, com granulação variável de 1.0 a $10.0 \mathrm{~mm}$ (predominando de 3.0 a $7.0 \mathrm{~mm}$ ). A Figura 48 mostra a alteração do plagioclásio (sericita) e as maclas presentes na sua microestrutura, além da presença de microtrincamentos.

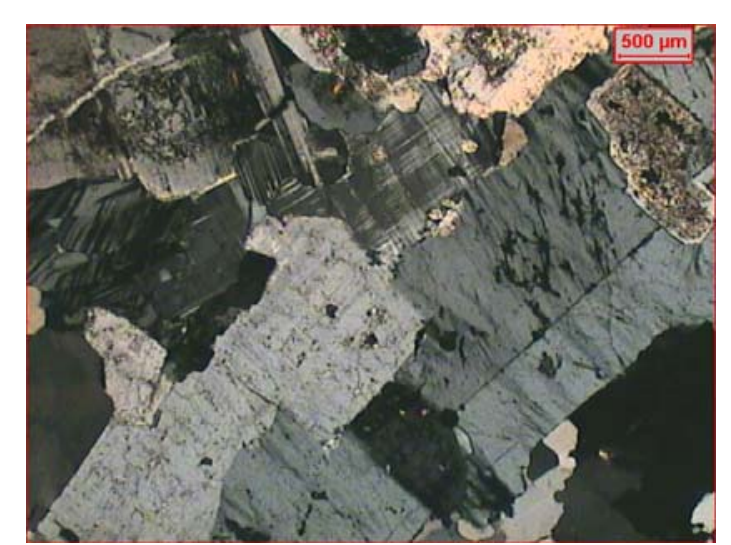

(a)

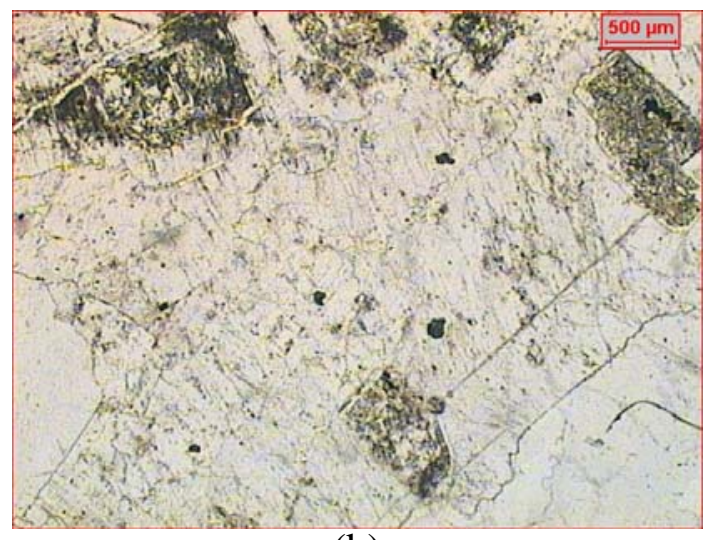

(b)

Figura 48 - Foto micrografia do plagioclásio do granito obtida via microscópio ótico por transmissão: (a) nicoles cruzados (b) nicoles paralelos. 
O granito apresenta uma estrutura maciça isotrópica, sua textura microscópica é fanerítica, hipidiomórfica, pouco inequigranular, com granulação variando de finamédia a média-grossa, predominantemente média. Os feldspatos apresentam contatos planos e raramente serrilhados. O quartzo apresenta contatos lobulados a côncavoconvexos, sendo comum a presença de grãos maiores microgranulados, recristalizados e com extinção ondulante. O microtrincamento é fraco, caracterizado predominantemente por planos intergraõs sem comunicação e quase exclusivamente sem preenchimento. Planos intergrãos são raros e restritos aos cristais de quartzo, conforme mostrado na Figura 49, a seguir.

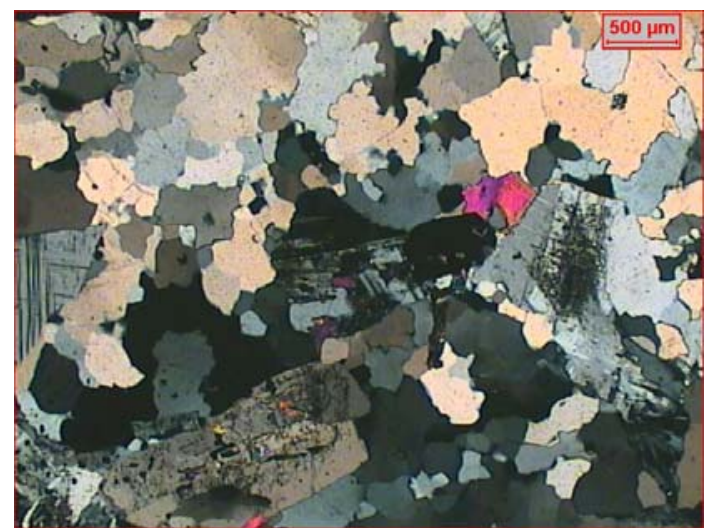

(a)

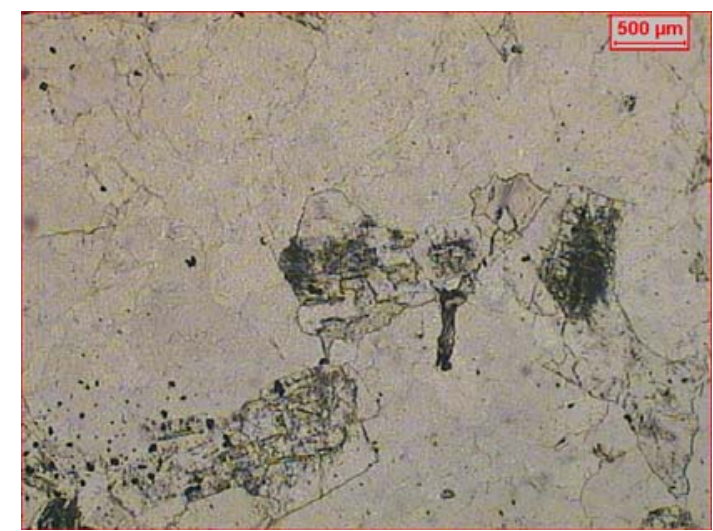

(b)

Figura 49 - Foto micrografía do quartzo obtida via microscópio ótico por transmissão: (a) nicoles cruzados (b) nicoles paralelos

Quanto à alteração do granito, ela se apresenta como sendo fraca no microclínio e média a forte no oligoclásio, produzindo argilo-minerais, carbonatos e sericita, que conferem aspecto turvo aos cristais deste último, especialmente na porção central. A biotita ocorre desde sã até parcial ou completamente transformada para clorita ou muscovita.

\subsection{Propriedades físicas e mecânicas das rochas ensaiadas}

Serão apresentados os ensaios necessários para a determinação das propriedades físicas e mecânicas, com a finalidade de caracterizar as rochas estudadas, verificar sua anisotropia e obter valores do módulo de elasticidade $(E)$ e do coeficiente de Poisson ( $v$ ) que são necessários para a determinação da tenacidade à fratura. 


\subsubsection{Propriedades Físicas}

O objetivo foi o de determinar as propriedades físicas das rochas (porosidade $(\eta)$, absorção e densidade seca $\left.\left(\rho_{d}\right)\right)$ utilizando os métodos sugeridos pela ISRM (1979). A presença de poros na estrutura de uma rocha faz com que sua resistência decresça e que haja um incremento de sua deformabilidade. Uma pequena fração de volume de poros pode produzir um efeito apreciável nas propriedades mecânicas das rochas. Em alguns casos, o valor da porosidade é suficiente para fornecer uma idéia preliminar quanto à maior ou menor resistência da rocha.

As propriedades físicas estão relacionadas entre si de tal maneira que qualquer propriedade pode ser calculada se forem conhecidas outras três. No entanto, se conhecemos os seguintes parâmetros, poderemos definir todas as propriedades físicas: volume externo $\left(V_{t o t}\right)$, peso seco $\left(W_{\text {seco }}\right)$, peso submerso $\left(W_{\text {sub }}\right)$ e peso saturado $\left(W_{\text {sat }}\right)$. $\mathrm{O}$ volume externo foi determinado utilizando o principio de Arquimedes, seguindo o procedimento sugerido pela ISRM (1979). Com os valores encontrados, calcularam-se a média e o desvio padrão para a porosidade $(\eta)$, a densidade seca $\left(\rho_{d}\right)$ e a absorção.

Foram caracterizados os materiais ensaiados (basalto e granito), obtendo-se os resultados mostrados na Tabela 5.

Tabela 5 - Propriedades físicas das rochas estudadas

BASALTO

\begin{tabular}{|c|c|c|c|c|c|c|c|c|}
\hline & $\begin{array}{l}W_{\text {seco }} \\
\text { (g) }\end{array}$ & $\begin{array}{l}W_{\text {sat }} \\
\text { (g) }\end{array}$ & $\begin{array}{l}W_{\text {sub }} \\
\text { (g) }\end{array}$ & $\begin{array}{c}V_{t o t} \\
\left(\mathrm{~cm}^{3}\right)\end{array}$ & $\begin{array}{l}V_{\text {vazio }} \\
\left(\mathrm{cm}^{3}\right)\end{array}$ & $\begin{array}{c}\text { Porosidade } \\
\text { (\%) }\end{array}$ & $\begin{array}{c}\text { Absorção } \\
\text { (\%) }\end{array}$ & $\begin{array}{c}\text { Densidade } \\
\text { seca } \\
\left(\mathrm{g} / \mathrm{cm}^{3}\right)\end{array}$ \\
\hline B1 & 216,72 & 217,08 & 142,87 & 74,21 & 0,36 & 0,49 & 0,17 & 2,92 \\
\hline B2 & 244,06 & 244,41 & 160,99 & 83,42 & 0,35 & 0,42 & 0,14 & 2,93 \\
\hline B3 & 241,68 & 242,05 & 159,46 & 82,59 & 0,37 & 0,45 & 0,15 & 2,93 \\
\hline B4 & 271,91 & 277,34 & 179,02 & 93,32 & 0,43 & 0,46 & 0,16 & 2,91 \\
\hline B5 & 252,72 & 253,15 & 166,63 & 86,52 & 0,43 & 0,50 & 0,17 & 2,92 \\
\hline & & & & Desvic & $\begin{array}{l}\text { Média } \\
\text { Padrão }\end{array}$ & $\begin{array}{l}0,46 \\
0,03\end{array}$ & $\begin{array}{l}0,16 \\
0,01\end{array}$ & $\begin{array}{c}2,92 \\
0,005\end{array}$ \\
\hline
\end{tabular}

\begin{tabular}{|c|c|c|c|c|c|c|c|c|}
\hline & $\begin{array}{c}W_{\text {seco }} \\
(\mathrm{g})\end{array}$ & $\begin{array}{c}W_{\text {sat }} \\
(\mathrm{g})\end{array}$ & $\begin{array}{c}W_{\text {sub }} \\
(\mathrm{g})\end{array}$ & $\begin{array}{c}V_{\text {tot }} \\
\left(\mathrm{cm}^{3}\right)\end{array}$ & $\begin{array}{c}V_{\text {vazio }} \\
\left(\mathrm{cm}^{3}\right)\end{array}$ & $\begin{array}{c}\text { Porosidade } \\
(\%)\end{array}$ & $\begin{array}{c}\text { Absorção } \\
(\%)\end{array}$ & $\begin{array}{c}\text { Densidade } \\
\text { seca } \\
\left(\mathrm{g} / \mathrm{cm}^{3}\right)\end{array}$ \\
\hline G1 & 286,00 & 287,06 & 178,01 & 109,05 & 1,06 & 0,97 & 0,37 & 2,62 \\
\hline G2 & 232,39 & 233,22 & 144,76 & 88,46 & 0,83 & 0,94 & 0,36 & 2,63 \\
\hline G3 & 214,27 & 215,01 & 133,46 & 81,55 & 0,74 & 0,91 & 0,35 & 2,63 \\
\hline G4 & 244,24 & 245,20 & 152,14 & 93,06 & 0,96 & 1,03 & 0,39 & 2,62 \\
\hline G5 & 231,98 & 232,77 & 144,54 & 88,23 & 0,79 & 0,90 & 0,34 & 2,63 \\
\hline \multicolumn{8}{|c|}{ Desvio } & $\begin{array}{c}\text { Média } \\
\text { Padrão }\end{array}$ \\
\hline
\end{tabular}




\subsubsection{Propriedades Mecânicas}

O objetivo da realização destes ensaios consiste na obtenção dos valores de resistência à compressão uniaxial $\left(\sigma_{c}\right)$ e à tração indireta $\left(\sigma_{t}\right)$ das rochas (basalto e granito), bem como na determinação do coeficiente de Poisson (v) e do Módulo de Elasticidade $(E)$.

As determinações da resistência à compressão uniaxial $\left(\sigma_{c}\right)$ e do Módulo de Elasticidade $(E)$ foram feitas segundo a ISRM (1979). As deformações radiais foram determinadas com o auxílio de um extensômetro que mede a variação circunferencial da amostra, determinando-se o coeficiente de Poisson conforme método sugerido pela ISRM (2000). O ensaio de tração indireta ou de compressão diametral (ensaio brasileiro) e a determinação da resistência à tração foram baseados na sugestão da ISRM (1978). A determinação da velocidade sônica do material foi feita conforme método sugerido pela $\operatorname{ISRM}$ (1979).

Os resultados obtidos são apresentados nas Tabelas 6 e 7 abaixo mostradas.

Tabela 6 - Propriedades mecânicas das rochas estudadas - Basalto

BASALTO

\begin{tabular}{|c|c|c|c|c|c|}
\hline \multicolumn{6}{|c|}{ Direção paralela ao eixo do corpo de prova $C B$} \\
\hline & $\begin{array}{l}\text { Resistência à } \\
\text { compressão } \\
\text { (MPa) }\end{array}$ & $\begin{array}{l}\text { Resistência à } \\
\text { tração } \\
\text { (MPa) }\end{array}$ & $\begin{array}{l}\text { Módulo de } \\
\text { Elasticidade } \\
\text { (GPa) }\end{array}$ & $\begin{array}{c}\text { Coeficiente } \\
\text { de Poisson }\end{array}$ & $\begin{array}{c}\text { Velocidade } \\
\text { sônica } \\
(\mathrm{km} / \mathrm{s})\end{array}$ \\
\hline B1 & 372,77 & 16,66 & 86,06 & 0,25 & 5,9595 \\
\hline B2 & 433,73 & 15,40 & 84,23 & 0,24 & 5,8937 \\
\hline B3 & 281,60 & 16,28 & 82,04 & 0,20 & 5,9606 \\
\hline B4 & 405,51 & 17,45 & 87,95 & 0,21 & 5,9732 \\
\hline B5 & 390,62 & 22,57 & 82,46 & 0,24 & 5,9032 \\
\hline Média & 376,85 & 17,67 & 84,55 & 0,229 & 5,9380 \\
\hline $\begin{array}{l}\text { Desvio } \\
\text { Padrão } \\
\end{array}$ & 57,74 & 2,84 & 2,48 & 0,018 & 0,037 \\
\hline \multicolumn{6}{|c|}{ Direção perpendicular ao eixo do corpo de prova $C B$} \\
\hline & $\begin{array}{l}\text { Resistência à } \\
\text { compressão } \\
\text { (MPa) }\end{array}$ & $\begin{array}{l}\text { Resistência à } \\
\text { tração } \\
\text { (MPa) }\end{array}$ & $\begin{array}{l}\text { Módulo de } \\
\text { Elasticidade } \\
\text { (GPa) }\end{array}$ & $\begin{array}{l}\text { Coeficiente } \\
\text { de Poisson }\end{array}$ & $\begin{array}{c}\text { Velocidade } \\
\text { sônica } \\
(\mathrm{km} / \mathrm{s})\end{array}$ \\
\hline B1 & 373,55 & 15,92 & 82,91 & 0,25 & 6,5571 \\
\hline B2 & 260,92 & 15,39 & 86,38 & 0,22 & 6,6481 \\
\hline B3 & 404,33 & 15,17 & 84,77 & 0,23 & 6,5544 \\
\hline Média & 346,27 & 15,49 & 84,69 & 0,234 & 6,5865 \\
\hline $\begin{array}{l}\text { Desvio } \\
\text { Padrão }\end{array}$ & 75,50 & 0,39 & 1,74 & 0,011 & 0,053 \\
\hline
\end{tabular}


Tabela 7 - Propriedades Mecânicas das rochas estudadas - Granito

GRANITO

\begin{tabular}{|c|c|c|c|c|c|}
\hline \multicolumn{6}{|c|}{ Direção paralela ao eixo do corpo de prova $C B$} \\
\hline & $\begin{array}{l}\text { Resistência à } \\
\text { compressão } \\
\text { (MPa) }\end{array}$ & $\begin{array}{l}\text { Resistência à } \\
\text { tração } \\
\text { (MPa) }\end{array}$ & $\begin{array}{l}\text { Módulo de } \\
\text { Elasticidade } \\
\text { (GPa) }\end{array}$ & $\begin{array}{l}\text { Coeficiente } \\
\text { de Poisson }\end{array}$ & $\begin{array}{l}\text { Velocidade } \\
\text { sônica } \\
\text { (Km/s) }\end{array}$ \\
\hline G1 & 160,85 & 10,36 & 52,32 & 0,30 & 5,0668 \\
\hline G2 & 165,93 & 8,28 & 53,73 & 0,31 & 4,9829 \\
\hline G3 & 177,05 & 8,87 & 57,15 & 0,29 & 5,0123 \\
\hline G4 & 177,90 & 9,14 & 55,20 & 0,29 & 5,0276 \\
\hline G5 & 170,82 & 7,67 & 58,86 & 0,28 & 4,9599 \\
\hline Média & 170,51 & 8,86 & 55,45 & 0,293 & 5,0099 \\
\hline $\begin{array}{l}\text { Desvio } \\
\text { Padrão }\end{array}$ & 7,28 & 1,01 & 2,61 & 0,009 & 0,041 \\
\hline \multicolumn{6}{|c|}{ Direção perpendicular ao eixo do corpo de prova $C B$} \\
\hline & $\begin{array}{c}\text { Resistência à } \\
\text { compressão } \\
\text { (MPa) }\end{array}$ & $\begin{array}{c}\text { Resistência à } \\
\text { tração } \\
\text { (MPa) }\end{array}$ & $\begin{array}{l}\text { Módulo de } \\
\text { Elasticidade } \\
\text { (GPa) }\end{array}$ & $\begin{array}{l}\text { Coeficiente } \\
\text { de Poisson }\end{array}$ & $\begin{array}{c}\text { Velocidade } \\
\text { sônica } \\
(\mathrm{Km} / \mathrm{s}) \\
\end{array}$ \\
\hline G1 & 168,60 & 10,59 & 59,39 & 0,31 & 4,7379 \\
\hline G2 & 176,11 & 9,87 & 57,30 & 0,32 & 4,7526 \\
\hline G3 & 169,30 & 10,71 & 59,57 & 0,29 & 4,8227 \\
\hline G4 & 172,35 & 10,53 & 58,98 & 0,31 & 4,8602 \\
\hline G5 & 172,35 & 10,13 & 60,20 & 0,33 & 4,8012 \\
\hline Média & 171,74 & 10,37 & 59,09 & 0,312 & 4,7949 \\
\hline $\begin{array}{l}\text { Desvio } \\
\text { Padrão }\end{array}$ & 2,98 & 0,35 & 1,10 & 0,013 & 0,050 \\
\hline
\end{tabular}

Um resumo dos resultados destes ensaios com suas respectivas propriedades físico-mecânicas das rochas estudadas são mostradas na Tabela 8.

Tabela 8 - Propriedades físico-mecânicas das rochas estudadas.

\begin{tabular}{|l|c|c|c|c|}
\hline \multicolumn{1}{c|}{$\begin{array}{c}\text { Propriedades } \\
\text { Físico-Mecânicas }\end{array}$} & \multicolumn{2}{c|}{ Basalto } & \multicolumn{2}{c|}{ Granito } \\
\cline { 2 - 5 }$\sigma_{c}(\mathrm{MPa})$ & Paralelo & Perpendicular & Paralelo & Perpendicular \\
\hline$\sigma_{t}(\mathrm{MPa})$ & 376.85 & 346.27 & 170.51 & 171.74 \\
\hline$E(\mathrm{GPa})$ & 17.67 & 15.49 & 8.86 & 10.37 \\
\hline$v$ & 84.55 & 84.69 & 55.45 & 59.09 \\
\hline Velocidade sônica $(\mathrm{km} / \mathrm{s})$ & 0.229 & 0.234 & 0.293 & 0.312 \\
\hline Porosidade (\%) & 5.94 & 6.59 & 5.01 & 4.79 \\
\hline Absorção $(\%)$ & \multicolumn{3}{|c|}{0.46} & \multicolumn{2}{c|}{0.95} \\
\hline Densidade seca $\left(\mathrm{g} / \mathrm{cm}^{3}\right)$ & \multicolumn{3}{|c|}{0.16} & \multicolumn{2}{c|}{2.63} \\
\hline
\end{tabular}

Na Tabela 9, apresentam-se os valores da tenacidade à fratura do basalto e do granito utilizando-se as correlações empíricas indicadas no Capítulo 3. 
Tabela 9 - Tenacidade à fratura das rochas estudadas utilizando correlações empíricas.

\begin{tabular}{|c|c|c|c|c|}
\hline \multirow{3}{*}{$\begin{array}{c}\text { Propriedades } \\
\text { Físico-Mecânicas }\end{array}$} & \multicolumn{4}{|c|}{ Tenacidade à fratura $\left(K_{I C}-\mathrm{MPa} \mathrm{m}^{1 / 2}\right)$} \\
\hline & \multicolumn{2}{|c|}{ Basalto } & \multicolumn{2}{|c|}{ Granito } \\
\hline & Paralelo & Perpendicular & Paralelo & Perpendicular \\
\hline \multicolumn{5}{|c|}{ Resistência à compressão $\left(\sigma_{c}-\mathrm{MPa}\right)$} \\
\hline Gunsallus e Kulhawy (1984) & 2.698 & 2.564 & 1.790 & 1.796 \\
\hline Whittaker et al., (1992) & 2.969 & 2.786 & 1.731 & 1.738 \\
\hline \multicolumn{5}{|c|}{ Resistência à tração $\left(\sigma_{t}-\mathrm{MPa}\right)$} \\
\hline Whittaker et al., (1992) & 2.160 & 1.927 & 1.218 & 1.379 \\
\hline Zhang et al., (1998) & 3.034 & 2.453 & 0.996 & 1.284 \\
\hline Zhang (2002) & 2.568 & 2.251 & 1.288 & 1.507 \\
\hline \multicolumn{5}{|c|}{ Módulo de elasticidade ( $E$-GPa) } \\
\hline Whittaker et al., (1992) & 0.739 & 0.740 & 0.484 & 0.516 \\
\hline \multicolumn{5}{|l|}{ Coeficiente de Poisson (v) } \\
\hline Whittaker et al., (1992) & 1.369 & 1.378 & 1.475 & 1.507 \\
\hline \multicolumn{5}{|l|}{ Velocidad sônica $\left(V_{P}-\mathrm{km} / \mathrm{s}\right)$} \\
\hline Whittaker et al., (1992) & 2.181 & 2.604 & 1.577 & 1.434 \\
\hline \multicolumn{5}{|l|}{ Densidade $\left(\rho-\mathrm{g} / \mathrm{cm}^{3}\right)$} \\
\hline Bearman (1991) & & 2.912 & & .941 \\
\hline Brown e Reddish (1997) & & 2.423 & & .492 \\
\hline
\end{tabular}

\subsection{Preparação, instrumentação e execução dos ensaios}

Para a preparação dos corpos de prova, utilizaram-se três blocos de basalto e dois blocos de granito com dimensões de $40 \mathrm{~cm} \mathrm{x} 40 \mathrm{~cm}$ x $50 \mathrm{~cm}$ e de $50 \mathrm{~cm}$ x $50 \mathrm{~cm}$ x $50 \mathrm{~cm}$, respectivamente. Para garantir a representatividade das amostras, os corpos de prova dos ensaios apresentados foram extraídos dos mesmos blocos. Os corpos de prova foram ensaiados em uma máquina hidráulica servo-controlada com capacidade máxima de $2700 \mathrm{kN}$ (MTS 815) e com uma célula de carga de $50 \mathrm{kN}$. As particularidades da instrumentação e da instalação dos corpos de prova para cada ensaio serão explicados nos itens correspondentes.

\subsubsection{Corpos de prova cilíndricos com entalhe “Chevron” sob flexão - Chevron Bend $(C B)$ ”}

O corpo de prova consiste de um cilindro longo com um entalhe central em “chevron” perpendicular a seu eixo. Este corpo de prova será submetido à flexão em três pontos, com vão entre os apoios de $254 \mathrm{~mm}$ para as duas rochas ensaiadas, conforme mostrado na Figura 52. Os corpos de prova tiveram $300 \mathrm{~mm}$ de comprimento e diâmetros que, depois de retificadas suas faces, variaram de 73,5 a 75,1 mm para o basalto e de 73,5 a 75,4 mm para o granito. 
O procedimento de preparação dos corpos de prova consistiu nas seguintes etapas:

1. Extração dos testemunhos cilíndricos a partir dos blocos de basalto e granito utilizando uma máquina de extração com brocas adiamantadas de $75 \mathrm{~mm}$ de diâmetro interno (Figura 50a). Os blocos foram orientados com riscos feitos com caneta à prova de água para que todos os corpos de prova tivessem a mesma direção de entalhe;

2. Os corpos de prova foram retificados em suas faces laterais para um melhor acabamento.

3. Realizou-se o corte das extremidades (Figura 50b) e posteriormente retificou-se suas faces (Figura 51a).

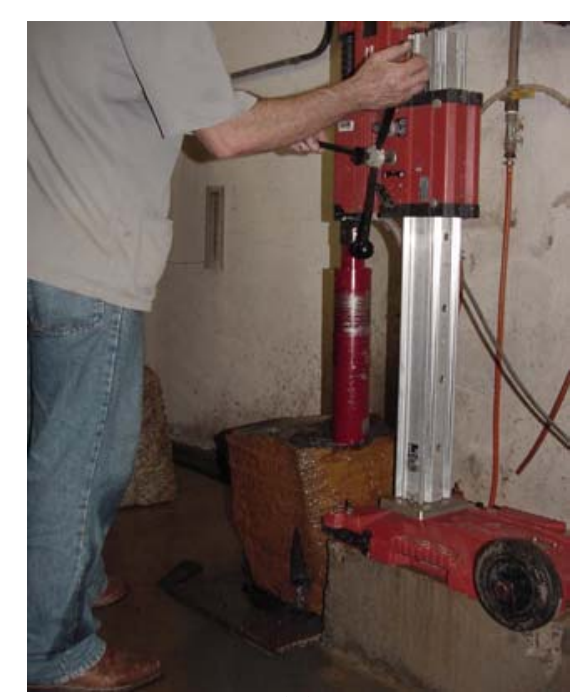

(a)

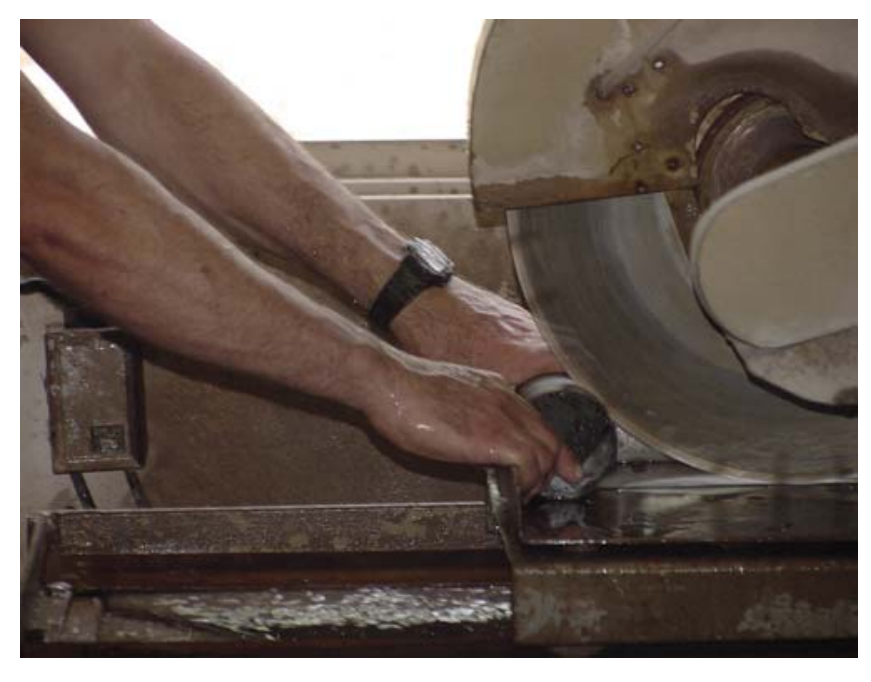

(b)

Figura 50 - Preparação dos corpos de prova $C B$ : (a) Extração dos testemunhos cilíndricos; (b) Corte das extremidades dos corpos de prova

4. Para confecção do entalhe foi utilizado um disco diamantado de $125 \mathrm{~mm}$ de diâmetro interno e 1,5 mm de espessura, além de um dispositivo para fixar o corpo de prova para fazer o entalhe. Este dispositivo consiste de um prisma vazado de seção quadrada com rasgo central para entrada do disco e com quatro roscas para colocar os parafusos que prendem o corpo de prova ao dispositivo (Figura 51b). 


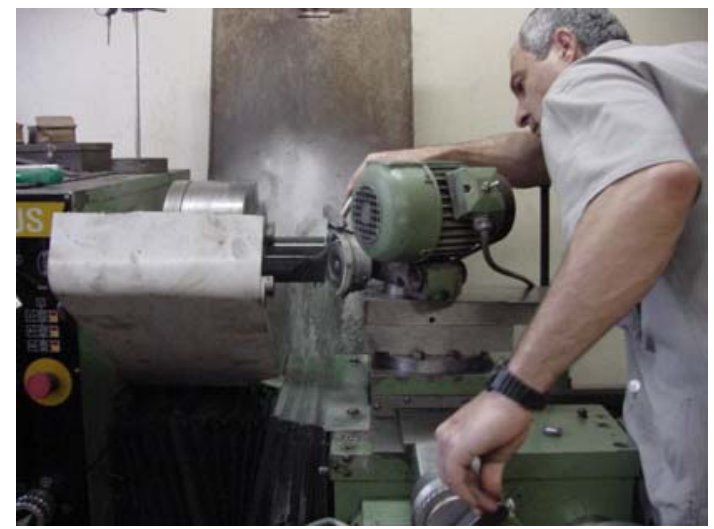

(a)

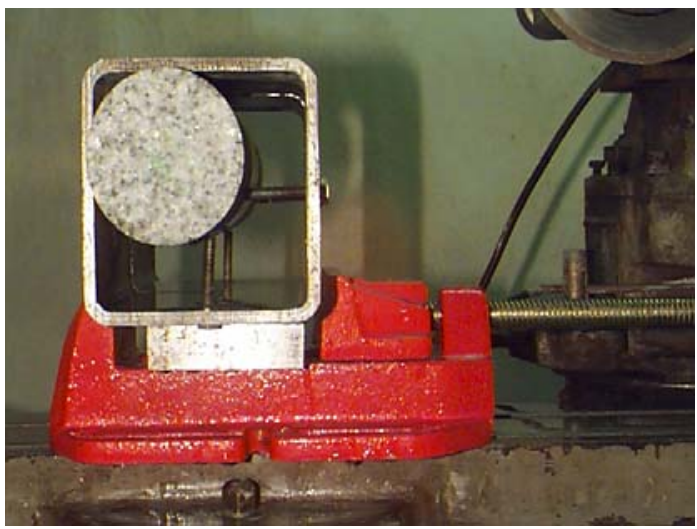

(b)

Figura 51 - Preparação dos corpos de prova $C B$ : (a) Retificação das faces no torno; (b) Confecção do entalhe "Chevron"

5. O dispositivo foi fixado na mesa da retífica através de uma morsa (Figura 51b);

6. Cortou-se o entalhe em um lado do corpo de prova, e posteriormente virou-se o dispositivo de fixação fazendo o corte no outro lado. A rotação do dispositivo permitiu obter o entalhe em ângulo "chevron” reto. A profundidade que o disco penetrou no corpo de prova foi de 0,25 vezes o diâmetro do corpo de prova (0,25D). Dessa maneira, a profundidade de corte para o basalto e para o granito foi de $19 \mathrm{~mm}$.

Para a realização do ensaio, são necessários alguns dispositivos de fixação e posicionamento sugeridos pela ISRM (1988), os quais foram descritos no Capítulo 3.

O procedimento de ensaio dos corpos de prova consistiu nas seguintes etapas:

1. O corpo de prova é colocado no dispositivo de posicionamento para garantir que a ponta do entalhe "chevron" do corpo de prova fique embaixo do eixo de carregamento e centrado em relação aos suportes;

2. Colocou-se um par de placas, uma de cada lado dos rasgos do dispositivo e que encaixe com o entalhe "chevron";

3. Procedeu-se à nivelação do corpo de prova mediante parafusos que devem estar perfeitamente alinhados com os apoios;

4. Retirou-se o dispositivo de posicionamento do corpo de prova e as placas dos rasgos do dispositivo e colocou-se o dispositivo de fixação dos LVDTs; este dispositivo é 
apoiado sobre o corpo de prova exatamente sobre as linhas de atuação dos apoios de reação;

5. As pontas móveis dos LVDTs foram apoiadas nos ombros de um dispositivo móvel, o qual é mantido pressionado ao entalhe por elásticos como mostrado na Figura 52b.

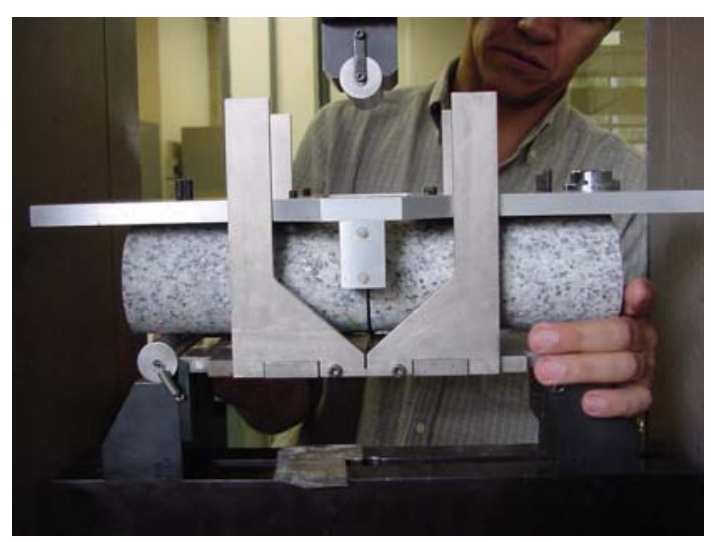

(a)

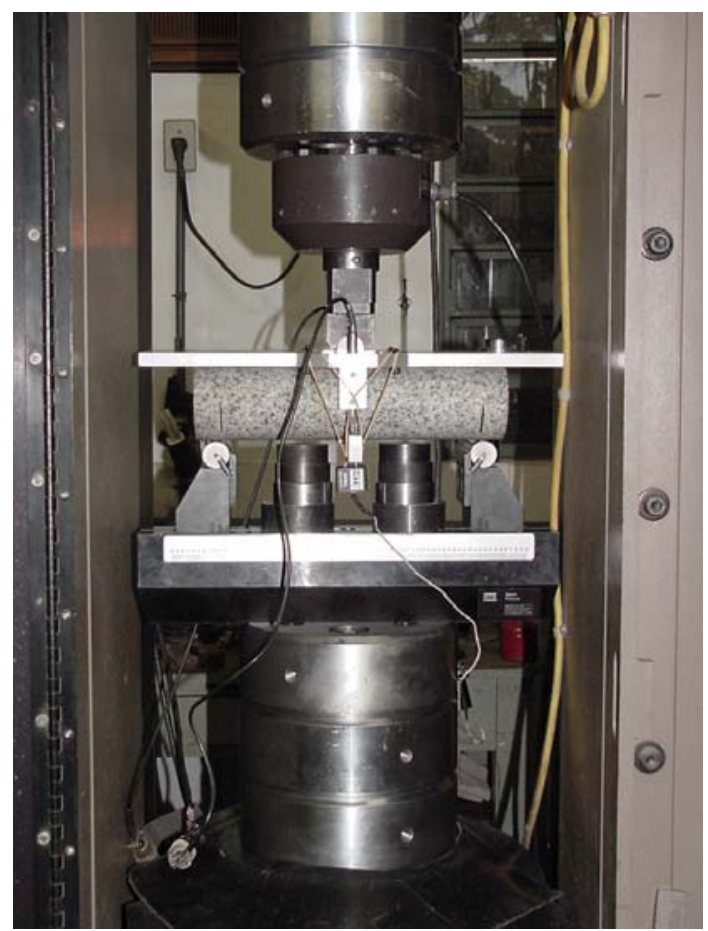

(b)

Figura 52 - Ensaio “Chevron Bend” sugerido pela ISRM (1988): (a) Dispositivos para fixação do corpo de prova; (b) Configuração geral do ensaio.

6. Para medir o deslocamento CMOD no nível II do ensaio, foi usado um extensômetro do tipo “clip gauge" com abertura de $5 \mathrm{~mm}$, ao passo que, para a medida do deslocamento $L P D$, usou-se dois LVDTs com extensão de 2,5 mm. Os LVDTs foram colocados simetricamente, dos dois lados da aplicação da carga, e o registro gráfico é correspondente ao valor médio (carga versus $L V D T_{m e d}$ ). A Figura 53b mostra um detalhe dos dispositivos para medir os deslocamentos no nível II do ensaio $C B$;

7. As velocidades de ensaio para o basalto e o granito foram lentas o suficiente para obter no mínimo três ciclos de carga e descarga antes do pico. Os resultados foram corrigidos com os respectivos fatores de correção $(p)$ para o nível II;

8. A velocidade de ensaio foi de $0,04 \mathrm{~mm} / \mathrm{min}$ para o basalto e de $0,05 \mathrm{~mm} / \mathrm{min}$ para 0 granito. 


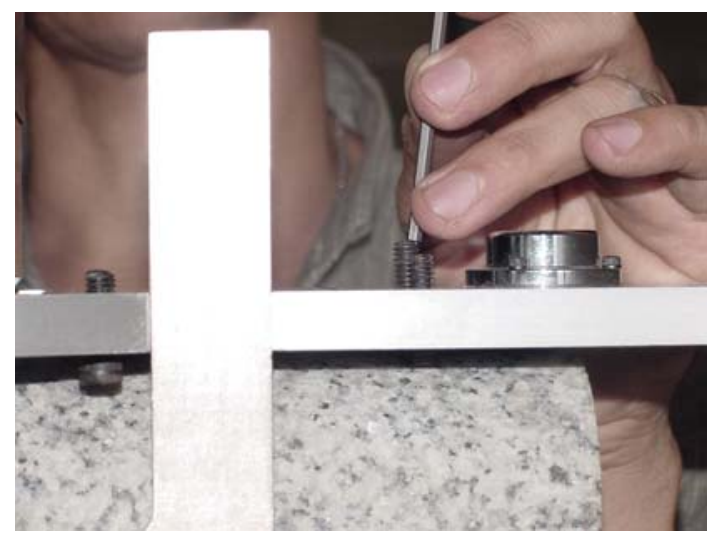

(a)

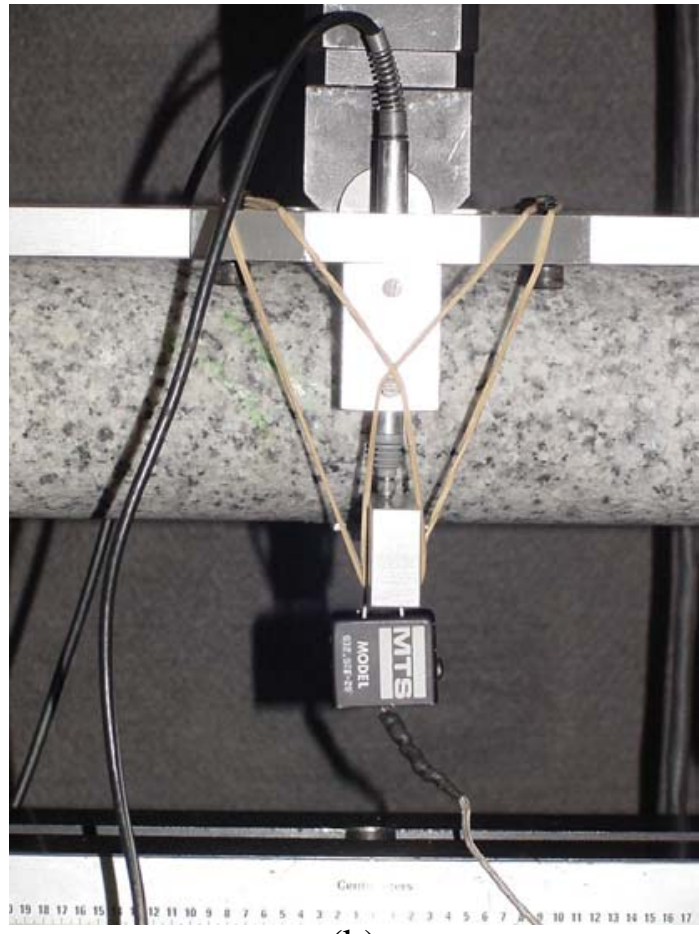

(b)

Figura 53 - Ensaio “Chevron Bend” sugerido pela ISRM (1988): (a) Nivelamento do corpo de prova; (b) Detalhes dos dispositivos e colocação dos LVDTs e do extensômetro do tipo “clip gauge”.

Foram realizados 16 ensaios $C B$, cuja representação típica dos resultados se dá conforme a Figura 54 abaixo, apresentada para fins de exemplificação. Os resultados de $K_{I C}$ foram determinados destes gráficos, segundo o procedimento e fórmulas sugeridas pela $\operatorname{ISRM}(I S R M, 1988)$ apresentados no Capítulo 3.

\section{Ensaio CB}

Corpo de prova CBG6

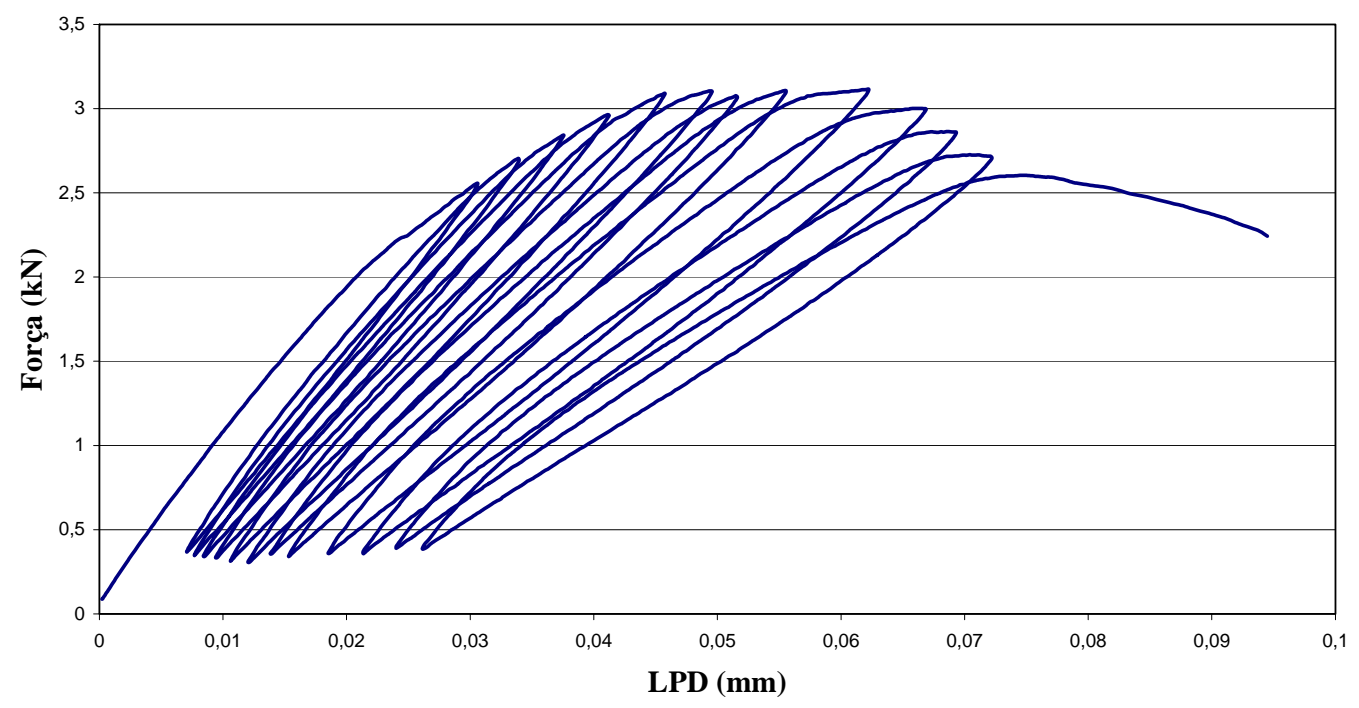

Figura 54 - Gráfico Força versus $L P D$ típico do ensaio $C B$ 
A Tabela 10 abaixo apresenta os respectivos resultados dos ensaios $C B$ sugerido pela $\operatorname{ISRM}(\operatorname{ISRM}, 1988)$ e realizados no basalto e no granito neste programa de pesquisa:

Tabela 10 - Resultados do ensaio em corpos de prova cilíndricos com entalhe “chevron” sob flexão $(C B)$

\begin{tabular}{|c|c|c|c|c|c|c|c|}
\hline BASALTO & $\begin{array}{c}D \\
(\mathrm{~mm})\end{array}$ & $\begin{array}{c}a_{0} \\
(\mathrm{~mm})\end{array}$ & $\begin{array}{l}F_{\max } \\
(\mathrm{kN})\end{array}$ & $\begin{array}{c}F_{c} \\
(\mathrm{kN})\end{array}$ & $p$ & $\begin{array}{c}K_{I C} \\
\left(\mathrm{MPa} \cdot \mathrm{m}^{1 / 2}\right)\end{array}$ & $\begin{array}{c}K_{I C}{ }^{C B} \\
\left(\mathrm{MPa}^{1 / 2}\right)\end{array}$ \\
\hline CBB2 & 74,2 & 13,4 & 3,58 & $>98 \%$ & 0,169 & 2,06 & 2,44 \\
\hline CBB4 & 73,7 & 12,8 & 3,52 & 3,45 & 0,225 & 2,01 & 2,48 \\
\hline CBB5 & 73,5 & 12,9 & 3,57 & 3,39 & 0,100 & 2,07 & 2,17 \\
\hline CBB6 & 74,2 & 12,9 & 3,80 & 3,60 & 0,148 & 2,14 & 2,35 \\
\hline CBB8 & 75,1 & 10,9 & 4,12 & $>98 \%$ & 0,356 & 2,05 & 2,13 \\
\hline \multicolumn{8}{|c|}{ Média } \\
\hline \multicolumn{6}{|r|}{ Desvio } & \multicolumn{2}{|l|}{ Padrão } \\
\hline GRANITO & $\begin{array}{c}D \\
(\mathrm{~mm})\end{array}$ & $\begin{array}{c}a_{0} \\
(\mathrm{~mm})\end{array}$ & $\begin{array}{l}F_{\max } \\
(\mathrm{kN})\end{array}$ & $\begin{array}{c}F_{c} \\
(\mathrm{kN})\end{array}$ & $\bar{p}$ & $\begin{array}{c}K_{I C} \\
\left(\mathrm{MPa}^{1 / 2}\right)\end{array}$ & $\begin{array}{c}K_{I C}{ }^{\mathrm{CB}} \\
\left(\mathrm{MPa}^{1 / 2}\right)\end{array}$ \\
\hline CBG2 & 73,5 & 11,9 & 2,70 & 2,60 & 0,178 & 1,50 & 1,72 \\
\hline CBG3 & 73,5 & 11,8 & 2,68 & 2,52 & 0,285 & 1,48 & 1,87 \\
\hline CBG4 & 74,0 & 11,8 & 3,17 & $>98 \%$ & 0,065 & 1,72 & 1,83 \\
\hline CBG5 & 74,0 & 11,9 & 3,02 & $>98 \%$ & 0,135 & 1,64 & 1,88 \\
\hline CBG6 & 73,5 & 11,9 & 3,11 & $>98 \%$ & 0,046 & 1,73 & 1,81 \\
\hline CBG7 & 75,4 & 11,0 & 3,58 & 3,40 & 0,068 & 1,77 & 1,80 \\
\hline CBG8 & 75,4 & 11,4 & 3,42 & $>98 \%$ & 0,032 & 1,72 & 1,78 \\
\hline & & & & & Des & $\begin{array}{l}\text { Média } \\
\text { Padrão }\end{array}$ & $\begin{array}{l}1,81 \\
0,05\end{array}$ \\
\hline
\end{tabular}

\subsubsection{Corpos de prova de haste curto com entalhe “chevron" sob tração - "Short $\operatorname{Rod}(S R) ”$}

O corpo de prova consiste de um cilindro curto com entalhe centralizado em forma de “chevron” paralelo ao maior eixo. Este corpo de prova sofrerá tração através de duas hastes encaixadas em duas placas coladas ao corpo de prova, conforme mostrado na Figura 56. Os corpos de prova tiveram $107 \mathrm{~mm}$ de comprimento e diâmetros que variaram de 73,5 a 74,6 mm para o basalto e de 73,4 a 74,0 mm para o granito.

O procedimento de preparação dos corpos de prova consistiu nas seguintes etapas:

1. Aproveitou-se uma das metades rompidas no corpo de prova " $C B$ ”. O risco feito com caneta à prova de água serviu como orientação para confecção do entalhe deste corpo de prova; 
2. A metade rompida do corpo de prova " $C B$ " foi cortada de forma que os corpos de prova de basalto ou de granito ficaram com $107 \mathrm{~mm}$ de comprimento para atender às dimensões exigidas pela ISRM;

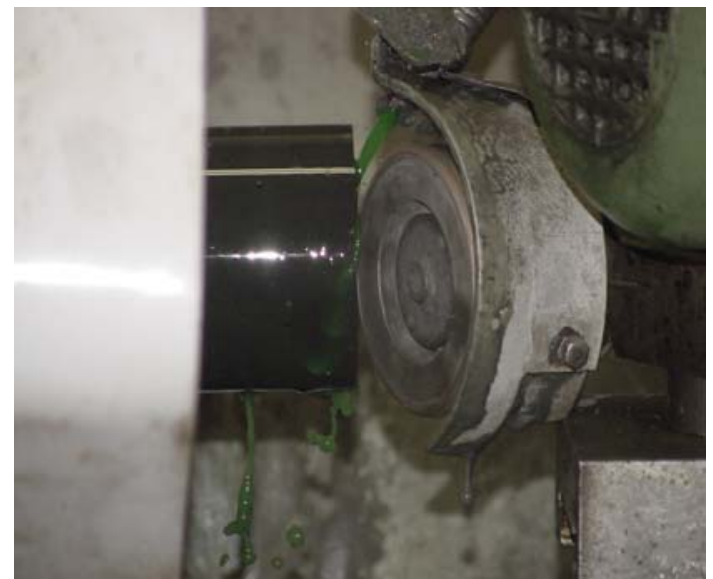

(a)

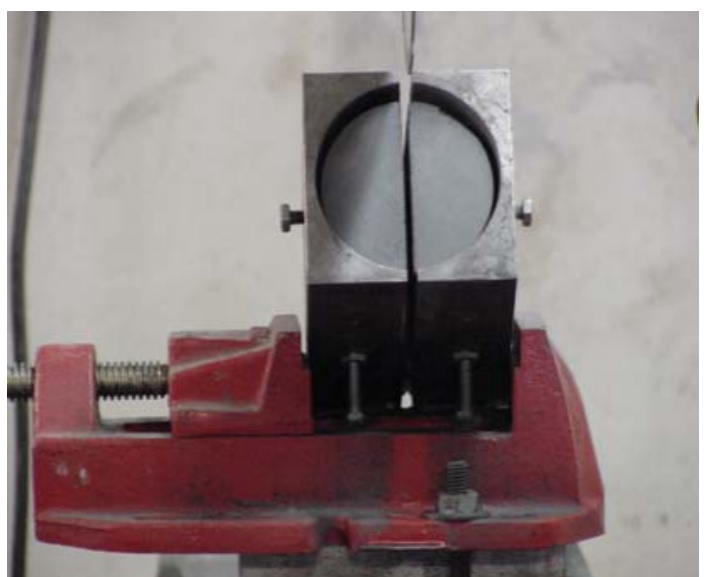

(b)

Figura 55 - Preparação do corpo de prova $S R$ : (a) Retificação das faces no torno; (b) Confecção do entalhe "Chevron" no ensaio $S R$

3. Para confecção do entalhe, utilizou-se um disco de $200 \mathrm{~mm}$ de diâmetro externo e 1,5 mm de espessura. Empregou-se um dispositivo de fixação do corpo de prova "SR" para confecção do entalhe, conforme mostra a Figura 55b. Este dispositivo foi fixado na mesa da retífica através de uma morsa;

4. Com um transferidor, fixou-se a inclinação da morsa em $27,3^{\circ}$ para realizar o corte do entalhe; após a confecção de um lado do entalhe, virou-se o dispositivo de fixação em um ângulo de $180^{\circ}$ mantendo-se o ângulo da inclinação da morsa, e em seguida fezse o entalhe do outro lado. A profundidade que o disco penetrou nos corpos de prova foi de $0,7477 D$. Desta maneira, a profundidade de corte em cada uma das extremidades dos corpos de prova para o basalto e o granito foi de $56 \mathrm{~mm}$.

Para a realização do ensaio, são necessários alguns dispositivos de fixação e posicionamento sugeridos pela ISRM (1988), os quais foram descritos no Capítulo 3.

O procedimento de ensaio dos corpos de prova consistiu nas seguintes etapas:

1.- Primeiramente, foram colados no corpo de prova duas pontas finas posicionadas exatamente na abertura da boca da trinca;

2.- a seguir, são coladas aos corpos de prova duas placas na sua face superior. 
3.- São fixadas as hastes do extensômetro do tipo "clip gauge" no corpo de prova, para as medidas dos deslocamentos;

4.- Aplica-se a força de tração através de duas hastes encaixadas nas placas coladas ao corpo de prova;

5.- O nível II requer o registro da relação carga-deslocamento $C M O D$, sendo este último controlado durante todo o ensaio. Para medir o $C M O D$ no ensaio Short Rod $(S R)$, usouse um extensômetro do tipo “clip-gauge” com capacidade de abertura de 5 mm, como mostrado nas Figuras 56b e 57b;

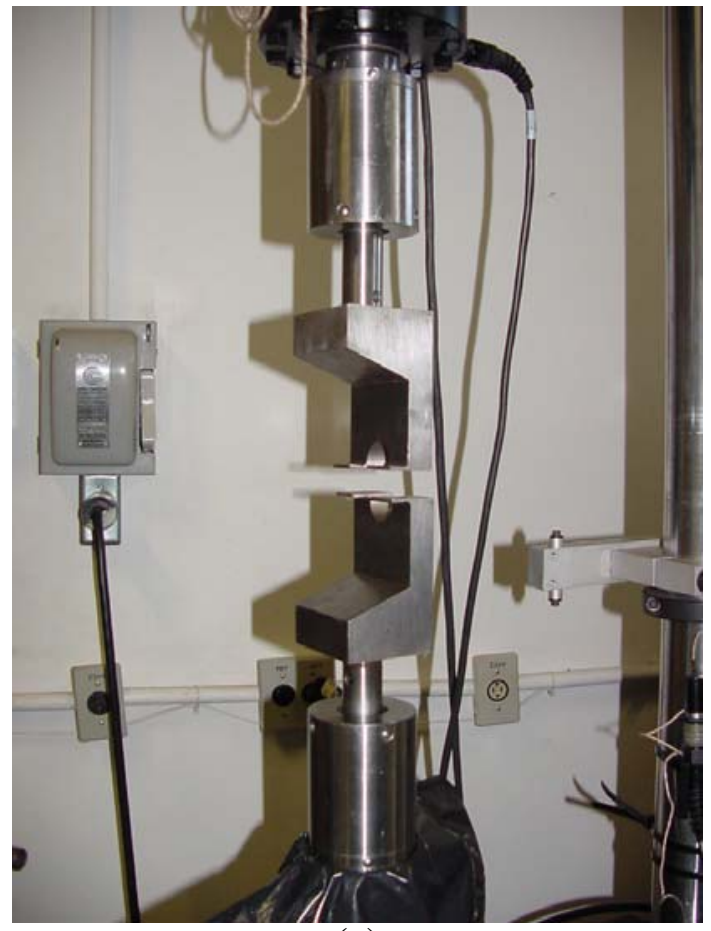

(a)

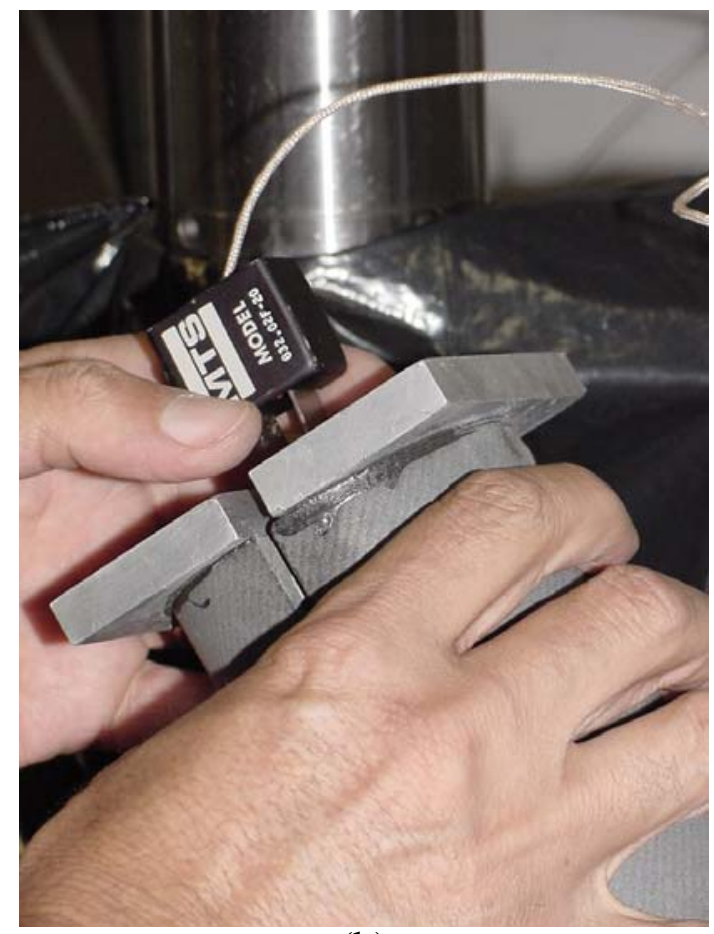

(b)

Figura 56 - Ensaio "Short Rod" sugerido pela ISRM (1988): (a) Dispositivos para fixação do corpo de prova; (b) Chapas coladas no corpo de prova e colocação das hastes do extensômetro do tipo "clip gauge".

6.- Salienta-se que as velocidades de ensaio adotadas atenderam aos requisitos sugeridos pela ISRM (1988) e os resultados obtidos foram corrigidos com os respectivos fatores de correção ( $p)$, para o nível II correspondente. A velocidade de ensaio para o basalto foi de $0,12 \mathrm{~mm} / \mathrm{min}$ e para o granito foi de $0,13 \mathrm{~mm} / \mathrm{min}$. 


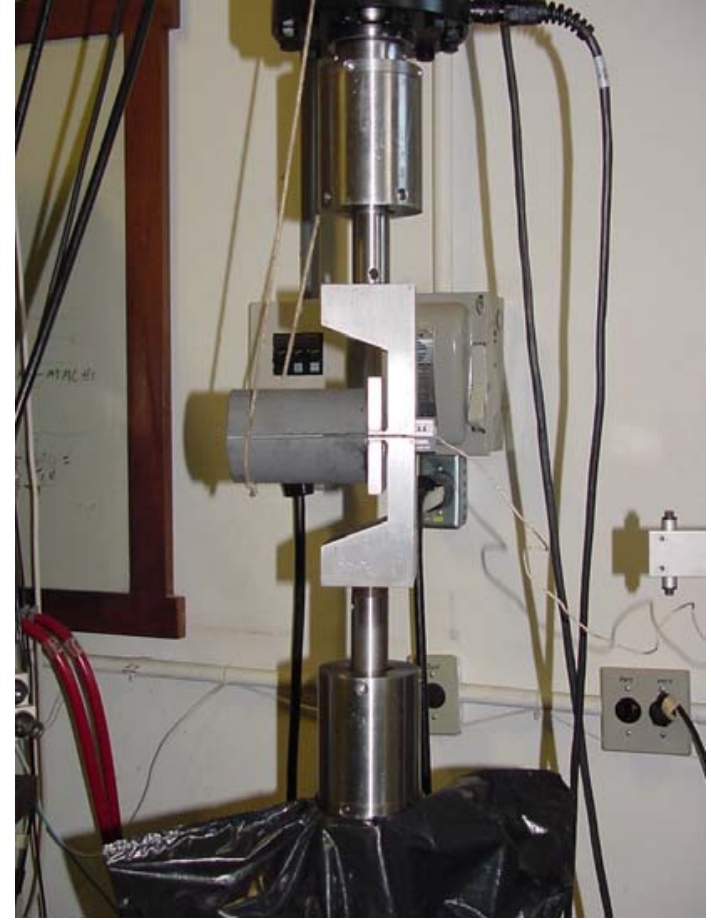

(a)

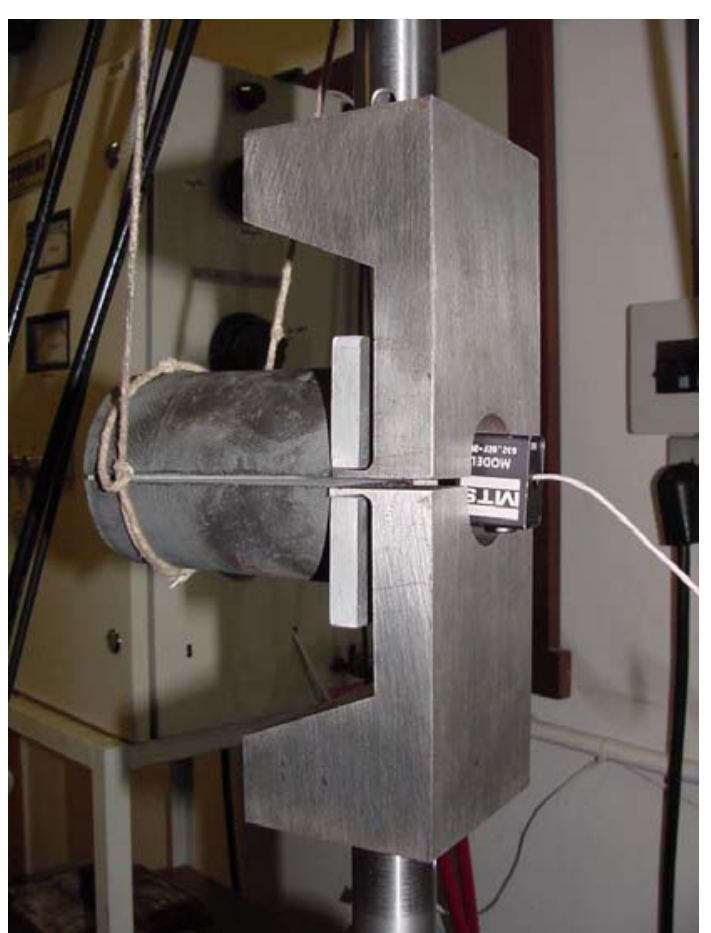

(b)

Figura 57 - Ensaio “Short Rod” sugerido pela ISRM (1988): (a) Configuração geral do ensaio; (b) Detalhe do dispositivo de medida de deslocamentos.

Foram realizados 12 ensaios $S R$ cuja representação típica dos resultados se dá conforme a Figura 58 abaixo, apresentada para fins de exemplificação. Os resultados de $K_{I C}$ foram determinados destes gráficos, segundo o procedimento e fórmulas sugeridas pela $\operatorname{ISRM}(I S R M, 1988)$ apresentados no Capítulo 3.

\section{Ensaio SR}

Corpo de prova SRG6

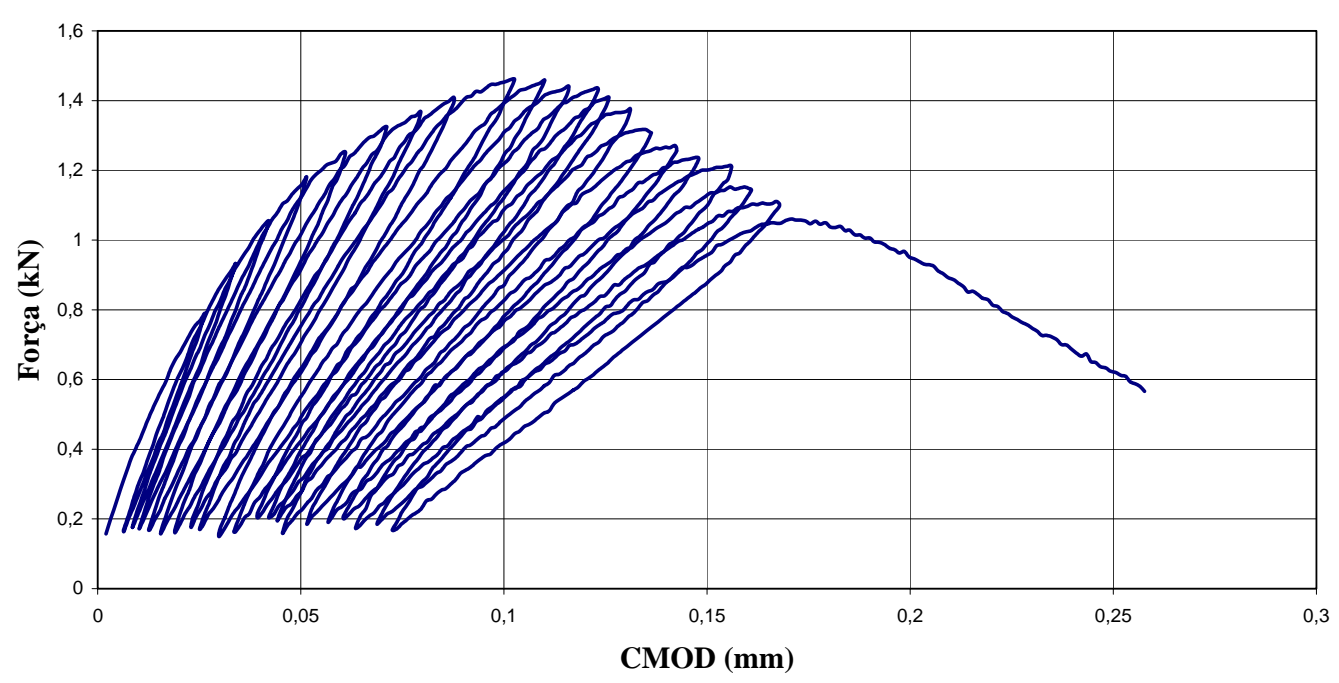

Figura 58 - Gráfico Força versus $C M O D$ típico do ensaio $S R$ 
A Tabela 11 abaixo apresenta os respectivos resultados dos ensaios $S R$ sugerido pela $\operatorname{ISRM}(\operatorname{ISRM}, 1988)$ e realizados no basalto e no granito neste programa de pesquisa:

Tabela 11 - Resultados do ensaio em corpos de prova de haste curto com entalhe “chevron” sob tração $(S R)$

\begin{tabular}{|c|c|c|c|c|c|c|c|c|c|}
\hline \multicolumn{10}{|c|}{ BASALTO } \\
\hline & $\begin{array}{c}a_{0} \\
(\mathrm{~mm})\end{array}$ & $\begin{array}{c}\theta \theta \\
\left({ }^{\circ}\right)\end{array}$ & $\begin{array}{c}D \\
(\mathrm{~mm})\end{array}$ & $\begin{array}{c}\text { Altura } \\
(\mathrm{mm})\end{array}$ & $p$ & $\begin{array}{l}F_{\max } \\
(\mathrm{kN})\end{array}$ & $\begin{array}{c}F_{c} \\
(\mathrm{kN})\end{array}$ & $\begin{array}{c}K_{I C} \\
\left(\mathrm{MPa}^{1 / 2}\right)\end{array}$ & $\begin{array}{c}K_{I C}^{S R} \\
\left(\mathrm{MPa} \cdot \mathrm{m}^{1 / 2}\right)\end{array}$ \\
\hline SRB1 & 38,0 & 55,0 & 74,6 & 106,8 & 0,181 & 1,69 & 1,64 & 2,05 & 2,39 \\
\hline SRB2 & 37,5 & 55,5 & 74,1 & 107,9 & 0,008 & 1,88 & $>98 \%$ & 2,32 & 2,33 \\
\hline SRB3 & 41,3 & 54,0 & 73,5 & 107,2 & 0,125 & 1,67 & 1,49 & 2,23 & 2,53 \\
\hline SRB4 & 41,0 & 55,5 & 74,6 & 107,8 & 0,067 & 1,91 & 1,84 & 2,46 & 2,54 \\
\hline SRB5 & 39,0 & 55,0 & $\begin{array}{l}73,5 \\
\end{array}$ & 106,9 & 0,023 & 1,96 & 1,91 & 2,52 & 2,52 \\
\hline SRB6 & 42,7 & 54,0 & 74,3 & 108,2 & 0,137 & 1,52 & 1,36 & 2,03 & 2,09 \\
\hline & & & & & & & Desvio & $\begin{array}{l}\text { Média } \\
\text { Padrão }\end{array}$ & $\begin{array}{l}2,40 \\
0,17\end{array}$ \\
\hline
\end{tabular}

GRANITO

\begin{tabular}{|c|c|c|c|c|c|c|c|c|c|}
\hline & $\begin{array}{c}a_{0} \\
(\mathrm{~mm})\end{array}$ & $\begin{array}{c}\theta \\
\left({ }^{\circ}\right)\end{array}$ & $\begin{array}{c}D \\
(\mathrm{~mm})\end{array}$ & $\begin{array}{c}\text { Altura } \\
(\mathrm{mm})\end{array}$ & $p$ & $\begin{array}{c}F_{\max } \\
(\mathrm{kN})\end{array}$ & $\begin{array}{c}F_{c} \\
(\mathrm{kN})\end{array}$ & $\begin{array}{c}K_{I C} \\
\left(\mathrm{MPa}^{1 / 2}\right)\end{array}$ & $\begin{array}{c}K_{I C}{ }^{S R} \\
\left(\mathrm{MPa}^{1 / 2}\right)\end{array}$ \\
\hline SRG1 & 40,0 & 55,5 & 73,4 & 106,8 & 0,191 & 1,44 & 1,35 & 1,89 & 2,15 \\
\hline SRG4 & 40,6 & 55,5 & 74,0 & 106,9 & 0,327 & 1,23 & $>98 \%$ & 1,60 & 2,24 \\
\hline SRG5 & 40,0 & 54,8 & 74,0 & 106,8 & 0,215 & 1,30 & $>98 \%$ & 1,67 & 2,08 \\
\hline SRG6 & 38,0 & 54,8 & 73,5 & 106,7 & 0,182 & 1,46 & $>98 \%$ & 1,85 & 2,22 \\
\hline & & & & & & & & Média & 2,17 \\
\hline & & & & & & & Desvio & Padrão & 0,07 \\
\hline
\end{tabular}

\subsubsection{Corpos de prova em forma de disco brasileiro com entalhe "Chevron" - "Cracked Circunferencial Notched Brazilian Disc (CCNBD)"}

O corpo de prova tem forma de um disco brasileiro com entalhe "chevron”, o qual é feito com dois cortes em ambos os lados do disco ao longo do mesmo plano de corte diametral. A carga é aplicada paralelamente ao plano do entalhe. Os corpos de prova tiveram 29,9 a 30,0 mm de espessura para o basalto e 29,5 a 30,0 para o granito e diâmetros que variaram de 73,4 a 74,2 mm para o basalto e de 73,5 a 74,0 mm para o granito.

O procedimento de preparação dos corpos de prova consistiu nas seguintes etapas:

1. As metades dos corpos de prova “ $C B$ ”, após fraturados, foram utilizadas para confecção dos corpos de prova do ensaio $C C N B D$. Cortaram-se discos de $30 \mathrm{~mm}$ de espessura na máquina de corte. No local do risco, feito na hora da extração do testemunho, mediu-se $90^{\circ}$ ao redor do mesmo e marcou-se a direção para fazer o 
entalhe, de maneira que fosse perpendicular aos entalhes feitos nos corpos de prova "CB" e "SR";

2. O disco diamantado usado para confecção do entalhe apresentou um diâmetro externo de $65 \mathrm{~mm}$ e 1,25 mm de espessura. A confecção do entalhe necessitou um dispositivo de fixação do corpo de prova que foi fixo na mesa da retífica através de uma morsa (Figura 59a). O disco penetrou no corpo de prova uma profundidade de 16,5 mm, depois se virou o dispositivo e cortou-se no outro lado (Figura 59b);

3. Após a confecção do entalhe, os corpos de prova foram lavados e em seguida; secos em estufa por 24 horas como sugere a ISRM (1995).

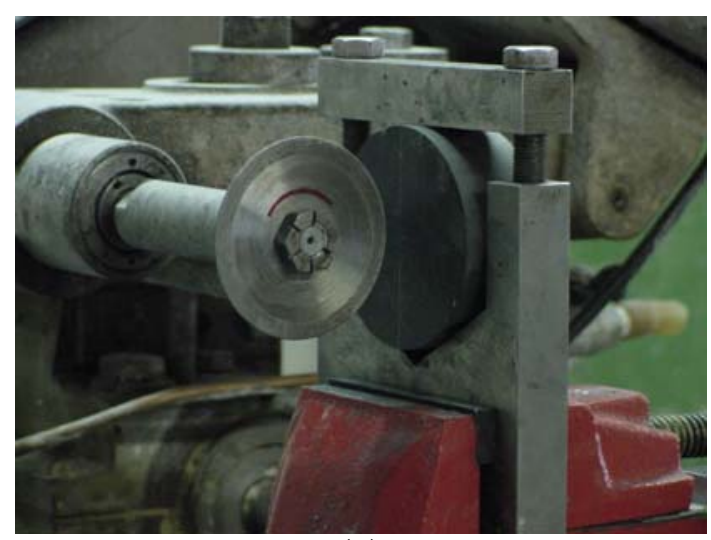

(a)

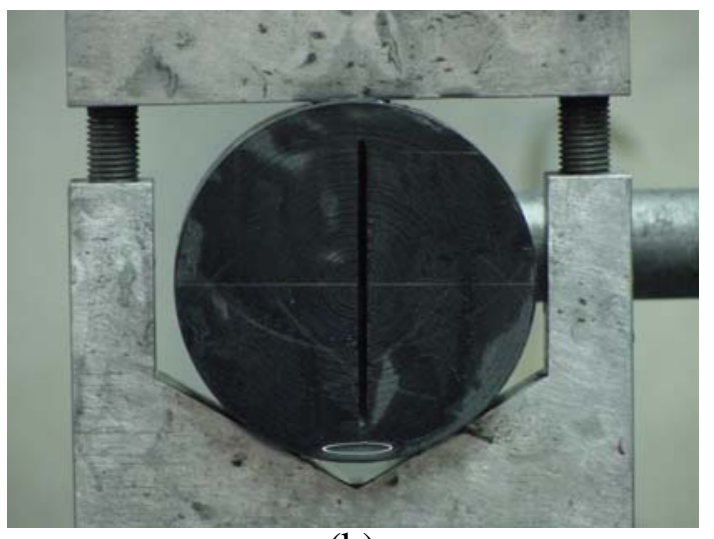

(b)

Figura 59 - Preparação do corpo de prova CCNBD: (a) Confecção do entalhe "Chevron" no ensaio $C C N B D$; (b) Detalhe do entalhe.

O procedimento de ensaio dos corpos de prova consistiu nas seguintes etapas:

1.- O corpo de prova é colocado cuidadosamente na máquina de ensaio, com um dispositivo para auxiliar o alinhamento da trinca perpendicular à placa de carregamento, conforme mostrado na Figura 60;

2.- O ensaio é feito sob controle de carga e a taxa de carregamento deve ser tal que a ruptura ocorra no máximo 20 segundos após o início do ensaio e requer somente o registro da carga máxima;

3.- As taxas de carregamento utilizadas foram de $1,30 \mathrm{kN} / \mathrm{s}$ para o basalto e de 1,05 $\mathrm{kN} / \mathrm{s}$ para o granito. 


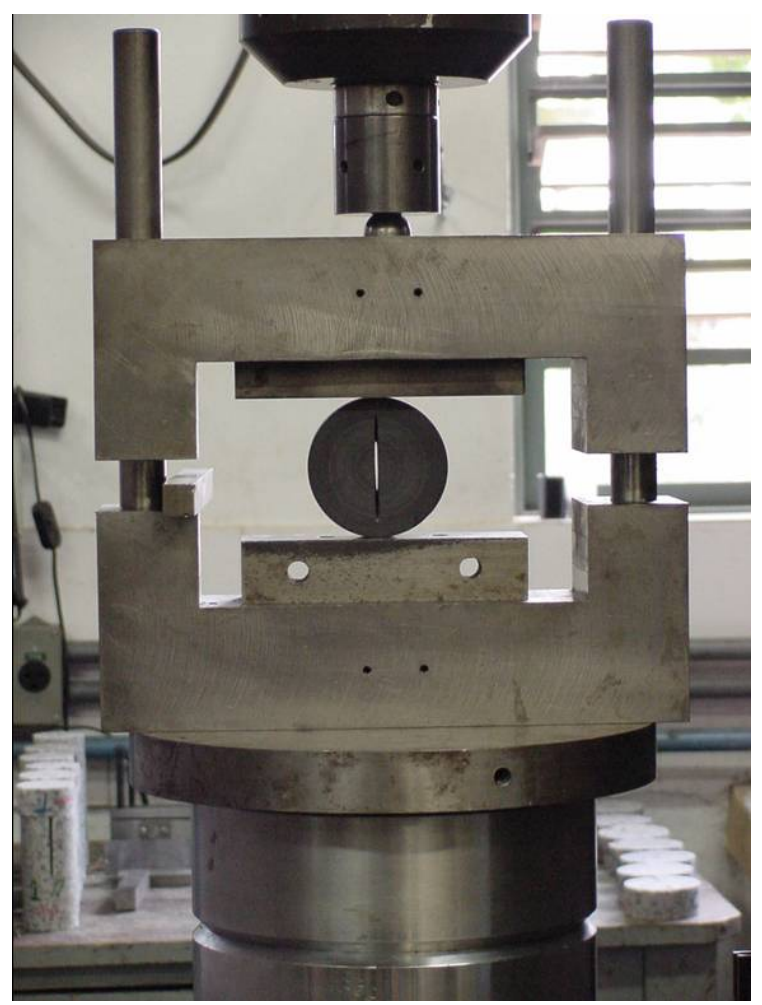

Figura 60 - Configuração geral do ensaio " $C C N B D$ ”

Foram realizados 14 ensaios $C C N B D$, cuja representação típica dos resultados se dá conforme a Figura 61 abaixo. Os resultados de $K_{I C}$ foram determinados destes gráficos, segundo o procedimento e fórmulas sugeridas pela ISRM (ISRM, 1995) apresentados no Capítulo 3.

\section{Ensaio CCNBD \\ Corpo de prova CCNBDB5}

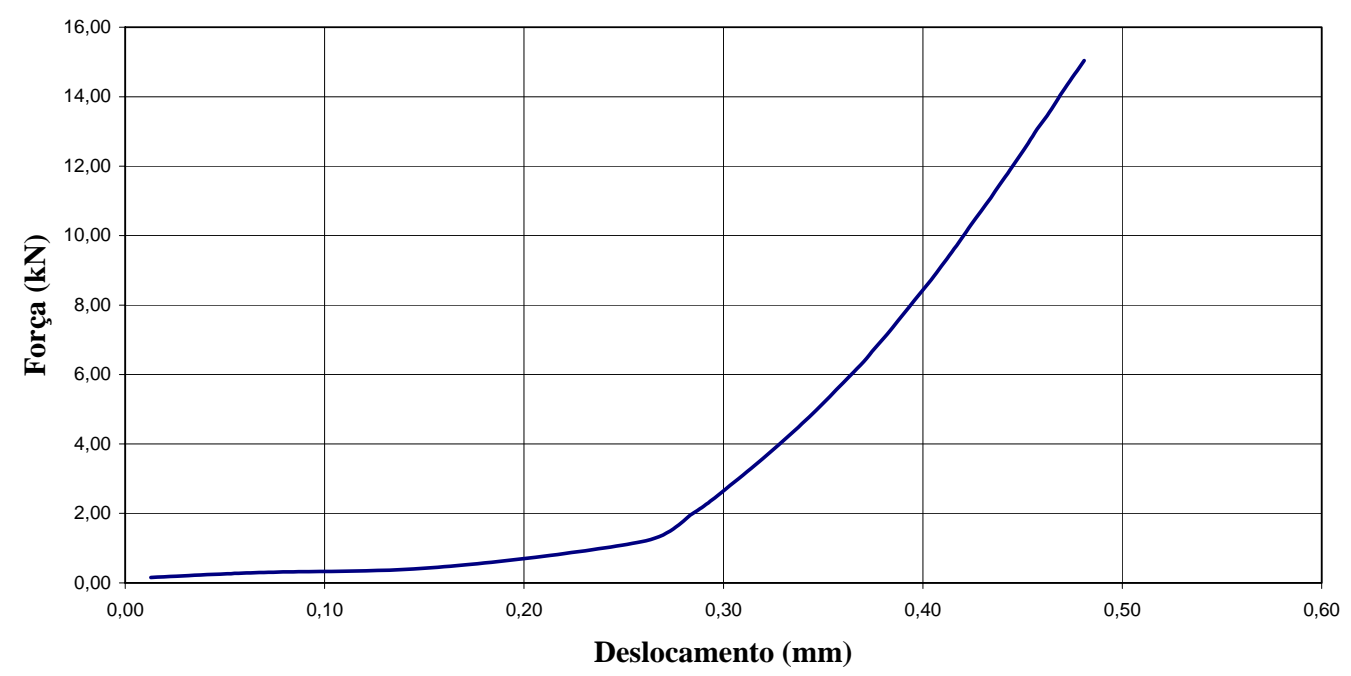

Figura 61 - Gráfico Força versus deslocamento típico do ensaio $C C N B D$ 
A Tabela 12 abaixo apresenta os respectivos resultados dos ensaios $C C N B D$ sugerido pela ISRM (ISRM, 1995) e realizados no basalto e no granito neste programa de pesquisa:

Tabela 12 - Resultados do ensaio em corpos de prova em forma de disco brasileiro fraturado com entalhe "chevron" (CCNBD)

\begin{tabular}{|c|c|c|c|c|c|c|c|c|c|}
\hline BASALTO & $\begin{array}{c}a_{0} \\
(\mathrm{~mm})\end{array}$ & $\begin{array}{c}a_{1} \\
(\mathrm{~mm})\end{array}$ & $\begin{array}{c}t \\
(\mathrm{~mm})\end{array}$ & $\begin{array}{c}D \\
(\mathrm{~mm})\end{array}$ & $u$ & $v$ & $Y_{\min }$ & $\begin{array}{l}F_{\max } \\
(\mathrm{kN})\end{array}$ & $\begin{array}{c}K_{I C} \\
\text { MPa.m }^{1 / 2}\end{array}$ \\
\hline CCNBDB1 & 13,05 & 28,85 & 30,0 & 73,5 & 0,278 & 1,753 & 1,099 & 12,61 & 1,70 \\
\hline CCNBDB2 & 12,43 & 28,90 & 30,0 & 74,1 & 0,275 & 1,757 & 1,082 & 12,46 & 1,65 \\
\hline CCNBDB3 & 11,10 & 28,90 & 30,0 & 73,5 & 0,271 & 1,758 & 1,078 & 12,28 & 1,63 \\
\hline CCNBDB4 & 13,17 & 28,75 & 29,9 & 73,7 & 0,278 & 1,753 & 1,092 & 13,11 & 1,76 \\
\hline CCNBDB5 & 12,24 & 28,75 & 29,9 & 73,4 & 0,274 & 1,756 & 1,086 & 15,36 & 2,06 \\
\hline CCNBDB6 & 9,99 & 28,75 & 30,0 & 74,2 & 0,267 & 1,760 & 1,045 & 12,96 & 1,66 \\
\hline CCNBDB7 & 12,24 & 28,85 & 29,9 & 73,4 & 0,274 & 1,756 & 1,092 & 14,26 & 1,92 \\
\hline \multicolumn{9}{|r|}{$\begin{array}{l}\text { Média } \\
\text { Padrão }\end{array}$} & $\begin{array}{l}1,77 \\
0,16\end{array}$ \\
\hline GRANITO & $\begin{array}{c}a_{0} \\
(\mathrm{~mm})\end{array}$ & $\begin{array}{c}a_{1} \\
(\mathrm{~mm})\end{array}$ & $\begin{array}{c}t \\
(\mathrm{~mm})\end{array}$ & $\begin{array}{c}D \\
(\mathrm{~mm})\end{array}$ & $u$ & $v$ & $Y_{\min }$ & $\begin{array}{l}F_{\max } \\
(\mathrm{kN})\end{array}$ & $\begin{array}{c}K_{I C} \\
\text { MPa.m }\end{array}$ \\
\hline CCNBDG1 & 11,41 & 28,70 & 30,0 & 74,0 & 0,271 & 1,758 & 1,062 & 10,23 & 1,33 \\
\hline CCNBDG2 & 11,86 & 28,75 & 29,9 & 73,5 & 0,273 & 1,758 & 1,080 & 9,61 & 1,28 \\
\hline CCNBDG3 & 13,06 & 28,75 & 29,8 & 73,6 & 0,278 & 1,754 & 1,093 & 8,74 & 1,18 \\
\hline CCNBDG4 & 12,06 & 28,70 & 30,0 & 74,0 & 0,273 & 1,758 & 1,069 & 10,28 & 1,35 \\
\hline CCNBDG5 & 10,61 & 28,75 & 29,5 & 74,0 & 0,269 & 1,761 & 1,058 & 8,95 & 1,18 \\
\hline CCNBDG6 & 11,05 & 28,70 & 29,9 & 73,5 & 0,270 & 1,758 & 1,068 & 9,81 & 1,29 \\
\hline CCNBDG7 & 11,80 & 28,75 & 29,7 & 73,5 & 0,273 & 1,758 & 1,080 & 8,25 & 1,11 \\
\hline & & & & & & & Desvic & Padrão & $\begin{array}{l}1,25 \\
0,09\end{array}$ \\
\hline
\end{tabular}

\subsubsection{Corpos de prova cilíndricos entalhados axialmente em ruptura por compressão -“Compression Splitting Test (CST)”}

O corpo de prova consiste de um cilindro com um pré-entalhe reto central paralelo ao maior eixo. Este corpo de prova sofrerá compressão através de um prato rígido de carregamento na parte superior, conforme mostrado na Figura 63. Os corpos de prova tiveram $110 \mathrm{~mm}$ de comprimento e diâmetros que variaram de 51,2 a 54,5 mm para o basalto e de 53,0 a 54,0 mm para o granito.

O procedimento de preparação dos corpos de prova consistiu nas seguintes etapas:

1. Extração dos testemunhos cilíndricos a partir dos blocos de basalto e granito com brocas diamantadas de 54,5 mm de diâmetro interno; 
2. Os corpos de prova foram retificados em suas faces laterais e faces paralelas no torno para um melhor acabamento, obtendo-se corpos de prova de $110 \mathrm{~mm}$ de comprimento e 53,5 mm de diâmetro em média;

3. Para confecção do entalhe reto foram utilizados um disco adiamantado de $200 \mathrm{~mm}$ de diâmetro externo e 1,50 mm de espessura e um dispositivo para fixar o corpo de prova para fazer o entalhe (Figura 62);

4. O dispositivo foi fixado na mesa da retífica através de uma morsa;.

5. Cortou-se um entalhe reto de $60 \mathrm{~mm}$ de comprimento em média;

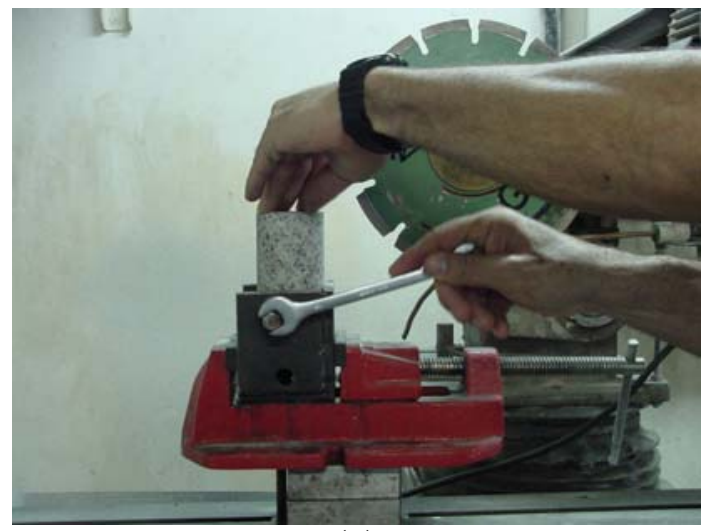

(a)

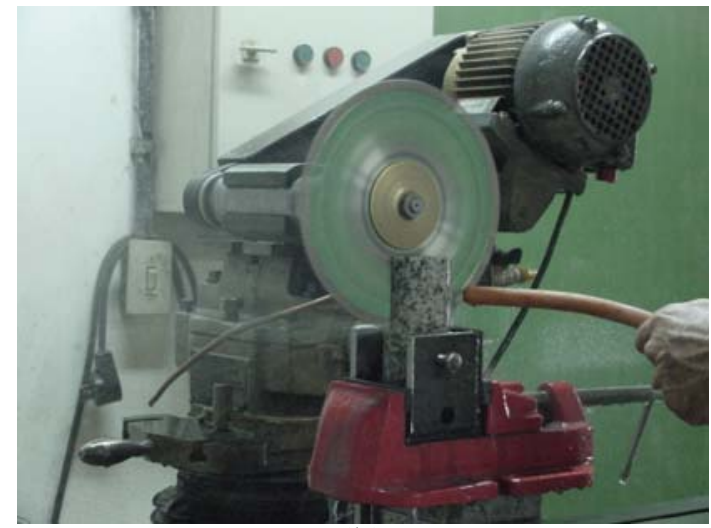

(b)

Figura 62 - Preparação do corpo de prova CST: (a) Colocação do corpo de prova; (b) Confecção do entalhe reto.

6. Confeccionou-se um prato rígido retangular aplainado de $20 \mathrm{~mm}$ de largura para comprimir a parte superior do corpo de prova;

7. Pintaram-se de branco os corpos de prova para facilitar a visualização do início do crescimento do pré-entalhe.

Verificou-se que as dimensões dos corpos de prova e o prato rígido de carregamento cumpriram as relações estabelecidas por Karihaloo $(1984,1985)$ para assegurar uma ruptura por partição axial, onde é necessário que o comprimento do pré-entalhe e a largura do prato estejam dentro dos seguintes limites: $w_{p} / W \leq 1 / 2$ e $1 \leq a / W \leq 3 / 2$.

O procedimento de ensaio dos corpos de prova consistiu nas seguintes etapas:

1. O prato de carregamento foi cuidadosamente instalado no corpo de prova e devidamente alinhado, tendo-se o cuidado de garantir o contato com toda a área submetida à compressão; 


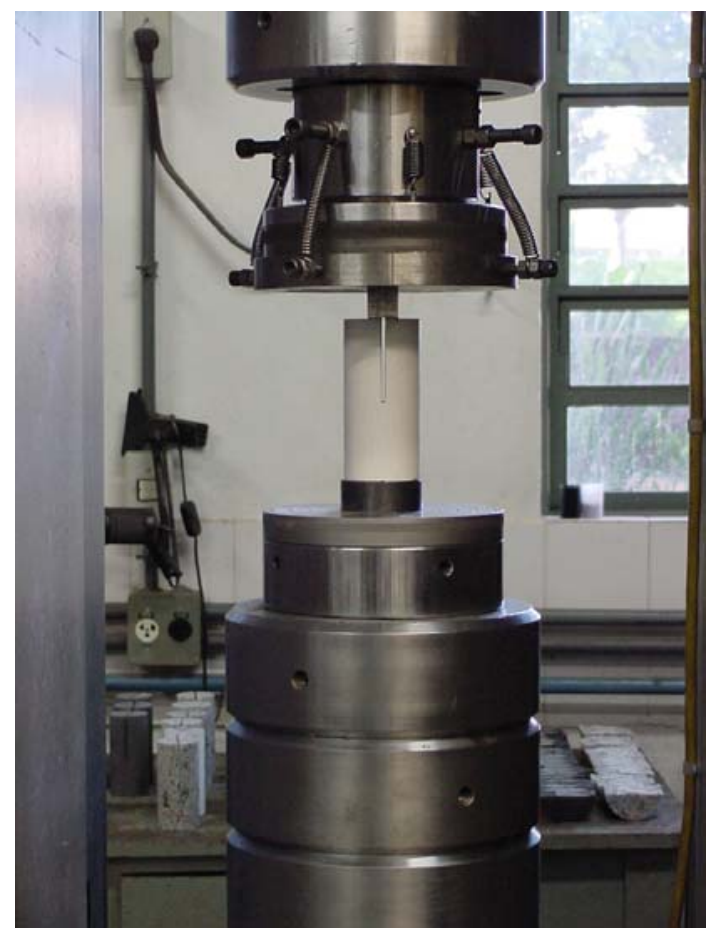

(a)

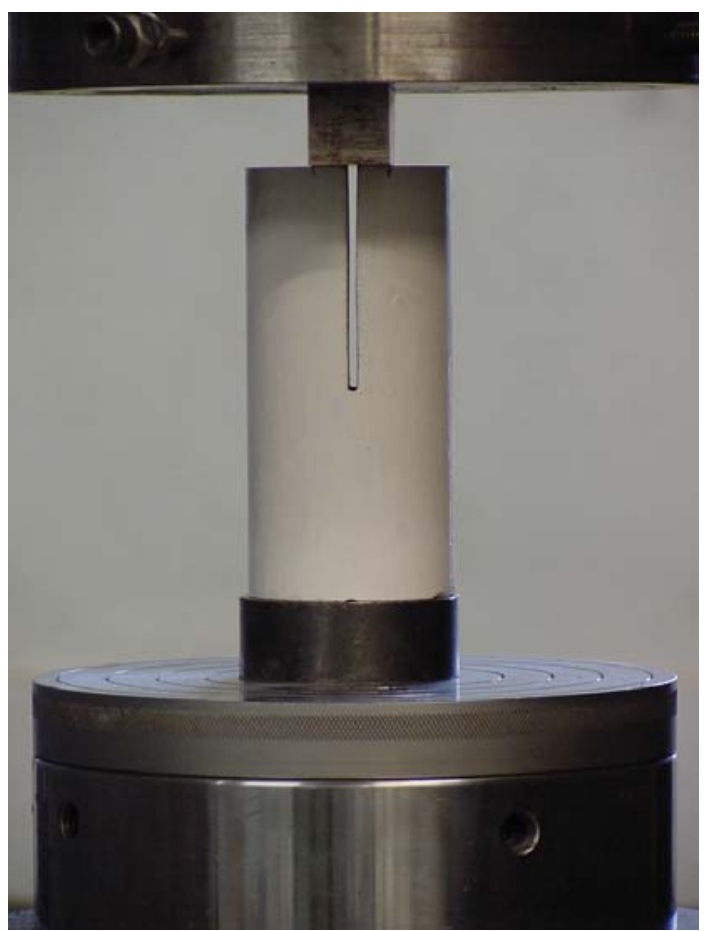

(b)

Figura 63 - Ensaio de corpos de prova cilíndricos entalhados axialmente em ruptura por compressão (CST): (a) Configuração geral do ensaio; (b) Detalhe do ensaio e da placa de aço rígida de largura " $w_{P}$ " na superfície superior do corpo de prova.

2. As superfícies do corpo de prova foram iluminadas para monitorar o progresso da frente da trinca, a qual aparece como uma linha escura na superfície pintada como mostrado na Figura 64;

3. A força foi aplicada com velocidades de carregamento de $0,0008 \mathrm{~mm} / \mathrm{s}$ e $0,002 \mathrm{~mm} / \mathrm{s}$, as quais foram mantidas constantes, enquanto que a frente da trinca era localizada em cada superfície;

Salienta-se que a força máxima considerada na fórmula empregada para determinação da tenacidade à fratura é considerada a partir do instante no qual a ponta do entalhe préexistente começa a propagar. Ressalta-se que o valor no gráfico carga-deslocamento ainda não é o correspondente ao máximo neste momento, ou seja, não corresponde à ruptura. Esta força máxima é de difícil definição por não se ter controle da abertura da boca da trinca, sendo difícil determinar o momento no qual acontece o início da propagação do pré-entalhe. Em alguns materiais, este início é facilmente visível e, portanto, facilmente determinado, não sendo o mesmo caso quando se trata de rochas. 


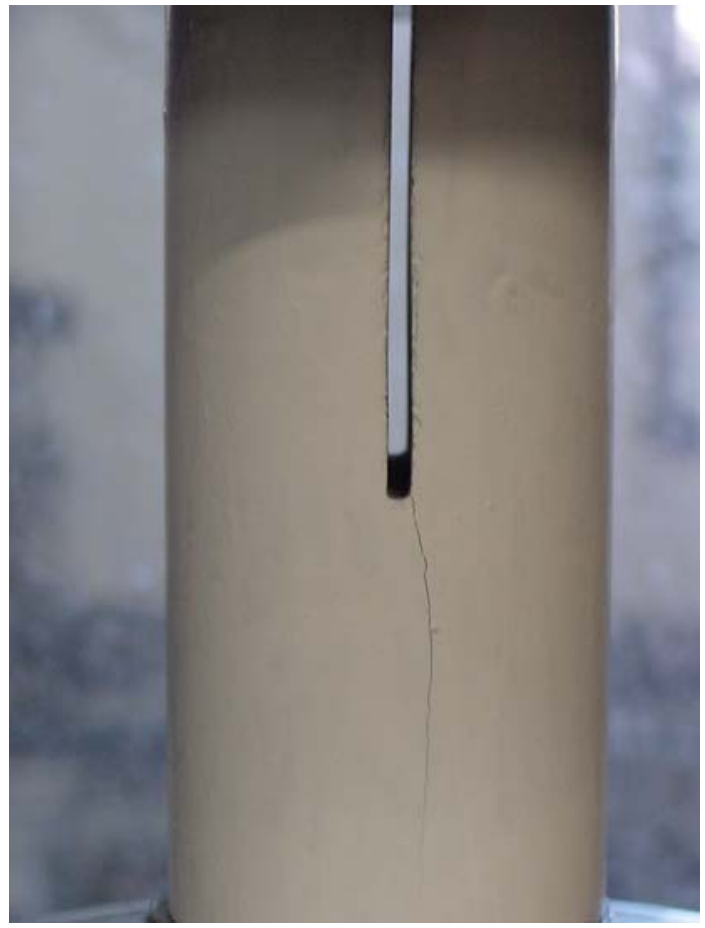

(a)

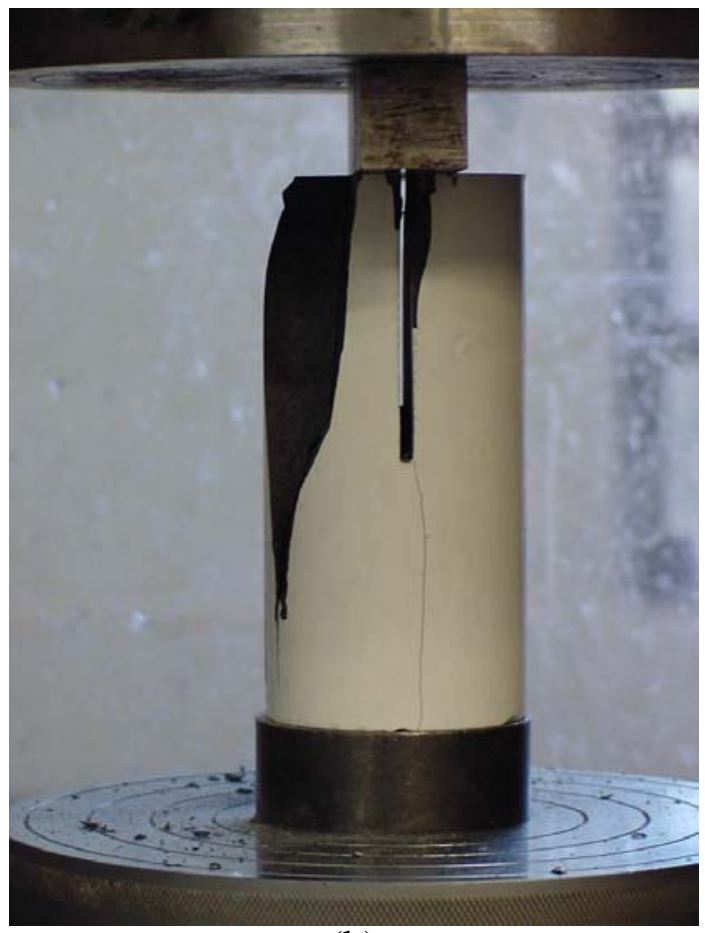

(b)

Figura 64 - Propagação do pré-entalhe: (a) Detalhe do corpo de prova; (b) Depois da propagação do pré-entalhe

Foram realizados 12 ensaios $C S T$, cuja representação típica dos resultados se dá conforme a Figura 65 abaixo. Os resultados de $K_{I C}$ foram determinados destes gráficos, segundo o procedimento e fórmulas sugeridos por Karihaloo $(1984 ; 1985)$ apresentados no Capítulo 3.

Ensaio CST

Corpo de prova CSTB5

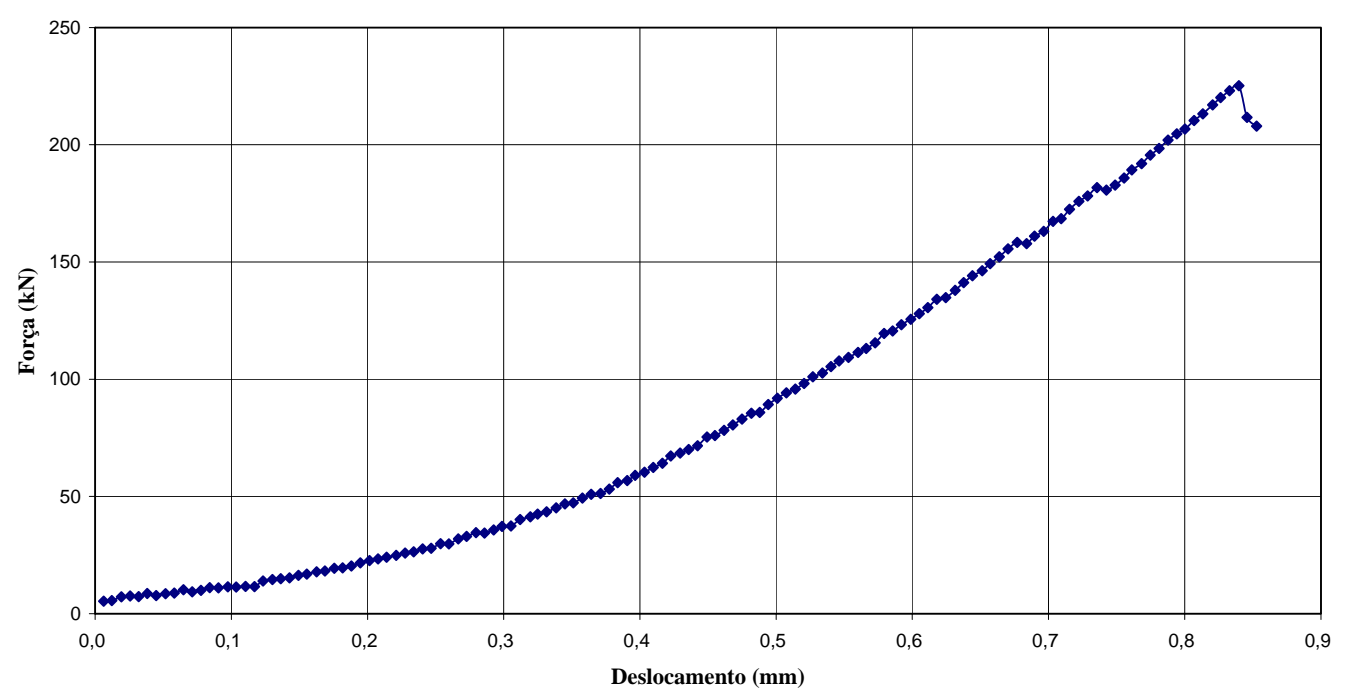

Figura 65 - Gráfico Força versus deslocamento típico do ensaio CST 
A Tabela 13 abaixo apresenta os respectivos resultados dos ensaios CST sugerido por Karihaloo (1984; 1985) e realizados no basalto e no granito neste programa de pesquisa:

Tabela 13 - Resultados do ensaio em corpos de prova cilíndricos entalhados axialmente em ruptura por compressão (CST)

\begin{tabular}{|l|c|c|c|c|c|c|c|c|}
\hline & $\begin{array}{c}c \\
(\mathrm{~mm})\end{array}$ & $\begin{array}{c}d \\
(\mathrm{~mm})\end{array}$ & $\begin{array}{c}F \\
(\mathrm{kN})\end{array}$ & $R$ & $B$ & $\begin{array}{c}K_{I C}{ }^{*} \\
\left({\mathrm{MPa} . \mathrm{m}^{1 / 2}}^{1 / 2}\right.\end{array}$ & $\begin{array}{c}K_{I C}{ }^{* *} \\
\left({\mathrm{MPa} . \mathrm{m}^{1 / 2}}^{1 / 2}\right.\end{array}$ & $\begin{array}{c}K_{I C}{ }^{* * *} \\
\left({\mathrm{MPa} . \mathrm{m}^{1 / 2}}^{1 / 2}\right.\end{array}$ \\
\hline CSTB1 & 59,0 & 54,5 & 121,44 & 0,00014 & 0,0431 & 3,58 & 3,47 & 3,57 \\
\hline CSTB2 & 59,6 & 53,8 & 93,29 & $8,56 \mathrm{E}-05$ & 0,0422 & 2,77 & 2,69 & 2,77 \\
\hline CSTB3 & 57,0 & 52,5 & 94,94 & $9,18 \mathrm{E}-05$ & 0,0406 & 2,87 & 2,79 & 2,86 \\
\hline CSTB5 & 60,0 & 54,0 & 85,83 & $7,21 \mathrm{E}-05$ & 0,0425 & 2,54 & 2,47 & 2,54 \\
\hline CSTB6 & 59,0 & 51,2 & 119,84 & 0,00015 & 0,0389 & 3,69 & 3,58 & 3,68 \\
\hline
\end{tabular}

GRANITO

\begin{tabular}{|c|c|c|c|c|c|c|c|c|}
\hline & $\begin{array}{c}c \\
(\mathrm{~mm})\end{array}$ & $\begin{array}{c}d \\
(\mathrm{~mm})\end{array}$ & $\begin{array}{c}F \\
(\mathrm{kN})\end{array}$ & $R$ & $B$ & $\begin{array}{c}K_{I C}{ }^{*} \\
\left({\left.\mathrm{MPa} . \mathrm{m}^{1 / 2}\right)}^{2}\right)\end{array}$ & 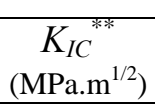 & $\begin{array}{c}K_{I C}{ }^{* * *} \\
\left(\mathrm{MPa} \cdot \mathrm{m}^{1 / 2}\right)\end{array}$ \\
\hline CSTG1 & 59,5 & 53,0 & 75,34 & $8,43 \mathrm{E}-05$ & 0,0429 & 2,31 & 2,19 & 2,30 \\
\hline CSTG3 & 65,0 & 53,4 & 76,79 & $8,66 \mathrm{E}-05$ & 0,0434 & 2,34 & 2,23 & 2,33 \\
\hline CSTG4 & 60,0 & 53,9 & 97,93 & 0,00014 & 0,0440 & 2,97 & 2,82 & 2,96 \\
\hline CSTG5 & 59,0 & 54,0 & 100,51 & 0,00015 & 0,0442 & 3,04 & 2,89 & 3,03 \\
\hline CSTG6 & 59,5 & 53,1 & 104,32 & 0,00016 & 0,0430 & 3,19 & 3,04 & 3,18 \\
\hline & & & & Desvio & $\begin{array}{l}\text { Média } \\
\text { Padrão }\end{array}$ & $\begin{array}{l}2,77 \\
0,42\end{array}$ & $\begin{array}{l}2,63 \\
0,39\end{array}$ & $\begin{array}{l}2,76 \\
0,41\end{array}$ \\
\hline
\end{tabular}

${ }^{*}$ CST considerando-se efeitos de cisalhamento;

${ }^{* *}$ CST considerando efeitos de cisalhamento e a energia de superfície da fratura em condições de deformação plana;

${ }^{* * *}$ CST sem considerar efeitos de cisalhamento;

\subsubsection{Corpos de prova semicirculares submetidos à flexão em três pontos - "Semicircular Bend specimen (SCB)"}

O corpo de prova está baseado na forma semicircular com um simples entalhe reto central na borda. Este corpo de prova é submetido a um carregamento de flexão a três pontos, conforme mostrado na Figura 67. Os corpos de prova tiveram 72,5 a 73,6 mm de diâmetro para o basalto e 72,2 a 72,5 para o granito; os entalhes variaram de 20,0 a $22,0 \mathrm{~mm}$ para o basalto e de 19,0 a 22,0 $\mathrm{mm}$ para o granito. O ensaio foi realizado com controle de abertura da boca da trinca $(C M O D)$.

O procedimento de preparação dos corpos de prova consistiu nas seguintes etapas:

1. As metades dos corpos de prova “ $C B$ ”, após fraturados, foram utilizados para a confecção destes corpos de prova; 
2. Cortaram-se discos de 29,70 a 31,90 mm de espessura na máquina de corte. Os discos foram cortados pela metade, obtendo-se corpos de prova semicirculares, dos quais um deles foi utilizado para o ensaio $S C B$;

3. Para confecção do entalhe reto, foram utilizados um disco adiamantado de $150 \mathrm{~mm}$ de diâmetro externo e $1 \mathrm{~mm}$ de espessura e um dispositivo para fixar o corpo de prova para fazer o entalhe;

4. Este dispositivo consiste em dois parafusos fixados a uma chapa metálica que prende o corpo de prova mediante duas chapas menores (Figura 66);

5. O disco penetrou o corpo de prova uma profundidade de $21 \mathrm{~mm}$ em média para obedecer aos requisitos propostos por Whittaker, Singh e Sun (1992) ( 0,25 $\leq \frac{a}{D} \leq 0,35$ e $\left.\frac{S}{D}=0,8\right)$ e por Lim, Johnston e Choi (1993) $\left(\frac{S}{R}=0,5 ; 0,61 ; 0,67\right.$ e 0,8 e $\left.0,03 \leq \frac{a}{R} \leq 0,8\right)$

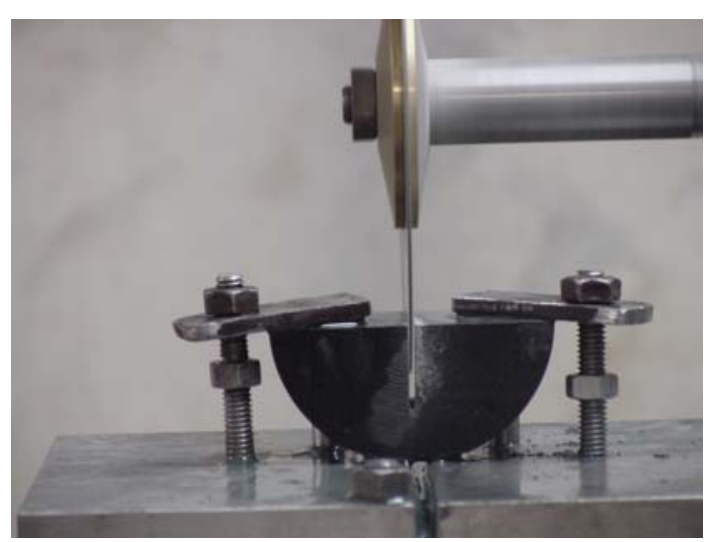

(a)

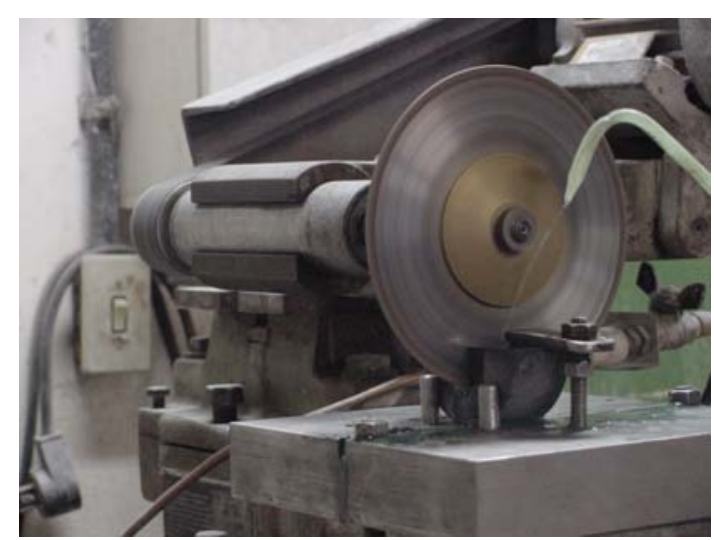

(b)

Figura 66 - Preparação do corpo de prova SCB: Confecção do entalhe reto (a) Frente. (b) Perfil

Verificou-se as dimensões dos corpos de prova segundo o recomendado por Whittaker, Singh e Sun (1992), com $0.25 \leq a / D \leq 0.35$ e $S / D=0.8$; e o recomendado por Lim, Johnston e Choi (1993), com $0.5 \leq S_{a} / r \leq 0.8$, onde:

$a / D$ : comprimento adimensional da trinca;

$D$ : diâmetro do corpo de prova;

$S$ : vão entre os apoios do corpo de prova; 
$S_{a / r}$ : relação atual do vão empregado (segundo proposta de LIM, JOHNSTON e CHOI, 1993)

O procedimento de ensaio dos corpos de prova consistiu nas seguintes etapas:

1. Primeiramente, foram coladas no corpo de prova duas hastes posicionadas exatamente na abertura da boca da trinca;

2. Para medir o deslocamento $C M O D$, se fixa o extensômetro do tipo "clip gauge" ao corpo de prova através das hastes como mostrado na Figura 67b, as quais suportam os ajustadores e servem como referência aos deslocamentos;

3. Aplica-se a força compressiva até que a ruptura e a carga de pico sejam determinadas;

4. A velocidade do ensaio utilizado foi de $0,001 \mathrm{~mm} / \mathrm{s}$ para o basalto e o granito;

5. As variáveis medidas são a carga máxima aplicada $\left(F_{\max }\right)$ e o deslocamento da abertura da boca da trinca $(C M O D)$.

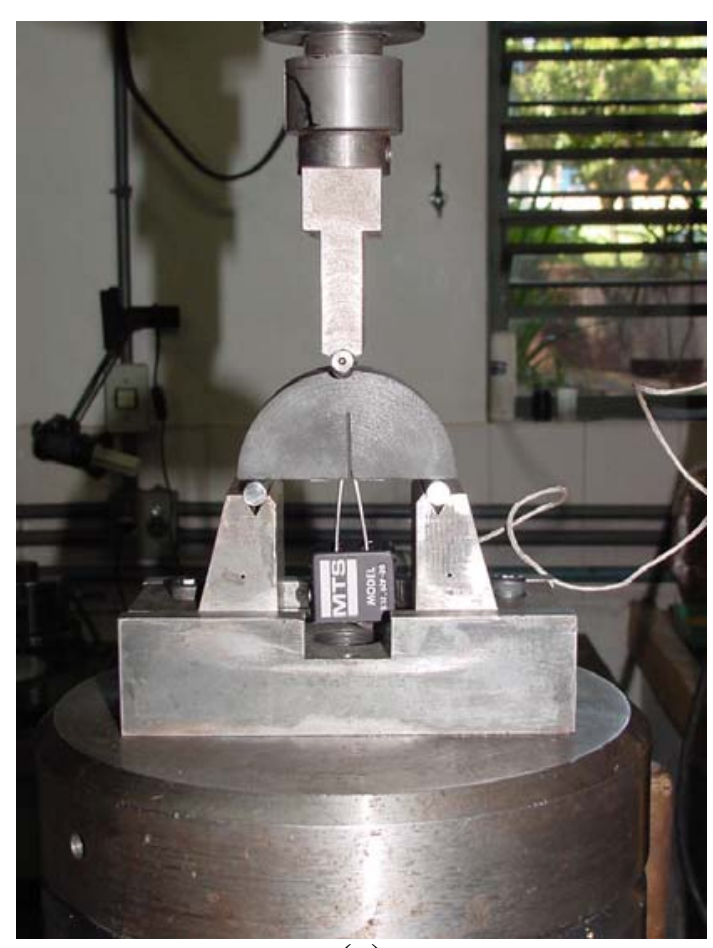

(a)

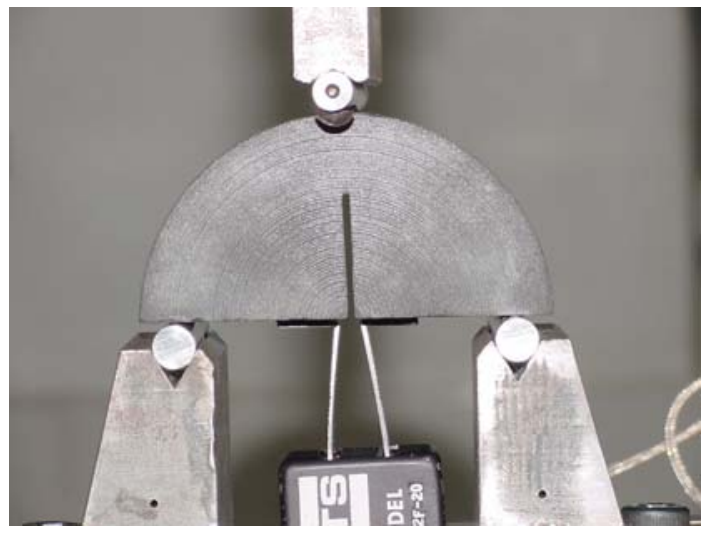

(b)

Figura 67 - Ensaio de corpos de prova semicirculares submetidos à flexão em três pontos ( $S C B$ ): (a) Configuração geral do ensaio; (b) Detalhe do ensaio mostrando o controle da abertura da boca da trinca por meio do extensômetro do tipo "clip gauge"

Foram realizados 10 ensaios $S C B$, cuja representação típica dos resultados se dá conforme a Figura 68 abaixo. Os resultados de $K_{I C}$ foram determinados destes gráficos, 
segundo o procedimento e fórmulas sugeridos por Whittaker, Singh e Sun (1992) e Lim, Johnston e Choi (1993) apresentados no Capítulo 3.

\section{Ensaio SCB}

Corpo de prova SCBB1

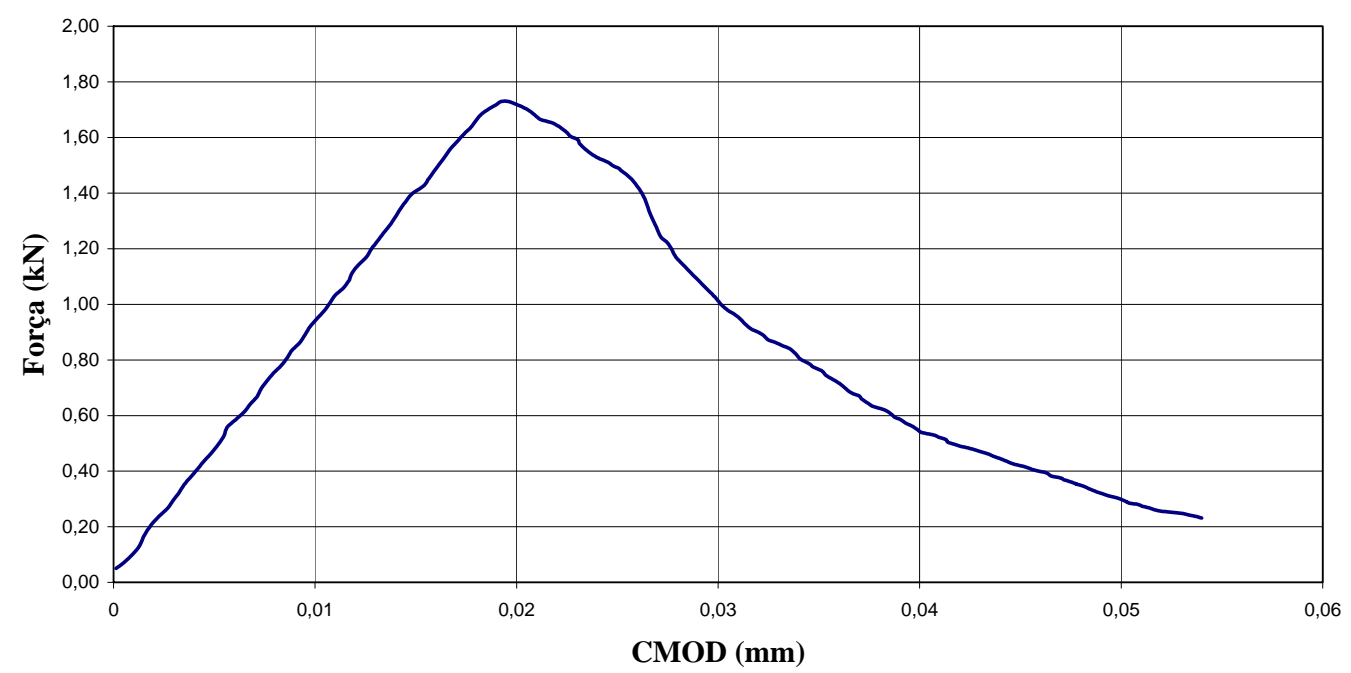

Figura 68 - Gráfico Força versus $C M O D$ típico do ensaio $S C B$

A Tabela 14 abaixo apresenta os respectivos resultados dos ensaios $S C B$ sugerido por Whittaker, Singh e Sun (1992) e realizados no basalto e no granito neste programa de pesquisa:

Tabela 14 - Resultados do ensaio em corpos de prova semicirculares submetidos à flexão em três pontos (segundo fórmula de Whittaker, Singh e Sun, 1992)

\begin{tabular}{|c|c|c|c|c|c|c|c|}
\hline & $\begin{array}{c}a \\
(\mathrm{~mm})\end{array}$ & $\begin{array}{c}D \\
(\mathrm{~mm})\end{array}$ & $a / D$ & $Y_{K}$ & $\begin{array}{c}t \\
(\mathrm{~mm})\end{array}$ & $\begin{array}{c}P \\
(\mathrm{kN})\end{array}$ & $\begin{array}{c}K_{I C} \\
\left(\mathrm{MPa}^{1 / 2}\right)\end{array}$ \\
\hline SCBB1 & 22,0 & 73,6 & 0,299 & 8,783 & 31,5 & 1,730 & 1,723 \\
\hline SCBB2 & 20,0 & 73,0 & 0,274 & 7,452 & 29,7 & 1,904 & 1,640 \\
\hline SCBB3 & 20,5 & 72,5 & 0,283 & 7,883 & 31,8 & 1,834 & 1,591 \\
\hline SCBB4 & 20,1 & 72,6 & 0,277 & 7,589 & 29,8 & 1,827 & 1,610 \\
\hline \multicolumn{70}{|c}{ Desvio } & $\begin{array}{c}\text { Média } \\
\text { Padrão }\end{array}$ & 1,64 \\
\end{tabular}

\begin{tabular}{|c|c|c|c|c|c|c|c|}
\hline & $\begin{array}{c}a \\
(\mathrm{~mm})\end{array}$ & $\begin{array}{c}D \\
(\mathrm{~mm})\end{array}$ & $a / D$ & $Y_{K}$ & $\begin{array}{c}t \\
(\mathrm{~mm})\end{array}$ & $\begin{array}{c}P \\
(\mathrm{kN})\end{array}$ & $\begin{array}{c}K_{I C} \\
\left(\mathrm{MPa}^{1 / 2}\right)\end{array}$ \\
\hline SCBG1 & 22,0 & 72,5 & 0,303 & 9,062 & 31,4 & 1,062 & 1,112 \\
\hline SCBG2 & 21,0 & 72,5 & 0,289 & 8,250 & 31,9 & 1,035 & 0,948 \\
\hline SCBG3 & 20,4 & 72,2 & 0,283 & 7,872 & 29,6 & 1,076 & 1,003 \\
\hline SCBG4 & 21,8 & 72,4 & 0,301 & 8,917 & 31,2 & 1,069 & 1,105 \\
\hline SCBG5 & 19,0 & 72,3 & 0,263 & 6,958 & 29,8 & 1,294 & 1,021 \\
\hline
\end{tabular}


A Tabela 15 abaixo apresenta os respectivos resultados dos ensaios $S C B$ sugerido por Lim, Johnston e Choi, (1993) e realizados no basalto e no granito neste programa de pesquisa:

Tabela 15 - Resultados do ensaio em corpos de prova semicirculares submetidos à flexão em três pontos (segundo fórmula de Lim, Johnston e Choi, 1993)

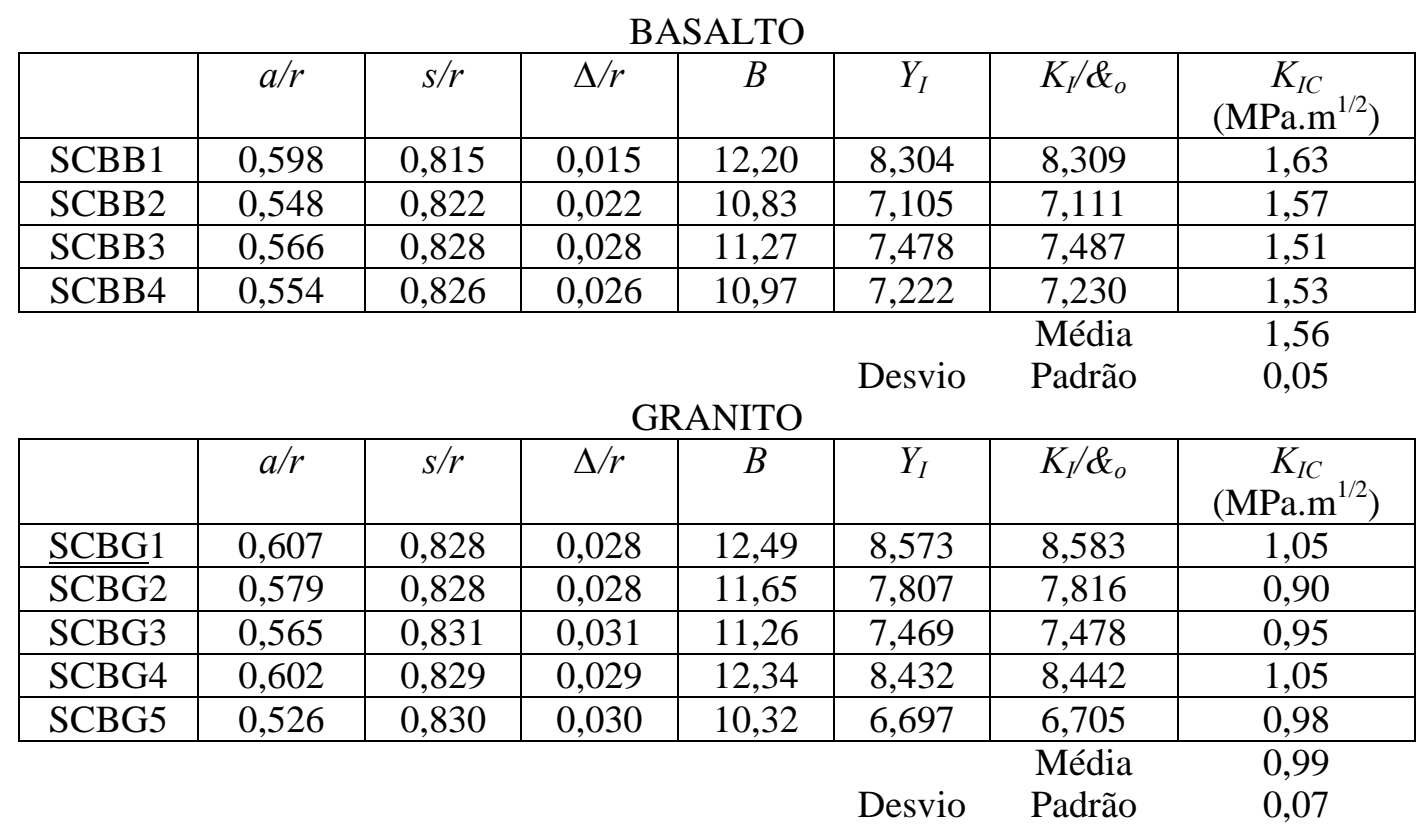

\subsubsection{Corpos de prova semicirculares com entalhe tipo "Chevron" submetidos à flexão em três pontos - "Chevron Notched Semicircular Bend (CNSCB)"}

O corpo de prova tem forma semicircular com um entalhe "chevron" central na borda. Este corpo de prova é submetido a um carregamento de flexão a três pontos, conforme mostrado na Figura 70. Os corpos de prova tiveram 29,7 a 31,9 mm de espessura para o basalto e 30,8 a 31,7 para o granito e raios que variaram de 36,2 a $36,75 \mathrm{~mm}$ para o basalto e de 36,1 a 36,2 mm para o granito. O ensaio foi realizado com controle de abertura da boca da trinca $(C M O D)$.

O procedimento de preparação dos corpos de prova consistiu nas seguintes etapas:

1. As metades dos corpos de prova " $C B$ ”, depois de fraturados, foram utilizadas para a confecção destes corpos de prova;

2. Cortaram-se discos de 29,70 $\mathrm{mm}$ a $31,90 \mathrm{~mm}$ de espessura na maquina de corte;

3. Os discos foram cortados pela metade, obtendo-se corpos de prova semicirculares, um dos quais foi utilizado para o ensaio $C N S C B$; 
4. Para confecção do entalhe "chevron", foi utilizado um disco adiamantado de $150 \mathrm{~mm}$ de diâmetro externo e 1,0 mm de espessura e um dispositivo para fixar o corpo de prova para fazer o entalhe. Este dispositivo consiste de uma dobradiça que permite fazer um corte a $45^{\circ}$ (Figura 69). O disco penetrou no corpo de prova uma profundidade de 16 mm. Deve-se ter o cuidado de se obedecer às dimensões estabelecidas por Kuruppu (1998) $\left(\frac{a_{0}}{R} \approx 0.24\right)$.

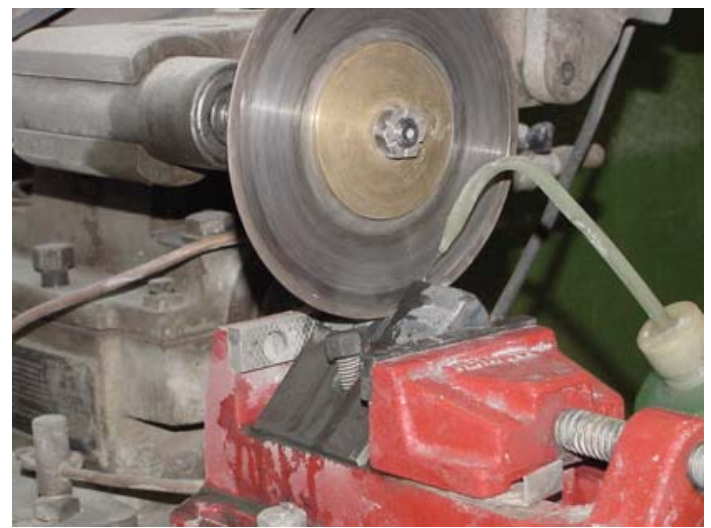

(a)

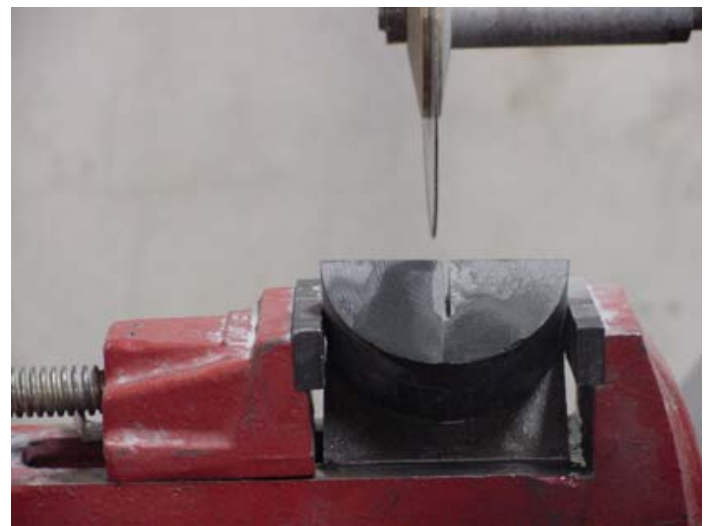

(b)

Figura 69 - Preparação do corpo de prova CNSCB: Confecção do entalhe “chevron”: (a) Perfil; (b) Frente

Segundo recomendado por Kuruppu (1998), utilizou-se no ensaio CNSCB uma relação de $a_{0} / R \approx 0.24$ ( $a_{0}=8.5 \mathrm{~mm}$ e $R \approx 36.75 \mathrm{~mm}$ ) com relação $S / R=0.8$. Salienta-se que estas relações foram usadas por Chang, Lee e Jeon (2002) com corpos de prova de $75 \mathrm{~mm}$ de diâmetro e 23 e 32 mm de espessura.

O procedimento de ensaio dos corpos de prova consistiu nas seguintes etapas:

1.- Primeiramente, foram colados no corpo de prova duas hastes posicionadas exatamente na boca da trinca;

2.- Para medir o deslocamento $C M O D$, fixa-se o extensômetro do tipo "clip gauge” ao corpo de prova através das hastes como mostrado na Figura 70b, as quais suportam os ajustadores e servem como referência aos deslocamentos;

3.- Aplica-se a força compressiva até que seja determinada a carga de pico;

4.- A velocidade do ensaio utilizada foi de $0,0013 \mathrm{~mm} / \mathrm{s}$ para o basalto e o granito. 


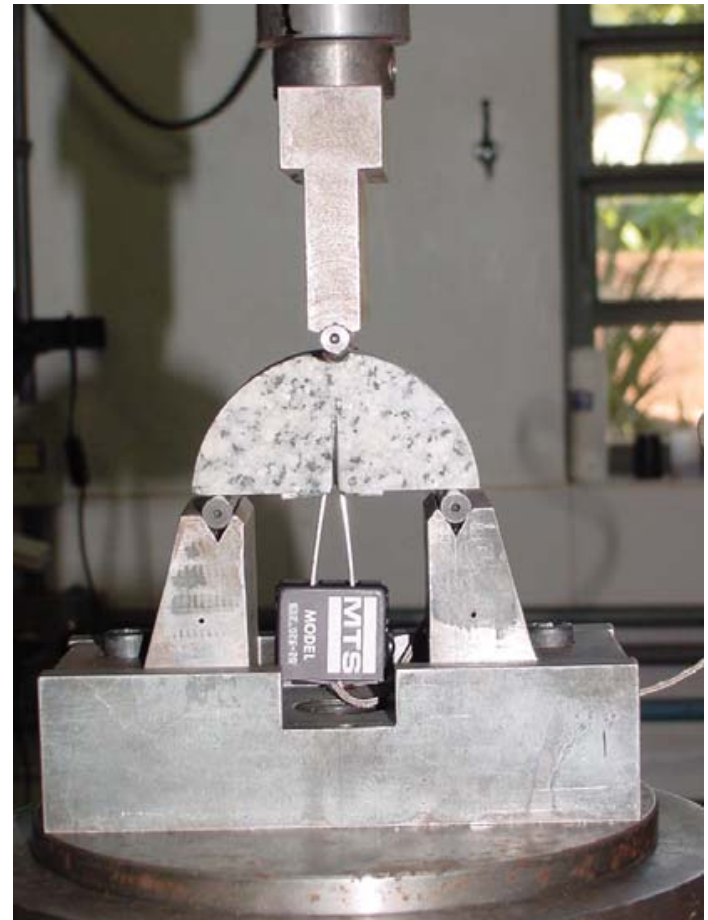

(a)

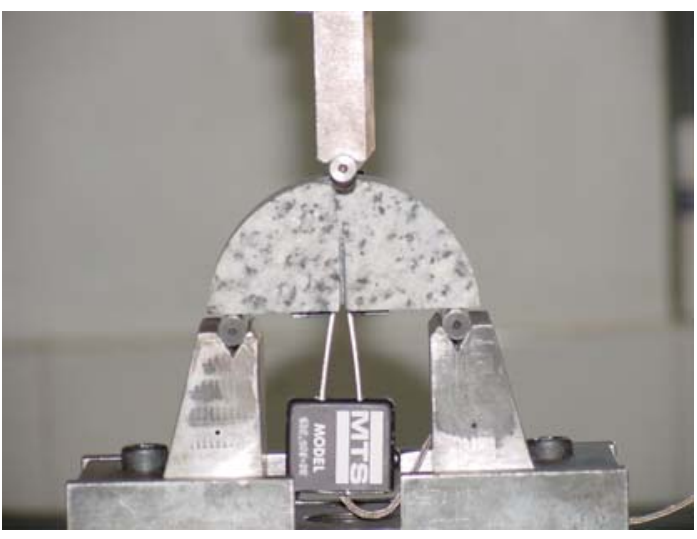

(b)

Figura 70 - Ensaio de corpos de prova semicirculares com entalhe "chevron" (CNSCB): (a) Configuração geral do ensaio; (b) Detalhe do ensaio mostrando o controle por meio do extensômetro do tipo "clip gauge".

Foram realizados 14 ensaios $C N S C B$, cuja representação típica dos resultados se dá conforme a Figura 71 abaixo. Os resultados de $K_{I C}$ foram determinados destes gráficos, segundo o procedimento e fórmulas sugeridos por Kuruppu (1997; 1998) apresentados no Capítulo 3.

\section{Ensaio CNSCB}

Corpo de prova CNSCBG2

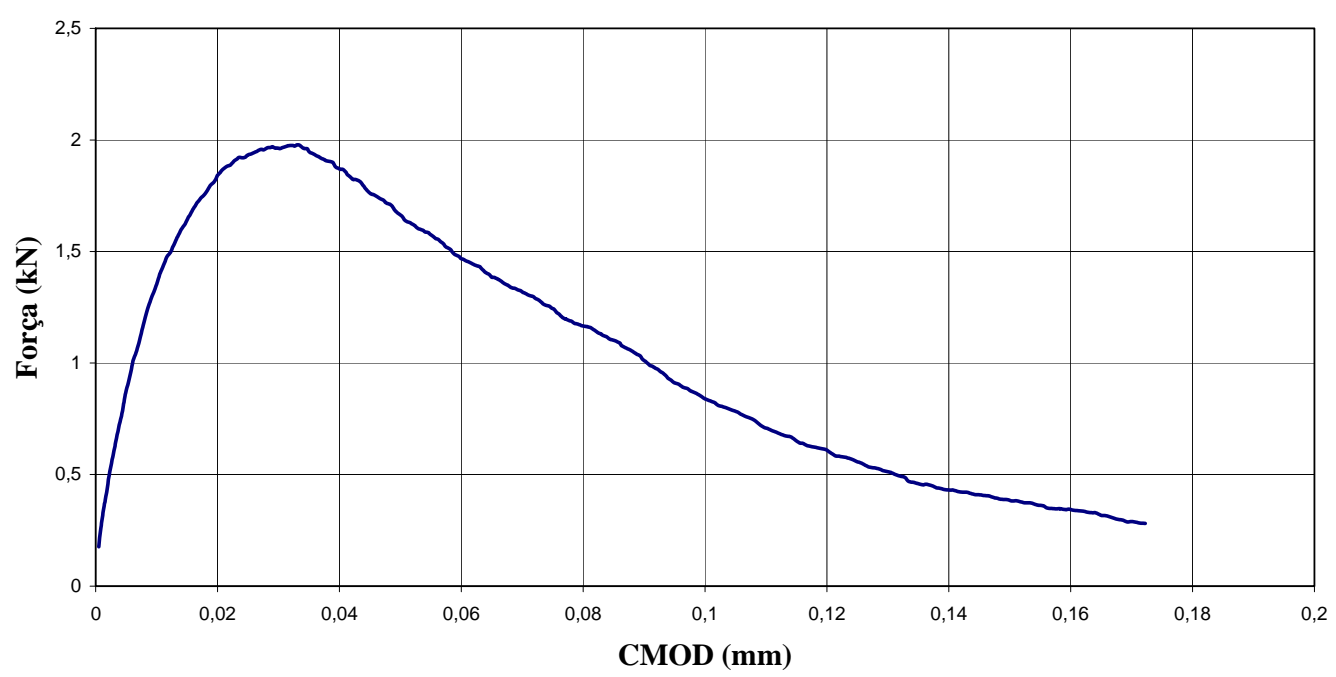

Figura 71 - Gráfico Força versus deslocamento típico do ensaio $C N S C B$ 
A Tabela 16 abaixo apresenta os respectivos resultados dos ensaios CNSCB sugerido por Kuruppu $(1997 ; 1998)$ e realizados no basalto e no granito neste programa de pesquisa:

Tabela 16 - Resultados do ensaio em corpos de prova semicirculares com entalhe tipo "chevron" submetidos à flexão em três pontos (CNSCB)

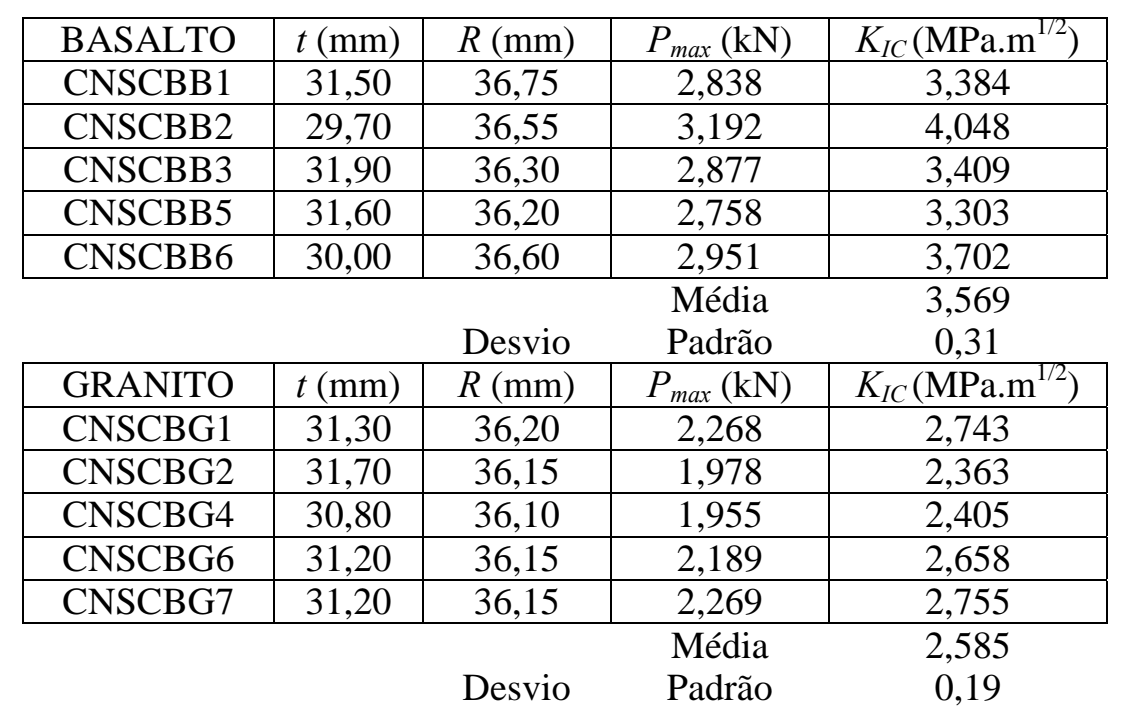

\subsubsection{Corpos de prova de anel modificado - "Modified Ring Test (MRT)”}

O corpo de prova tem a forma de disco brasileiro com furo central e com duas superfícies de carregamento aplainadas e opostas diametralmente, conforme mostrado na Figura 73.

Os corpos de prova tiveram 29,5 a 30,2 mm de espessura para o basalto e 26,5 a 27,1 para o granito; os diâmetros dos corpos de prova variaram de 57,3 a 58,7 mm para o basalto e de 53,6 a 54,2 mm para o granito; o diâmetro do furo interno foi de 11,5 mm para o basalto e de 10,5 mm para o granito; a largura da superfície aplainada variou de 15 a $16 \mathrm{~mm}$ para o basalto e de 15,2 a 16,9 mm para o granito.

O ensaio foi realizado com controle de deslocamento $L P D$ e a carga crítica considerada na primeira queda do carregamento antes de alcançar a carga máxima.

O procedimento de preparação dos corpos de prova consistiu nas seguintes etapas:

1. Extração de testemunhos cilíndricos a partir dos blocos de basalto e granito com brocas diamantadas de 60 e 54,5 mm de diâmetro interno, respectivamente. Os blocos de basalto e granito foram marcados antes da extração dos testemunhos cilíndricos para assegurar sua orientação durante o ensaio; 
2. Os testemunhos cilíndricos foram retificados em suas faces laterais e paralelas;

3. Cortaram-se os testemunhos com um disco diamantado de 200 mm de diâmetro externo e 1,50 mm de espessura;

4. Para confecção do furo central nos corpos de prova, usou-se uma broca de vídea de 11 mm de diâmetro para o basalto e 10 mm de diâmetro para o granito;

5. A broca de vídea é colocada no torno a uma velocidade de $100 \mathrm{rpm}$ para verificar e facilitar o furo no centro do corpo de prova (Figura 72a). O emprego do torno assegura que as faces dos discos sejam normais a seu próprio eixo, o que é fundamental para realizar o aplainamento das superfícies onde serão carregados os corpos de prova;

6. Os corpos de prova foram fixados em um dispositivo na retífica plana universal que permite o aplainamento das superfícies diametralmente opostas. Primeiramente aplainou-se a primeira superfície, depois virou-se o dispositivo de fixação fazendo o aplainamento no outro lado (Figura 72b).

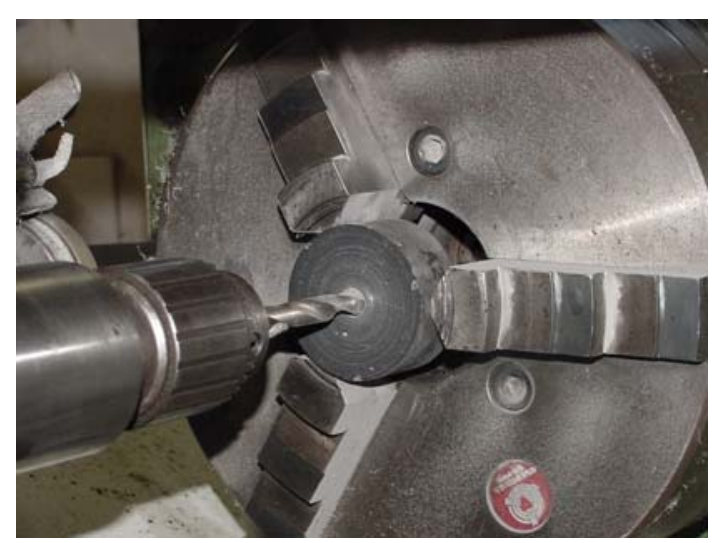

(a)

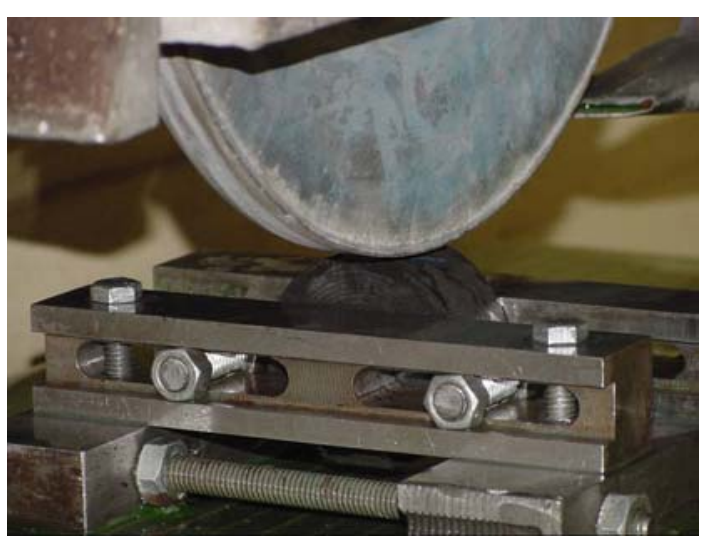

(b)

Figura 72 - Preparação do corpo de prova MRT: (a) Confecção do furo central. (b) Confecção das faces aplainadas

O procedimento de ensaio dos corpos de prova consistiu nas seguintes etapas:

1. Antes de ensaiar os corpos de prova, foram medidos o raio interno, o raio externo, a largura da superfície aplainada e a espessura de cada corpo de prova;

2. Verificaram-se as relações propostas por Thiercelin e Roegiers (1986) para os corpos de prova: $r_{i} / r_{0}=0.20$ e $0.1 \leq b / r_{0} \leq 0.35$;

3. Colocou-se o corpo de prova na máquina hidráulica servo-controlada com controle de deslocamento LPD (deslocamento do ponto de carregamento); 
4. Durante o ensaio, a carga e o deslocamento (dos pratos da máquina de ensaios) são automaticamente registrados;

5. A velocidade de carregamento no ensaio foi de $0,012 \mathrm{~mm} / \mathrm{min}$ para o basalto e o granito;

6. É determinada a carga aplicada $P$ local mínima no gráfico carga-deslocamento.

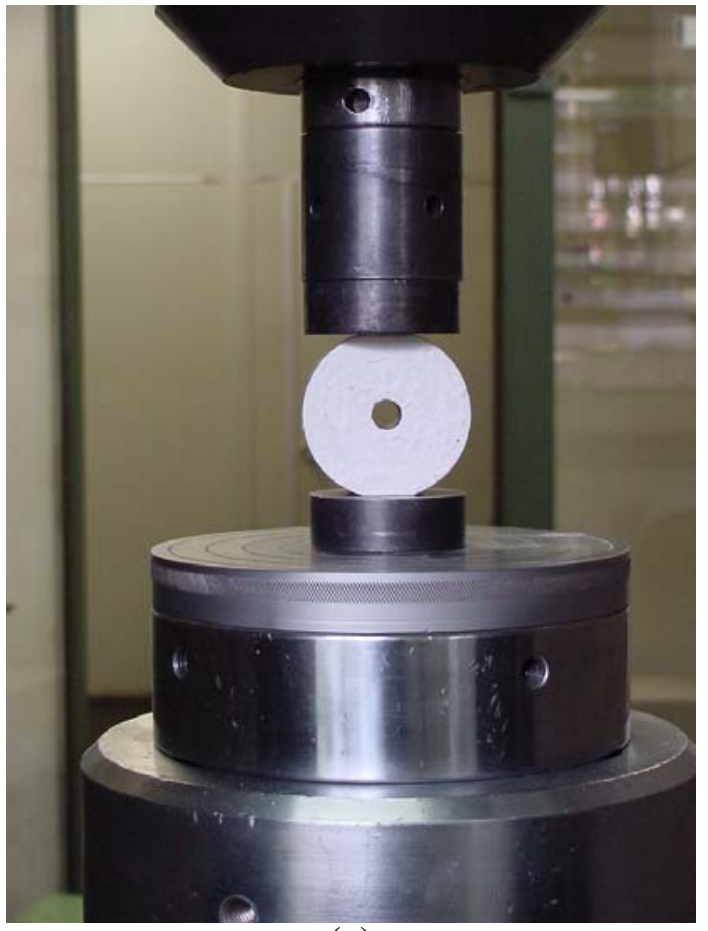

(a)

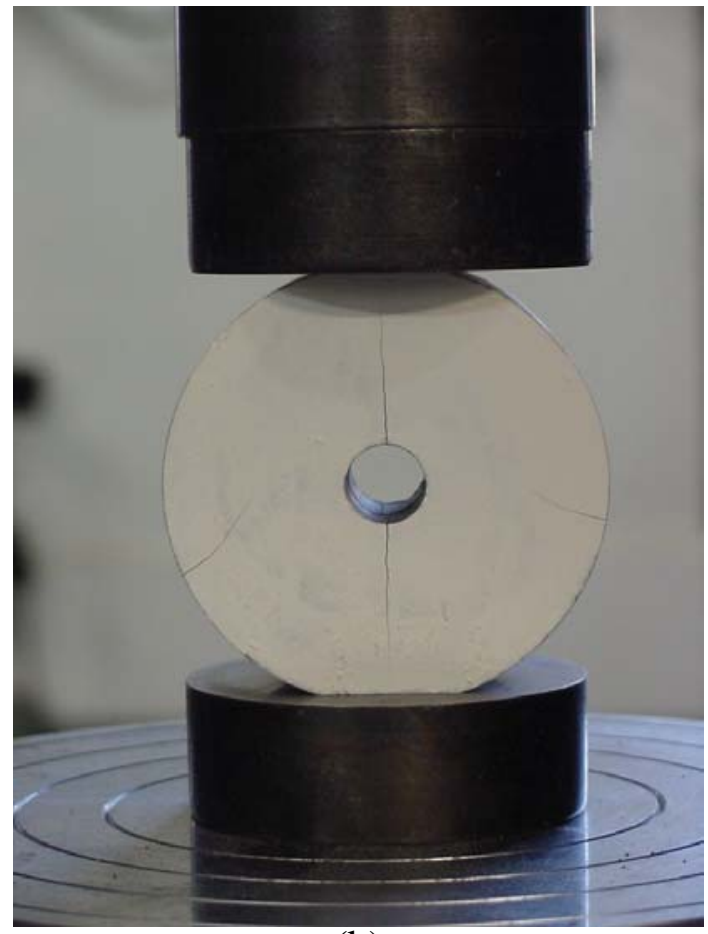

(b)

Figura 73 - Ensaio de corpos de prova de anel modificado (MRT): (a) Configuração geral do ensaio; (b) Detalhe do ensaio mostrando a propagação da trinca pelo centro do corpo de prova.

Foram realizados 12 ensaios $M R T$, cuja representação típica dos resultados se dá conforme a Figura 74 abaixo. Os resultados de $K_{I C}$ foram determinados destes gráficos, segundo o procedimento e fórmulas sugeridos por Whittaker, Singh e Sun, (1992) apresentados no Capítulo 3. 
Ensaio MRT

Corpo de prova MRTB3

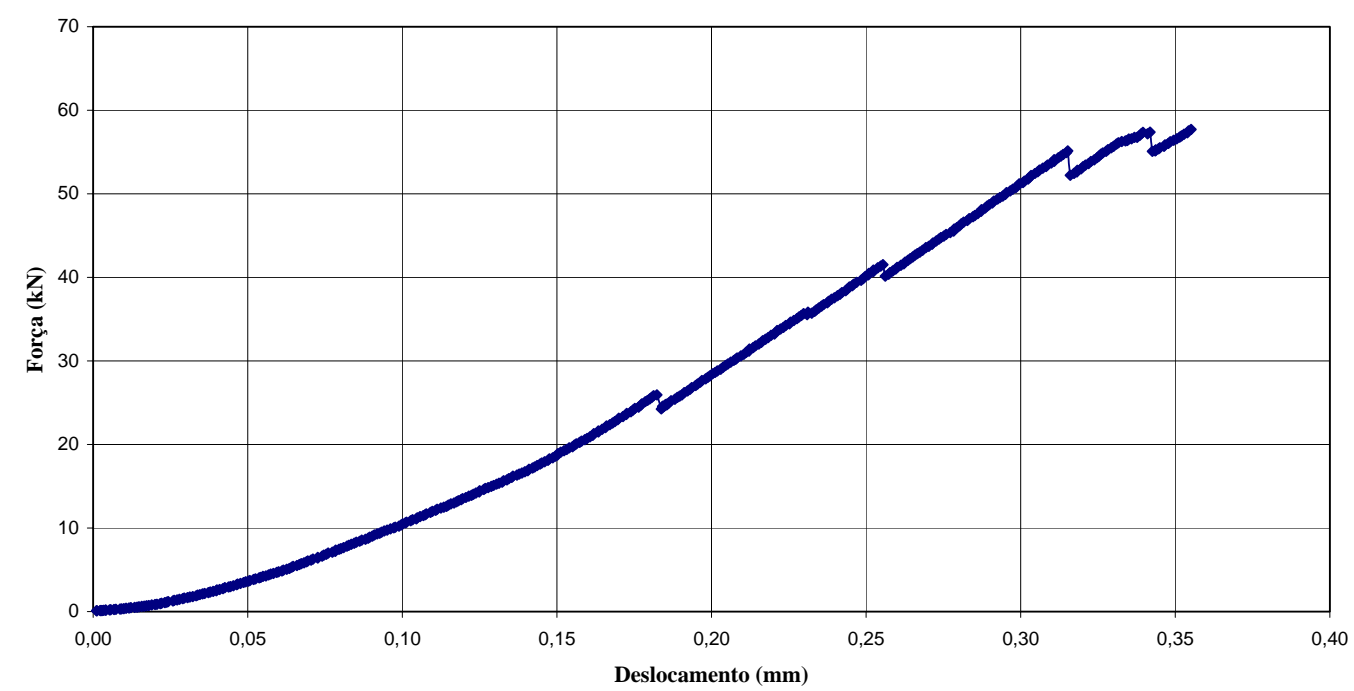

Figura 74 - Gráfico Força versus deslocamento típico do ensaio MRT

A Tabela 17 abaixo apresenta os respectivos resultados dos ensaios $M R T$ sugerido por Thiercelin e Roegiers (1986) e realizados no basalto e no granito neste programa de pesquisa:

Tabela - 17. Resultados do ensaio em corpos de prova de anel modificado (MRT)

\begin{tabular}{|}
\begin{tabular}{|c|c|c|c|c|c|c|c|c|}
\hline BASALTO & $\begin{array}{c}b \\
(\mathrm{~mm})\end{array}$ & $\begin{array}{c}r_{0} \\
(\mathrm{~mm})\end{array}$ & $\begin{array}{c}r_{i} \\
(\mathrm{~mm})\end{array}$ & $\begin{array}{c}B \\
(\mathrm{~mm})\end{array}$ & $b / r_{0}$ & $r_{i} / r_{0}$ & $\begin{array}{c}P_{\min } \\
(\mathrm{kN})\end{array}$ & $\begin{array}{c}K_{I C} \\
\mathrm{MPa} \cdot \mathrm{m}^{1 / 2}\end{array}$ \\
\hline MRTB2 & 7,50 & 29,05 & 56,5 & 30,00 & 0,258 & 0,196 & 19,15 & 2,818 \\
\hline MRTB3 & 8,00 & 29,35 & 56,0 & 29,50 & 0,273 & 0,194 & 21,50 & 3,049 \\
\hline MRTB4 & 7,78 & 29,05 & 56,0 & 29,90 & 0,268 & 0,194 & 15,40 & 2,202 \\
\hline MRTB5 & 7,65 & 29,30 & 56,5 & 30,00 & 0,261 & 0,194 & 19,88 & 2,883 \\
\hline MRTB6 & 7,95 & 29,35 & 56,0 & 30,20 & 0,271 & 0,196 & 17,97 & 2,503 \\
\hline GRANITO & $b$ & $r_{0}$ & $\begin{array}{c}r_{i} \\
(\mathrm{~mm})\end{array}$ & $\begin{array}{c}B \\
(\mathrm{~mm})\end{array}$ & $b / r_{0}$ & $r_{i} / r_{0}$ & $\begin{array}{c}P_{\text {min }} \\
(\mathrm{km})\end{array}$ & $\begin{array}{c}K_{I C} \\
\text { MPa.m }\end{array}$ \\
\hline MRTG1 & 7,58 & 27,10 & 52,0 & 27,10 & 0,279 & 0,199 & 15,75 & 2,475 \\
\hline MRTG2 & 7,60 & 26,85 & 52,5 & 26,50 & 0,283 & 0,195 & 12,59 & 2,014 \\
\hline MRTG3 & 8,08 & 27,10 & 52,5 & 27,00 & 0,298 & 0,191 & 15,67 & 2,331 \\
\hline MRTG5 & 8,45 & 27,10 & 52,5 & 26,60 & 0,312 & 0,193 & 18,77 & 2,709 \\
\hline MRTG6 & 7,80 & 26,80 & 52,5 & 27,00 & 0,291 & 0,191 & 21,73 & 3,331 \\
\hline
\end{tabular}
\end{tabular}

\subsubsection{Disco com entalhe na borda com partição por cunha - "Edge Notched Disc} Wedge Splitting Test (END)"

O corpo de prova tem forma de discos com entalhe reto na borda. O carregamento é feito com uma força de partição aplicada por uma simples cunha, a qual 
produz duas forças iguais e opostas na boca da trinca, conforme mostrado na Figura 76. Os corpos de prova tiveram 57,4 a 58,1 mm de diâmetro para o basalto e 53,3 a 54,1 mm para o granito, e comprimento de pré-entalhe que variaram de 29,2 a 31,5 mm para o basalto e de 26,0 a 26,5 mm para o granito. O ensaio foi realizado com controle de deslocamento $L P D$ por uma máquina hidráulica servo-controlada de circuito fechado, sendo considerada a carga máxima aplicada resultante da propagação da trinca (carga de pico) como carga crítica para a determinação da tenacidade à fratura.

O procedimento de preparação dos corpos de prova consistiu nas seguintes etapas:

1. Extração de testemunhos cilíndricos a partir dos blocos de basalto e granito com brocas diamantadas de 60 e 54,5 mm de diâmetro interno, respectivamente;

2. Os corpos de prova foram retificados em suas faces laterais e paralelas;

3. Cortaram-se os testemunhos com um disco adiamantado de 200 mm de diâmetro externo e $1,50 \mathrm{~mm}$ de espessura;

4. Usou-se uma morsa que foi fixada na mesa da retífica para sujeitar o corpo de prova (Figura 75a);

5. Para confecção do entalhe reto foi utilizado um disco adiamantado de $150 \mathrm{~mm}$ de diâmetro externo e 1,0 mm de espessura.

6. Cortou-se um entalhe reto de $28 \mathrm{~mm}(0.5 \mathrm{D})$ de comprimento em média (Figura $75 \mathrm{~b}$ ).

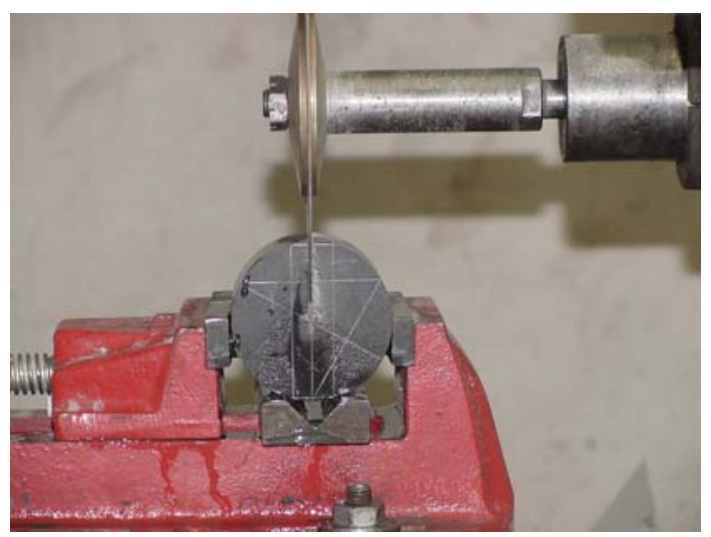

(a)

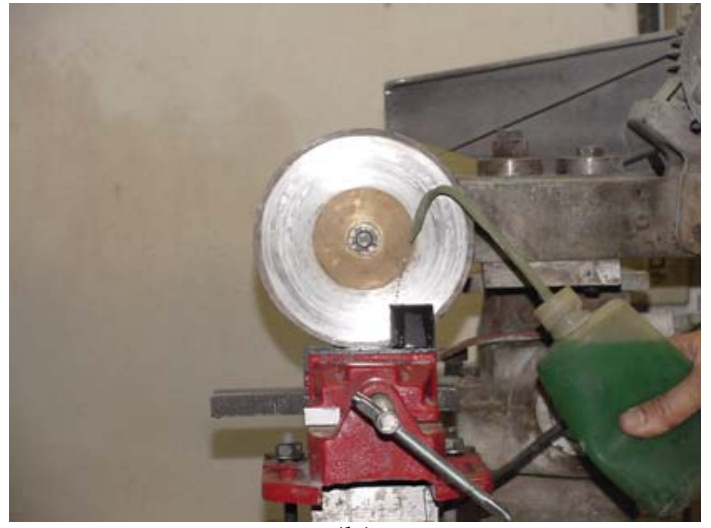

(b)

Figura 75 - Preparação do corpo de prova END: Confecção do entalhe reto (a) Frente. (b) Perfil

O procedimento de ensaio dos corpos de prova consistiu nas seguintes etapas:

1. Colocou-se o corpo de prova sob uma cunha; 
2. Aplicou-se uma pré-carga para colocar o corpo de prova de maneira que ele esteja alinhado com o prato de carregamento superior;

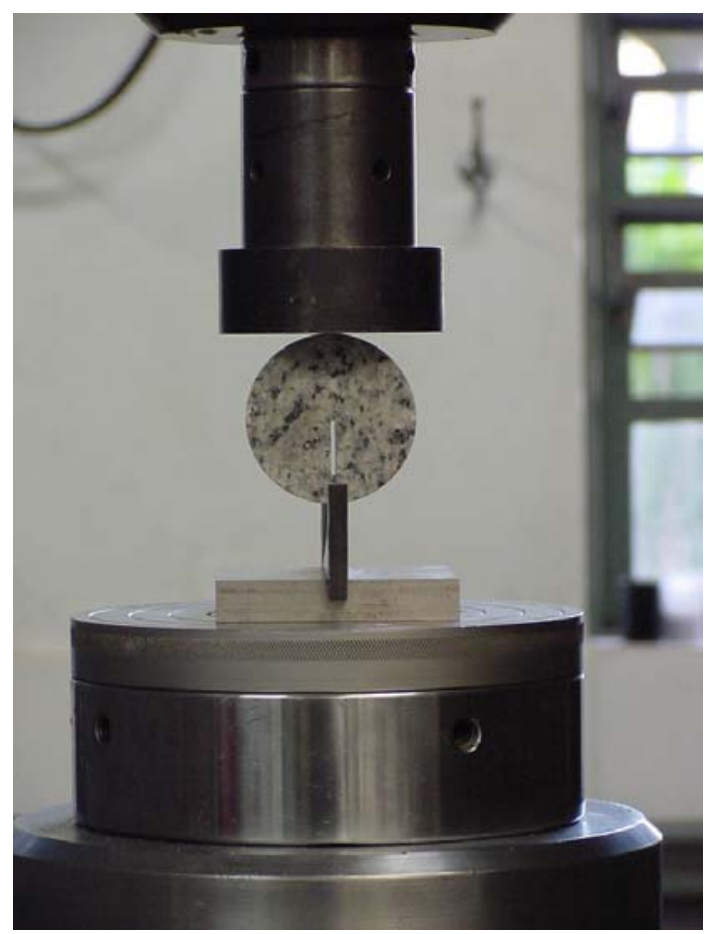

(a)

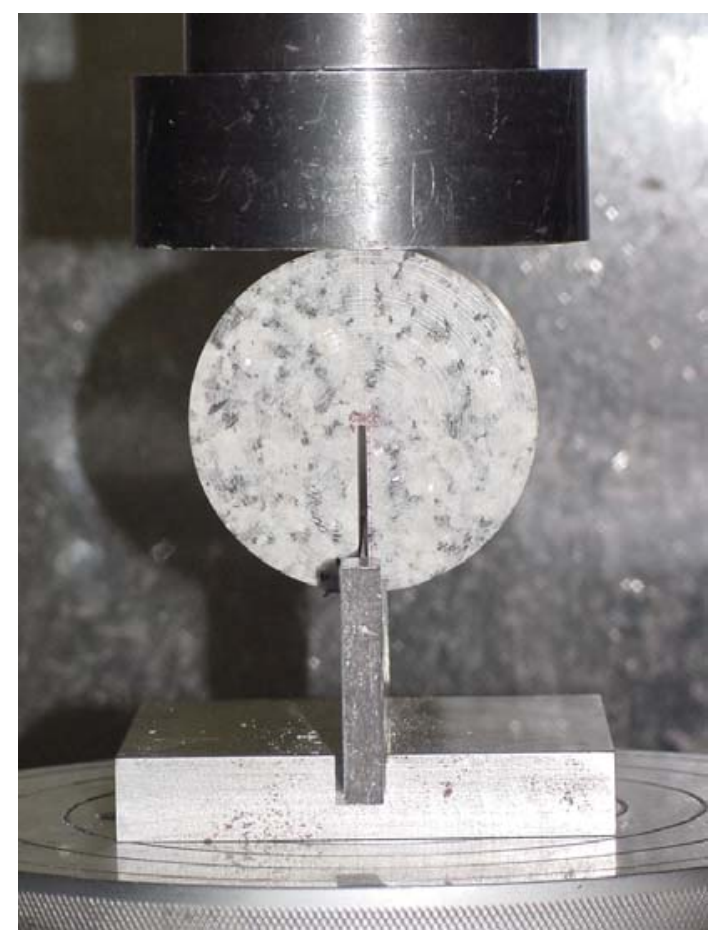

(b)

Figura 76 - Ensaio de discos com entalhe na borda com partição por cunha (END): (a) Configuração geral do ensaio; (b) Detalhe do ensaio mostrando a cunha utilizada.

3. A carga e os dados do deslocamento da linha da carga são registrados diretamente por um sistema computacional de aquisição de dados;

4.Empregaram-se velocidades de carregamento de 0,001 e 0,003 mm/s para o basalto e de $0,003 \mathrm{~mm} / \mathrm{s}$ para o granito;

5. Registra-se a carga máxima (carga de pico).

Visto que, para a determinação da tenacidade à fratura, é necessário quantificar o coeficiente de atrito para cada tipo de rocha ensaiada, foi empregado o ensaio "tilt test" para determinar $\mu$, sendo $\phi$ o ângulo de deslizamento e onde $\tan \phi$ é igual a $\mu$ (BARTON, 1977). 


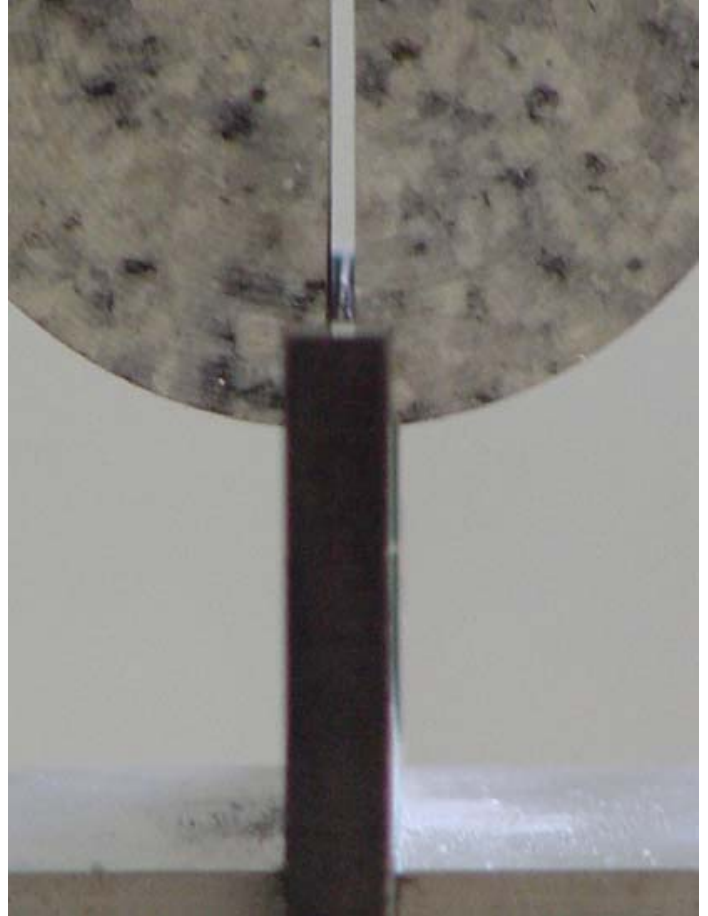

(a)

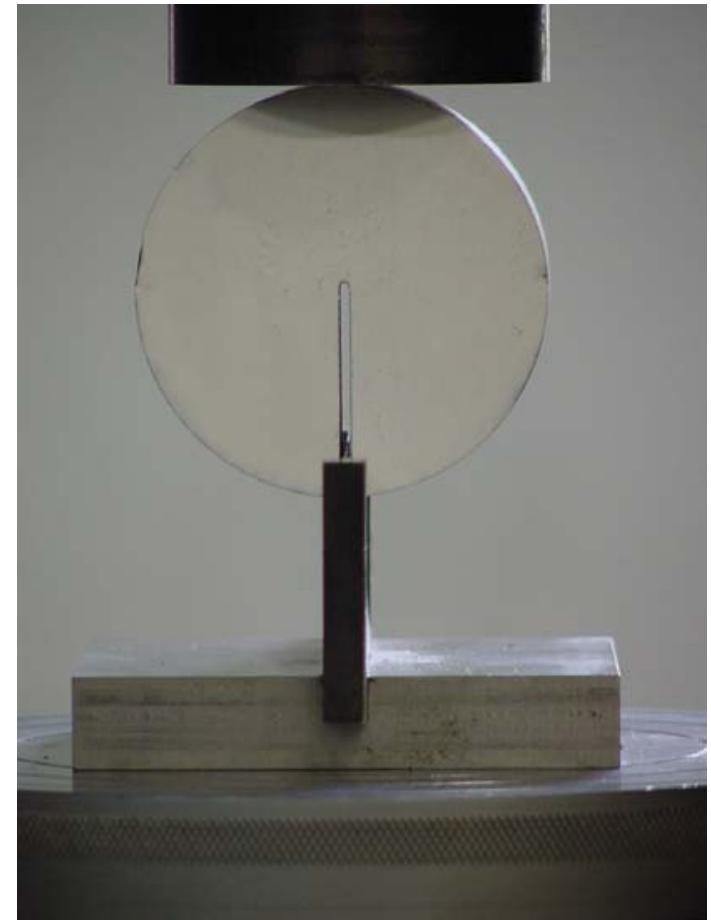

(b)

Figura 77 - Ensaio de discos com entalhe na borda com partição por cunha (END): (a) Detalhe da cunha penetrando no corpo de prova; (b) Corpo de prova pintado para visualizar a propagação da trinca, a partir do pré-entalhe

Foram realizados 10 ensaios $E N D$, cuja representação típica dos resultados se dá conforme a Figura 78 abaixo. Os resultados de $K_{I C}$ foram determinados destes gráficos, segundo o procedimento e fórmulas sugeridos por Donovan (2003) apresentados no Capítulo 3.

\section{ENSAIO END}

Corpo de prova ENDB4

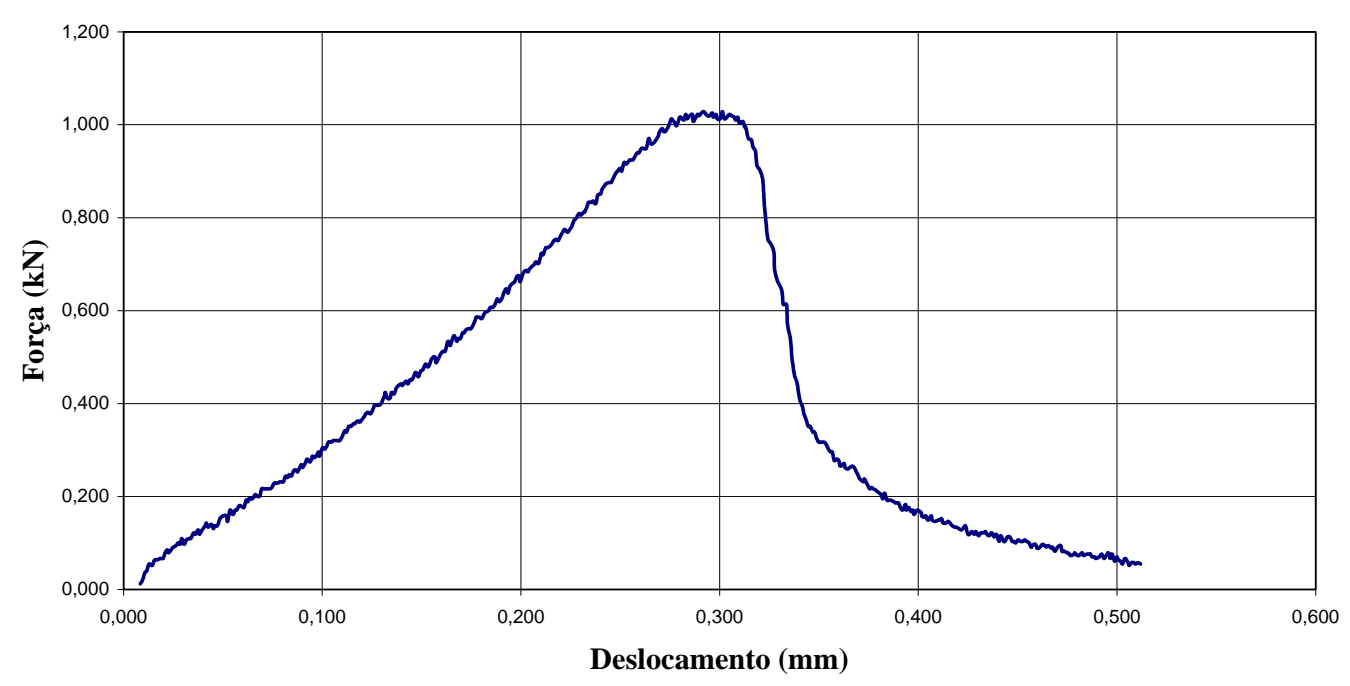

Figura 78 - Gráfico Força versus deslocamento típico do ensaio END. 
A Tabela 18 abaixo apresenta os respectivos resultados dos ensaios END sugerido por Donovan (2003) e realizados no basalto e no granito neste programa de pesquisa:

Tabela 18 - Resultados do ensaio em discos com entalhe na borda com partição por cunha (END)

\begin{tabular}{|c|c|c|c|c|c|c|c|}
\hline BASALTO & $\begin{array}{c}a \\
(\mathrm{~mm})\end{array}$ & $\begin{array}{c}D \\
(\mathrm{~mm})\end{array}$ & $K_{1}$ & $K_{2}$ & $\begin{array}{c}F_{\text {Gregory }} \\
(\mathrm{kN})\end{array}$ & $\begin{array}{c}F_{v} \\
(\mathrm{kN})\end{array}$ & $\begin{array}{c}K_{I C} \\
\left(\mathrm{MPa}^{1 / 2}\right)\end{array}$ \\
\hline ENDB1 & 31,5 & 58,0 & 0,649 & 0,201 & 0,850 & 0,824 & 2,009 \\
\hline ENDB2 & 29,9 & 58,0 & 0,564 & 0,195 & 0,759 & 0,845 & 1,889 \\
\hline ENDB3 & 29,2 & 57,4 & 0,548 & 0,195 & 0,743 & 1,041 & 2,292 \\
\hline ENDB4 & 30,4 & 58,1 & 0,586 & 0,197 & 0,783 & 1,028 & 2,351 \\
\hline ENDB5 & 29,4 & 57,6 & 0,552 & 0,195 & 0,747 & 0,970 & 2,143 \\
\hline
\end{tabular}

\begin{tabular}{|c|c|c|c|c|c|c|c|}
\hline \multicolumn{1}{|c|}{ GRANITO } & $\begin{array}{c}a \\
(\mathrm{~mm})\end{array}$ & $\begin{array}{c}D \\
(\mathrm{~mm})\end{array}$ & $K_{l}$ & $K_{2}$ & $\begin{array}{c}F_{\text {Gregory }} \\
(\mathrm{kN})\end{array}$ & $\begin{array}{c}F_{v} \\
(\mathrm{kN})\end{array}$ & $\begin{array}{c}K_{I C} \\
\left(\mathrm{MPa.m}^{1 / 2}\right)\end{array}$ \\
\hline ENDG1 & 26,0 & 54,1 & 0,491 & 0,195 & 0,686 & 0,528 & 1,288 \\
\hline ENDG2 & 26,4 & 54,1 & 0,509 & 0,197 & 0,706 & 0,650 & 1,619 \\
\hline ENDG3 & 26,0 & 53,6 & 0,504 & 0,197 & 0,701 & 0,577 & 1,432 \\
\hline ENDG4 & 26,5 & 54,1 & 0,514 & 0,197 & 0,711 & 0,598 & 1,498 \\
\hline ENDG5 & 26,5 & 54,1 & 0,514 & 0,197 & 0,711 & 0,613 & 1,535 \\
\hline
\end{tabular}

\subsubsection{Corpos de prova em Dupla-torção - “Double torsion specimen (DT)”}

O corpo de prova é uma placa retangular com um entalhe central para orientar a propagação da trinca. É carregado em flexão a quatro pontos, conforme mostrado na Figura 80. Os corpos de prova tiveram de 160,3 a 162,9 mm de comprimento para o basalto e de 159,4 a 161,7 mm para o granito, largura de 77,2 a 82,6 mm para o basalto e de 80,6 a $83,0 \mathrm{~mm}$ para o granito e espessura de 8,8 a 11,9 mm para o basalto e de 12,0 a 13,6 mm para o granito. Estabeleceu-se a proporção aproximada de espessuralargura-comprimento de 1:8:16. O ensaio mecânico foi realizado em uma máquina hidráulica servo-controlada de circuito fechado, MTS 810/458, com controle de deslocamento $L P D$, sendo considerada a carga máxima (carga de pico) aplicada resultante da propagação da trinca como carga crítica para a determinação da tenacidade à fratura.

O procedimento de preparação dos corpos de prova consistiu nas seguintes etapas:

1. Os basaltos foram obtidos a partir de lajes encontradas na pedreira com espessuras da ordem de centímetros, sendo escolhidas de maneira que suas espessuras fossem um 
pouco maiores que as alturas dos corpos de prova. Os granitos foram preparados a partir de um bloco, realizando-se perfurações com brocas diamantadas de maneira a se obter uma amostra de forma paralelepípeda com espessura um pouco maior que os corpos de prova;

2. Estas lajes e o bloco foram cortadas no tamanho desejado $(1 \mathrm{~cm} \times 8 \mathrm{~cm} \times 16 \mathrm{~cm}$ em média) com um disco adiamantado de 200 mm de diâmetro;

3. O sulco central axial de aproximadamente $2 \mathrm{~mm}$ de largura, foi cortado com uma profundidade de $2 \mathrm{~mm}$ (Figura 79a) ao longo do comprimento de cada corpo de prova com um disco diamantado de $150 \mathrm{~mm}$ de diâmetro externo e $1 \mathrm{~mm}$ de espessura;

4. Além do sulco central, foi cortado um entalhe a $45^{\circ}$, com aproximadamente $10 \mathrm{~mm}$ de comprimento e $1 \mathrm{~mm}$ de largura em cada extremidade de cada placa ao longo da linha do sulco axial (Figura 79b);

5. Usou-se uma dobradiça para fazer o ângulo de $45^{\circ}$;

6. O entalhe foi feito de modo que no carregamento a propagação da fratura ocorresse a partir do entalhe em uma direção paralela ao comprimento do corpo de prova.

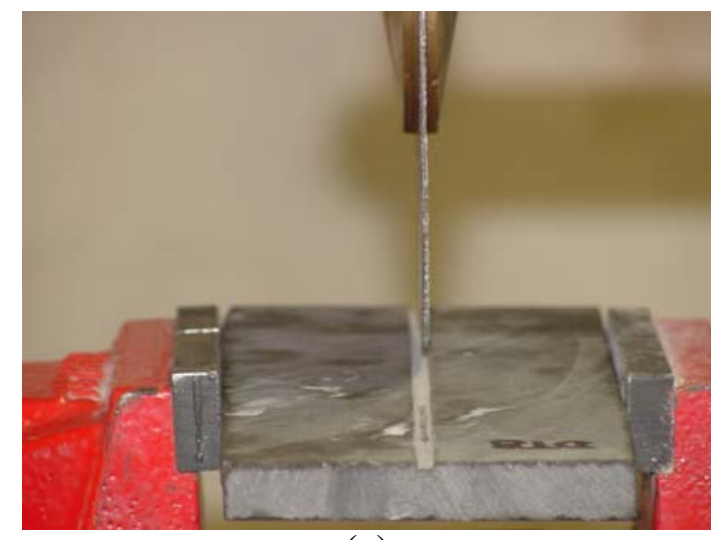

(a)

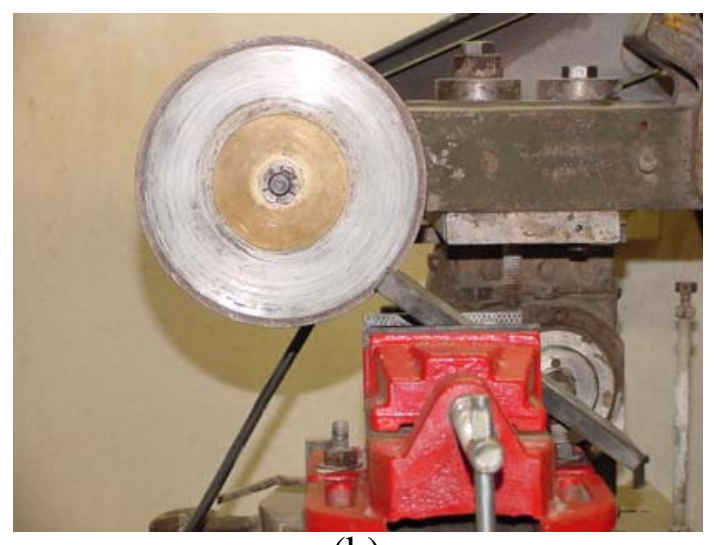

(b)

Figura 79 - Preparação do corpo de prova do ensaio de dupla torção: (a) Confeç̧ão do sulco central. (b) Confecção do entalhe a $45^{\circ}$.

Os dispositivos empregados para a execução do ensaio foram os utilizados por Albuquerque (2003), e realizados no Departamento de Engenharia de Materiais (DEMA) da Universidade Federal de São Carlos. Esses dispositivos de apoio, a aplicação da carga e a configuração geral do ensaio são mostrados nas Figuras 80 e 81. 


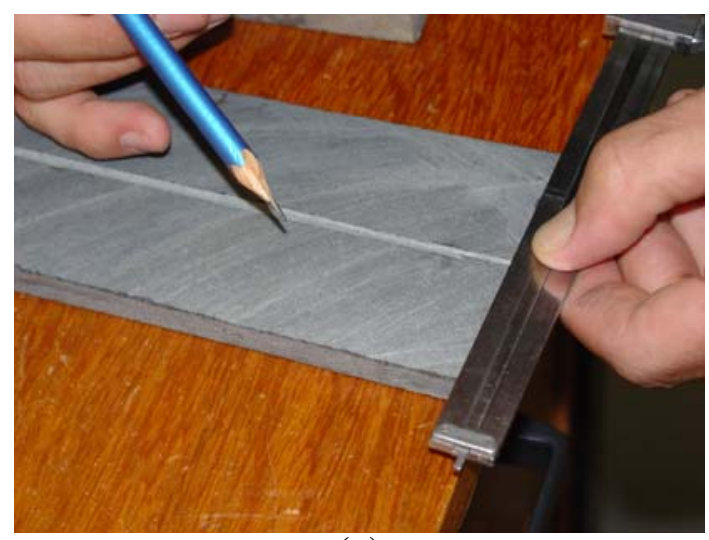

(a)

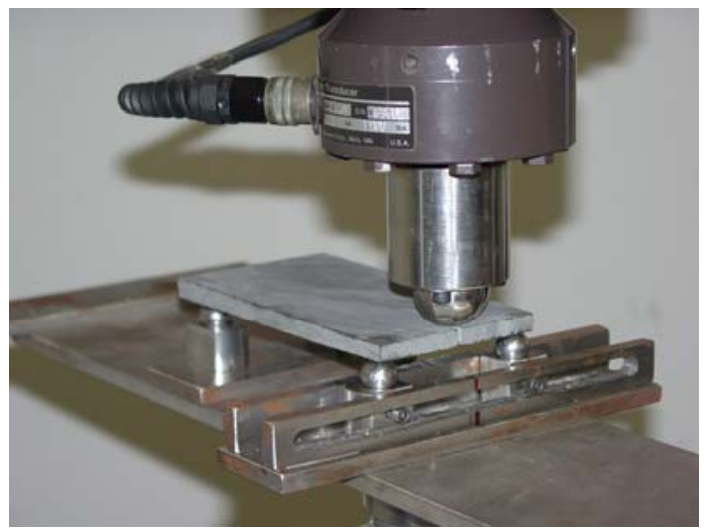

(b)

Figura 80 - Ensaio de dupla-torção: (a) Corpo de prova; (b) Configuração geral do ensaio.

O procedimento de ensaio dos corpos de prova consistiu nas seguintes etapas:

1. Mediu-se cuidadosamente os vãos dos apoios dos corpos de prova;

2. Colocou-se o corpo de prova nos apoios e aplicou-se um pré-carregamento para fixar o corpo de prova;

3. A carga e os dados do deslocamento da linha da carga são registrados diretamente por um sistema computacional de aquisição de dados;

4. O ensaio foi realizado sob controle de deslocamento com uma velocidade de 50 $\mu \mathrm{m} / \mathrm{min}$ para o basalto e o granito;

5. Registra-se a carga crítica (carga de pico) para uma fratura rápida do corpo de prova; Observa-se que a frente da trinca prossegue ao longo de uma linha reta que parte do entalhe inicial e é guiada pelo sulco central, como mostrado na Figura 81.

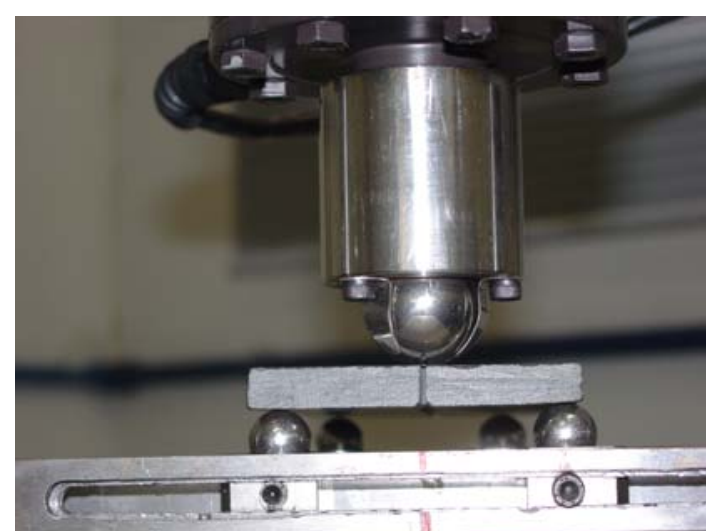

(a)

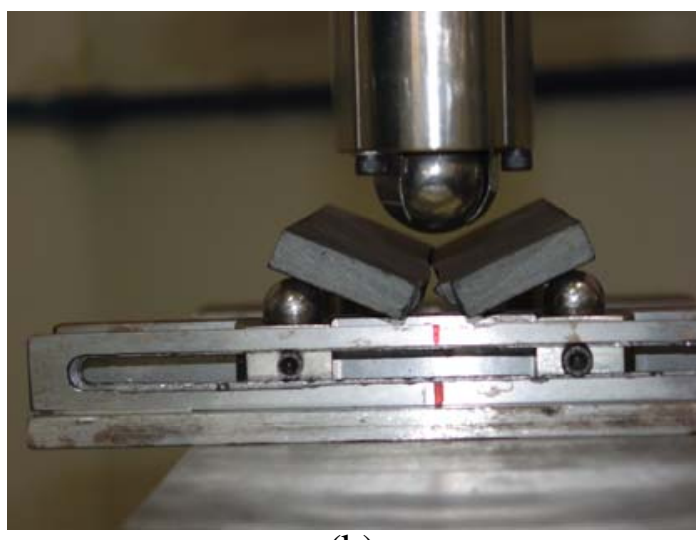

(b)

Figura 81 - Ensaio de dupla-torção: (a) Detalhe da aplicação da carga sob o corpo de prova; (b) Corpo de prova ensaiado (notar a propagação do pré-entalhe pelo sulco central). 
Foram realizados 12 ensaios $D T$, cuja representação típica dos resultados se dá conforme a Figura 82 abaixo. Os resultados de $K_{I C}$ foram determinados destes gráficos, segundo o procedimento e fórmulas sugeridos por Williams e Evans (1973) apresentados no Capítulo 3.

\section{ENSAIO DT}

Corpo de prova DTB3

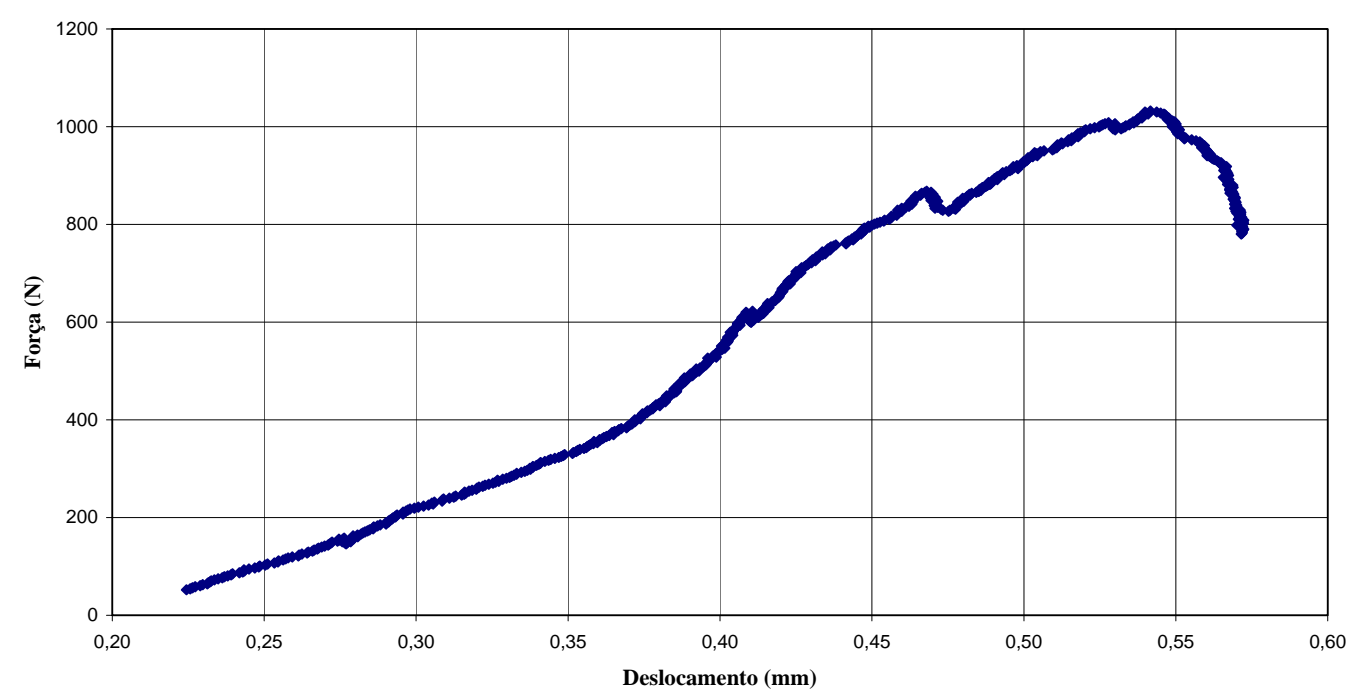

Figura 82 - Gráfico Força versus deslocamento típico do ensaio $D T$

A Tabela 19 abaixo apresenta os respectivos resultados dos ensaios $D T$ sugerido por Williams e Evans (1973) e realizados no basalto e no granito neste programa de pesquisa:

Tabela 19 - Resultados do ensaio em dupla-torção (DT)

\begin{tabular}{|c|c|c|c|c|c|c|c|}
\hline BASALTO & $\begin{array}{c}d \\
(\mathrm{~mm})\end{array}$ & $\begin{array}{c}d_{n} \\
(\mathrm{~mm})\end{array}$ & $\begin{array}{c}L \\
(\mathrm{~cm})\end{array}$ & $\begin{array}{c}W \\
(\mathrm{~mm})\end{array}$ & $\begin{array}{l}P_{\max } \\
(\mathrm{N})\end{array}$ & $K_{I C}$ & $\begin{array}{c}K_{I C} \\
\left.\text { (MPa.m }^{1 / 2}\right)\end{array}$ \\
\hline DTB1 & 9,9 & 6,8 & 16,19 & 77,2 & 855,78 & 82,92 & 2,62 \\
\hline DTB2 & 10,4 & 7,3 & 16,29 & 80,0 & 1032,06 & 88,06 & 2,78 \\
\hline DTB3 & 11,9 & 9,1 & 16,03 & 81,2 & 1289,32 & 79,90 & 2,53 \\
\hline DTB4 & 10,8 & 7,8 & 16,05 & 82,6 & 1047,69 & 80,42 & 2,54 \\
\hline DTB5 & 9,0 & 6,0 & 16,07 & 81,3 & 728,25 & 84,45 & 2,67 \\
\hline DTB6 & 8,8 & 5,4 & 16,05 & 81,5 & 691,87 & 87,37 & 2,76 \\
\hline \multirow{2}{*}{\multicolumn{6}{|c|}{ Desvio }} & Média & 2,65 \\
\hline & & & & & & $\begin{array}{c}\text { Padrão } \\
K_{I C}\end{array}$ & 0,11 \\
\hline GRANITO & $\begin{array}{c}d \\
(\mathrm{~mm})\end{array}$ & $\begin{array}{c}d_{n} \\
(\mathrm{~mm})\end{array}$ & $\begin{array}{c}L \\
(\mathrm{~cm})\end{array}$ & $\begin{array}{c}W \\
(\mathrm{~mm})\end{array}$ & $\begin{array}{l}P_{\max } \\
(\mathrm{N})\end{array}$ & $K_{I C}$ & $\begin{array}{c}K_{I C} \\
\left(\mathrm{MPa}^{1 / 2}\right)\end{array}$ \\
\hline DTG1 & 13,6 & 11,6 & 15,95 & 82,0 & 1531,50 & 70,39 & 2,22 \\
\hline DTG2 & 13,5 & 11,5 & 16,17 & 82,1 & 1486,26 & $\begin{array}{l}69,33 \\
\end{array}$ & 2,19 \\
\hline DTG3 & 13,5 & 11,8 & 15,94 & 80,6 & 1472,57 & 68,58 & 2,17 \\
\hline DTG4 & 12,0 & 10,5 & 15,95 & 83,0 & 1093,33 & 63,34 & 2,00 \\
\hline DTG5 & 12,0 & 10,0 & 15,95 & 81,0 & 1145,86 & 68,86 & 2,18 \\
\hline & & & & & & Média & 2,15 \\
\hline
\end{tabular}




\subsubsection{Corpos de prova axiais e irregulares para o ensaio de carga pontual - “Axial and irregular Point load test (PLT)”}

Neste ensaio, os corpos de prova de forma cilíndrica, axiais ou irregulares, são carregados até a ruptura, empregando-se um esforço pontual através de pontas cônicas. Ele baseia-se no princípio do esforço de tração induzido dentro do corpo pela aplicação de uma força pontual compressiva.

O procedimento de preparação dos corpos de prova consistiu nas seguintes etapas:

1. Empregaram-se corpos de prova axiais obtidos das pontas dos testemunhos cortados para os corpos de prova dos ensaios $E N D, M R T$ e $C S T$, os quais não foram utilizados nos ensaios correspondentes devido ao tamanho dos discos. Os discos utilizados para o ensaio de carga pontual cumpriam as dimensões estabelecidas no método sugerido pela ISRM (1985) e as dimensões sugeridas por Bearman (1999);

2. Os corpos de prova irregulares foram obtidos dos blocos de basalto e granito por meio de golpes de martelo, obtendo fragmentos de diferentes tamanhos.

O procedimento de ensaio em corpos de prova carregados axialmente é como se segue:

1. Os corpos de prova cilíndricos utilizados neste ensaio devem cumprir com a relação espessura do corpo de prova ou distância entre pontos de contato/diâmetro do corpo de prova $(L / D)$ de 0,3 a 1,0 . Os ensaios devem contemplar pelo menos 10 corpos de prova por amostra, com a possibilidade de um número maior se a amostra é heterogênea ou anisotrópica;

2. O corpo de prova é colocado na máquina de ensaio e as pontas cônicas devem juntarse até fazer contato com um diâmetro do corpo de prova como mostrado na Figura 83. Se a amostra é de material brando de maneira que se produz uma significativa penetração das pontas no momento da ruptura, deve-se registrar esta distância como $D$. A distância $D$ é registrada com aproximação em mm;

3. A carga é aplicada bombeando de forma constante a fim de que a ruptura ocorra dentro dos 10 ou 60 segundos após iniciada a carga. Anota-se a carga de ruptura $F$;

4. Se a superfície de ruptura passa somente através de um ponto de carregamento, o ensaio não será considerado válido. 

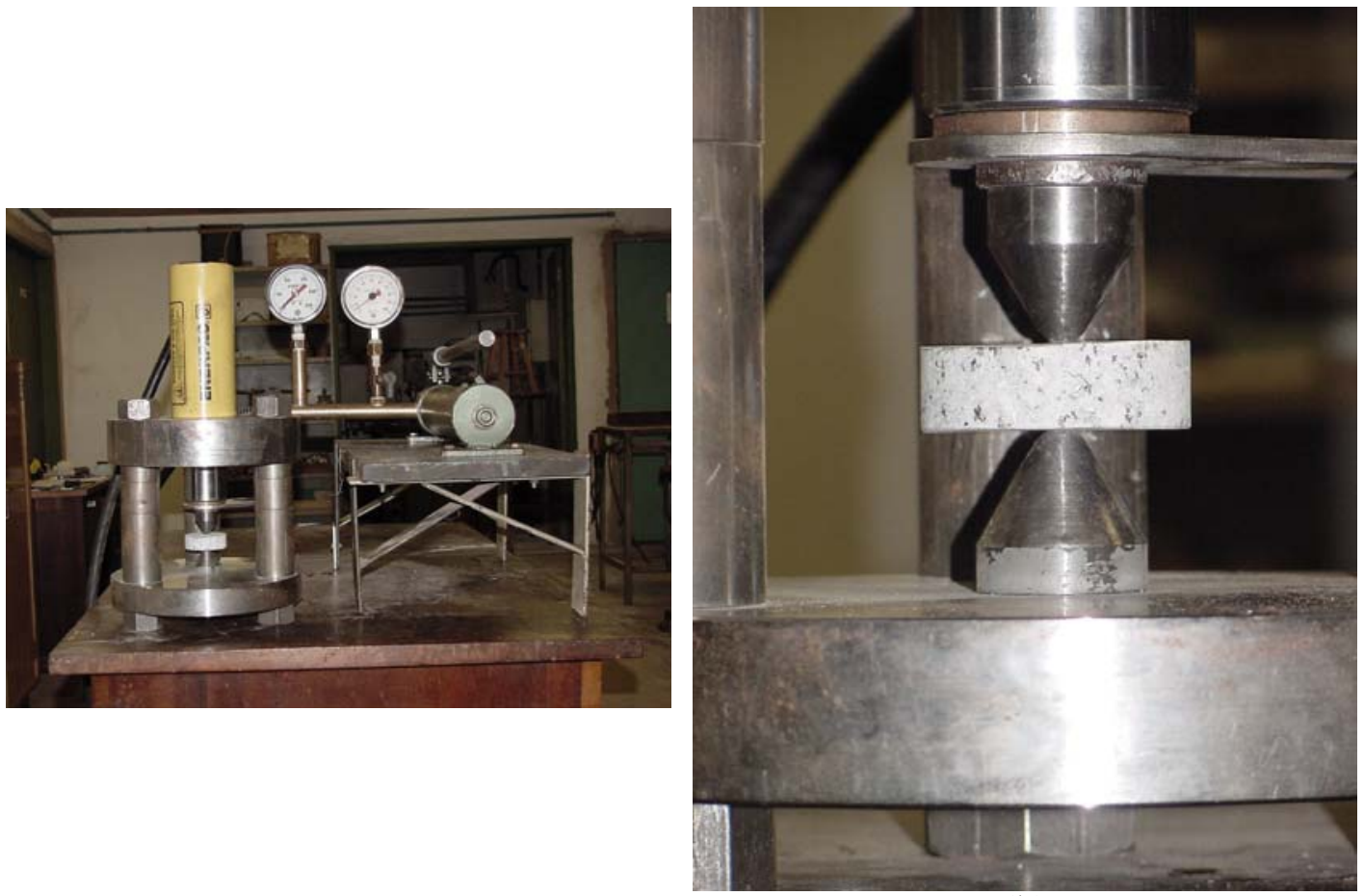

(a)

(b)

Figura 83 - Ensaio de carga pontual com corpos de prova carregados axialmente: (a) Configuração geral do ensaio; (b) Detalhe do ensaio mostrando as pontas cônicas e o corpo de prova axial

A Tabela 20 abaixo apresenta os respectivos resultados dos ensaios de carga pontual com corpos de prova axiais conforme sugerido por Bearman (1999), a relação L/D foi de 0,333 a 0,535 para o basalto e de 0,333 a 0,527 para o granito neste programa de pesquisa:

Tabela 20 - Resultados do ensaio de carga pontual com corpos de prova axiais

BASALTO

\begin{tabular}{|c|c|c|c|c|c|c|c|c|c|}
\hline & $\begin{array}{c}W \\
(\mathrm{~mm})\end{array}$ & $\begin{array}{c}D \\
(\mathrm{~mm})\end{array}$ & $\begin{array}{c}F \\
(\mathrm{kN})\end{array}$ & $\begin{array}{c}K_{I C} \\
(\mathrm{~mm})\end{array}$ & & $\begin{array}{c}W \\
(\mathrm{~mm})\end{array}$ & $\begin{array}{c}D \\
(\mathrm{~mm})\end{array}$ & $\begin{array}{c}F \\
(\mathrm{kN})\end{array}$ & $\begin{array}{c}K_{I C} \\
(\mathrm{~mm})\end{array}$ \\
\hline CPB1 & 50,50 & 27,00 & 22,94 & 2,72 & CPB5 & 53,10 & 24,30 & 21,39 & 2,64 \\
\hline СРB2 & 53,60 & 26,70 & 25,05 & 2,86 & CPB6 & 55,30 & 20,60 & 20,41 & 2,76 \\
\hline СРB3 & 54,60 & 25,60 & 21,46 & 2,49 & CPB7 & 55,20 & 20,10 & 19,78 & 2,73 \\
\hline CPB4 & 55,30 & 23,30 & 24,77 & 3,06 & CPB8 & 55,20 & 18,40 & 16,54 & 2,44 \\
\hline & & & & & & & io & $\begin{array}{l}\text { Média } \\
\text { Padrão }\end{array}$ & $\begin{array}{l}2,71 \\
0,20\end{array}$ \\
\hline
\end{tabular}

GRANITO

\begin{tabular}{|c|c|c|c|c|c|c|c|c|c|}
\hline & $\begin{array}{c}W \\
(\mathrm{~mm})\end{array}$ & $\begin{array}{c}D \\
(\mathrm{~mm})\end{array}$ & $\begin{array}{c}F \\
(\mathrm{kN})\end{array}$ & $\begin{array}{c}K_{I C} \\
(\mathrm{~mm})\end{array}$ & & $\begin{array}{c}W \\
(\mathrm{~mm})\end{array}$ & $\begin{array}{c}D \\
(\mathrm{~mm})\end{array}$ & $\begin{array}{c}F \\
(\mathrm{kN})\end{array}$ & $\begin{array}{c}K_{I C} \\
(\mathrm{~mm})\end{array}$ \\
\hline CPG1 & 55,00 & 29,00 & 12,67 & 1,33 & CPG5 & 55,40 & 21,20 & 11,54 & 1,53 \\
\hline CPG2 & 53,20 & 25,80 & 12,67 & 1,49 & CPG6 & 55,30 & 20,50 & 9,57 & 1,30 \\
\hline CPG3 & 55,10 & 23,50 & 11,68 & 1,44 & CPG7 & 55,40 & 18,90 & 9,29 & 1,34 \\
\hline CPG4 & 55,40 & 21,00 & 10,63 & 1,42 & CPG8 & 55,10 & 18,20 & 10,42 & 1,55 \\
\hline & & & & & & & 10 & Padrão & $\begin{array}{l}1,43 \\
0,09\end{array}$ \\
\hline
\end{tabular}


O procedimento de ensaio em corpos de prova irregulares é como se segue:

1. Neste ensaio, utilizam-se blocos de rochas ou pedaços irregulares de dimensões entre 15 a 85 mm e com as formas mostradas na Figura 84. A relação distância entre pontos de contacto/largura mêdia do corpo de prova $(L / W)$ deve ser entre 0,3 e 1,0. Os corpos de prova deste tamanho e forma serão selecionados se já estiverem disponíveis ou preparados mediante golpes de martelo;

2. O corpo de prova é colocado na máquina de ensaios e as pontas cônicas se ajustarão até fazer contato com a menor dimensão do bloco ou pedaço considerado como mostrado na Figura 84. Fazem-se pelo menos 10 corpos de prova por amostra e possivelmente um número maior se a amostra é heterogênea ou anisotrópica;

3. A distância $D$ entre os pontos de contato do corpo de prova com as pontas cônicas é tomado com aproximação de $0,1 \mathrm{~mm}$. A largura $W$ perpendicular à direção do carregamento é anotada com uma aproximação de milímetros. Se as faces não são paralelas, então $W$ é calculada como $\left(W_{1}+W_{2}\right) / 2$;

4. A carga deve ser aplicada constantemente de maneira que a ruptura ocorra entre os 10 e 60 segundos após iniciado o carregamento. A carga última $F$ é anotada. O ensaio deverá ser anulado se a superfície de falha não passa através dos pontos de aplicação da carga.

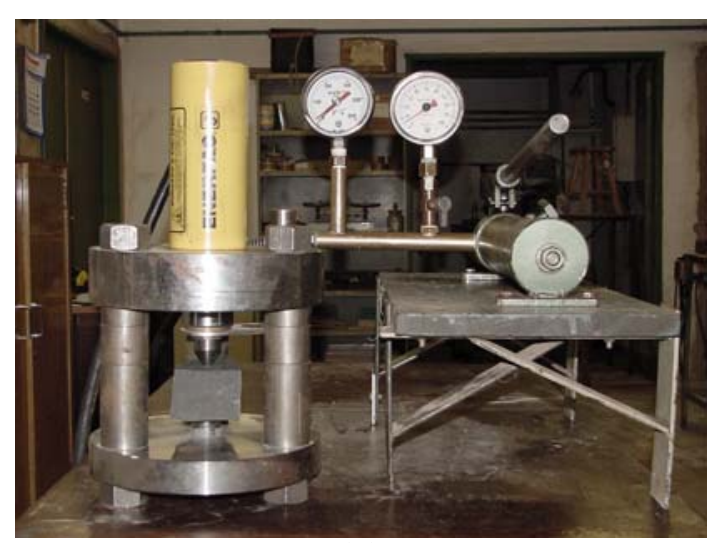

(a)

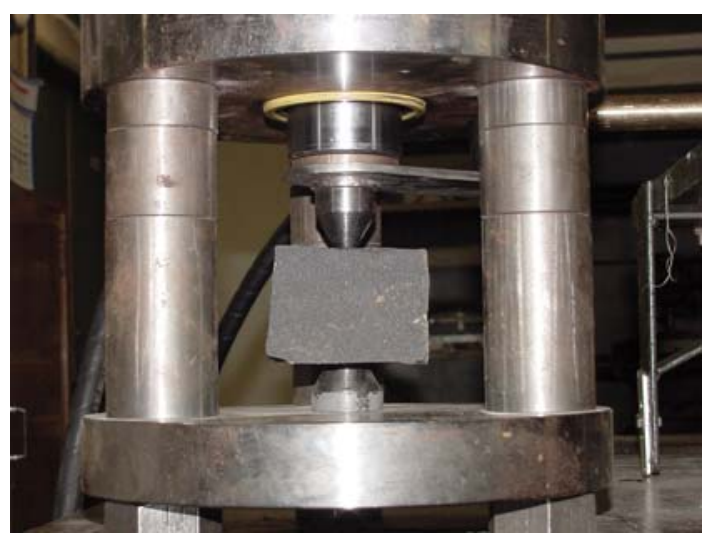

(b)

Figura 84 - Ensaio de carga pontual com corpos de prova irregulares: (a) Configuração geral do ensaio; (b) Detalhe do ensaio mostrando as pontas cônicas e o corpo de prova irregular

A Tabela 21 abaixo apresenta os respectivos resultados dos ensaios de carga pontual com corpos de prova irregulares sugerido por Bearman (1999), a relação L/D foi de 0,527 a 0,812 para o basalto e de 0,489 a 0,98 para o granito neste programa de pesquisa: 
Tabela 21 - Resultados do ensaio de carga pontual com corpos de prova irregulares

BASALTO

\begin{tabular}{|l|c|c|c|c|c|c|c|c|c|}
\hline & $\begin{array}{c}W \\
(\mathrm{~mm})\end{array}$ & $\begin{array}{c}D \\
(\mathrm{~mm})\end{array}$ & $\begin{array}{c}F \\
(\mathrm{kN})\end{array}$ & $K_{I C}$ & & $\begin{array}{c}W \\
(\mathrm{~mm})\end{array}$ & $\begin{array}{c}D \\
(\mathrm{~mm})\end{array}$ & $\begin{array}{c}F \\
(\mathrm{kN})\end{array}$ & $K_{I C}$ \\
\hline CPB1 & 56,60 & 29,80 & 23,51 & 2,37 & CPB10 & 59,00 & 36,70 & 30,97 & 2,59 \\
\hline CPB2 & 43,60 & 28,60 & 24,21 & 3,06 & CPB11 & 57,90 & 35,80 & 30,26 & 2,62 \\
\hline CPB3 & 44,80 & 32,30 & 20,83 & 2,36 & CPB12 & 46,20 & 37,50 & 27,31 & 2,70 \\
\hline CPB4 & 46,40 & 33,60 & 31,67 & 3,39 & CPB13 & 50,50 & 33,60 & 32,37 & 3,25 \\
\hline CPB5 & 51,30 & 34,20 & 26,18 & 2,56 & CPB14 & 47,90 & 38,50 & 36,59 & 3,45 \\
\hline CPB6 & 51,50 & 28,50 & 24,49 & 2,74 & CPB15 & 56,30 & 32,40 & 30,97 & 2,95 \\
\hline CPB7 & 41,30 & 30,20 & 24,91 & 3,15 & CPB16 & 52,50 & 35,70 & 32,37 & 3,02 \\
\hline CPB8 & 46,00 & 32,40 & 29,56 & 3,27 & CPB17 & 51,00 & 38,90 & 37,30 & 3,33 \\
\hline CPB9 & 47,80 & 38,20 & 29,56 & 2,81 & & & \multicolumn{5}{c|}{ Desvio } & $\begin{array}{c}\text { Padrdia } \\
\text { CPão }\end{array}$ & 2,96 \\
\hline
\end{tabular}

GRANITO

\begin{tabular}{|l|c|c|c|c|c|c|c|c|c|}
\hline & $\begin{array}{c}W \\
(\mathrm{~mm})\end{array}$ & $\begin{array}{c}D \\
(\mathrm{~mm})\end{array}$ & $\begin{array}{c}F \\
(\mathrm{kN})\end{array}$ & $\begin{array}{c}K_{I C} \\
(\mathrm{~mm})\end{array}$ & & $\begin{array}{c}W \\
(\mathrm{~mm})\end{array}$ & $\begin{array}{c}D \\
(\mathrm{~mm})\end{array}$ & $\begin{array}{c}F \\
(\mathrm{kN})\end{array}$ & $\begin{array}{c}K_{I C} \\
(\mathrm{~mm})\end{array}$ \\
\hline CPG1 & 48,25 & 28,00 & 13,02 & 1,55 & CPG10 & 45,90 & 38,00 & 16,19 & 1,59 \\
\hline CPG2 & 55,25 & 27,00 & 12,95 & 1,43 & CPG11 & 58,30 & 40,30 & 19,71 & 1,55 \\
\hline CPG3 & 52,15 & 37,70 & 16,19 & 1,46 & CPG12 & 45,50 & 35,60 & 14,64 & 1,52 \\
\hline CPG4 & 43,55 & 38,90 & 16,82 & 1,69 & CPG13 & 47,40 & 35,30 & 15,34 & 1,56 \\
\hline CPG5 & 53,75 & 29,00 & 12,53 & 1,34 & CPG14 & 44,00 & 40,00 & 17,17 & 1,68 \\
\hline CPG6 & 45,50 & 32,00 & 15,27 & 1,72 & CPG15 & 66,80 & 39,70 & 18,44 & 1,33 \\
\hline CPG7 & 44,70 & 43,80 & 16,33 & 1,47 & CPG16 & 54,70 & 35,30 & 16,47 & 1,50 \\
\hline CPG8 & 49,40 & 36,00 & 14,85 & 1,44 & CPG17 & 58,30 & 40,40 & 22,59 & 1,77 \\
\hline CPG9 & 52,60 & 35,80 & 14,22 & 1,32 & & \multicolumn{5}{c}{ Desvio } & Padrão & 1,51 \\
\hline
\end{tabular}




\section{DISCUSSÃO E ANÁLISE DOS RESULTADOS}

\subsection{Introdução}

Neste capítulo, apresenta-se a discussão e a análise dos resultados obtidos nos diferentes ensaios destinados à determinação da tenacidade à fratura realizados na presente pesquisa. Primeiramente, são analisados os resultados obtidos por cada tipo de ensaio, indicando algumas particularidades ou detalhes especiais a serem considerados. Na seqüência, é mostrada uma comparação dos ensaios entre si e, finalmente, realizada uma comparação dos resultados obtidos com os valores da tenacidade à fratura encontrados na literatura para as rochas estudadas.

\subsection{Propriedades físicas e mecânicas das rochas estudadas}

A dependência da tenacidade à fratura com relação ao tamanho de grão é provavelmente causada pela influência do contato intergrãos sobre o fator de intensidade de tensão na ponta do entalhe. Contudo, quanto maior o tamanho de grão, maiores são as trincas na fronteira dos grãos, assim como as trincas intergranulares.

Um resumo dos resultados obtidos é mostrado na Tabela 8, podendo-se observar uma certa anisotropia nas direções paralela e perpendicular à extração dos corpos de prova do ensaio CB. Na Tabela 9, apresentam-se os valores da tenacidade à fratura das rochas estudadas, utilizando-se correlações empíricas encontradas na literatura.

Conforme visto na Tabela 9, observa-se que os resultados obtidos são muito dispersos entre si, mas é importante salientar que, comparados com os valores da tenacidade à fratura obtidos mediante os métodos sugeridos pela ISRM (Tabelas $10 \mathrm{e}$ 11), é possível indicar que as relações empíricas com a resistência à compressão 
segundo Gunsallus e Kulhawy (1984) e com a densidade segundo Bearman (1991) são as que apresentam os valores mais próximos dos correspondentes aos métodos $C B$ e $S R$.

\subsection{Ensaios sugeridos pela ISRM}

Os ensaios $C B$ e $S R$ no nível II do modo I são baseados nos modelos elastoplásticos submetidos a ciclos de carregamento e descarregamento, permitindo a determinação de um fator de correção “ $p$ ” por não linearidade. Nenhum dos outros ensaios foi submetido a ciclos de carregamento e descarregamento. Salienta-se que estes são ensaios mais lentos que o nível I, mas fornecem valores mais precisos que o nível I, pois considera a carga real que leva o corpo de prova ao ponto de avaliação da tenacidade à fratura. Por este motivo, na presente pesquisa, foi considerado o ensaio no nível II do ensaio $C B$ como comparativo com os outros ensaios, além de ser o mais utilizado e estudado para calcular a tenacidade à fratura em rochas. $\mathrm{O}$ fator $p$ obtido nestes ensaios representa a relação da deformação irreversível e é uma medida simplificada e objetiva da não linearidade nos ensaios de tenacidade à fratura das rochas.

Em estudos anteriores, Liu, Sun e Wang (1994) indicaram que os fatores $p$ dos corpos de prova rochosos eram maiores que 0.15, embora seus diâmetros fossem tão grandes quanto 100 milímetros, incluindo rochas mais duras tais como granitos. Estes autores concluíram que o fator não linear ( $p$ ) para a rocha reflete tanto os efeitos das micro-trincas na região na frente da ponta da trinca, como os efeitos da região intertravada.

Quanto aos resultados obtidos no ensaio CB mostrados na Tabela 10, salienta-se que existe um maior desvio padrão para a determinação da tenacidade à fratura no caso dos basaltos $(0,16)$ que no caso dos granitos $(0,05)$. Quanto aos valores de $p$, pode-se observar que variam de 0,100 a 0,356 para o basalto, e de 0,032 a 0,285 para o granito. Contudo, como mostrado na Tabela 11, no ensaio SR também existe um maior desvio padrão para o basalto $(0,17)$ que para o granito $(0,07)$. Quanto aos valores de $p$, observase uma variação de 0,008 a 0,181 para o basalto, e de 0,182 a 0,327 para o granito. Supõe-se que a diferença nos fatores não lineares entre o basalto e o granito seja causada pela diferença dos mecanismos não lineares presentes na ponta da trinca.

$\mathrm{O}$ ensaio $C C N B D$ apresentou menores valores da tenacidade à fratura que os ensaios $C B$ e $S R$ como apresentado na Tabela 12. Salienta-se que os valores de desvio 
padrão seguem sendo consistentes com o afirmado anteriormente, obtendo um desvio padrão de 0,16 para o basalto e de 0,09 para o granito.

\subsection{Ensaios não padronizados pela ISRM}

O ensaio CST foi originalmente desenvolvido para outros tipos de materiais como materiais vítreos (perspex, araldite), materiais cimentícios (argamassa, concreto) e cerâmicas, não existindo na literatura valores obtidos em rochas. Neste ensaio, a força máxima é de difícil definição, a partir da qual a ponta do entalhe pré-existente começa a se propagar por não ter controle da abertura da boca da trinca, sendo difícil determinar o momento no qual acontece o início da propagação do entalhe. Em alguns materiais, este início é facilmente visível e, portanto, facilmente determinado, não sendo o mesmo caso quando se trata de rochas. Por esse motivo, os valores da tenacidade à fratura (3,00 MPa.m ${ }^{1 / 2}$ para o basalto e 2,65 para o granito) e do desvio padrão (0,50 para o basalto e 0,40 para o granito) mostrados na Tabela 13 para este ensaio são muito altos em comparação com os dos outros ensaios empregados na presente pesquisa. Salienta-se que a variação da velocidade de ensaio $(0,0008 \mathrm{~mm} / \mathrm{s}$ e $0,002 \mathrm{~mm} / \mathrm{s})$ não influiu na determinação da tenacidade à fratura.

Os valores da tenacidade à fratura e o desvio padrão no ensaio SCB são mostrados nas Tabelas 14 e 15. Observa-se que os valores do desvio padrão para os dois tipos de rochas estudadas (0,06 para o basalto e 0,07 para o granito) são os que representam a melhor reprodutibilidade dos resultados de todos os ensaios estudados na presente pesquisa.

Os valores do desvio padrão no ensaio SCB indicam uma melhor reprodutibilidade dos resultados, os valores da tenacidade à fratura mediante este método estão muito abaixo dos valores obtidos nos ensaios $C B$ e $S R$ sugeridos pela ISRM. Contudo, o ensaio $S C B$ é aquele cujos resultados estão mais próximos dos valores obtidos pelo ensaio CCNBD.

Os ensaios SCB e CNSCB podem ser comparáveis devido ao fato que estes foram realizados com cada uma das metades do corpo de prova $C B$, tendo as mesmas dimensões e diferenciando-se somente no tipo de entalhe (reto no SCB e "chevron" no $C N S C B$ ). Os valores obtidos no ensaio $S C B$ são significativamente menores que os obtidos pelo ensaio CNSCB. 
O ensaio CNSCB, o qual tem entalhe do tipo “chevron”, não contempla ciclos de carregamento e descarregamento como os outros ensaios com o referido entalhe, o que não permite realizar a correção por não linearidade (fator $p$ ). Os valores da tenacidade à fratura e o desvio padrão são mostrados na Tabela 16. Observa-se que o valor da tenacidade à fratura e o desvio padrão (0,34 para o basalto e 0,50 para o granito) são altos. Salienta-se que neste ensaio, para o cálculo da tenacidade à fratura, foi utilizado um fator de intensidade de tensão normalizado $(7,2)$, o qual foi calibrado mediante um modelo de elementos finitos em 3-D com código ANSYS (Kuruppu, 1998). Em uma comunicação pessoal, Kuruppu (2004) manifestou que este valor deve ser revisado porque se obtém valores maiores de tenacidade à fratura que os obtidos em comparação a outros métodos.

Apresentam-se na Tabela 17 os valores da tenacidade à fratura determinados mediante o ensaio MRT para o basalto e o granito. Observa-se que o desvio padrão é alto para os dois tipos de rochas (0,34 para o basalto e 0,49 para o granito). O valor da tenacidade à fratura é similar para as duas rochas estudadas (2,69 para o basalto e 2,57 para o granito).

O ensaio END utiliza corpos de prova circulares, com geometria facilmente reprodutível e simples de preparar, requerendo somente um entalhe reto e aquisição de dados e avaliação direta da carga aplicada crítica para o calculo da tenacidade à fratura $K_{I C}$. Salienta-se que os valores obtidos com os corpos de prova preparados para o ensaio END aproximam-se daqueles obtidos pelos ensaios sugeridos pela ISRM (CB e $S R$ ), sendo de fácil preparação e execução, além de possibilitar a realização de uma melhor análise estatística dos dados. O inconveniente é que os valores dependem das perdas friccionais que podem ocorrer entre o material da cunha (aço) e a rocha, sendo necessário quantificar o coeficiente de atrito para cada tipo de rocha, o que pode levar a determinação da tenacidade à fratura a uma outra fonte de erro.

Os valores da tenacidade à fratura e o desvio padrão são mostrados na Tabela 18. Observa-se que o valor da tenacidade à fratura e o desvio padrão (0,19 para o basalto e 0,12 para o granito) são razoáveis em comparação com os resultados obtidos com base nos métodos sugeridos pela ISRM (CB e $S R)$.

No caso do ensaio de dupla-torção, cortam-se placas de rochas com dimensões determinadas, o que requer uma melhor preparação do corpo de prova. Para este ensaio, deve-se realizar um entalhe central para orientar a propagação da trinca. A principal dificuldade associada a este ensaio é que a trinca se propaga com a frente curvada. Por 
esse motivo, realizou-se um corte de $45^{\circ}$, que possibilitou o acompanhamento da propagação uniforme da trinca.

Os valores da tenacidade à fratura e o desvio padrão são mostrados na Tabela 19. Em comparação aos outros métodos de ensaio estudados na presente pesquisa, observase que o valor da tenacidade à fratura e o desvio padrão (0,11 para o basalto e 0,09 para o granito) obtido pelo ensaio de dupla torção são os mais próximos aos resultados obtidos por meio dos métodos sugeridos pela ISRM (CB e SR).

Os valores da tenacidade à fratura e o desvio padrão do ensaio de carga pontual com corpos de prova axiais e irregulares são mostrados nas Tabelas 20 e 21. Observa-se que o valor do desvio padrão para os corpos de prova axiais (0,20 para o basalto e 0,09 para o granito) são razoáveis comparados com os resultados obtidos com base nos outros métodos sugeridos pela ISRM; contudo, no caso do basalto, para os corpos de prova irregulares, obteve-se um desvio padrão muito alto $(0,48)$. Recomenda-se, portanto, utilizar corpos de prova axiais para a determinação da tenacidade à fratura mediante carga pontual.

Tabela 22 - Resumo dos resultados experimentais do basalto (CB, SR, CCNBD, SCB e CNSCB)

\begin{tabular}{|c|c|c|c|c|c|}
\hline Ensaios & $C B$ & $S R$ & CCNBD & $S C B$ & CNSCB \\
\hline $\begin{array}{c}\text { Tamanho do corpo } \\
\text { de prova }\end{array}$ & Grande & Pequeno & Pequeno & Pequeno & Pequeno \\
\hline $\begin{array}{c}\text { Dimensões do } \\
\text { corpo de prova - } \\
\text { Basalto }\end{array}$ & $\begin{array}{c}L=300 \mathrm{~mm} \\
D=75 \mathrm{~mm}\end{array}$ & $\begin{array}{c}L=108 \mathrm{~mm} \\
D=75 \mathrm{~mm}\end{array}$ & $\begin{array}{l}B=30 \mathrm{~mm} \\
D=75 \mathrm{~mm}\end{array}$ & $\begin{array}{c}D=73,5 \mathrm{~mm} ; \\
B=29,60- \\
31,90 \mathrm{~mm}\end{array}$ & $\begin{array}{c}D=73,5 \mathrm{~mm} ; \\
B=29,70- \\
31,90 \mathrm{~mm}\end{array}$ \\
\hline $\begin{array}{c}\text { Preparação do } \\
\text { corpo de prova. }\end{array}$ & Complexo & Complexo & Simples & Simples & Complexo \\
\hline $\begin{array}{l}\text { Instalação do } \\
\text { equipamento }\end{array}$ & Complexo & Complexo & Simples & Simples & Simples \\
\hline $\begin{array}{c}\text { Tipo de } \\
\text { carregamento }\end{array}$ & Compressivo & Trativo & Compressivo & Compressivo & Compressivo \\
\hline $\begin{array}{c}\text { Método de } \\
\text { carregamento }\end{array}$ & $\begin{array}{c}\text { Flexão a três } \\
\text { pontos }\end{array}$ & Trativo & Compressivo & $\begin{array}{c}\text { Flexão a três } \\
\text { pontos }\end{array}$ & $\begin{array}{c}\text { Flexão a três } \\
\text { pontos }\end{array}$ \\
\hline $\begin{array}{l}\text { Velocidade de } \\
\text { ensaio - Basalto }\end{array}$ & $0,04 \mathrm{~mm} / \mathrm{min}$ & $0,12 \mathrm{~mm} / \mathrm{min}$ & $1,30 \mathrm{kN} / \mathrm{s}$ & $0,001 \mathrm{~mm} / \mathrm{s}$ & $0,0013 \mathrm{~mm} / \mathrm{s}$ \\
\hline Controle do ensaio & $C M O D$ e $L P D$ & CMOD & Força & $C M O D$ & CMOD \\
\hline $\begin{array}{c}\text { Reprodutibilidade } \\
\text { dos dados }\end{array}$ & Razoável & Razoável & Excelente & Excelente & Difícil \\
\hline \multirow{2}{*}{$\begin{array}{l}\text { Equipamento } \\
\text { necessário ao } \\
\text { ensaio }\end{array}$} & $\begin{array}{c}\text { Nível I - } \\
\text { Convencional } \\
\end{array}$ & $\begin{array}{c}\text { Nível I - } \\
\text { Convencional } \\
\end{array}$ & \multirow[b]{2}{*}{ Convencional } & \multirow{2}{*}{$\begin{array}{l}\text { Servo- } \\
\text { controlado }\end{array}$} & \multirow{2}{*}{$\begin{array}{c}\text { Servo- } \\
\text { controlado }\end{array}$} \\
\hline & $\begin{array}{l}\text { Nível II - Servo- } \\
\text { controlado }\end{array}$ & $\begin{array}{c}\text { Nível II - } \\
\text { Servo- } \\
\text { controlado } \\
\end{array}$ & & & \\
\hline $\begin{array}{c}\text { Número de corpos } \\
\text { de prova }\end{array}$ & 5 & 6 & 7 & 5 & 5 \\
\hline \multirow{2}{*}{$\begin{array}{c}\text { Tenacidade à } \\
\text { fratura - Basalto } \\
\left(\mathrm{MPa} \cdot \mathrm{m}^{1 / 2}\right) \\
\end{array}$} & \multirow[b]{2}{*}{$2,31 \pm 0,16$} & \multirow[b]{2}{*}{$2,40 \pm 0,17$} & \multirow[b]{2}{*}{$1,77 \pm 0,16$} & $1,64 \pm 0,06$ & \multirow[b]{2}{*}{$3,57 \pm 0,31$} \\
\hline & & & & $1,56 \pm 0,05$ & \\
\hline \multirow{2}{*}{$\begin{array}{l}\text { Coeficiente de } \\
\text { Variação (\%) }\end{array}$} & \multirow{2}{*}{6,93} & \multirow{2}{*}{7,08} & \multirow{2}{*}{9,04} & 3,66 & \multirow{2}{*}{8,68} \\
\hline & & & & 3,21 & \\
\hline
\end{tabular}


Tabela 23 - Resumo dos resultados experimentais do basalto (CST, Carga pontual, Dupla-torção, $M R T$ e END)

\begin{tabular}{|c|c|c|c|c|c|}
\hline Ensaios & CST & Carga pontual & Dupla-torção & $M R T$ & $E N D$ \\
\hline $\begin{array}{c}\text { Tamanho do corpo } \\
\text { de prova }\end{array}$ & Pequeno & Pequeno & Pequeno & Pequeno & Pequeno \\
\hline $\begin{array}{l}\text { Dimensões do } \\
\text { corpo de prova - } \\
\text { Basalto }\end{array}$ & $\begin{array}{c}D=51,20- \\
54,50 \mathrm{~mm} ; a= \\
57-65 \mathrm{~mm} ; w_{P} \\
\quad=20 \mathrm{~mm}\end{array}$ & $\begin{array}{l}\text { Axial: } \\
\text { Variável } \\
\text { Irregular: } \\
\text { Variável }\end{array}$ & $\begin{array}{c}L=160 \mathrm{~mm} ; W \\
=80 \mathrm{~mm} ; W_{m}= \\
36 \mathrm{~mm} ; B=10- \\
11 \mathrm{~mm}\end{array}$ & $\begin{array}{c}D_{\text {ext }}=57,3- \\
58,7 \mathrm{~mm} ; D_{\text {int }} \\
=11,5 \mathrm{~mm} ; B \\
=29,50- \\
30,20 \mathrm{~mm}\end{array}$ & $\begin{array}{c}D=57,4- \\
58,2 \mathrm{~mm} ; B= \\
28,50-30,00 \\
\text { mm. }\end{array}$ \\
\hline $\begin{array}{c}\text { Preparação do } \\
\text { corpo de prova. }\end{array}$ & Simples & Simples & Complexo & Complexo & Simples \\
\hline $\begin{array}{l}\text { Instalação do } \\
\text { equipamento }\end{array}$ & Simples & Simples & Simples & Simples & Simples \\
\hline $\begin{array}{c}\text { Tipo de } \\
\text { carregamento }\end{array}$ & Compressivo & Compressivo & Compressivo & Compressivo & Compressivo \\
\hline $\begin{array}{c}\text { Método de } \\
\text { carregamento }\end{array}$ & Compressivo & Compressivo & Torção & Compressivo & Compressivo \\
\hline $\begin{array}{l}\text { Velocidade de } \\
\text { ensaio - Basalto }\end{array}$ & $\begin{array}{c}0,0008 \text { e } 0,002 \\
\mathrm{~mm} / \mathrm{s}\end{array}$ & $\begin{array}{l}\text { Aplicação do } \\
\text { carregamento } \\
\text { entre } 10 \text { e } 60 \\
\text { segundos } \\
\end{array}$ & $50 \mu \mathrm{m} / \min$ & $0,012 \mathrm{~mm} / \mathrm{min}$ & $\begin{array}{c}0,003 \text { e } 0,001 \\
\mathrm{~mm} / \mathrm{s}\end{array}$ \\
\hline Controle do ensaio & $\begin{array}{l}\text { Deslocamento } \\
\text { do émbolo }\end{array}$ & & $\begin{array}{l}\text { Deslocamento } \\
\text { do émbolo }\end{array}$ & $\begin{array}{c}\text { Deslocamento } \\
\text { do émbolo }\end{array}$ & $\begin{array}{c}\text { Deslocamento } \\
\text { do émbolo }\end{array}$ \\
\hline $\begin{array}{l}\text { Reprodutibilidade } \\
\text { dos dados }\end{array}$ & Difícil & Excelente & Excelente & Razoável & Excelente \\
\hline $\begin{array}{l}\text { Equipamento } \\
\text { necessário ao } \\
\text { ensaio }\end{array}$ & Convencional & Portátil & $\begin{array}{l}\text { Servo- } \\
\text { controlado }\end{array}$ & Convencional & Convencional \\
\hline $\begin{array}{c}\text { Número de corpos } \\
\text { de prova }\end{array}$ & 5 & $\begin{array}{c}\text { Axial : } 10 \\
\text { Irregular : } 20\end{array}$ & 6 & 5 & 5 \\
\hline \multirow{2}{*}{$\begin{array}{l}\text { Tenacidade à } \\
\text { fratura - Basalto } \\
\qquad\left(\mathrm{MPa} \cdot \mathrm{m}^{1 / 2}\right)\end{array}$} & $2,998 \pm 0,49$ & $\begin{array}{c}\text { Axial : } 2,71 \pm \\
0,20\end{array}$ & \multirow{2}{*}{$2,65 \pm 0,11$} & \multirow{2}{*}{$2,69 \pm 0,34$} & \multirow{2}{*}{$2,14 \pm 0,19$} \\
\hline & $\frac{3,09 \pm 0,51}{3,08+0,51}$ & $\begin{array}{c}\text { Irregular : 2,96 } \\
+048\end{array}$ & & & \\
\hline \multirow{3}{*}{$\begin{array}{c}\text { Coeficiente de } \\
\text { Variação (\%) }\end{array}$} & 16,34 & 7,38 & \multirow{3}{*}{4,15} & \multirow{3}{*}{12,64} & \multirow{3}{*}{8,88} \\
\hline & 16,50 & \multirow{2}{*}{16,22} & & & \\
\hline & 16,56 & & & & \\
\hline
\end{tabular}

onde:

L: comprimento do corpo de prova;

$B$ : espessura do corpo de prova;

D: diâmetro de corpo de prova;

a: comprimento da trinca;

$w_{P}$ : largura do prato superior de carregamento;

$W$ : largura do corpo de prova;

$W_{m}$ : braço de momento de cada barra;

$D_{\text {ext }}$ : diâmetro externo do corpo de prova;

$D_{\text {int: }}$ : diâmetro do furo central.

Tabela 24 - Resumo dos resultados experimentais do granito (CB, SR, CCNBD, SCB e CNSCB)

\begin{tabular}{|c|c|c|c|c|c|}
\hline Ensaios & $C B$ & $S R$ & CCNBD & SCB & CNSCB \\
\hline $\begin{array}{c}\text { Tamanho do corpo } \\
\text { de prova }\end{array}$ & Grande & Pequeno & Pequeno & Pequeno & Pequeno \\
\hline $\begin{array}{c}\text { Dimensões do } \\
\text { corpo de prova }- \\
\text { Granito }\end{array}$ & $\begin{array}{c}L=300 \mathrm{~mm} ; D= \\
75 \mathrm{~mm}\end{array}$ & $\begin{array}{c}L=108 \mathrm{~mm} ; \\
D=75 \mathrm{~mm}\end{array}$ & $\begin{array}{c}B=30 \mathrm{~mm} ; \\
D=75 \mathrm{~mm}\end{array}$ & $\begin{array}{c}D=73,5 \mathrm{~mm} ; \\
B=29,60- \\
31,90 \mathrm{~mm}\end{array}$ & $\begin{array}{c}D=73,5 \\
\mathrm{~mm} ; \\
31,90 \mathrm{~mm}\end{array}$ \\
\hline $\begin{array}{c}\text { Preparação do } \\
\text { corpo de prova }\end{array}$ & Complexo & Complexo & Simples & Simples & Complexo \\
\hline $\begin{array}{c}\text { Instalação do } \\
\text { equipamento }\end{array}$ & Complexo & Complexo & Simples & Simples & Simples \\
\hline
\end{tabular}




\begin{tabular}{|c|c|c|c|c|c|}
\hline Ensaios & $C B$ & $S R$ & CCNBD & $S C B$ & CNSCB \\
\hline $\begin{array}{c}\text { Tipo de } \\
\text { carregamento }\end{array}$ & Compressivo & Trativo & Compressivo & Compressivo & Compressivo \\
\hline $\begin{array}{c}\text { Método de } \\
\text { carregamento }\end{array}$ & $\begin{array}{c}\text { Flexão a três } \\
\text { pontos }\end{array}$ & Trativo & Compressivo & $\begin{array}{c}\text { Flexão a três } \\
\text { pontos }\end{array}$ & $\begin{array}{c}\text { Flexão a três } \\
\text { pontos }\end{array}$ \\
\hline $\begin{array}{l}\text { Velocidade de } \\
\text { carregamento - } \\
\text { Granito }\end{array}$ & $0,05 \mathrm{~mm} / \mathrm{min}$ & $0,13 \mathrm{~mm} / \mathrm{min}$ & $1,05 \mathrm{kN} / \mathrm{s}$ & $0,001 \mathrm{~mm} / \mathrm{s}$ & $0,0013 \mathrm{~mm} / \mathrm{s}$ \\
\hline Controle de ensaio & $C M O D$ e $L P D$ & CMOD & Força & $C M O D$ & $C M O D$ \\
\hline $\begin{array}{c}\text { Reprodutibilidade } \\
\text { dos dados }\end{array}$ & Razoável & Razoável & Excelente & Excelente & Difícil \\
\hline \multirow{2}{*}{$\begin{array}{l}\text { Equipamento } \\
\text { necessário ao } \\
\text { ensaio }\end{array}$} & $\begin{array}{c}\text { Nível I - } \\
\text { Convencional }\end{array}$ & $\begin{array}{c}\text { Nível I - } \\
\text { Convencional }\end{array}$ & \multirow[b]{2}{*}{ Convencional } & \multirow[b]{2}{*}{$\begin{array}{l}\text { Servo- } \\
\text { controlado }\end{array}$} & \multirow[b]{2}{*}{$\begin{array}{l}\text { Servo- } \\
\text { controlado }\end{array}$} \\
\hline & $\begin{array}{l}\text { Nível II - Servo- } \\
\text { controlado }\end{array}$ & $\begin{array}{c}\text { Nível II - } \\
\text { Servo- } \\
\text { controlado }\end{array}$ & & & \\
\hline $\begin{array}{c}\text { Número de corpos } \\
\text { de prova }\end{array}$ & 7 & 4 & 7 & 5 & 5 \\
\hline \multirow{2}{*}{$\begin{array}{l}\text { Tenacidade à } \\
\text { fratura - Granito } \\
\left(\mathrm{MPa} \cdot \mathrm{m}^{1 / 2}\right)\end{array}$} & \multirow[b]{2}{*}{$1,81 \pm 0,05$} & \multirow[b]{2}{*}{$2,17 \pm 0,07$} & \multirow[b]{2}{*}{$1,25 \pm 0,16$} & $1,04 \pm 0,07$ & \multirow[b]{2}{*}{$2,58 \pm 0,31$} \\
\hline & & & & $0,99 \pm 0,075$ & \\
\hline $\begin{array}{l}\text { Coeficiente de } \\
\text { Variação (\%) }\end{array}$ & 2,76 & 3,23 & 12,80 & $\begin{array}{l}6,73 \\
750\end{array}$ & 12,02 \\
\hline
\end{tabular}

Tabela 25 - Resumo dos resultados experimentais do granito (CST, Carga pontual, Dupla-torção, $M R T$ e END)

\begin{tabular}{|c|c|c|c|c|c|}
\hline Ensaios & CST & Carga pontual & Dupla-torção & MRT & END \\
\hline $\begin{array}{c}\text { Tamanho do corpo } \\
\text { de prova }\end{array}$ & Pequeno & Pequeno & Pequeno & Pequeno & Pequeno \\
\hline $\begin{array}{l}\text { Dimensões do } \\
\text { corpo de prova - } \\
\text { Granito }\end{array}$ & $\begin{array}{c}D=51,20- \\
54,50 \mathrm{~mm} ; a= \\
57-65 \mathrm{~mm} ; w_{P} \\
\quad=20 \mathrm{~mm}\end{array}$ & $\begin{array}{l}\text { Axial: } \\
\text { Variável } \\
\text { Irregular: } \\
\text { Variável }\end{array}$ & $\begin{array}{c}L=160 \mathrm{~mm} ; W \\
=80 \mathrm{~mm} ; W_{m}= \\
36 \mathrm{~mm} ; B=10- \\
11 \mathrm{~mm}\end{array}$ & $\begin{array}{c}D_{\text {ext }}=53,6- \\
54,2 \mathrm{~mm} ; D_{\text {int }} \\
=10,5 \mathrm{~mm} ; B \\
=26,50- \\
27,10 \mathrm{~mm}\end{array}$ & $\begin{array}{c}D=53,3- \\
54,1 \mathrm{~mm} ; B= \\
26,80-27,50 \\
\text { mm. }\end{array}$ \\
\hline $\begin{array}{l}\text { Preparação do } \\
\text { corpo de prova }\end{array}$ & Simples & Simples & Complexo & Complexo & Simples \\
\hline $\begin{array}{l}\text { Instalação do } \\
\text { equipamento }\end{array}$ & Simples & Simples & Simples & Simples & Simples \\
\hline $\begin{array}{c}\text { Tipo de } \\
\text { carregamento }\end{array}$ & Compressivo & Compressivo & Compressivo & Compressivo & Compressivo \\
\hline $\begin{array}{c}\text { Método de } \\
\text { carregamento }\end{array}$ & Compressivo & Compressivo & Torção & Compressivo & Compressivo \\
\hline $\begin{array}{l}\text { Velocidade de } \\
\text { ensaio - Granito }\end{array}$ & $\begin{array}{c}0,0008 \text { e } 0,002 \\
\mathrm{~mm} / \mathrm{s}\end{array}$ & $\begin{array}{l}\text { Aplicação de } \\
\text { carregamneto } \\
\text { entre } 10 \text { e } 60 \\
\text { segundos }\end{array}$ & $50 \mu \mathrm{m} / \mathrm{min}$ & $0,012 \mathrm{~mm} / \mathrm{min}$ & $0,003 \mathrm{~mm} / \mathrm{s}$ \\
\hline Controle do ensaio & $\begin{array}{l}\text { Deslocamento } \\
\text { do émbolo }\end{array}$ & & $\begin{array}{c}\text { Deslocamento } \\
\text { do émbolo }\end{array}$ & $\begin{array}{c}\text { Deslocamento } \\
\text { do émbolo }\end{array}$ & $\begin{array}{c}\text { Deslocamento } \\
\text { do émbolo }\end{array}$ \\
\hline $\begin{array}{c}\text { Reprodutibilidade } \\
\text { dos dados }\end{array}$ & Difícil & Excelente & Excelente & Razoável & Excelente \\
\hline $\begin{array}{l}\text { Equipamento } \\
\text { necessário ao } \\
\text { ensaio }\end{array}$ & Convencional & Portátil & $\begin{array}{c}\text { Servo- } \\
\text { controlado }\end{array}$ & Convencional & Convencional \\
\hline $\begin{array}{c}\text { Número de corpos } \\
\text { de prova }\end{array}$ & 5 & $\begin{array}{c}\text { Axial: } 10 \\
\text { Irregular: } 20\end{array}$ & 6 & 5 & 5 \\
\hline \multirow{2}{*}{$\begin{array}{l}\text { Tenacidade à } \\
\text { fratura - Granito } \\
\qquad\left(\mathrm{MPa} . \mathrm{m}^{1 / 2}\right)\end{array}$} & $2,635 \pm 0,39$ & $\begin{array}{c}\text { Axial: } 1,43 \pm \\
0,09\end{array}$ & \multirow{2}{*}{$2,15 \pm 0,09$} & \multirow{2}{*}{$2,57 \pm 0,49$} & \multirow{2}{*}{$1,47 \pm 0,19$} \\
\hline & $\begin{array}{l}2,77 \pm 0,42 \\
2,76 \pm 0,41\end{array}$ & $\begin{array}{l}\text { Irregular: } 1,51 \\
\quad \pm 0,19\end{array}$ & & & \\
\hline \multirow{2}{*}{$\begin{array}{l}\text { Coeficiente de } \\
\text { Variação (\%) }\end{array}$} & 14,80 & 6,29 & \multirow[b]{2}{*}{4,19} & \multirow[b]{2}{*}{19,07} & \multirow[b]{2}{*}{12,93} \\
\hline & $\begin{array}{l}15,16 \\
1486\end{array}$ & 12,58 & & & \\
\hline
\end{tabular}


onde:

L: comprimento do corpo de prova;

$B$ : espessura do corpo de prova;

$D$ : diâmetro de corpo de prova;

$a$ : comprimento da trinca;

$w_{P}$ : largura do prato superior de carregamento;

$W$ : largura do corpo de prova;

$W_{m}$ : braço de momento de cada barra;

$D_{\text {ext }}$ : diâmetro externo do corpo de prova;

$D_{\text {int: }}$ diâmetro do furo central.

\subsection{Comparação dos ensaios entre si e os valores encontrados na literatura}

Os valores da tenacidade à fratura, determinados por diferentes geometrias, mostram uma dispersão significativa, em parte devido a diversas condições na direção de carregamento, além de uma certa anisotropia das amostras como mostrado na Tabela 10.

Os entalhes do tipo “chevron" apresentaram maiores vantagens do que os entalhes retos no que diz respeito ao controle da propagação das trincas, como pode ser observada nos gráficos típicos força versus deslocamento no capítulo anterior.

Ao preparar os entalhes, ocorre uma alteração na ponta da trinca; as microtrincas naturais presentes no corpo de prova são incrementadas, produzindo um maior tamanho destas microtrincas e danificando a zona de processo da fratura (ZPF). Salienta-se a importância de se considerar a influência da forma da ponta da trinca e os efeitos produzidos na mesma quando se faz o entalhe reto, visto que, nessa condição, as microtrincas absorvem mais energia, podendo influir na determinação da tenacidade à fratura.

Segundo a direção da propagação da trinca, os seguintes ensaios podem ser comparados entre si: i) $C B, M R T$, END e carga pontual; ii) $S R$, CST e dupla-torção e iii) CCNBD, CNSCB e SCB.

Nos ensaios de $S R$, CCNBD, SCB e CNSCB, aproveitaram-se as metades dos corpos de prova $C B$ rompidos. A dificuldade para a preparação dos corpos de prova dos ensaios $C B, S R, C C N B D$ e CNSCB consiste na preparação do entalhe “chevron”. Este entalhe não é de fácil reprodução quando comparados aos entalhes padrões ou retos cortados com serras. A preparação requer cuidados especiais nas dimensões conforme as calibrações impostas pela ISRM ou para determinadas geometrias e condições calculadas por meio dos métodos dos elementos finitos. 
Os ensaios $C B$ e $S R$ necessitam de dispositivos de fixação para a preparação dos corpos de prova, de dispositivos de fixação para o controle do deslocamento com LVDTs e da aplicação de carregamentos durante a realização dos ensaios. Tais dispositivos possibilitam a execução adequada dos ensaios, garantindo a segurança dos corpos de prova com redução de perdas de amostras.

Os corpos de prova dos ensaios MRT e CNSCB devem ser cuidadosamente preparados, pois os modelos para determinar o fator de intensidade de tensão são influenciados pela geometria do corpo de prova (dimensões, relação entre os diâmetros externo e interno, superfícies aplainadas), pelo tipo de entalhe (“chevron”, reto ou furo central) e pelas condições de contorno.

Segundo recomendado por Kuruppu (1998), utilizou-se no ensaio CNSCB uma relação de $a_{0} / R \approx 0.24$ ( $a_{0}=8.5 \mathrm{~mm}$ e $R \approx 36.75 \mathrm{~mm}$ ), com relação $S / R=0.8$. Salienta-se que estas relações foram usadas por Chang et al (2002) com corpos de prova de $75 \mathrm{~mm}$ de diâmetro e 23 e 32 mm de espessura.

Os valores obtidos com os corpos de prova $S R$ são ligeiramente maiores que os apresentados pelos corpos de prova $C B$ em 3,90 \% para o basalto e 19,89\% para o granito (Tabelas 22 e 24).

As vantagens dos corpos de prova cilíndricos residem na mínima preparação das amostras, com aproveitamento dos testemunhos obtidos das perfurações das amostras. No caso do ensaio de dupla-torção, cortam-se placas de rochas com dimensões determinadas, o que requer maior dificuldade na preparação das amostras. Salienta-se, contudo, que o valor da tenacidade à fratura calculada mediante este ensaio (duplatorção) é o mais próximo aos obtidos pelos métodos sugeridos pela ISRM (CB e $S R$ ). Com relação ao ensaio $C B$, o valor médio obtido por dupla-torção é 14,72\% maior para o basalto e maior em 18,79\% para o granito. Com relação ao ensaio $S R$, o valor médio obtido por dupla-torção é $10,42 \%$ maior para o basalto e menor em 0,92\% para o granito.

Outros dois ensaios que tiveram maior proximidade aos métodos sugeridos pela ISRM ( $C B$ e $S R$ ) foram os ensaios de corpos de prova de discos com entalhe na borda com partição por cunha (END) e os ensaios de carga pontual com corpos de prova axiais e irregulares. Os valores médios do ensaio $C B$ são ligeiramente maiores que os valores médios obtidos mediante o ensaio END em $8 \%$ para o basalto e $20 \%$ para o granito. Contudo, os valores obtidos mediante o ensaio de carga pontual (axial) é maior em $17,32 \%$ para o basalto e menor em $21 \%$ para o granito. 
A Figura 85 foi ordenada de maneira descendente para melhor visualizar os resultados e para se ter a possibilidade de estabelecer alguma comparação entre os métodos de ensaio e o tipo de rocha estudada. Sendo o ensaio $C B$ o ensaio mais difundido para a determinação da tenacidade à fratura, sendo inclusive considerado como o ensaio que fornece melhores resultados, todos os outros ensaios foram comparados em relação a este.

Nas Figuras 85 e 86, observa-se que os valores de tenacidade à fratura nos ensaios MRT, CST e CNSCB foram superestimados quando comparados com os métodos sugeridos pela ISRM (CB e $S R$ ) em cada uma das direções da propagação da trinca ensaiada e para cada tipo de rocha estudada (basalto e granito). Contudo, os valores de tenacidade à fratura nos ensaios $E N D, C C N B D$ e $S C B$ foram subestimados.

A superestimação ou a subestimação dos valores da tenacidade à fratura parecem ser característicos do ensaio porque, independentemente do tipo de rocha, essa relação é constante (para os ensaios MRT, CST e CNSCB, os valores são superestimados e para os ensaios END, CCNBD e SCB, eles são subestimados).

Os valores obtidos mediante o ensaio $D T$ é ligeiramente maior ao ensaio $C B$, mas é muito próximo ao ensaio $S R$, sobretudo para o caso do granito.

O ensaio de carga pontual tem um comportamento diferente dos outros ensaios. Neste ensaio, podemos observar que, para o caso do basalto, os valores de tenacidade à fratura são superestimados, mas próximos aos valores de tenacidade à fratura obtidos mediante os métodos sugeridos pela ISRM ( $C B$ e $S R$ ), ao passo que, para o granito, os valores são subestimados e muito inferiores aos valores obtidos mediante os ensaios $C B$ e $S R$.

\section{- Ensaio CB}

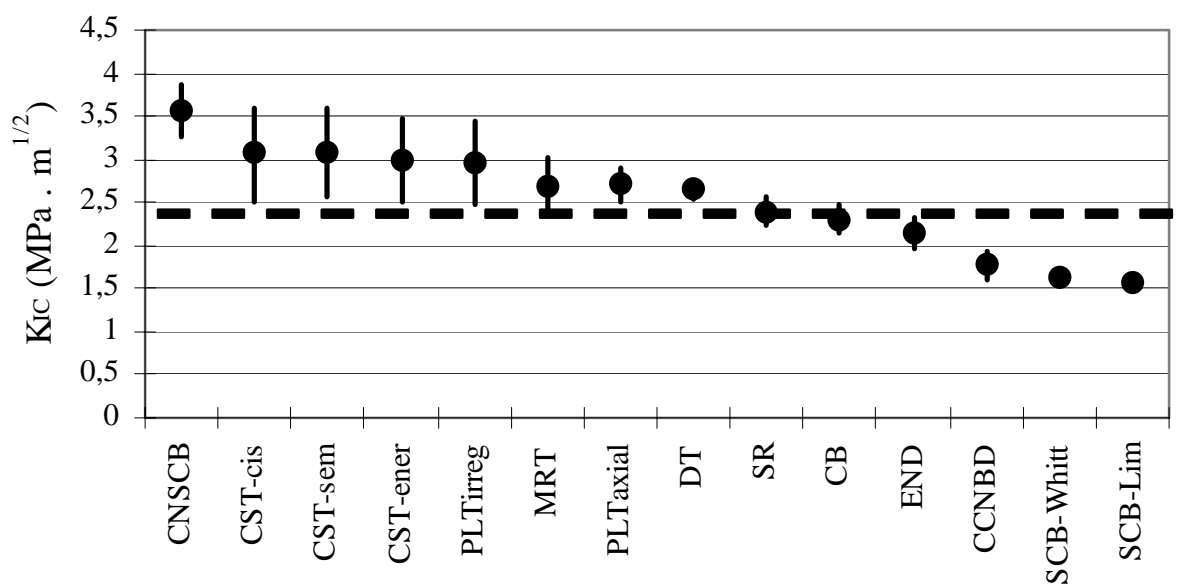

Figura 85. Comparação entre os diferentes métodos de ensaio - Basalto 
- Ensaio CB

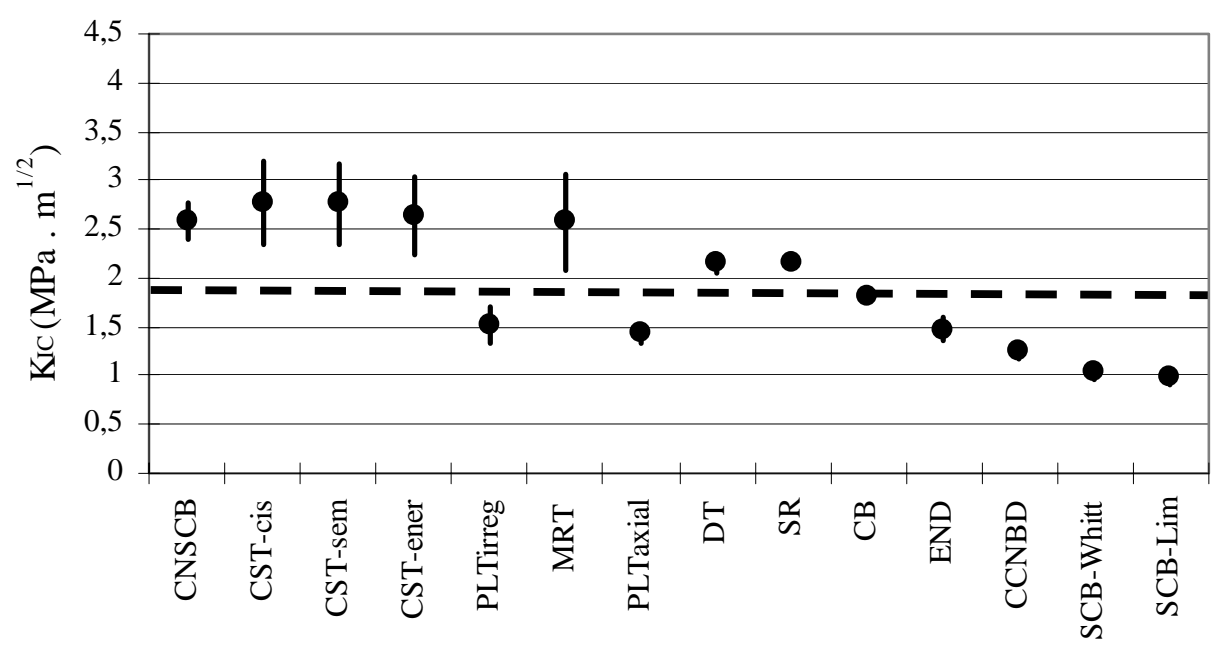

Figura 86. Comparação entre os diferentes métodos de ensaio - Granito

Realizou-se uma pesquisa bibliográfica dos valores de tenacidade à fratura do basalto e do granito publicados na literatura, os quais são apresentados nas Figuras 87 e 88. No caso do basalto, conforme mostrado na Figura 87, os valores determinados em alguns ensaios como $C N S C B, C P$ e $D T$ são relativamente altos comparados à literatura. Salienta-se que a variação da tenacidade à fratura do basalto na literatura se encontra no intervalo de 1,61 - 2,65 MPa.m².

No caso do $C N S C B$, o valor obtido na literatura corresponde a um basalto alterado, ao passo que na presente pesquisa o basalto é praticamente uma rocha sã. O mesmo acontece com o valor do granito, porém neste caso a razão é diferente, dependendo do tipo e do tamanho de grão do granito empregado.

Conforme foi indicado no item anterior, os valores da tenacidade à fratura determinados mediante o ensaio CNSCB são muito altos em comparação aos outros métodos, o que confirma o que fora expresso por Kuruppu (2004) em uma comunicação pessoal onde manifestava que o fator de intensidade de tensão máximo considerado $(7,2)$ devia ser revisado porque ele tinha informes de seus alunos que indicavam que os valores determinados mediante o ensaio CNSCB eram maiores que aqueles determinados mediante outros ensaios.

No caso do granito (Figura 88), os valores da tenacidade à fratura estão dentro do intervalo de valores comparados à literatura. Salienta-se o amplo intervalo de valores em que há variação da tenacidade à fratura do granito na literatura $(0,62-2,80)$. O microtrincamento na frente da ponta da trinca e o desenvolvimento subseqüente da ZPF são influenciados pela microestrutura ou tamanho do grão da rocha. Existem diferentes 
tipos de granito, com diferentes tamanhos de grãos, arranjos e alteração dos corpos de prova, o qual pode explicar o amplo intervalo de valores da tenacidade à fratura encontrado na literatura.

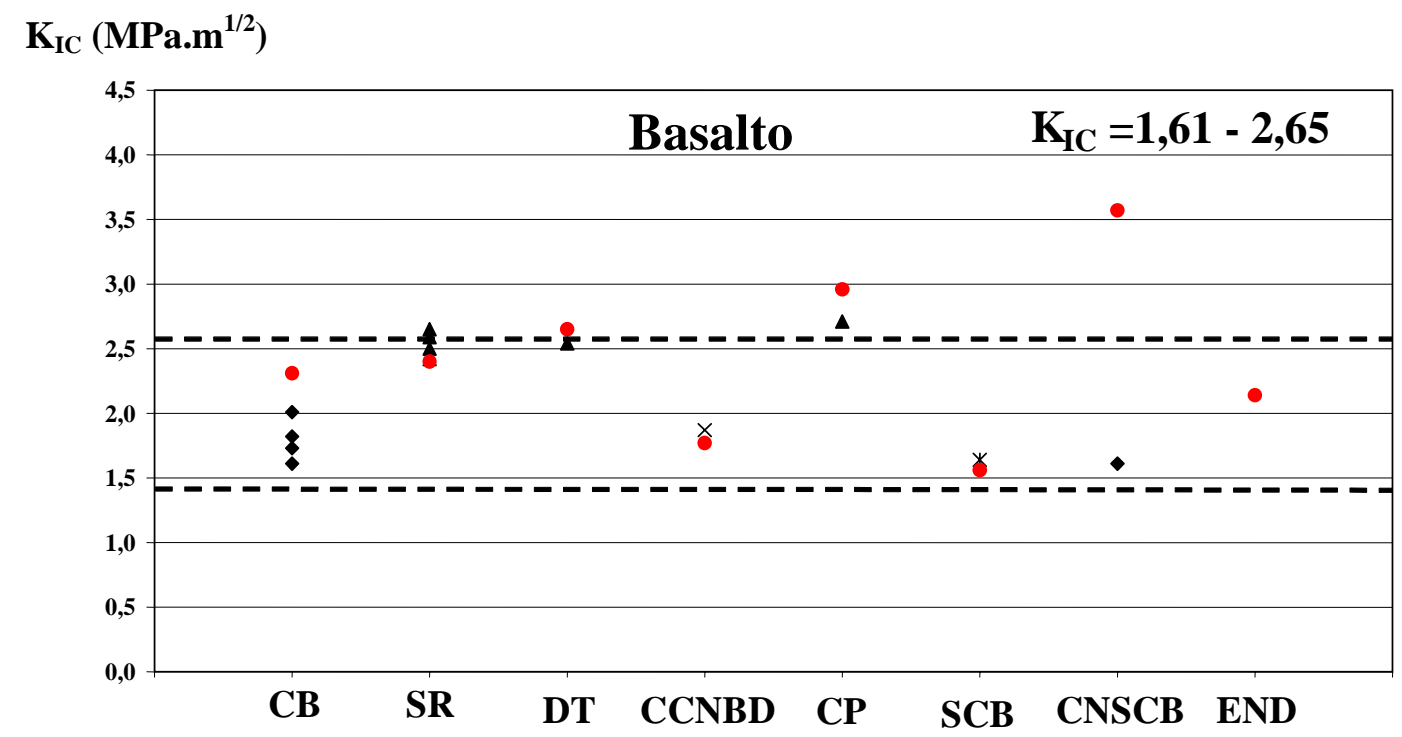

Figura 87. Comparação entre os valores obtidos nos ensaios e os valores da literatura - Basalto

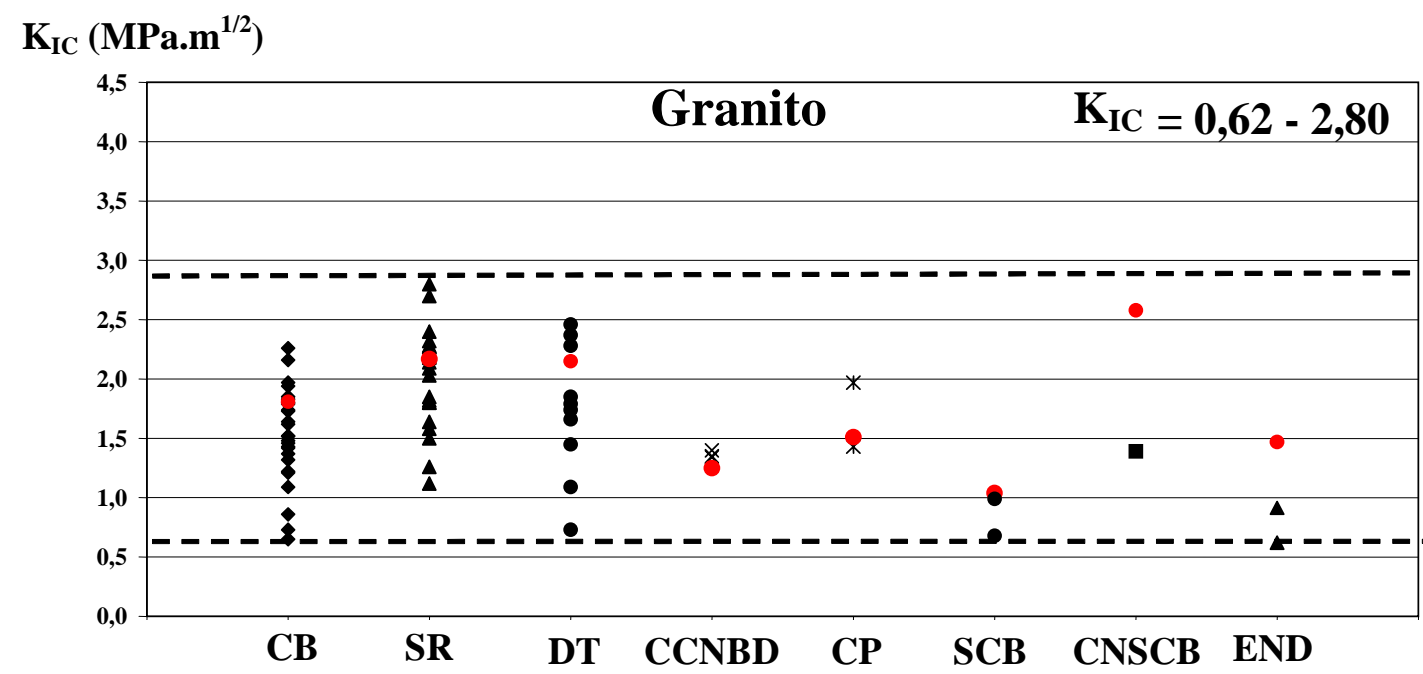

Figura 88. Comparação entre os valores obtidos nos ensaios e os valores da literatura - Granito 


\section{CONCLUSÕES E SUGESTÕES PARA TRABALHOS FUTUROS}

Os valores da tenacidade à fratura, aqui determinados por diferentes ensaios, mostram uma dispersão significativa, devido a diversas condições de geometria e de carregamentos, além da certa anisotropia microestrutural das amostras baseadas nas propriedades físico-mecânicas mostradas na Tabela 8.

Quanto ao tipo de entalhe, os entalhes tipo "chevron" apresentam maiores vantagens do que os entalhes retos no que diz respeito ao controle da propagação das trincas, como pode ser observado nos gráficos típicos força versus deslocamento no capítulo 4.

Quanto à dificuldade da preparação dos corpos de prova, as vantagens dos corpos de prova cilíndricos residem na mínima preparação das amostras, com aproveitamento dos testemunhos obtidos das perfurações das amostras.

A confecção do corpo de prova $C B$ é mais fácil que a do corpo de prova $S R$, mas em contrapartida, ela apresenta maiores dificuldades de realização que o ensaio $S R$, pois pode acontecer um escorregamento do balancim, perdendo-se assim o corpo de prova e o ensaio devido à perda das medidas dos LVDTs.

Os valores da tenacidade à fratura no nível II do modo I determinados por ensaios $C B$ e $S R$ são próximos entre si.

No caso do ensaio em dupla-torção, cortam-se placas de rochas com dimensões determinadas, o que requer maior preparação, mas salienta-se que o valor da tenacidade à fratura determinado mediante este ensaio (dupla-torção) é o mais próximo aos obtidos pelos métodos sugeridos pela ISRM (CB e $S R)$. 
Ressalta-se que os outros dois ensaios que tiveram maior proximidade aos métodos sugeridos pela ISRM ( $C B$ e $S R$ ) foram os ensaios de corpos de prova de discos com entalhe na borda com partição por cunha $(E N D)$ e os ensaios de carga pontual, sendo de fácil preparação e execução, além de possibilitar um melhor estudo estatístico dos dados. No caso do ensaio de carga pontual, ele é econômico e o equipamento de ensaio é portátil, podendo ser levado ao local de estudo, economizando tempo e dinheiro.

Salienta-se que a escolha do ensaio mais conveniente para a determinação da tenacidade à fratura depende principalmente das condições de ensaio e da disponibilidade do equipamento necessário para a execução do mesmo. Sendo assim, recomenda-se para a determinação da tenacidade à fratura em laboratórios com máquinas hidráulicas servocontroladas, o ensaio de dupla-torção; em laboratórios com máquinas convencionais, o ensaio de corpos de prova de discos com entalhe na borda com partição por cunha (END) e para ensaios in-situ com a finalidade de comparação e uma estimativa expedita da tenacidade à fratura, o ensaio de carga pontual.

Algumas sugestões para trabalhos futuros são apresentadas na seqüência:

1. Comparação dos diferentes métodos de ensaio estudados na presente pesquisa utilizandose outros tipos de rochas (por exemplo arenitos, mármores, calcários) com a finalidade de estudar o comportamento destes outros tipos de rochas (sedimentares, anisotrópicas, etc.).

2. Comparação de diferentes tipos de granito e basalto para estudar a influência do tamanho de grãos, visando aprofundar o aspecto microestructural.

3. Realizar os ensaios de CST e END com entalhe "chevron" e com controle de abertura da boca da trinca para se obter um melhor controle de propagação.

4. Aprofundar um pouco mais a determinação da tenacidade à fratura mediante o ensaio de carga pontual devido à facilidade de preparação do CP, execução e transporte do equipamento. 


\section{REFERENCIAS}

ALBURQUERQUE, M. (1998). Determinação da tenacidade à fratura em rochas brasileiras. Dissertação (Mestrado) - Escola de Engenharia de São Carlos, Universidade de São Paulo, São Carlos, SP. 110 p.

ALBURQUERQUE, M (2003). Adaptação do ensaio de dupla-torção para determinação da curva-R de concretos refratários. Tese (Doutorado) - Universidade Federal de São Carlos, São Carlos, SP.

AMARAL, P.M.; GUERRA ROSA, L.; CRUZ FERNANDES, J. (1999). Fracture toughness of different types of granite. International Journal of Rock Mechanics and Mining Sciences, Oxford, v.36, n.6, p.839-842, Sept.

ANSTIS, G.R. et al. (1981). A critical evaluation of indentation techniques for measuring fracture toughness: I, direct crack measurements. Journal of the American Ceramic Society, Easton, v.64, p.533-538.

ATKINSON, B.K. (1979). Fracture toughness of Tennesse sandstone and Carrara marble using the double torsion testing method. International journal of rock mechanics and mining science \& geomechanics Abstracts, Oxford, v.16, n.1, p.49-53, Feb.

ATKINSON, B.K. (1982). Subcritical crack propagation in rocks: theory, experimental results and applications. Journal of Structural Geology, Oxford, v.4, n.1, p.41-56.

ATKINSON, B.K.; AVDIS, V. (1980). Fracture mechanics parameters of some rockforming minerals determined using an indentation technique. International Journal of Rock Mechanics and Mining Sciences \& Geomechanics Abstracts, Oxford, v.17, n.6, p.383-386, Oct.

ATKINSON, C.; SMELSER, R.E.; SANCHEZ, J. (1982). Combined mode fracture via the cracked Brazilian disk test. International Journal of Fracture, Alphen aan den Rijn, v.18, n.4, p.279-91.

BACKERS, T. (2001). Punch-through shear test (PTS-Test) of drill core a new method for $K_{I I C}$ testing. Thesis (PhD) - Division of Engineering geology, Department of Civil and Environmental Engineering, Royal Institute of Technology, Stockholm. 
BACKERS, T. et al. (2003). Effect of loading rate on mode I fracture toughness, roughness and micromechanics of sandstone. International Journal of Rock Mechanics and Mining Sciences, Oxford, v.40, n.3, p.425-33, Apr.

BARENBLATT, G.I. (1962). The mathematical theory of equilibrium of cracks in brittle fracture. Advances in Applied Mechanics, Oxford, v.7, p.55-129.

BARKER, L.M. (1979). Theory for determining $\mathrm{K}_{\mathrm{IC}}$ from small, non-LEFM specimens, supported by experiments on aluminium. International Journal of Fracture, local, v.15, n.6, p.515-536.

BARTON, N.; CHOUBEY, V. (1977). The shear strength of rock joints in theory and practice. Rock Mechanics, Vienna, v.10, p.1-54.

BARTON, C.C. (1983). Variables in fracture energy and toughness of rock. In: SYMPOSIUM ON ROCK MECHANICS, 24., 1983. Proceedings... California: University of California. p.449-462.

BEAR, T.J. (1976). New fracture toughness tests for rock and concrete with particular reference to rock structure design. Thesis ( $\mathrm{PhD})$ - Department of Civil Engineering and Building, The Polytechnic of Wales, Treforest, Mid-Glamorgan.

BEARMAN, R.A. (1991). The application of rock mechanics parameters to the prediction of crusher performance. Thesis (PhD) - Camborne School of Mines, 1991.

BEARMAN, R.A. (1999). The use of the point load test for the rapid estimation of mode I fracture toughness. International Journal of Rock Mechanics and Mining Sciences, Oxford, v.36, n.2, p.257-263, Feb.

BESTE, U. (2003). [Mensagem pessoal]. Mensagem recebida por <ulrik.best@angstrom.uu.se> em 10 Oct.

BHAGAT, R.B. (1985). Mode I fracture toughness of coal. Int. J. Min. Eng., v.3, p.229236.

BIENIAWSKI, Z.T. (1967). Mechanics of brittle fracture of rocks, part I, II and III. International Journal of Rock Mechanics and Mining Sciences \& Geomechanics Abstracts, Oxford, v.4, n.4, p.395-430, Oct. 
BLUHM, J.I. (1975). Slice synthesis of a three dimensional "work of fracture” specimen. Engineering Fracture Mechanics, New York, v.7, n.3, p.593-604, Sept.

BORTOLUCCI, A.A. (1993). Modelo de ruptura em compressão de materiais frageis baseado na mecânica da fratura e aplicado ao efeito escala. Tese (Doutorado) - Escola de Engenharia de São Carlos, Universidade de São Paulo, São Carlos, 1993.

BRADT, R.C. (2003). [Mensagem pessoal]. Mensagem recebida por $<$ Rcbradt@coe.eng.ua.ed> em 16 Oct.

BROCH, E.; FRANKLIN, J.A. (1972). The point load strength test. International Journal of Rock Mechanics and Mining Sciences \& Geomechanics Abstracts, Oxford, v.9, n.6, p.669-697, Nov.

BROWN, G.J.; REDDISH, D.J. (1997). Experimental relationship between rock fracture toughness and density. International Journal of Rock Mechanics and Mining Sciences, Oxford, v.34, n.2, p.153-155, Mar.

BROWN, W.F.; SRAWLEY, J.E. (1966). Plane strain fracture toughness testing of high strength metallic materials. Philadelphia: ASTM. (ASTM-STP, 410).

BRÜWHILER, E.; SAOUMA, V.E. (1990). Fracture testing of rock by the wedge splitting test. In: U.S. SYMPOSIUM ON ROCK MECHANICS, 31., 1990, Golden. Rock Mechanics contributions and challenges: Proceedings... Rotterdam: A.A.Balkema. p.28794.

BÜECKNER H.F. (1970). A novel principle for the computation of stress intensity factors. Zeitschrift Angrewandte Mathematic und Mechanic, Berlin, v.50, p.529-546.

BUSH, A.J. (1976). Experimentally determined stress intensity factor for single-edge crack round bar loaded in bending. Experimental Mechanics, Easton, v.16, p.249-257.

CELESTINO T.B.; BORTOLUCCI, A.A. (1992). Rock fracture toughness determination by diametral compression tests. Escola de Engenharia de São Carlos, Universidade de São Paulo. Report G-1-93.

CELESTINO, T.B.; BORTOLUCCI, A.A.; NOBREGA, C.A. (1995). Determination of rock fracture toughness under creep and fatigue. In: SYMPOSIUM ON ROCK MECHANICS, 35., 1995, Reno. Proceedings... Rotterdam: A.A.Balkema. p.147-152. 
CHANG, S.; LEE, C.; JEON, S. (2002). Measurement of rock fracture toughness under modes I and II and mized-mode conditions by using disc-type specimens. Engineering Geology, Amsterdam, v.66, n.3, p.79-97, Apr.

CHEN, C.S.; PAN, E.; AMADEI, B. (1998). Determination of deformability and tensile strength of anisotropic rock using Brazilian tests. International Journal of Rock Mechanics and Mining Sciences \& Geomechanics Abstracts, Oxford, v.35, n.1, p.43-61.

CHEN, F.; SUN, Z.; XU, J. (2001). Mode I fracture analysis of the double edge cracked Brazilian disk using a weight function method. International Journal of Rock Mechanics and Mining Sciences, Oxford, v.38, n.3, p.475-479, Apr.

CHEN, J.F. (1990). The development of the cracked-chevron-notched Brazilian disc method for rock fracture toughness measurement. In: SEM SPRING CONFERENCE ON EXPERIMENTAL MECHANICS, 1990, Albuquerque. Proceedings... p.18-23.

CHONG, K.P.; KURUPPU, M.D. (1984). New specimens for fracture toughness determination of rock and other materials. International Journal of Fracture, v.26, p.R5962.

CHONG, K.P.; KURUPPU, M.D. (1988). New specimens for mixed mode fracture investigations of geomaterials. Engineering Fracture Mechanics, Amsterdam, v.30, n.5, p.701-712.

CHONG, K.P.; KURUPPU, M.D.; KUSZMAUL, J.S. (1987). Fracture toughness determination of rocks with core-based specimens. In: SEM/RILEM INTERNATIONAL CONFERENCE ON FRACTURE OF CONCRETE AND ROCK, 1987, Houston. Proceedings... New York: Springer-Verlag. p.9-15.

CHONG, K.P. et al. (1987). Strain rate dependent mechanical properties of western oil shale. In: SYMPOSIUM ON ROCK MECHANICS, 28., 1987, Arizona. Proceedings... Rotterdam: A.A.Balkema. p.157-164.

CLIFTON, R.J. et al. (1976). Determination of the critical-stress-intensity factor $\mathrm{K}_{\mathrm{IC}}$ from internally pressurized thick-walled vessels. Experimental Mechanics, Easton, p.233-238, June.

CZOBOLY, E. et al. (1986). Appropriate fracture mechanics specimens for testing rocks. Fracture control of engineering structures. In: BIENNAL EUROPEAN CONFERENCE ON FRACTURE, 6. Proceedings.... p.2205-2115. 
DANELL, R. et al. (1987). Fracture toughness testing of geological materials. In: SEM/RILEM INTERNATIONAL CONFERENCE ON FRACTURE OF CONCRETE AND ROCK, 1987, Houston. Proceedings... New York: Springer-Verlag. p.433-443.

DONOVAN, J.G. (2003). Fracture toughness based models for the prediction of powder consumption, product size, and capacity of jaw crushers. Thesis (PhD) - Mining and Minerals engineering, Virginia Polytechnic Institute and State University. Blacksburg, 2003.

DONOVAN J.G.; KARFAKIS M.G. (2004). Adaptation of a simple wedge test for the rapid determination of mode I fracture toughness and the assessment of relative fracture resistance. International Journal of Rock Mechanics and Mining Sciences, Oxford, v.41, n.4, p.695-701, June.

DOOLIN, D.M. (1994). Fracture toughness testing using the modified ring test. Thesis (Undergraduate honors) - Deptment of Geology, The University of Tennessee, Knoxville, 1994.

DOWLING, N.E. (1999). Mechanical behavior of materials - engineering methods for deformation, fracture and fatigue. Upper Saddle River: Prentice Hall.

ELFGREN, L. (1989). Fracture mechanics of concrete structures. London: Chapman and Hall.

EVANS, A.G. (1972). A method for evaluating the time dependent failure characteristics of brittle materials and its application to polycrystalline alumina. Journal of Materials Science, New York, v.7, p.1137-1146.

EWALDS, H.L.; WANHILL, R.J.H. (1986). Fracture mechanics. 3.ed. London: Edward Arnold.

FENGHUI, W. (2000). Prediction of intrinsic fracture toughness for brittle materials from the apparent toughness of notched-crack specimen. Journal of Materials Science, New York, v.35, p.2443-2546.

FERREIRA, L.E.T. (2002). Sobre a resistência ao fraturamento do concreto e do concreto reforçado com fibras de aço. Tese (Doutorado) - Escola Politécnica, Universidade de São Paulo, São Paulo, 2002. 
FERREIRA, L.E.T. et al. (2002). R-curve behavior in notched beam tests of rocks. Engineering Fracture Mechanics, v.69, p.1845-1852.

FISCHER, M.P. et al. (1996). Finite element analysis of the modified ring test for determining mode I fracture toughness. International Journal of Rock Mechanics and Mining Sciences \& Geomechanics Abstracts, Oxford, v.33, n.1, p.1-15, Jan.

FONG, F.L.C.; NELSON, P.P. (1986). R-curve fracture toughness measurement: testing procedures, correlations with other rock properties, and applications in rock breakage studies. In: SEM SPRING CONFERENCE ON EXPERIMENTAL MECHANICS, 1986. Proceedings...p.148-154.

GRAMBERG, J. (1989). A non-conventional view on rock mechanics and fracture mechanics. Rotterdam: A.A. Balkema.

GREGORY, R.D. (1979). The edge-cracked circular disc under symmetric pin-loading. Mathematical Proceedings of the Cambridge Philosophical Society, Cambridge, v.85, .52338.

GRIFFITH, A.A. (1921). The phenomena of rupture and flow in solids. Proceedings of the Royal Society of London, London, v.A221, p.163-98.

GRIFFITH, A.A. (1924). The theory of rupture. In: INTERNATIONAL CONGRESS ON APPLIED MECHANICS, Delft. Proceedings...Part I, p.55-63.

GUEST, B.W.; KARIHALOO, B.L. (1985). Fracture of glassy brittle materials. Journal of Materials Science Letters, v.4, p.1285-1289.

GUO, H. (1990). Rock cutting using fracture mechanics principle. Thesis (PhD) University of Wollongong, Australia, 1990.

GUO, H.; AZIZ, N.I.; SCHMIDT, L.C. (1993). Rock fracture toughness determination by the Brazilian test. Engineering Geology, Amsterdam, v.33, p.177-188.

GUNSALLUS, K.L.; KULHAWY, F.H. (1984). A comparative evaluation of rock strength measures. Intewrnational Journal of Rock Mechanics and Mining Sciences \& Geomechanics Abstracts, Oxford, v.24, n.5, p.233-248, Aug. 
HABERFIELD, C.M.; JOHNSTON, I.W. (1990). Determination of the fracture toughness of a saturated soft rock. Canadian Geotechnical Journal, Ottawa, v.27, p.276-84.

HENRY, J.P.; PAQUET, J.; TANCREZ, J.P. (1977). Experimental study of crack propagation in calcite rocks. International Journal of Rock Mechanics and Mining Sciences \& Geomechanics Abstracts, Oxford, v.18, n.5, p.445-449, Oct.

HILLERBORG, A. (1985). The theoretical basis of a method to determine the fracture energy $\mathrm{G}_{\mathrm{F}}$ of concrete. Materials and Structures, Paris, v.18, n.106.

HOAGLAND, R.G.; HAHN, G.T.; ROSENFIELD, A.R. (1973). Influence of microstructure on fracture propagation in rock. Rock Mechanics, Vienna, v.5, p.77-106.

HORII, H.; NEMAT-NASSER, S. (1985). Compression-induced micro-crack growth in brittle solids: axial splitting and shear failure. Journal of Geophysical Research, Washington, v.90, p.3105-3125.

HORII, H.; HASEGAWA, A.; NISHINO, F. (1987). Process zone model and influencing factors in fracture of concrete. In: SEM/RILE INTERNATIONAL CONFERENCE ON FRACTURE OF CONCRETE AND ROCK, 1987, Houston. Proceedings... New York: Springer-Verlag. p.299-307.

HUANG, J.; WANG, S. (1985). An experimental investigation concerning the comprehensive fracture toughness of some brittle rocks. International Journal of rock mechanics and Mining Sciences \& Geomechanics Abstracts, v.22, n.2, p.99-104, Apr.

HUDSON, J.A.; HARRISON, J.P. (1997). Engineering rock mechanics - an introduction to the principles. Amsterdam: Pergamon.

INGLIS, C.E. (1913). Stresses in a plate due to the presence of cracks and sharp corners. Institution of Naval Architects, London, v.55, p.219-30.

INGRAFFEA, A.R. (1977). Discrete fracture propagation in rock laboratory tests and finite element analysis. Dissertation (PhD) - University of Colorado, Boulder, Colorado, 1977.

IRWIN, G.R. (1948). Fracture dynamics, fracture of metals. Metals Park: American Society of Metals. p.147-166. 
IRWIN, G.R. (1957). Analysis of stresses and strains near the end of a crack traversing a plate. Journal of Applied Mechanics, New Yor, v.24, p.361-364.

IRWIN, G.R. (1958). Fracture. In: HANDBUCH der Physik. Berlin: Springer-Verlag . v.6, p.551-590.

IRWIN, G.R.; KIES, J.A. (1952). Fracturing and fracture dynamics. Welding Journal of Research Supplement, p.95-100.

IRWIN, G.R.; KIES, J.A. (1954). Critical energy rate analysis of fracture strenght. Welding Journal of Research Supplement, p.193-198.

IRWIN, G.R.; KIES, J.A.; SMITH, H.L. (1958). Fracture stengths relative to the onset and arrest of crack propagation. Philadelphia: ASTM. p.640-57.

ISIDA, M.; IMAI, R.; TSURU, H. (1979). Symmetric plane problems of artitrarily shaped plates with an edge crack. Transactions of the Japanese Society of Mechanical Engineers, v.45, n.395, p.743-749.

INTERNATIONAL SOCIETY OF ROCK MECHANICS (1978a). Suggested methods for determining sound velocity. International Journal of Rock Mechanics and Mining Sciences \& Geomechanics Abstracts, Oxford, v.15, n.2, p.53-58, Apr.

INTERNATIONAL SOCIETY OF ROCK MECHANICS (1978b). Suggested methods for determining tensile strength of rock materials. International Journal of Rock Mechanics and Mining Sciences \& Geomechanics Abstracts, Oxford, v.15, n.3, p.99-103, June.

INTERNATIONAL SOCIETY OF ROCK MECHANICS (1979a). Suggested methods for determining the uniaxial compressive strength and deformability of rock materials. International Journal of Rock Mechanics and Mining Sciences \& Geomechanics Abstracts, Oxford, v.16, n.2, p.135-140, Apr.

INTERNATIONAL SOCIETY OF ROCK MECHANICS (1979b). Suggested methods for determining water content, porosity, density, absorption and related properties and swelling and slake durability index properties. International Journal of Rock Mechanics and Mining Sciences \& Geomechanics Abstracts, Oxford, v.16, n.2, p.141-156, Apr. 
INTERNATIONAL SOCIETY OF ROCK MECHANICS (1985). Suggeted method for determining point load strength. International Journal of Rock Mechanics and Mining Sciences, Oxford, v.22, n.2, p.51-60.

INTERNATIONAL SOCIETY OF ROCK MECHANICS (1988). Suggested methods for determining the fracture toughness of rock. International Journal of Rock Mechanics and Mining Sciences, Oxford, v.25, p.71-96.

INTERNATIONAL SOCIETY OF ROCK MECHANICS (1995). Suggested methods for determining mode I fracture toughness using cracked chevron notched brazilian disc (CCNBD) specimens. International Journal of Rock Mechanics and Mining Sciences, Oxford, v.32, p.57-64.

JENQ, T.S.; SHAH, S.P. (1985). Two parameter fracture model for concrete. Journal of Engineering Mechanics, New York, v.111, n.10, p.1227-1241.

JOHN, R.; SHAH, S.P. (1987). Effect of high strength and rate of loading on fracture toughness of concrete. In: SEM/RILE INTERNATIONAL CONFERENCE ON FRACTURE OF CONCRETE AND ROCK, 1987, Houston. Proceedings... New York: Springer-Verlag. p.35-52.

JOHNSON J.N. et al. (1973). Analysis of fracture for hollow cylindrical and spherical rock specimens subjected to internal pressure with application to underground containment. Salt Lake City. Terra Tek Report on Contract No. DNA 001-73-C-0153.

KANNINEM, M.F. (1973). An augement double cantilever beam mode of studying crack propagation and arrest. International Journal of Fracture, Alphen ann den Rijn, v.9, n.1, p.83-92.

KARFAKIS, M.G.; CHONG, K.P.; KURUPPU, M.D. (1986). A critical review of fracture toughness testing of rocks. In: U.S. ROCK MECHANICS SYMPOSIUM, 27., 1986. Proceedings... p.3-10.

KAPLAN, M.F. (1961). Crack propagation and the fracture of concrete. Journal of the American Concrete Institute, Detroit, v.58, n.5, p.591-610.

KARIHALOO, B.L. (1979). A note on complexities of compression failure. Proceedings of the Royal Society of London, London, v.A368, p.483-493. 
KARIHALOO, B.L. (1980). Two-strut model for compression failure of brittle materials. In: CONFERENCE OF THE AUSTRALIAN FRACTURE GROUP: living with cracks \& understanding fracture, Dorset Gardens. Proceedings... p.80-83.

KARIHALOO, B.L. (1984). Compressive fracture of glassy brittle materials. In: INTERNATIONAL CONFERENCE ON FRACTURE, 6., 1984, New Delhi. Advances in fracture research. p.2641-2648.

KARIHALOO, B.L. (1985). Compression splitting method for determining fracture toughness of brittle materials. In: SYMPOSIUM OF THE AUSTRALIAN FRACTURE GROUP, 1985, Proceedings... p.123-131.

KARIHALOO, B.L. (1986). Fracture toughness of plain concrete from compression splitting tests. The International Journal of Cement Composites and Lightweight Concrete, Harlow, v.8, n.4, p.251-259.

KARIHALOO, B.L. (1987). Do plain and fibre-reinforced concretes have an R-curve behaviour?. In: SEM/RILEM INTERNATIONAL CONFERENCE ON FRACTURE OF CONCRETE AND ROCK, 1987, Houston. Proceedings... New York: Springer-Verlag. p.96-105.

KARIHALOO, B.L.; NALLATHAMBI, P. (1989). Effective crack model and tensionsoftening laws. In: SEM/RILEM INTERNATIONAL CONFERENCE FRACTURE OF CONCRETE AND ROCK, 1987, Houston. Proceedings... New York: Springer-Verlag. p.701-710.

KENDALL, K. (1978). Complexities of compression failure. Proceedings of the Royal Society of London, London, v.A361, p.245-63.

KHAN, K.; AL-SHAYEA, N.A. (2000). Effect of specimen geometry and testing method on mixed mode I-II fracture toughness of a limestone rock from Saudi Arabia. Rock Mechanics and Rock Engineering, v.33, n.3, p.179-206.

KIM, K.; STOUT, M.G. (1978). Determination of effective elastic modulus by compliance calibration for measurement of fracture toughness of rock. In: U.S. SYMPOSIUM ON ROCK MECHANICS, 19. Proceedings... p.203-209. 
KRAFFT, J.M.; SULLIVAN, A.M.; BOYLE, R.W. (1961). Effect of dimensions on fast fracture instability of notched sheets. In: CRACK-PROPAGATION SYMPOSIUM. Proceedings... v.1, p.8-28.

KOBAYASHI, R.; MATSUKI, K.; OTSUKA, N. (1986). Size effect in the fracture toughness of Ogino tuff. International Journal of Rock Mechanics and Mining Sciences \& Geomechanics Abstracts, Oxford, v.23, n.1, p.13-18 Feb.

KRISHNAN, G.R. et al. (1998). Fracture toughness of a soft sandstone. International Journal of Rock Mechanics and Mining Sciences, Oxford, v.35, n.6, p.695-710, Sept.

KURUPPU, M.D. (1997). Fracture toughness measurement using chevron notched semicircular bend specimen. International Journal of Fracture, Alphen aan den Rijn, v.86, p.L33-38.

KURUPPU, M.D. (1998). Stress intensity factors of chevron-notched semi-circular specimen. In: REGIONAL APCOM SYMPOSIUM, 3., 1998, Kalgoorlie. Proceedings... p.111-112.

KURUPPU, M.D. (2004). [Mensagem pessoal]. Mensagem recebida por $<$ M.Kuruppu@curtin.edu.au> em 06 May.

LABUZ, J.F.; SHAH, S.P.; DOWDING, C.H. (1983). Post peak tensile load displacement response and the fracture process zone in rock. In: U.S. SYMPOSIUM ON ROCK MECHANICS, 24. Proceedings... p.421-8.

LABUZ, J.F.; SHAH, S.P.; DOWDING, C.H. (1985). Experimental analysis of crack propagation in granite. International Journal of Rock Mechanics and Mining Sciences \& Geomechanics Abstracts, Oxford, v.22, n.2, p.85-98, Apr.

LABUZ, J.F.; SHAH, S.P.; DOWDING, C.H. (1987). The fracture process zone in granite: evidence and effect. Journal of Rock Mechanics and Mining Sciences \& Geomechanics Abstracts, Oxford, v.24, n.4, p.235-246, Aug.

LAUGIER, M.T. (1984). Hertzian indentation of sintered alumina. Journal of Materials Sciences, New York, v.19, p.254-258. 
LAWN, B.R. (1981). The indentation crack as a model surface flaw. In: BRADT, R.C.; HASSELMAN, D.P.H.; LANGE, F.F. (Ed.). Fracture Mechanics of Ceramics. Cap.5, p.1-26.

LAWN, B.R.; WILSHAW, T.R.; HARTLEY, N.E.W. (1974). A computer simulation study of Hertzian cone crack growth. International Journal of Fracture, Alphen aan den Rijn, v.10, p.1-16.

LAWN, B.R.; FULLER, E.R.; WIEDERHORN, S.M. (1976). Strength degradation of brittle surfaces: sharp indenters. Journal of the American Ceramic Society, Easton, v.59, n.5-6, p.193-197.

LAWN, B.R.; SWAIN, M.V. (1975). Microfracture beneath point indentation in brittle solids. Journal of Materials Science, New York, v.10, p.113-122.

LAWN, B.R.; WILSHAW, T.R. (1975). Indentation fracture: principles and applications. Journal of Materials Science, Oxford, v.10, p.1049-1081.

LEMISZKI, P.J.; LANDES, J.D. (1986). Fracture toughness testing of core from the cambro-ordovician section on the oak ridge reservation. Oak Ridge National Laboratory. Report DE-AC05-96OR22464.

LIBATSKII, L.L.; KOVCHIK, S.E. (1967). Fracture of discs containing crack. Sovietic Materials Science, v.3, p.334-339.

LIM, I.L; JOHNSTON, I.W; CHOI, S.K. (1993). Stress intensity factors for semi-circular specimens under three point bending. Engineering Fracture Mechanics, v.44, n.3, p.363382.

LIM, I.L. et al. (1994). Fracture testing of a soft rock with semi-circular specimens under three-point bending. Part 1 - mode I. International Journal of Rock Mechanics and Mining Sciences and Geomechanics Abstracts, Oxford, v.31, n.3, p.185-197, June.

LIU, D.; SUN, Z.; WANG, S. (1994). Cracked belt feature of rock fracture. In: INTERNATIONAL CONFERENCE OF NEW DEVELOPMENT OF ROCK MECHANICS AND ENGINEERING, 1994, Proceedings... Shenyang: Northeastern University Press. p.470-473. 
LIU, D.; WANG, S.; LI, L. (2000). Investigation of fracture behaviour during rock mass failure. International Journal of Rock Mechanics and Mining Sciences, Oxford, v.37, p.489-497.

MARCHIORI, D.G. (1997). A mecânica da fratura elástica linear e o modelo coesivo na previsão do fraturamento de rochas. Dissertação (Mestrado) - Escola de Engenharia de São Carlos, Universidade de São Paulo, São Carlos, 1997.

MARDER, M.; FINEBERG, J. (1996). How things break. Phyics Today, New York, p.2429, Sept.

Mc CLINTOCK, F.A.; WALSH, J.B. (1962). Friction on griffith cracks in rock under pressure. In: NATIONAL CONGRESS OF APPLIED MECHANICS, 4. Berkeley. Proceedings... p.1015-1021.

MEHTA, P.K.; MONTEIRO, P.J.M. (1993). Concrete: structure, properties and materials. 2.ed. Englewood Cliffs: Prentice-Hall.

MELLOR, M.; HAWKES, I. (1971). Measurement of tensile strength by diametral compression of disks and annuli. Engineering Geology, Amsterdam, v.5, n.3, p.173-225, Oct.

MÜLLER, W.; RUMMEL, F. (1984). Bruchzähigkeitsmessungen an Gesteinen. Bochum: Ruhr University. Bericht zu den BMFT-FE-Vorhaben 03E-3068-B.

MUNZ, D.; BUBSEY, R.T.; SHANNON Jr., J.L. (1980). Fracture toughness determination of $\mathrm{Al}_{2} \mathrm{O}_{3}$ using four-point-bending specimens with straight-through and chevron notches. Journal of the American Ceramic Society, Easton, v.63, n.5-6, p.300-305.

NEMAT-NASSER, S.; HORII, H. (1985). Compression-induced nonplanar crack extension with application to splitting, exfolation and rockburst. Journal Geophysical Research, Washington, v.87, p.6805-6821.

NEWMAN Jr., J.C. (1981). Stress intensity factors and crack opening displacement for round compact specimens. International Journal of Fracture, Alphen aan den Rijn, v.17, n.6, p.567-578. 
NOLEN-HOEKSEMA, R.C.; GORDON, R.B. (1987). Optical detection of crack patterns in the opening-mode fracture of marble, technical note. International Journal of Rock Mechanics and Mining Sciences \& Geomechanics Abstracts, Oxford, v.24, n.2, p.135-144, Apr.

NORDLUND, E.; LI, C.; CARLSSON, B. (1999). Mechanical properties of the diorite in the prototype repository at Äspö $H R L$ - laboratory tests. Local. International Progress Report, IPR-99-25, SKB, June 1999.

OROWAN, E. (1949). Fracture and strength of solids. Reports on Progress in Physics, Bristol, v.12, n.1, p.185-232.

OSTOJIC, P.; MC PHERSON, R. (1987). A review of indentation fracture theory: its development, principles and limitations. International Journal of Fracture, Alphen aan den Rijn, v.33, p.297-312.

OUCHTERLONY, F. (1980). Compliance measurements on notched rock cores in bending. Stockolm: Swedish Detonic Research Foundation. Report DS 1980:2.

OUCHTERLONY, F. (1982). Fracture toughness testing of rock, part 2 of lectures at the CISM. Stockolm: Swedish Detonic Research Foundation. SveDeFo Report DS 1982:5.

OUCHTERLONY, F. (1983). Fracture toughness testing of rocks. In: ROSSMANITH, H.P. (Ed.). Rock fracture mechanics. Wien: Springer-Verlag. p.68-155. (Courses and Lectures/International Centre for Mechanical Science, 275).

OUCHTERLONY, F. (1986). A core bend specimen with chevron edge notch for fracture toughness measurements. Rock mechanics: key to energy production. In: U.S. SYMPOSIUM ON ROCK MECHANICS, 27. Proceedings... Littleton: SME. p.177-184.

OUCHTERLONY, F. (1989). On the background to the formulae and accuracy of rock fracture toughness measurements using ISRM standard core specimens. International Journal of Rock Mechanics and Mining Sciences \& Geomechanics Abstracts, Oxford, v.26, n.1, p.13-23, Jan.

OUCHTERLONY, F. (1990). Fracture toughness testig of rock with core based specimens. Engineering Fracture Mechanics, v.35, n.1/3, p.351-366. 
OUCHTERLONY, F.; SWAN, G.; SUN, Z. (1982). A comparison of displacement measuring methods in the bending of notched rock cores. Stockolm: Swedish Detonic Research Foundation. SveDeFo Report DS 1982:16.

PERKINS, T.K.; KRECH, W.W. (1966). Effect of cleavage rate and stress level on apparent surface energies of rocks. Society of Petroleum Engineers Journal, Dallas, p.308314.

RICE, J.C. (1968). A path independent integral and the approximate analysis of strain concentrations by notches and cracks. Journal of Applied Mechanics, New York, v.35, p.379-386.

RICE, J.C. (1972). Some remarks on elastic crack-tip stress fields. International Journal of Solids and Structures, New York, v.8, n.6, p.751-758, June.

ROEGIERS, J.C.; ZHAO, X.L. (1991a). The measurement of fracture toughness of rocks under simulated downhole conditions. In: INTERNATIONAL CONGRESS ON ROCK MECHANICS, 7., 1991. Proceedings... v.1, p.603-608.

ROEGIERS, J.C.; ZHAO, X.L. (1991b). Rock fracture tests in simulated downhole conditions. Rock mechanics as a multidisciplinay science. In: U.S. SYMPOSIUM ON ROCK MECHANICS, 32., 1991, Oklahoma. Proceedings... p.221-230.

ROOKE, D.P.; TWEED, J. (1973). The stress intensity factors of an edge crack in a finite rotation disc. International Journal Engineering Science, New York, v.11, n.2, p.279-283, Feb.

ROSSMANITH, H.P. (1983). Modelling of fracture process zones and singularity dominated zones. Engineering Fracture Mechanics, v.17, n.66, p.509-525.

RUMMEL, F.; WINTER, R.B. (1983). Fracture mechanics as applied to hydraulic fracturing stress measurements. Earthq. Predict. Res, v.2, p.33-45.

SCHMIDT, R.A. (1975). Fracture toughness testing of rock. Closed Loop, MTS System. v.5, p.3-12.

SCHMIDT, R.A. (1976). Fracture toughness testing of limestone. Experimental Mechanics, Esaton, v.16, p.161-167. 
SCHMIDT, R.A. (1980). A microcrack model and its significance to hydraulic fracturing and fracture toughness testing. In: U.S. SYMPOSIUM ON ROCK MECHANICS, 21., 1980, Rolla. Proceedings... p.581-590.

SCHMIDT, R.A.; HURDLE, C.W. (1977). Effect of confining pressure on fracture toughness of Indiana limestone. International Journal of Rock Mechanics and Mining Sciences \& Geomechanics Abstracts, Oxford, v.14, n. 5-6, p.289-293, Nov.

SCHMIDT, R.A.; LUTZ, T.J. (1979). $\mathrm{K}_{\mathrm{IC}}$ and $\mathrm{J}_{\mathrm{IC}}$ of westerly granite - effects of thickness and inplane dimensions. In: FREIDMAN, S.W. (Ed.). Fracture mechanics: applied to brittle materials. Philadelphia: ASTM. p.166-82. (ASTM-STP, 678).

SCHMIDT, R.A.; ROSSMANITH, H.P. (1983). Basics of rock fracture mechanics. In: Rossmanith, H.P. (Ed.). Rock Fracture Mechanics: courses and lectures No 275. New York: Technical University of Vienna; Springer-Verlag.

SCHOENERT, K. (1972). Role of fracture physics in understanding comminution phenomena. Transactions SME/AIME, v.252, p.21-26.

SHETTY, D.K.; ROSENFIELD, A.R.; DUCKWORTH, W.H. (1985). Fracture toughness of ceramics measured by a chevron-notched diametral-compression test. Journal of the American Ceramic Society, Easton, v.68, n.12, p.C325-327.

SHETTY, D.K.; ROSENFIELD, A.R.; DUCKWORTH, W.H. (1986). Mixed-mode fracture of ceramic in diametral compression. Journal of the American Ceramic society, Easton, v.69, n.6, p.437-443.

SHIRYAEV, A.M.; KOTKIS, A.M. (1982). Methods for determining fracture toughness of brittle porous materials. Industrial Laboratory, v.48, n.9, p.917-918.

SIH, G.C. (1973). Handbook of stress intensity factors for researchers and engineers. Lehigh: Lehigh University; Institute of Fracture and Solid Mechanics.

SINGH, R.N.; PATHAN, A.G. (1988). Fracture toughness of some British rocks by diametral loading of discs. Mining Science and Technology, Amsterdam, n.6, p.179-190. 
SINGH, R.N.; SUN, G.X. (1990). A numerical and experimental investigation for determining fracture toughness of Welsh Limestone. Mining Science and Technology, Amsterdam, v.1, n.10, p.64-73.

SNEDDON, I.N. (1946). The distribution of stress in the neighbourhood of a crack in an elastic solid. Philosophical Transactions of the Royal Society of London, London, v.A187, p.229-260.

SRAWLEY, J.; GROSS, B. (1976). Side-cracked plates subjected to combined direct and bending forces. In: CRACKS and Fractures. Philadelphioa: ASTM. p.559-579. (ASTMSTP, 601).

STEPHANSSON, O. (2001). What can fracture mechanics do for us. In: ISRM REGIONAL SYMPOSIUM EUROCK, 2001, Espoo. Proceedings... Lisse: A.A.Balkema. p.21-25.

SUN, Z.Q. (1983). Fracture mechanics and tribology of rocks and rock joints. Thesis (PhD) - Lulea University, Sweden, 1983.

SUN, Z.Q.; OUCHTERLONY, F. (1986). Fracture toughness of stripa granite cores. International Journal of Rock Mechanics and Mining Sciences \& Geomechanics Abstracts, Oxford, v.23, n.6, p.399-409.

SWAIN, M.V.; ATKINSON, B.K. (1978). Fracture surface energy of olivine. Geofisica Pura e Applicata, Milano, v.116, p.866-872.

SWAIN, M.V.; LAWN, B.R. (1973). A microprobe technique for measuring slow crack velocities in brittle solids. International Journal of Fracture, Alphen aan den Rijn, v.9, p.481-483.

SWAN, G. (1980). Fracture stress scale effects for rocks in bending. International Journal of Rock Mechanics and Mining Sciences \& Geomechanics Abstracts, Oxford, v.17, n.6, p.317-324, Dec.

SWANSON, P.L. (1981). Subcritical crack propagation in westerly granite: an investigation into the double torsion method. International Journal of Rock Mechanics and Mining Sciences \& Geomechanics Abstracts, Oxford, v.18, n.5, p.445-449, Oct. 
SWANSON, P.L. (1984). Subcritical crack growth and other time-and environment dependent behaviour in crustal rocks. Journal of Geophysical Research, Washington, v.39, p.4137-4152.

SWEARENGEN, J.C.; BEAUCHAMP, E.K.; EAGAN, R.J. (1978). Fracture toughness of reinforced glasses. In: BRADT, R.C.; HASSELMAN, D.P.H.; LANGE, F.F. (Ed.). Fracture mechanics of ceramics. New York: Plenum Press. v.4, p.973-987.

SZENDI-HORVATH, G. (1980). Fracture toughness determination of brittle materials using small specimens. Engineering Fracture Mechanics, v.13, p.955-961.

SZENDI-HORVATH, G. (1982). On the fracture toughness testing of coal. The Australian Journal of Mining Technology and Research, n.2, p.51-57.

TADA, H.; PARIS, P.S.; IRWIN, G.R. (1985). The stress analysis of cracks handbook. 2.ed. St.Louis: Paris Production.

TADA, H.; PARIS, P.S.; IRWIN, G.R. (2000). The stress analysis of cracks handbook. New York: ASME.

THIERCELIN, M. (1987). Fracture toughness under confining pressure using the modified ring test. In: U.S. SYMPOSIUM ON ROCK MECHANICS, 28., 1987, Tucso. Proceedings... Rotterdam: A.A.Balkema. p.149-156.

THIERCELIN M.; ROEGIERS, J.C. (1986). Toughness determination with the modified ring test. In: U.S. SYMPOSIUM ON ROCK MECHANICS, 27., 1986. Proceedings... p.615-622.

WANG Q.Z.; XING L. (1999). Determination of fracture toughness $\mathrm{K}_{\mathrm{IC}}$ by using the flattened Brazilian disk specimen for rocks. Engineering Fracture Mechanics, v.64, p.193201.

WANG, Q.Z.; JIA, X.M.; WU, L.Z. (2004). Wide-range stress intensity factors for the ISRM suggested method using CCNBD specimens for rock fracture toughness tests. International Journal of Rock Mechanics and Mining Sciences, Oxford, v.41, n.4, p.709716, June. 
WANG, Q.Z. et al. (2003). More accurate stress intensity factor derived by finite element analysis for the ISRM suggested rock fracture toughness specimen-CCNBD. International Journal of Rock Mechanics and Mining Sciences, Oxford, v.40, n.2, p.233-241, Feb.

WEIBULL, W. (1939). A statistical theory of the strength of materials. Ing Vet Akad, v.151, p.1-39.

WELLS, A.A. (1956). Strain energy releasy rates for fractures caused by wedge action. NRL Report, n.4705.

WESTERGAARD, H.M. (1939). Bearing pressures and cracks. Journal of Applied Mechanics, New York, v.24, p.31-34.

WHITTAKER B.N.; SINGH, R.N.; SUN, G. (1992). Rock fracture mechanics: principles, design and applications. Amsterdam: Elservier.

WIEDERHORN, S.M.; SHORB, A.M. (1968). Critical analysis of the theory of the double cantilever method of measuring fracture surface energy. Journal of Applied Physics, Menasha, v.39, n.3, p.1569-1572, Feb.

WILLIAMS, D.P.; EVANS, A.G. (1973). A simple method for studying slow crack growth. Journal Testing and Evaluation, Philadelphia, v.1, n.4, p.264-270.

WITTMANN, F.H. (1983). Fracture mechanics of concrete. Amsterdam: Elservier. WU, X.R.; CARLSSON, A.J. (1991). Weight functions and stress intensity factor solutions. New York: Pergamon.

XU, S.; REINHARDT, H.W. (2000). A simplified method for determining double-K fracture parameters for three-point bending test. International Journal of Fracture, Alphen aan den Rijn, v.104, p.181-209.

XU, C.; FOWELL, R.J. (1994). Stress intensity factor evaluation for cracked chevron notched Brazilian disc specimen. International Journal of Rock Mechanics and Mining Sciences \& Geomechanics Abstracts, Oxford, v.31, n.3, p.157-162, June. 
YAREMA, S.Y.; KRESTIN, G.S. (1966). Determination of the modulus of cohesion of brittle materials by compressive tests on disc specimens containing cracks. Sovietic Materials Science, v.2, p.7-10.

YI, X. et al. (1991). Fracture toughness of Kallax gabbro and specimen size effect. International Journal of Rock Mechanics and Mining Sciences \& Geomechanics Abstracts, Oxford, v.28, n.2/3, p.445-449, May.

YU, Y. (2001). Measuring properties of rock from the site of permanent shiplock in three Gorges project. Yangtze River Scientific Research Institute. Test Report, June.

ZHANG, Z.X. (2002). An empirical relation between mode I fracture toughness and the tensile strength of rock. International Journal of Rock Mechanics and Mining Sciences, Oxford, v.39, n.3, p.401-406, Apr.

ZHANG, Z.X. et al. (1998). The relationship between the fracture toughness and tensile strength of rock. In: STRENGTH theories: applications, developments \& prospects for 21st century. New York: Science Press. p.215-19.

ZHAO, X.L.; ROEGIERS J.C. (1990). The measurement of fracture toughness of rocks. In: CONGRESO SUDAMERICANO DE MECÁNICA DE ROCAS, 3., 1990, Caracas. Anais... Caracas: Sociedad Venezoelana Mecanics Del Suelo e Ingenieria Fundaciones. p.641-652. 


\section{ANEXO A}

Tabelas correspondentes aos valores de $u$ e $v$ para a determinação da tenacidade à fratura em corpos de prova na forma de disco brasileiro com entalhe em "chevron" - CCNBD 
Tabela 26. Valores de $u$

\begin{tabular}{|c|c|c|c|c|c|c|c|c|c|c|c|c|c|c|}
\hline$\alpha_{0}$ & 0.100 & 0.150 & 0.175 & 0.200 & 0.225 & 0.250 & 0.275 & 0.300 & 0.325 & 0.350 & 0.375 & 0.400 & 0.425 & 0.450 \\
\hline & & & & & & & $u$ & & & & & & & \\
\hline \multicolumn{15}{|l|}{$\alpha_{B}$} \\
\hline 0.440 & 0.2747 & 0.2774 & 0.2791 & 0.2808 & 0.2825 & 0.2844 & 0.2865 & 0.2883 & 0.2914 & 0.2943 & 0.2979 & 0.3024 & 0.3069 & 0.3120 \\
\hline 0.480 & 0.2727 & 0.2752 & 0.2765 & 0.2782 & 0.2795 & 0.2812 & 0.2833 & 0.2856 & 0.2882 & 0.2918 & 0.2954 & 0.2994 & 0.3039 & 0.3090 \\
\hline 0.520 & 0.2708 & 0.2727 & 0.2740 & 0.2757 & 0.2771 & 0.2788 & 0.2806 & 0.2828 & 0.2857 & 0.2887 & 0.2925 & 0.2968 & 0.3013 & .3060 \\
\hline 0.560 & 0.2689 & 0.2705 & 0.2716 & 0.2733 & 0.2744 & 0.2763 & 0.2781 & 0.2805 & 0.2831 & 0.2867 & 2901 & 0.2943 & 0.2989 & 0.3039 \\
\hline 0.600 & 0.2667 & 0.2684 & 0.2696 & 0.2709 & 0.2721 & 0.2739 & 0.2757 & 0.2782 & 0.2812 & 0.2844 & 0.2882 & 0.2921 & 0.2967 & 0.3015 \\
\hline 0.640 & 0.2649 & 0.2665 & 0.2674 & 0.2685 & 0.2701 & 0.2719 & 0.2738 & 0.2764 & 0.2791 & 0.2825 & 0.2863 & 0.2905 & 0.2947 & 0.2992 \\
\hline 0.680 & 0.2632 & 646 & 0.2655 & 0.2667 & 0.2682 & 0.2704 & 0.2718 & 0.2744 & 0.2774 & 0.2807 & 0.2848 & 0.2888 & 0.2930 & .2971 \\
\hline 0.720 & 0.2611 & 0.2628 & 0.2637 & 0.2650 & 0.2667 & 0.2683 & 0.2705 & 0.2727 & 0.2763 & 0.2794 & 0.2831 & 0.2871 & 0.2916 & 0.2954 \\
\hline 0.760 & 0.2598 & 0.2612 & 0.2625 & 0.2637 & 0.2650 & 0.2668 & 0.2693 & 0.2719 & 0.2744 & 0.2781 & 0.2819 & 0.2860 & 0.2895 & 0.2934 \\
\hline 0.800 & 0.2582 & 0.2602 & 0.2611 & 0.2625 & 0.2641 & 0.2657 & 0.2680 & 0.2706 & 0.2736 & 0.2772 & 0.2811 & 0.2845 & 0.2878 & 0.2916 \\
\hline 0.840 & 0.2572 & 0.2586 & 0.2599 & 0.2612 & 0.2628 & 0.2649 & 0.2672 & 0.2699 & 0.2727 & 0.2763 & 0.2801 & 0.2831 & 0.2867 & 0.2891 \\
\hline 0.880 & 0.2562 & 0.2578 & 0.2593 & 0.2602 & 0.2621 & 0.2642 & 0.2668 & 0.2691 & 0.2723 & 0.2754 & 0.2793 & 0.2816 & 0.2853 & 0.2867 \\
\hline 0.920 & 0.2553 & 0.2572 & 0.2582 & 0.2598 & 0.2613 & 0.2634 & 0.2658 & 0.2684 & 0.2716 & 0.2747 & 0.2782 & 0.2811 & 0.2831 & 0.2856 \\
\hline 0.960 & 0.2549 & 0.2566 & 0.2578 & 0.2593 & 0.2612 & 0.2633 & 0.2655 & 0.2685 & 0.2710 & 0.2746 & 0.2767 & 0.2799 & 0.2811 & 0.2825 \\
\hline 1.000 & 0.2547 & 0.2564 & 0.2576 & 0.2591 & 0.2610 & 0.2630 & 0.2653 & 0.2679 & 0.2709 & 0.2738 & 0.2768 & 0.2786 & 0.2794 & 0.2794 \\
\hline 1.040 & 0.2544 & 0.2565 & 0.2576 & 0.2593 & 0.2608 & 0.2627 & 0.2653 & 0.2678 & 0.2708 & 0.2727 & 0.2747 & 0.2769 & 0.2769 & 0.2765 \\
\hline
\end{tabular}


Tabela 27. Valores de $v$

\begin{tabular}{|c|c|c|c|c|c|c|c|c|c|c|c|c|c|c|}
\hline$\alpha_{0}$ & 0.100 & 0.150 & 0.175 & 0.200 & 0.225 & 0.250 & 0.275 & 0.300 & 0.325 & 0.350 & 0.375 & 0.400 & 0.425 & 0.450 \\
\hline & & & & & & & $v$ & & & & & & & \\
\hline \multicolumn{15}{|l|}{$\alpha_{B}$} \\
\hline 0.440 & 1.7813 & 1.7820 & 1.7820 & 1.7833 & 1.7863 & 1.7893 & 1.7923 & 1.7967 & 1.7966 & 1.7977 & 1.7973 & 1.7932 & 1.7901 & 1.7850 \\
\hline 0.480 & 1.7748 & 1.7763 & 1.7787 & 1.7800 & 1.7843 & 1.7881 & 1.7907 & 1.7934 & 1.7952 & 1.7929 & 1.7923 & 1.7901 & 1.7866 & 1.7811 \\
\hline 0.520 & 1.7694 & 1.7734 & 1.7758 & 1.7769 & 1.7808 & 1.7845 & 1.7884 & 1.7907 & 1.7911 & 1.7920 & 1.7897 & 1.7860 & 1.7823 & 1.7784 \\
\hline 0.560 & 1.7644 & 1.7701 & 1.7732 & 1.7748 & 1.7794 & 1.7822 & 1.7856 & 1.7877 & 1.7885 & 1.7864 & 1.7857 & 1.7820 & 1.7779 & 1.7725 \\
\hline 0.600 & 1.7620 & 1.7668 & 1.7692 & 1.7727 & 1.7770 & 1.7792 & 1.7826 & 1.7835 & 1.7833 & 1.7831 & 1.7805 & 1.7782 & 1.7733 & 1.7689 \\
\hline 0.640 & 1.7580 & 1.7631 & 1.7671 & 1.7707 & 1.7732 & 1.7757 & 1.7788 & 1.7794 & 1.7795 & 1.7779 & 1.7753 & 1.7716 & 1.7686 & 1.7652 \\
\hline 0.680 & 1.7550 & 1.7602 & 1.7640 & 1.7676 & 1.7707 & 1.7711 & 1.7757 & 1.7759 & 1.7754 & 1.7741 & 1.7700 & 1.7666 & 1.7630 & 1.7612 \\
\hline 0.720 & 1.7536 & 1.7580 & 1.7616 & 1.7647 & 1.7661 & 1.7698 & 1.7708 & 1.7722 & 1.7693 & 1.7683 & 1.7652 & 1.7617 & 1.7574 & 1.7562 \\
\hline 0.760 & 1.7497 & 1.7553 & 1.7568 & 1.7600 & 1.7635 & 1.7656 & 1.7649 & 1.7652 & 1.7662 & 1.7624 & 1.7593 & 1.7554 & 1.7548 & 1.7528 \\
\hline 0.800 & 1.7474 & 1.7506 & 1.7538 & 1.7557 & 1.7581 & 1.7611 & 1.7613 & 1.7603 & 1.7596 & 1.7561 & 1.7525 & 1.7512 & 1.7509 & 1.7494 \\
\hline 0.840 & 1.7430 & 1.7487 & 1.7500 & 1.7522 & 1.7545 & 1.7547 & 1.7551 & 1.7548 & 1.7535 & 1.7499 & 1.7469 & 1.7473 & 1.7448 & 1.7497 \\
\hline 0.880 & 1.7392 & 1.7438 & 1.7446 & 1.7487 & 1.7490 & 1.7492 & 1.7478 & 1.7487 & 1.7463 & 1.7452 & 1.7403 & 1.7434 & 1.7414 & 1.7493 \\
\hline 0.920 & 1.7357 & 1.7390 & 1.7413 & 1.7423 & 1.7440 & 1.7446 & 1.7443 & 1.7432 & 1.7411 & 1.7389 & 1.7360 & 1.7363 & 1.7417 & 1.7448 \\
\hline 0.960 & 1.7299 & 1.7337 & 1.7358 & 1.7370 & 1.7372 & 1.7373 & 1.7372 & 1.7346 & 1.7344 & 1.7309 & 1.7343 & 1.7331 & 1.7414 & 1.7483 \\
\hline 1.000 & 1.7243 & 1.7279 & 1.7300 & 1.7308 & 1.7310 & \begin{tabular}{|l|l}
1.7307 \\
\end{tabular} & 1.7306 & 1.7297 & 1.7273 & 1.7270 & 1.7258 & 1.7302 & 1.7394 & 1.7525 \\
\hline 1.040 & 1.7196 & 1.7213 & 1.7231 & 1.7232 & 1.7246 & 1.7256 & 1.7237 & 1.7231 & 1.7204 & 1.7238 & 1.7272 & 1.7293 & 1.7423 & 1.7569 \\
\hline
\end{tabular}

